\title{
The impacts of ocean acidification and warming on the Antarctic bivalve, Laternula elliptica
}

\section{Christine Heather Bylenga}

\author{
A thesis \\ submitted to Victoria University of Wellington \\ in fulfillment of the requirements for the degree of \\ Doctor of Philosophy
}





\section{Acknowledgements}

First of all, I would like to thank my supervisors, Ken and Vonda. You have been a massive help throughout my entire $\mathrm{PhD}$, and I greatly valued all your support, advice, comments and edits. You have inspired me to be the best I can be. Thank you for providing me with this amazing opportunity, I could not have done it without you.

Neill and Graeme, you have provided so much support throughout my research. You probably saved my sanity on multiple occasions. Thank you for always being there and being willing to take time out of your busy days to help when I needed it.

Thank you to NIWA, VUW and Antarctica New Zealand who all help support my research and facilitated two wonderful opportunities to go to Antarctica. These are experiences I will never forget.

To all those who helped me along the way in my research I give a grateful thank you. The dive teams (USA and NIWA) who collected Laternula elliptica for me on three occasions. Kim Currie for her wonderful work on all the seawater samples. David Flynn for providing the SEM and training me in how to use it. Mark Gall who provided me with the respiration measurement system and went out of his way to help with trouble shooting. Lisa Northcote, who provided her lab space on multiple occasions. Dalice Sim and Lisa Woods, who on multiple occasions provided much needed advice on stats work. Mary Sewell for allowing me the use of her lab, equipment and time. Josefina PetersDidier and the lab group at UofA who helped train me, assisted me and supported me during my time in Auckland. Stefanie Menashe for helping me count all those larvae.

I thank you Sonja Hempel. You stuck with me for three years, always cheerfully willing to spend hours in the cold room lending a hand, your help was invaluable. You were so much more than a helping hand in the lab, you have been a great friend. Thank you.

I also thank those who helped me in other ways here in New Zealand. James, Rebecca and Zoë, always willing to grab a cup of coffee. Thanks for all the long lunches. Miriam M., Miriam G., Jessie, Sarah, and Lucy, you people are the best flatmates one could hope for. Thank you for sharing a home with me. Bill and Jackie, and the congregation of the Reformed Church of Wellington, you have made this country a home away from home, thank you so much for all your support and care.

Finally, I thank my support group back home, thank you for the Skype calls, the letters and the care packages. Mom and Dad, I know always were thinking and praying for me. You have been amazingly supportive, despite me moving halfway around the world. Janna, Erin, Stephanie and Elizabeth you have been my friends for so many years, thank you for all your love and support. 


\section{Abstract}

Laternula elliptica are large bivalves found in high densities in soft sediments in coastal regions of the Southern Ocean. L. elliptica form an important part of the ecosystem, due to significant sediment stabilisation and deposition. Despite the important role L. elliptica play in their environment, little is known about how projected ocean change will impact future populations of this species. Invertebrate larvae are considerably more sensitive to environmental stressors than juveniles and adults, and increases in mortality and minor reductions in dispersal could significantly reduce future population sizes. In a rapidly changing climate, some of the greatest changes are expected at high latitudes. The greatest rates of warming of surface waters are occurring in the Southern Ocean. Additionally, undersaturation of aragonite due to ocean acidification is expected to affect these waters within decades. Calcifying organisms such as molluscs may be particularly sensitive to reduced $\mathrm{pH}$ and saturation states associated with ocean acidification. However, information on larval responses to these stressors in Antarctic species is limited.

The larvae of L. elliptica are large and lecithotrophic. Maternally provided energy reserves sustain development until the completion of metamorphosis. While large reserves may support long development times and extended encapsulation, they are finite and cannot be replenished. Any stress during larval development could increase metabolic costs and deplete reserves, preventing metamorphosis. These stressors may also impact the calcification process and shell structures, resulting in weaker larvae at settlement that are more vulnerable to injury. Small reductions in larval survival could limit recruitment and population growth may decline. Various responses to ocean acidification (OA) and warming were studied in the larvae of L. elliptica. Larvae were raised under control $\mathrm{pH}$ and temperatures ( 8.00 and $1.7^{\circ} \mathrm{C}$, respectively) and conditions representing projections for the Antarctic by the end of the century and $2300\left(\mathrm{pH} 7.80,7.65\right.$ and $-0.5,+0.5$ and $\left.+1.5^{\circ} \mathrm{C}\right)$, both individually and in combination. The effect of these stressors on fertilisation rates, development timing and rates of abnormalities at various life stages were examined. Furthermore, SEM analysis determined the impacts of OA and warming on larval shell growth and morphology. Respiration rates and lipid reserves in developing larvae were also determined. 
Information on OA and temperature responses in Antarctic larvae is limited, and this is the first study on the effects of these stressors in Antarctic bivalves. Elevated temperatures largely improved development, increased early fertilisation rates, and accelerated development through all larval stages and larvae reached competency $5 \mathrm{~d}$ ahead of larvae at the control temperature. This would allow for faster settlement, significantly reducing time spent in more vulnerable development stages. Elevated temperatures also improved calcification in later D-stage larvae increasing shell lengths and reducing pitting and cracking, suggesting these larvae will be in a better condition at settlement. Reduced $\mathrm{pH}$ improved fertilisation at control temperatures, but impaired it at elevated temperatures, although overall fertilisation was greater at $\mathrm{pH} 7.65 / 0.4^{\circ} \mathrm{C}$ compared to the control temperatures (60\% and 50\%, respectively). Developmental delays were observed at reduced $\mathrm{pH}$; however the effect varied between experiments. In the first, developmental delays due to reduced $\mathrm{pH}$ were observed at all experimental temperatures and were greatest at $0.4^{\circ} \mathrm{C}$, while in the second experiment, delays only occurred at ambient temperature. The delay at ambient temperature was $2 \mathrm{~d}$ in both experiments. The delaying effect in the first experiment was mitigated by the overall faster development with elevated temperature. Larvae at $\mathrm{pH}$ $7.65 / 0.4^{\circ} \mathrm{C}$ reached competency at $22 \mathrm{~d}$ compared to $24 \mathrm{~d}$ at $\mathrm{pH} 7.98 /-1.6^{\circ} \mathrm{C}$. Larvae from the most extreme treatment $\left(\mathrm{pH} 7.65\right.$ and $0.4^{\circ} \mathrm{C}$ ) still reached the D-larvae stage two days ahead of those at control conditions $\left(\mathrm{pH} 7.98\right.$ and $\left.-1.6^{\circ} \mathrm{C}\right)$.

This also was the first study to perform a detailed analysis of the effect of $\mathrm{pH}$ and temperature on shell size and ultra-structure in Antarctic bivalve larvae. D-larvae from reduced $\mathrm{pH}$ treatments had significantly larger shells at elevated temperatures. While light microscopy suggested no significant effect of $\mathrm{pH}$ on development, SEM analysis revealed that reduced $\mathrm{pH}$ severely impaired the quality of the larval shell at all temperatures. They were more likely to have abnormal larval shapes, as well as malformed hinges and edges. These malformations will carry over into juvenile stages, impairing swimming and feeding capacity, which would reduce settlement success and condition. Additionally, these larvae had lower shell integrity, with high frequencies of pitting and shell damage, including cracking under reduced $\mathrm{pH}$, although elevated temperatures partially ameliorated this effect. Larval shells at reduced $\mathrm{pH}$ were weaker, indicating they will be more susceptible to injury and predation. This would flow on to later life-history stages, impairing success in settlement when juveniles must bury in the sediments. 
This is the second study, and the first for molluscs and Antarctic species, to perform a detailed biochemical analysis of the use of energetic reserves in larvae in response to OA. The larvae of L. elliptica are lecithotrophic, depending on maternally provided energy for development to competency. However, the composition and size of the reserves were unknown. The lipid reserves in the larvae were large, dominated by triacylglycerols and phospholipids. Despite significant depletion of both these lipid classes during development, more than $65 \%$ of the original lipid pool remained at the D-larval stage, suggesting significant reserves exist for later metamorphosis. Higher metabolic rates are expected in response to $\mathrm{pH}$ and temperature stress and supporting these rates may be energetically demanding. However, larvae did not alter use of any of the lipid classes at elevated temperatures. Increases in oxygen consumption in the larvae at elevated temperature indicated low temperature tolerances in L. elliptica larvae, possibly around $-0.5^{\circ} \mathrm{C}$. These may place increased energetic demands on later life stages that cannot depend on maternally provided resources. Under OA, the energetic demands of calcification are expected to increase due to the costs of active maintenance of the $\mathrm{pH}$ of cellular fluids. However, respiration rates were unaffected by reduced $\mathrm{pH}$ and a greater lipid reserve remained in larvae at $\mathrm{pH} 7.65 /-1.7^{\circ} \mathrm{C}$ compared to all other treatments, suggesting larvae may respond to $\mathrm{OA}$ by reducing calcification.

Additionally, the impact of reduced $\mathrm{pH}$ on biodeposition was assessed in adult L. elliptica. Short term (48 h) exposure to reduced $\mathrm{pH}$ (to $\mathrm{pH}$ 7.54) did not influence biodeposition rates or the organic composition of faeces and pseudofaeces, although compositional changes may have occurred in the latter due to increased mucous production or altered particle selection.

Overall, some resilience to projected climate change conditions was observed in the larvae of L. elliptica. Under future elevated temperatures, larger populations could occur due to improved fertilisation as well as larvae reaching competency sooner with no added energetic costs. However, changes in respiration rates indicate that temperature tolerance thresholds are low. The increased metabolic demands with temperatures above $-0.5^{\circ} \mathrm{C}$ could impair growth beyond the D-larval stage, when they are no longer dependent on maternally provided energetic reserves. Additionally, larvae may be compromised by reduced $\mathrm{pH}$, as shell quality and integrity were significantly impaired. This could significantly influence recruitment and mortality rates in settlement, exposing larvae to crushing fractures in burial or reducing burial capacity. Even with slightly greater larval numbers and faster development, an overall 
population decline would occur if larvae fail in settlement. This study has shown that the larvae of L. elliptica are highly sensitive to future ocean change conditions, but future studies of later life history stages are needed to confirm the impacts of these changes on the greater population. 


\section{Table of Contents}

Acknowledgements ........................................................................................................................................

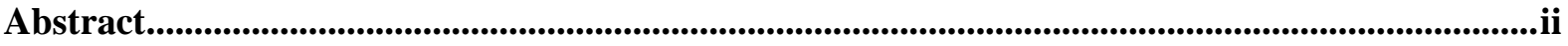

Table of Contents ...................................................................................................................................................... vi

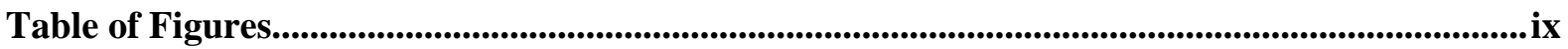

Table of Tables ...........................................................................................................................................................

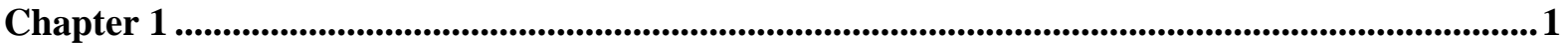

Introduction......................................................................................................................................................... 1

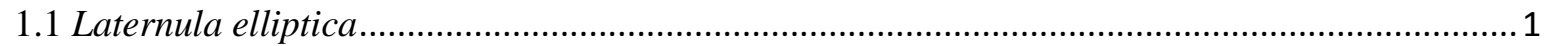

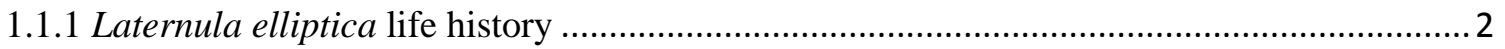

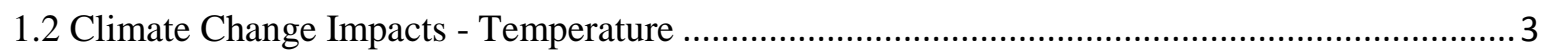

1.2.1 Responses of L. elliptica to ocean warming................................................................. 4

1.3 Climate Change Impacts - Ocean Acidification ........................................................................ 5

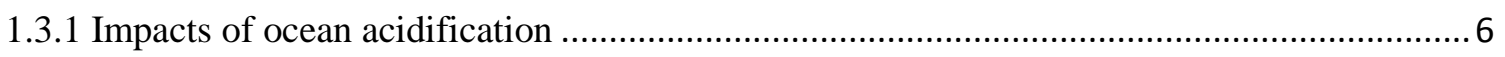

1.3.2 Responses of L. elliptica to ocean acidification..................................................................

1.4 Climate Change Impacts - Other Stressors........................................................................... 11

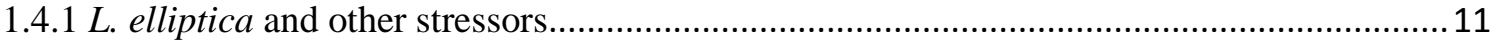

1.5 Larval Responses to Climate Change ……........................................................................ 12

1.5.1 Observed impacts on early life stage survival and development rate ................................ 13

1.5.2 Observed impacts on calcification and larval sizes........................................................... 14

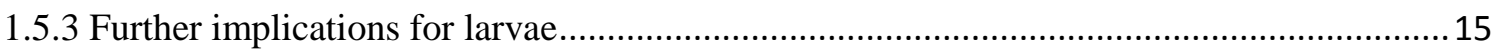

1.5.4 Impacts of climate change stressors on Antarctic larvae .................................................. 16

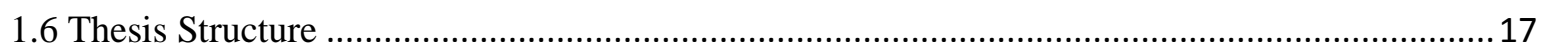

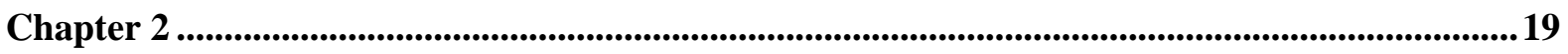

Fertilisation and larval development in the Antarctic bivalve, Laternula elliptica, under reduced pH and elevated temperature....................................................................................................................19

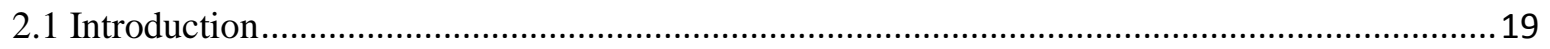

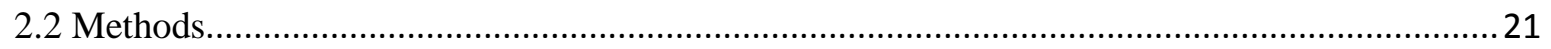

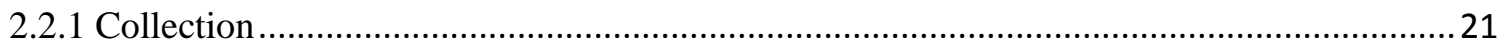




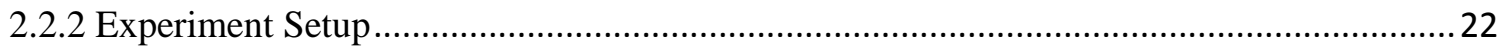

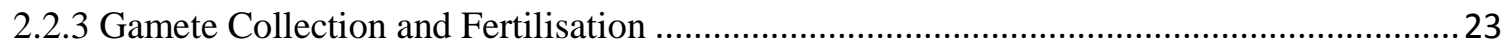

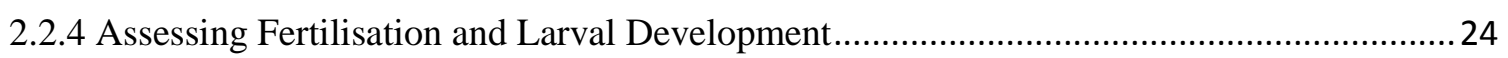

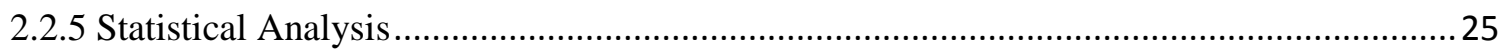

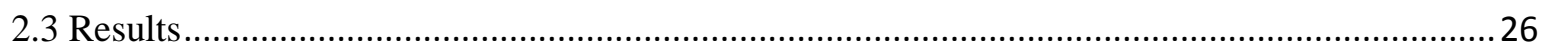

2.3.1 Fertilisation Success and Early Embryonic Stages ........................................................... 28

2.3.2 Trochophore and Veliger Stage Development .................................................................... 31

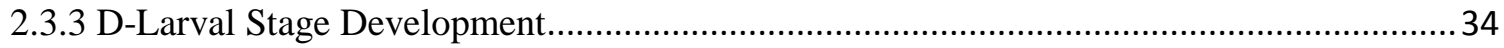

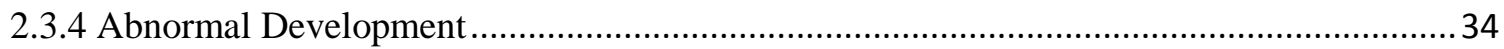

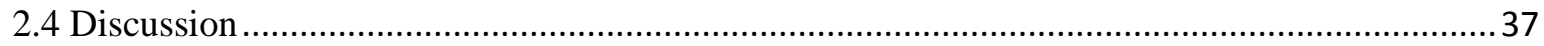

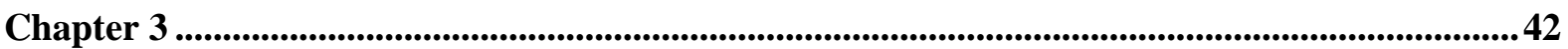

Larval shell development in Laternula elliptica exposed to future climate change conditions .... 42

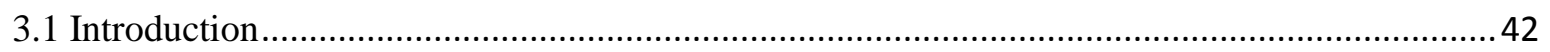

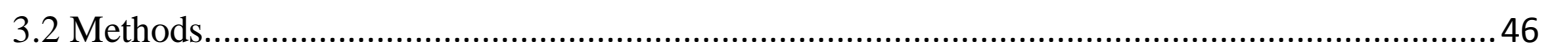

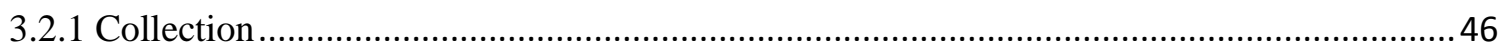

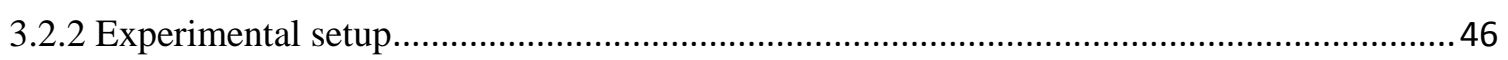

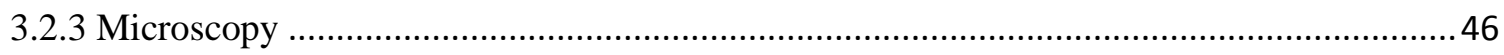

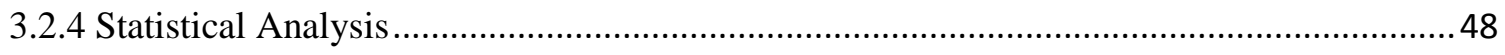

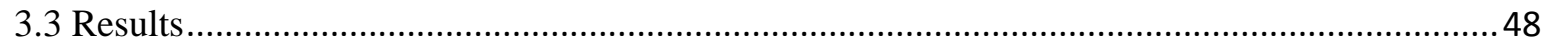

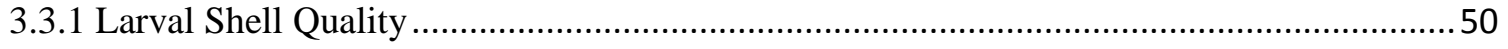

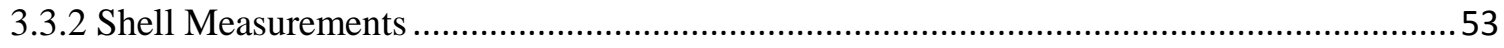

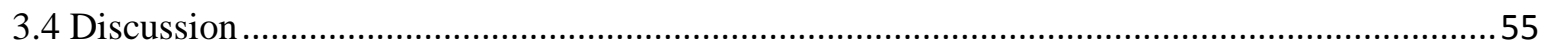

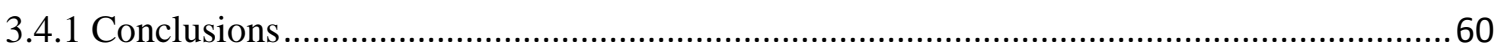

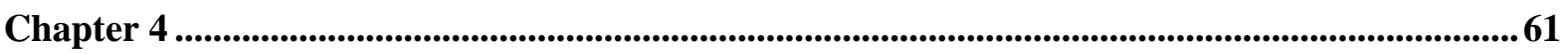

Lipid use in the lecithotrophic larvae of Laternula elliptica under pH and temperature stress ..61

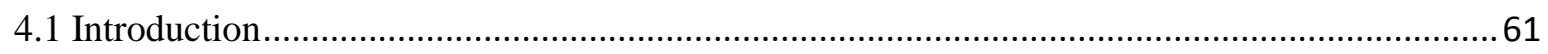

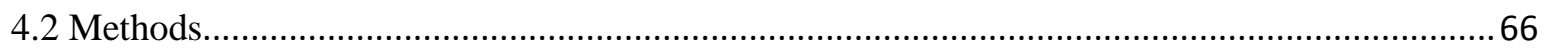

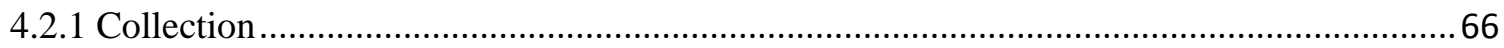

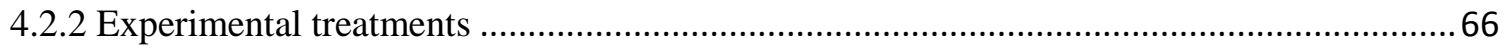

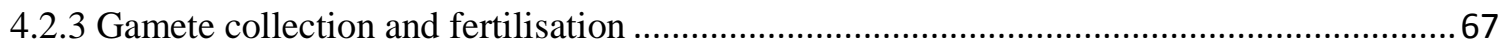

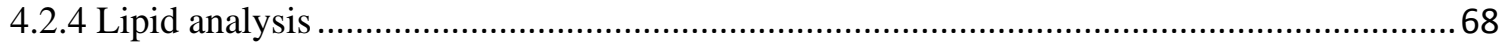

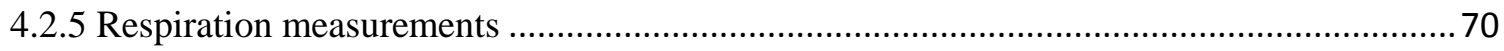

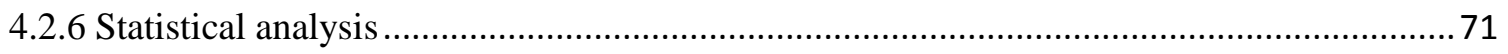




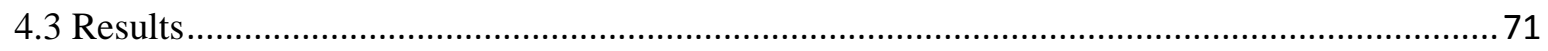

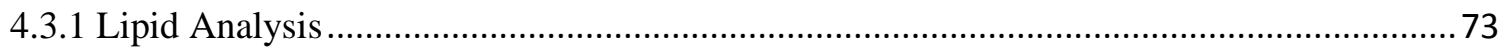

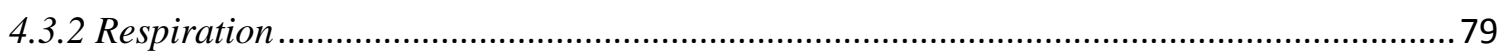

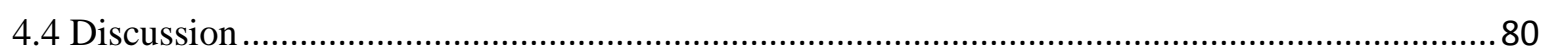

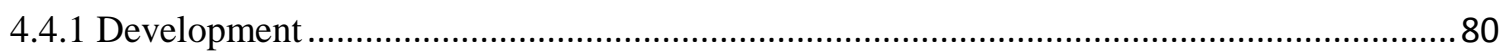

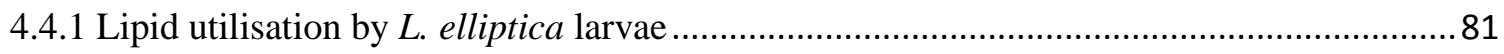

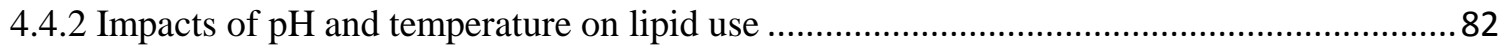

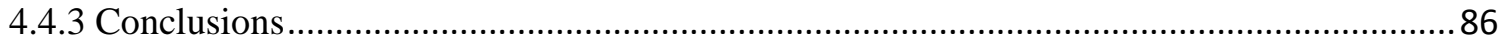

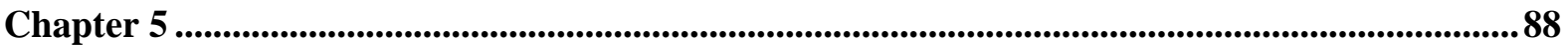

Ocean acidification does not impact biodeposition by the Antarctic bivalve Laternula elliptica. 88

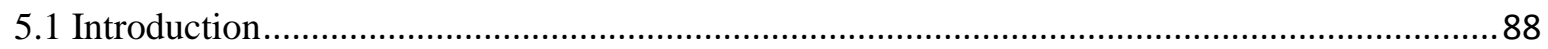

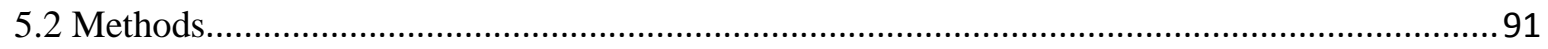

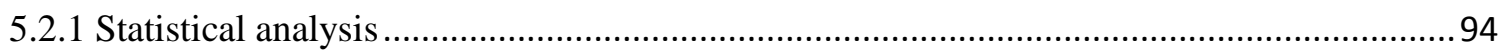

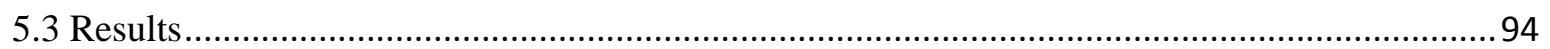

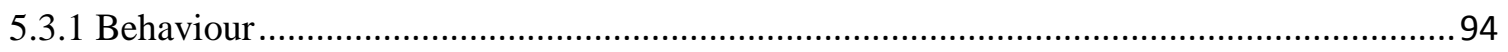

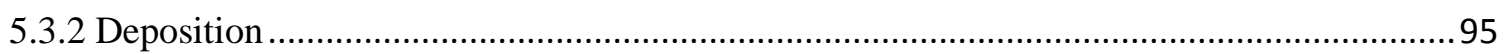

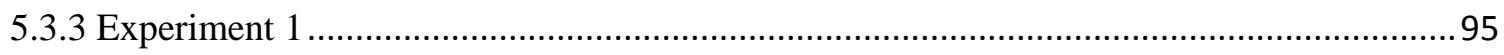

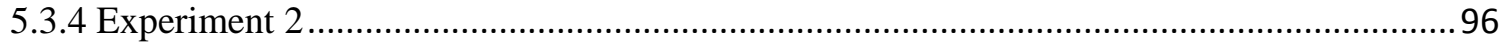

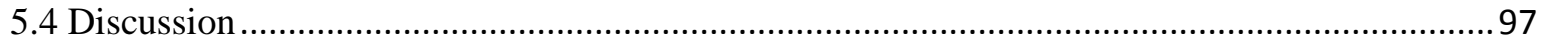

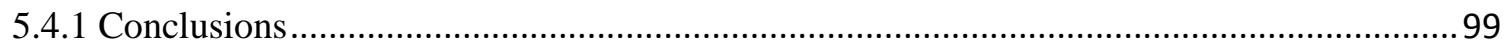

Chapter 6 ..............................................................................................................................................................101

Discussion ........................................................................................................................................................101

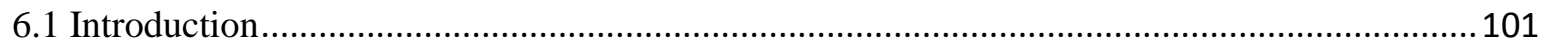

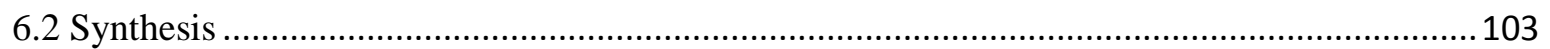

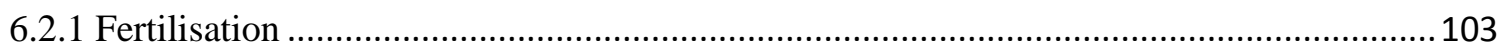

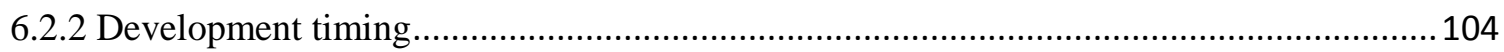

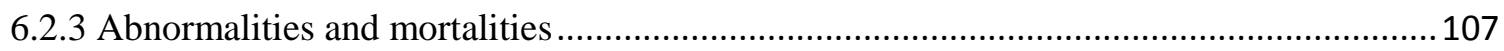

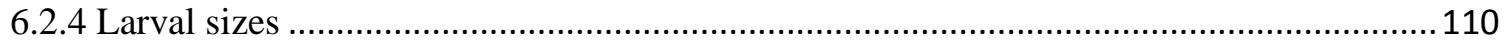

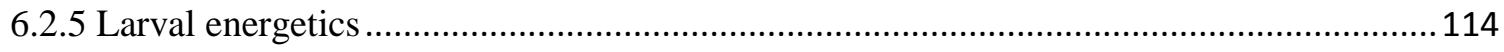

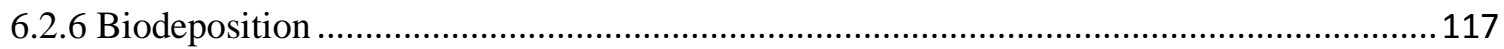

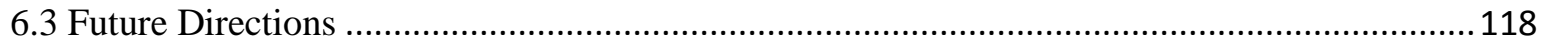

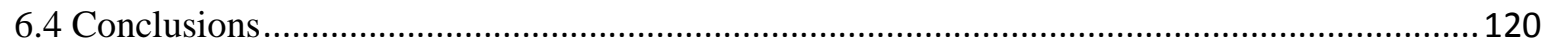




\section{Table of Figures}

\section{Chapter 2}

Fig. 2.1. Examples of embryos and larvae 25

Fig. 2.2. Percentage of eggs fertilised at experimental temperatures and $\mathrm{pH}$...................28

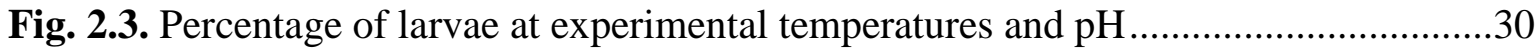

Fig. 2.4. Progression of normal larval development through the trochophore stage ...........31

Fig. 2.5. Percentage of developing larvae at the veliger stage ........................................32

Fig. 2.6. Percentage of normally developing D-larvae ....................................................33

Fig. 2.7. Percentage of developing larvae that were abnormal .........................................35

\section{Chapter 3}

Fig. 3.1. SEM image of the shell of a L. elliptica D-shape larva .....................................45

Fig. 3.2. D-larvae displaying encapsulated development.................................................49

Fig. 3.3. SEM images of D-larvae from experimental treatments ...................................51

Fig. 3.4. Percentage of D-larvae in each treatment that were abnormally shaped ...............52

Fig. 3.5. Shell damage in normal D-shaped larvae from each treatment ...........................53

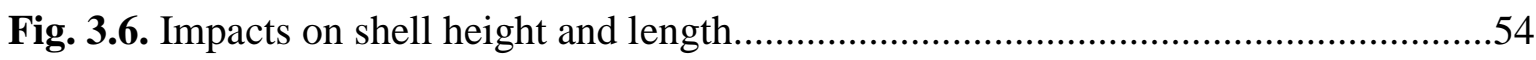

Fig. 3.7. Impacts of reduced $\mathrm{pH}$ and elevated temperatures on PII .................................55

\section{Chapter 4}

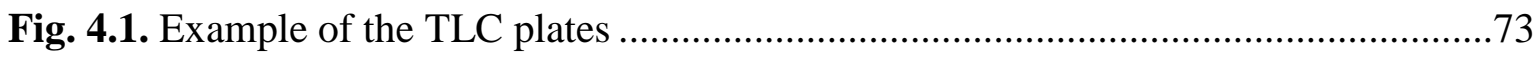

Fig. 4.2. Percent depletion during early development................................................ 77

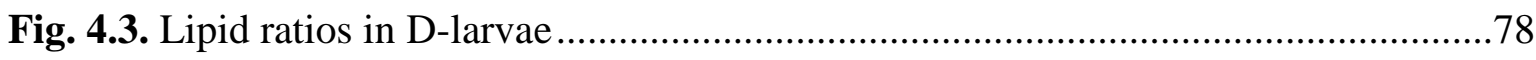


Fig. 4.4. Oxygen consumption in D-larvae .80

\section{Chapter 5}

Fig. 5.1. Set up for biodeposition experiment .92

Fig. 5.2. Average organic and inorganic content of individual daily deposition 95

Fig. 5.3. Total organic and inorganic deposition 97

\section{Chapter 6}

Fig. 6.1. Images of larvae from the Chapter 2 and 3 experiments 109

Fig. 6.2. SEM image of a normal D-shape larva 


\section{Table of Tables}

\section{Chapter 2}

Table 2.1. Seawater conditions for all experimental treatments......................................23

Table 2.2. Projected first observations of individual larval stages ....................................24

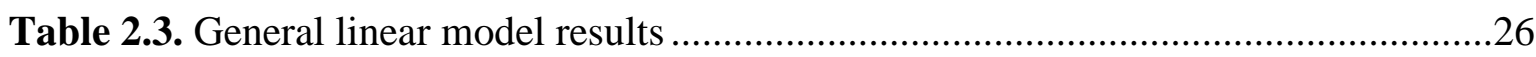

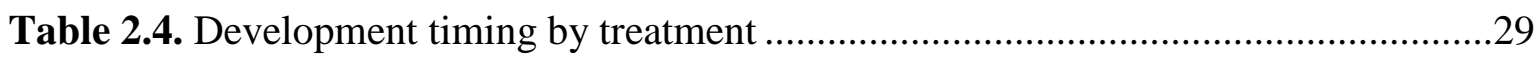

\section{Chapter 3}

Table 3.1. Seawater conditions for all experimental treatments ......................................48

Table 3.2. Summary table of 2 -way ANOVA for factors $\mathrm{pH}$ and temperature...................50

\section{Chapter 4}

Table 4.1. Seawater conditions for each experimental treatment ...................................72

Table 4.2. Days post-fertilisation of first observations of D-larvae .................................72

Table 4.3. Summary of lipid content and ratios in embryos ............................................74

Table 4.4. Summary of one-way ANOVA for difference in lipid content .........................75

Table 4.5. Summary table of 2-way ANOVA for percent depletion .................................76

Table 4.6. Summary table of 2-way ANOVA for respiration .........................................79

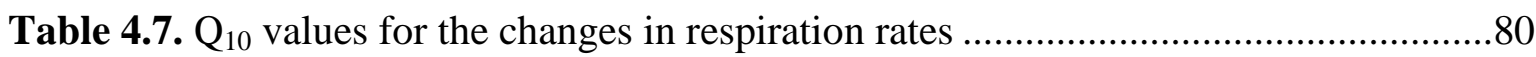

\section{Chapter 5}

Table 5.1. Results of one-way ANOVA on biodeposition in Experiment 1 .....................96

Table 5.2. Results of one-way ANOVA on deposition in Experiment 2.........................96

\section{Chapter 6}

Table 6.1. Summary of the experimental results 101 


\section{Chapter 1}

\section{Introduction}

\subsection{Laternula elliptica}

The Antarctic clam, Laternula elliptica (Laternulidae, King and Broderip), is one of the largest and most ubiquitous molluscs in the Southern Ocean. They are found in densities ranging from 30 to nearly 170 ind. $\mathrm{m}^{-2}$ and with estimated mean biomasses of $4.8 \mathrm{~kg} \mathrm{~m}^{-2}$ (Hardy, 1972; Ahn, 1993). They are slow growing and long lived, reaching shell lengths of $\sim 120 \mathrm{~mm}$ at nearly 40 years of age (Urban and Mercuri, 1998; Philipp et al., 2005). L. elliptica has been found at depths ranging from 1 to $360 \mathrm{~m}$ but is most abundant shallower than $20 \mathrm{~m}$ (Hendler, 1982; Ahn, 1994) and has even been found intertidally (Waller et al., 2016). The upper bounds of this depth range are limited by the influence of ice movements and the lower bounds by phytoplankton availability (Ahn, 1994). These clams burrow deep into most sediments types at settlement (Ralph and Maxwell, 1977; Ansell and Rhodes, 1997). Similar to many infaunal bivalves, L. elliptica have large siphons that they extend up through the sediments to feed.

L. elliptica are suspension feeders that rely on phytoplankton and resuspended benthic material as a food source (e.g. Norkko et al., 2007). Suspension feeders ingest phytoplankton and other seston and sort them for digestion. Rejected particles are bound in mucous strands and are ejected as pseudofaeces, which then are incorporated into the sediments along with faeces (Bayne et al., 1988). In Antarctic environments, many benthic and infaunal organisms rely on such deposits for food, as indicated by the co-occurrence of benthic deposit feeders (Ahn, 1993). During phytoplankton blooms, L. elliptica biodeposition increases, at rates equal to the temperate mussel Mytilus edulis at similar food concentrations, suggesting a high feeding efficiency (Ahn and Shim, 1998). Biodeposits increase the amount of organic and inorganic material deposited in marine sediments compared to passive settling, with organic carbon flux estimated to be $95 \mathrm{mg} \mathrm{C} \mathrm{m}^{-2} \mathrm{~d}^{-1}$ (Bayne et al., 1988; Ahn, 1993). L. elliptica also influences the deposition of terrigenous mineral particles, indicating the clam plays an important role in the sedimentation process. Due to their prevalence in soft bottom areas, $L$. elliptica are an important part of the ecosystem, significantly enhancing particle flux and sediment stabilisation (Ahn, 1993). Since L. elliptica is an important organism in benthic 
coupling, any change in feeding behaviour or population density could significantly alter the carbon content of Antarctic sediments (Ahn, 1993).

Exposure to adverse conditions predicted in climate models may affect L. elliptica's ecological role. Prolonged exposure to warmer temperatures and reduced $\mathrm{pH}$ experienced under climate change scenarios may impact populations through reduced survival, altered behaviour or reduced recruitment. Negative impacts to such a prevalent and important member of the Antarctic fauna could have flow-on effects to the local benthic environment. However, there are some significant gaps in our understanding of their responses to a changing environment.

\subsubsection{Laternula elliptica life history}

There is limited information on the early life history of L. elliptica. L. elliptica is a hermaphroditic, broadcast spawning species. Male and female gonads are fused and are nearly indistinguishable (Ahn et al., 2003) and adults reach sexual maturity at around 2-3 years old, although high reproductive output is not reached until later ages, with the greatest rates occurring in individuals around 76-85 mm in length (Bigatti et al., 2001; Kang et al., 2003). The timing of spawning events varies significantly between regions of the Antarctic and may be linked to timing of local primary production (Urban and Mercuri, 1998; Ahn et al., 2000). In Potter Cove, King George Island, changes in gonad state indicated that approximately $75 \%$ of the population spawned in February and March (Urban and Mercuri, 1998). On the Eastern Coast of the Antarctic Peninsula spawning was observed from December through February (Ahn et al., 2000), while in McMurdo Sound, in the southern Ross Sea, spawning was observed from late March to early April, extending into May (Bosch and Pearse, 1988). Fertilisation success in L. elliptica is dependent on much higher sperm concentrations than in temperate species $\left(5 \times 10^{6}\right.$ to $5 \times 10^{7}$ sperm $\mathrm{ml}^{-1}$ compared to $10^{3}$ to a maximum of $10^{6}$ sperm $\mathrm{ml}^{-1}$ ), which may indicate a higher energetic cost to spawning (Powell et al., 2001). The eggs are large and thickly encapsulated with total diameters $>200$ $\mu \mathrm{m}$ (Ansell and Harvey, 1997). The capsule protects the developing larvae until the shell is developed, at which time they hatch and settle as juveniles in the sediments, although there are indications the larvae may have a short pelagic stage before settlement (Pearse et al., 1985, 1986; Bosch and Pearse, 1988; Berkman et al., 1991; Ansell and Harvey, 1997).

L. elliptica has long embryonic and larval development times, reaching the trochophore stage in $240 \mathrm{~h}$ compared to a range of 8 to $84 \mathrm{~h}$ in related, temperate species (Peck et al., 
2007b). Low metabolic rates as well as sizable energetic reserves in larvae may allow for extended periods of encapsulation before metamorphosis and settlement (Pearse et al., 1986; Peck et al., 2007b). Due to low fecundity and relatively long generation times, genetic adaptation is an unlikely response to a rapidly changing environment. Persistence in this species is more likely to be reliant on an individual animal's adaptive capacity and phenotypic plasticity at various life stages. While responses in larvae have not been studied, comparisons of non-lethal thermal stress responses suggest juvenile L. elliptica are more resilient to temperature stress compared to adults (Clark et al., 2016). The responses of larvae to stressors will be the determining factor in recruitment and long term population abundances. Despite this, the impact that climate change related stressors will have on early life stages is unknown in this species.

\subsection{Climate Change Impacts - Temperature}

Since the beginning of the industrial revolution, levels of atmospheric $\mathrm{CO}_{2}$ have increased, exceeding preindustrial values by around 40\% through anthropogenic activities such as combustion of fossil fuels, increased agriculture and deforestation (Raven et al., 2005; Doney et al., 2009; IPCC 2013). Atmospheric concentrations are far above levels experienced over the last 800,000 years (> $400 \mathrm{ppm}$ compared to a historic range of 172 to $300 \mathrm{ppm}$ ) (Lüthi et al., 2008; Tans and Keeling, 2015). In addition, in recent decades, the increase has occurred at a far greater rate than any change for at least 22,000 years, and if current trends continue, atmospheric $\mathrm{CO}_{2}$ could approach 1000 ppm by 2100 (Raven et al., 2005; Steinacher et al., 2009; IPCC 2013). Increases in greenhouse gases are driving rapid change in the earth's climate, with an increase in the average global surface temperature of around $0.78^{\circ} \mathrm{C}$ in the past 150 years and increases of $0.3-4.8^{\circ} \mathrm{C}$ projected for the end of the century (IPCC, 2013). Atmospheric energy is taken up by the oceans, with over $60 \%$ of the increased energy in the climate system stored in the upper $700 \mathrm{~m}$ (IPCC, 2013). This has led to warming of surface waters of approximately $0.11^{\circ} \mathrm{C}$ per decade with the largest warming observed in the Southern Ocean (IPCC, 2013).

Organism responses to temperature change are variable and will be dependent on their evolutionary history, adaptive capacity, as well as the magnitude of the temperature increase. Adaptive capacity is particularly important in determining long term responses as it allows the rise of tolerant phenotypes. However, adaptive potential is dependent on generation times as well as the natural variability of environmental conditions experienced by the organism 
(Pörtner, 2010; Matson et al., 2012; Kelly and Hofmann, 2013). Organisms that typically experience a greater range in temperature or other stressors may already have mechanisms that allow them to withstand such environmental changes, unless they are already close to tolerance boundaries (Pörtner, 2002a, b). Additionally, even if adaptive mechanisms exist, longer lived species with deferred maturity and long generation times may have limited time in which to develop tolerant phenotypes in a rapidly changing climate.

Changing sea temperatures impact species by increasing biochemical reaction rates and metabolism until thermal thresholds are reached (Morley et al., 2014). Under further warming, organisms experience reductions in physiological activity or mortality (Pörtner, 2002a). Pejus temperatures represent a turning point, where there is a shortfall between oxygen supply and demand, and animal functionality begins to be lost. At higher "critical temperatures" metabolism becomes anaerobic (Pörtner, 2002a) and thereafter lie lethal boundaries. Pejus and critical temperatures are appropriate measures of species' tolerance as they represent a negative change in animal function, where continued exposure would lead to mortalities (Peck et al., 2002; Morley et al., 2012b). Therefore, these limits form the boundaries of thermal sensitivity and tolerance that influence species distribution ranges. As sea temperatures rise, shifts in the northern and southern boundaries of these ranges may be observed. Tolerance windows may be narrower in polar species where cold temperatures dominate (stenothermy) (Peck and Conway, 2000; Pörtner, 2002a). Sensitivities, as well as acclimation capacity, may be governed by the rate of warming, the length of exposure time, as well as life history stages (Peck et al., 2002; Pörtner, 2008; Pörtner, 2010; Morley et al., 2014).

\subsubsection{Responses of L. elliptica to ocean warming}

Under stress, an organism may have a number of differing responses involving different levels of coping or repair mechanisms. Under thermal stress, L. elliptica ceases most metabolic activity until favourable conditions resume. L. elliptica is highly stenothermic, having a temperature tolerance range of around -2 to $+2.5^{\circ} \mathrm{C}$ (Peck et. al 2002, 2004). Animals from the Antarctic Peninsula ceased burrowing activity following exposure to $2^{\circ} \mathrm{C}$ seawater and temperatures of 7.5-9.0 ${ }^{\circ} \mathrm{C}$ were lethal (Pörtner et al., 2006; Morley et al., 2007, 2009; Peck et al., 2007a). Under long term exposure (5 mo.) to elevated temperatures $\left(1-2^{\circ} \mathrm{C}\right.$ above ambient), increased mortality and decreases in physiological condition were observed for adults while the variability of metabolic responses increased, indicating a lack of 
adaptation or acclimation (Hempel, 2016). However, populations of L. elliptica have been found intertidally, where sediment temperatures reached $7.5^{\circ} \mathrm{C}$, suggesting select populations may be adapted to elevated temperatures (Waller et al., 2016).

Under elevated temperatures, L. elliptica increases expression of heat shock proteins (Park et al., 2007; Clark et al., 2008). Heat shock proteins are highly conserved across species and are used in response to cellular damage to aid in protein folding and stabilisation, transportation across membranes as well as regulating heat shock responses (Park et al., 2007). In L. elliptica, heat shock proteins may be part of a cold adaption strategy as they are permanently induced even under nonstressful conditions. Additionally, since the 1990s, a shift in L. elliptica growth rates has been observed in response to temperature in populations along the Antarctic Peninsula (Brey et. al 2011). Coinciding with changing air temperatures as well as increased sedimentation and run-off, the maximum obtainable size has diminished in this species (Brey et al., 2011). Through analysis of decadal patterns of shell growth and energy budgets, over a 50 year period a $25 \%$ drop in maximum sizes was observed that was partially associated with increases in metabolic costs (Brey et al., 2011).

In general, among adult clams, the impacts of environmental change appear to hit hardest on older and larger individuals, possibly due to slower cellular and immune responses, lower metabolic capacity, as well as life time accumulation of cellular waste products and metals (Morley et al., 2009; Husmann et al., 2011; Husmann et al., 2012; Clark et al., 2013; Clark et al., 2016) . Not only are changing temperatures causing a shift in maximum obtainable size, but added stress may also reduce maximum age, and subsequent persistence in this long lived species (Brey et al., 2011; Clark et al., 2013).

\subsection{Climate Change Impacts - Ocean Acidification}

Changes in ocean chemistry may negatively impact invertebrate species, particularly those that calcify. Approximately one third of atmospheric carbon dioxide is taken up by the oceans, making them important carbon sinks (Sabine et al., 2004). As $\mathrm{CO}_{2}$ dissolves in the oceans, carbonic acid $\left(\mathrm{H}_{2} \mathrm{CO}_{3}\right)$ forms and dissociates into hydrogen $\left(\mathrm{H}^{+}\right)$and bicarbonate $\left(\mathrm{HCO}_{3}{ }^{-}\right)$, and further into carbonate $\left(\mathrm{CO}_{3}{ }^{2-}\right)$, as summarised in the following equation (Doney et al., 2009):

$$
\mathrm{CO}_{2}+\mathrm{H}_{2} \mathrm{O} \leftrightarrow \mathrm{H}_{2} \mathrm{CO}_{3} \leftrightarrow \mathrm{HCO}_{3}^{-}+\mathrm{H}^{+} \leftrightarrow \mathrm{CO}_{3}{ }^{2-}+2 \mathrm{H}^{+}
$$


In seawater around $\mathrm{pH} 8.1, \mathrm{CO}_{2}$, along with carbonic acid $\left(\mathrm{H}_{2} \mathrm{CO}_{3}\right)$, makes up less than $1 \%$ of the total dissolved inorganic carbon (DIC) content, while $\mathrm{HCO}_{3}{ }^{-}$accounts for over $90 \%$ of total oceanic DIC and $\mathrm{CO}_{3}{ }^{2-}$ approximately $8 \%$ (Raven et al., 2005; Doney et al., 2009). An overabundance of $\mathrm{CO}_{2}$ shifts the equilibrium and increases the ocean concentrations of $\mathrm{HCO}_{3}{ }^{-}$and $\mathrm{H}^{+}$, subsequently reducing oceanic $\mathrm{pH}$ and $\left[\mathrm{CO}_{3}{ }^{2-}\right]$ due to the increase in $\left[\mathrm{H}^{+}\right]$(Doney et al., 2009). In the past 200 years, an approximate 30\% increase in $\left[\mathrm{H}^{+}\right]$has led to a decrease of 0.1 units in the $\mathrm{pH}$ of surface seawater in the open ocean, in a process referred to as ocean acidification (OA). If current emissions continue unabated, a further decrease of 0.2-0.3 pH units could occur by the year 2100 (Feely et al., 2004; IPCC, 2013). This rate of change is around 10 times greater than any event over the past 300 million years (IGBP et al., 2013). Using $\mathrm{CO}_{2}$ observations from 1975 to 2000 and projections for the years 2000 to 2100 (IS92a scenario, Houghton et al., 2001), an estimated maximum reduction in pH of 0.77 may occur in surface waters by 2300 (Caldeira and Wickett, 2003). This model also showed that oceanic $\mathrm{pH}$ is particularly sensitive to increased $\left[\mathrm{CO}_{2}\right]$ in the short term, as long term change is buffered by interactions with carbonate minerals (Caldeira and Wickett, 2003). Due to the higher solubility of $\mathrm{CO}_{2}$ at colder temperatures and the large differences between seawater and atmospheric partial pressure of $\mathrm{CO}_{2}\left(\mathrm{CCO}_{2}\right)$ at high latitudes, these regions will act as the greatest sinks, and will likely see the most important $p \mathrm{CO}_{2}$ associated decreases in pH (Mostofa et al., 2015).

\subsubsection{Impacts of ocean acidification}

The potential impacts of OA on invertebrates are varied and may include stress through elevated $\mathrm{CO}_{2}$ in internal fluids (hypercapnia), reduced internal $\mathrm{pH}$ (acidosis), impaired calcification and dissolution of calcified structures. Organisms may be influenced through any number of these pathways, the strength and number of which may vary with life history stage as well as other stressors.

\subsubsection{Hypercapnia and acidosis}

As external $p \mathrm{CO}_{2}$ rises, so does intracellular $p \mathrm{CO}_{2}$ (hypercapnia), which impacts diffusion gradients across cell membranes. Increases in seawater $p \mathrm{CO}_{2}$ will reduce organism capacity for $\mathrm{CO}_{2}$ diffusion out of the cell. This will lead to the accumulation of respiratory $\mathrm{CO}_{2}$, which elevates $\left[\mathrm{H}^{+}\right]$and increases internal $\mathrm{pH}$ (acidosis). Organisms may be able to regulate their internal $\mathrm{pH}$ through the metabolic consumption or active transport of protons across membranes, or by reducing respiration to prevent cellular $\mathrm{CO}_{2}$ build up (Pörtner, 2002a, 
2010; Michaelidis et al., 2005). However, these responses may only be effective in the short term. Regulation of cellular acidosis is an active process limited by animal energy budgets and the strength of the stressor (see Thomsen and Melzner, 2010; Hammer et al., 2011). Active regulatory responses and higher metabolic rates would require the use of energy above baseline levels (e.g. Parker et al., 2013). As response mechanisms are metabolically related, they may be absent or limited in organisms with a more sessile habit (Parker et al., 2013). Organisms could provide extra energy for upregulation of metabolism either through redistribution of energy budgets or by changing feeding behaviour (Fernández-Reiriz et al., 2011; Melzner et al., 2011; Navarro et al., 2013; Vargas et al., 2013). However, redistribution of energy would occur at the expense of growth or reproduction, reducing long term population survival. Furthermore, increased food intake may be itself energetically costly and may not be possible if food availability is altered by similar stressors.

A range of factors may determine an organism's ability to withstand hypercapnia and acidosis. For example, most bivalves are particularly sensitive to OA due to a low capacity to regulate acid-base balance of haemolymph, especially at vulnerable early stages (Lindinger et al., 1984; Melzner et al., 2011; Waldbusser et al., 2013; Walbusser et al., 2015). However, there are indications that infaunal organisms may be more resistant to $\mathrm{pH}$ as they have developed mechanisms to cope with the naturally lower $\mathrm{pH}$ found in sediments (Talmage and Gobler, 2011; Styf et al., 2013). Some organisms may have the capacity to buffer pH by increasing $\left[\mathrm{HCO}_{3}{ }^{-}\right]$, however this may come at the expense of calcified structures, as $\mathrm{HCO}_{3}{ }^{-}$ is obtained through shell dissolution (Michaelidis et al., 2005). Organisms using this compensatory mechanism may experience weakened calcified structures not only due to buffering, but also to dissolution and reduced calcification due to the undersaturation of calcium carbonate in seawater (Michaelidis et al., 2005; Berge et al., 2006; Wicks and Roberts, 2012).

\subsubsection{Impacts on calcification}

Organisms may be further impacted by $\mathrm{OA}$ due to the decreased availability of $\mathrm{CO}_{3}{ }^{-2}$, and subsequent reductions in the saturation of calcium carbonate in seawater. The saturation state $(\Omega)$ of calcium carbonate is dependent on a combination of ionic concentrations of $\mathrm{Ca}^{+}$and $\mathrm{CO}_{3}^{-2}$ at a specific temperature, salinity and pressure (Yamamoto-Kawai et al., 2009). $\Omega$ is determined when the product of the concentrations of the calcium and carbonate ions is divided by the apparent stoichiometric solubility product $\left(K_{\mathrm{sp}}{ }\right)($ Steinacher et al., 2009): 


$$
\Omega=\left[\mathrm{Ca}^{2+}\right]\left[\mathrm{CO}_{3}^{2-}\right] / K_{\text {sp }}^{\prime}
$$

As $\left[\mathrm{CO}_{3}{ }^{-2}\right]$ decreases, $\Omega$ is reduced. When $\Omega>1, \mathrm{CaCO}_{3}$ precipitation is favoured, when $\Omega$ $<1$, dissolution of carbonate structures will occur (Fabry et al., 2008). Therefore, as seawater $p \mathrm{CO}_{2}$ rises and $\Omega$ lowers, organisms may have difficulty in biomineralisation or experience dissolution of existing shells and skeletons.

Calcium carbonate has a variety of polymorphs that are precipitated naturally or through biogenic processes (Yamamoto-Kawai et al., 2009). Aragonite and calcite, which are forms of calcium carbonate secreted by marine organisms, have differing $K_{\text {sp }}$ values, leading to differing saturation states (Steinacher et al., 2009). The saturation state of aragonite $\left(\Omega_{\mathrm{Ar}}\right)$ is about $50 \%$ lower than calcite $\left(\Omega_{\mathrm{Ca}}\right)$ meaning organisms with higher aragonite shell compositions may experience dissolution or reduced calcification before organisms with calcite shells (Steinacher et al., 2009). $\Omega_{\mathrm{Ar}}$ and $\Omega_{\mathrm{Ca}}$ decrease with depth due to increased pressure and lower temperature (Orr et al., 2005). The depth at which a polymorph is no longer deposited (i.e. $\Omega_{\mathrm{Ar}}<1$ ) is referred to as the saturation horizon (Orr et al., 2005), and organisms residing near this point are at greater risk of dissolution.

Low production and cold temperatures in polar winters will lead to undersaturation of aragonite as early as 2050 in high latitude waters (Feely et al., 2004; Orr et al., 2005). Year round undersaturation of aragonite is projected for 2100 in the Southern Ocean (McNeil and Matear, 2008; McNeil et al., 2010). The melting of ice in the poles further reduces the saturation state of aragonite through the reduction of salinity, total alkalinity (TA) and DIC (Yamamoto-Kawai et al., 2009).

Reductions in $\left[\mathrm{CO}_{3}^{-2}\right]$ may only impact biomineralisation rates in organisms that rely on $\mathrm{CO}_{3}^{-2}$. In some organisms, including bivalves, $\mathrm{HCO}_{3}{ }^{-}$from seawater, or converted from respiratory $\mathrm{CO}_{2}$, is the important substrate used in calcification (Roleda et al., 2012; Thomsen et al., 2015). Organisms such as these will not be directly impacted by reduced $\left[\mathrm{CO}_{3}^{-2}\right]$ and may be capable of calcification even under extremely low $\mathrm{pH}$ conditions (see Tunnicliffe et al., 2009). However, as biomineralisation is dependent on the saturation states and $\mathrm{pH}$ of calcifying fluids, active calcification may still be impaired by OA. In bivalves, calcification occurs in the extrapallial fluid, between the shell and the mantle (McConnaughey and Gillikin, 2008), and is a complex process, highly controlled and energetically costly to regulate (Wicks and Roberts, 2012). Organisms may modify the saturation state of seawater at the site of calcification by adding calcium ions and actively removing protons, creating a 
microenvironment with a high saturation state (McConnaughey and Gillikin, 2008). The formation of $\mathrm{HCO}_{3}{ }^{-}$, as well as maintenance of internal saturation state and $\mathrm{pH}$ are active processes, meaning organisms may still experience reductions in calcification due to increased energetic cost rather than direct dissolution (Tunnicliffe et al., 2009; Thomsen and Melzner, 2010; Wicks and Roberts, 2012).

Impacts on calcification vary with species. Reduced calcification has been observed in coralline algae (Hall-Spencer et al., 2008), molluscs (Gazeau et al., 2007; Thomsen and Melzner, 2010; Waldbusser et al., 2011), echinoderms (Ries et al., 2009; Dupont et al., 2010), corals (Cohen et al., 2009; Whittmann and Pörtner, 2013) and other invertebrate species (Riebesell et al., 2000; Ries et al., 2009; Whittmann and Pörtner, 2013). Other observed impacts include net dissolution (Orr et al., 2005; Hall-Spencer et al., 2008), altered shell structure (Beniash et al., 2010) and reduced shell size and integrity (Hall-Spencer et al., 2008; Melatunan et al., 2013; Range et al., 2012). Other species show no response or even increases in calcification rates (Iglesias-Rodriguez et al., 2008; Ries et al., 2009; Range et al., 2011). OA may also influence interspecies competition, resulting in reduced biodiversity and trophic complexity within ecosystems (Kroeker et al., 2011; Kroeker et al., 2013b).

Despite the short time until polar waters become undersaturated, information on the impacts on polar organisms is limited. The polar pteropods Limacina helicina and L. helicina antarctica, planktonic molluscs with an aragonite shell, reduce calcification and experience dissolution following exposure to reduced $\mathrm{pH}$ and $\Omega_{\mathrm{Ar}}$ (Comeau et al., 2012a, b). These species are commonly found near or below the saturation horizon for aragonite, indicating the presence of a protective mechanism (Comeau et al., 2012a). Scanning electron imagery (SEM) of the shells of four Antarctic $\mathrm{CaCO}_{3}$ depositing invertebrates, including L. elliptica, exposed to reduced $\mathrm{pH}$ shows significant dissolution and exposure of internal crystalline structure (McClintock et al., 2009). However, the shells were exposed post-mortem, showing only that dissolution occurs without protective measures. The impacts on shells of living specimens remain unknown.

\subsubsection{Responses of $L$. elliptica to ocean acidification}

The impacts of OA on L. elliptica are not as well understood as those of elevated temperatures. The shell of L. elliptica is composed exclusively of aragonite, although the chondrophore, the hinge support on a bivalve shell, also contains calcite and vaterite, an unstable form of $\mathrm{CaCO}_{3}$ (Nehrke et al., 2012). Calcification and shell integrity in this species 
is therefore likely to be susceptible to the lower $\mathrm{pH}$ conditions predicted under future climate scenarios. However, L. elliptica may have some level of control over $\mathrm{pH}$ stress responses, as they are able to maintain calcification while buried in sediments, which are naturally low in pH (see Talmage and Gobler, 2011; Styf et al., 2013).

Under ocean acidification, adult L. elliptica increased oxygen consumption rates (after 4 mo.) and expression of the heat shock protein HSP7O and chitin synthase (after $21 \mathrm{~d}$ ), although no mortalities occurred (Cummings et al., 2011). The increases in the expression of chitin synthase, an enzyme involved in the synthesis of bivalve shells, indicates calcification may become more difficult (Cummings et al., 2011). Following 5 mo. exposure to reduced $\mathrm{pH}$, no statistically significant impacts were observed on overall mortality, metabolic rates or physiological condition (Hempel, 2016). However, nothing is known of the responses in early life history stages.

The shells of L. elliptica are thin and are composed of a thin prismatic/nacreous layer and a thicker outer homogenous layer, typical of more primitive bivalve forms and indicative of a low energetic cost of calcification (Sato-Okoshi and Okoshi, 2008; Sato-Okoshi et al., 2010). Prolonged exposure to seawater undersaturated in aragonite impacts these calcified structures. As noted above, fresh empty shells of L. elliptica exposed to low $\mathrm{pH}$ displayed significant dissolution and brittleness after 28 days (McClintock et al., 2009). However, dissolution in the shells of dead individuals is not a realistic indicator of a species response to changing ocean conditions. A living specimen may be able to maintain calcification and/or actively compensate for external pressures. Additionally, structures such as the epithelium or periostracum may protect calcified structures from dissolution (see Tunnicliffe et al., 2009; Przeslawski et al., 2015; Peck et al., 2016). The ability of calcifying organisms to survive ocean acidification is contingent on their capacity to continue growing and developing.

The total body masses of calcifying species from the Southern Ocean have lower inorganic content than those from warmer latitudes, indicating lower shell masses (Watson et al., 2012). This may be related to reduced predation pressure, increased costs of cold water calcification or to lower metabolic rates. Some Southern Ocean species have high plasticity in skeleton formation, reducing energetic costs by minimising calcification but maintaining the capacity to respond to environmental pressures such as ice related disturbances or low $\Omega$ (Watson et al., 2012). Some level of plasticity in calcification exists in L. elliptica. For example, significant variation in shell morphology observed between populations was attributed to the 
frequency of local ice impact events rather than genetic variation, indicating calcification in this species responds to environmental input (Harper et al., 2012). Additionally, repair of shell damage has been observed in specimens from more disturbed areas, suggesting that active maintenance of established structures can occur (Harper et al., 2012).

\subsection{Climate Change Impacts - Other Stressors}

In addition to ocean warming and acidification, increased air temperatures will impact salinity, sea levels, sea ice extent, water column stratification, oxygen saturation, patterns of water circulation, precipitation and freshwater input (Arrigo and Thomas, 2004; IPCC, 2013). The rates of change in many of these stressors are high and accelerating (Doney et al., 2012). Not only will these factors directly influence individual organisms, but their impacts cascade to populations and ecosystems due to changing abundances, food availability and seasonality, as well as shifts in population boundaries. Changes in ice regimes due to global warming may also influence trophic structures. Sea ice is a major driver of ecosystem function in polar regions, influencing light availability and subsequently, primary production (Arrigo and Thomas, 2004; Norkko et al., 2007). Additionally, sea ice indirectly influences benthic diversity by seeding benthic environments with ice algae (e.g. Norkko et al., 2007).

As the most isolated continent, Antarctica remains one of the most untouched regions of the world; however it is not fully free of anthropogenic influences. A number of permanent research stations around the continent distribute various pollutants to the surrounding land and sea (Ahn et al., 2001). Increased run off due to glacier retreat would impact not only salinity, but also the amount of lithogenic particles, changing the inorganic and organic content of the seston, and possibly introducing toxins, such as heavy metals from research stations or volcanic soils (Husmann et al., 2012; Sahade et al., 2015). Changes in sedimentation may also have significant consequences to biodiversity in benthic assemblages (Sahade et al., 2015).

\subsubsection{L. elliptica and other stressors}

The cues for increases in feeding behaviour and other activity in L. elliptica show a strong link to variations in air temperatures, opposed to sea water temperature (Brey et al., 2011). Rather than being a direct response, this is likely due to elevated air temperatures increasing glacier melt, subsequently impacting salinity or increasing sediment load (see Brey et al., 2011). Increased air temperatures may also alter the timing of these blooms and subsequent 
cues in L. elliptica. Additionally, elevated temperatures may cause changes in sea ice cover that could change the seasonality of food supply. However, the impacts may be minimal. Phytoplankton bloom timing typically varies year to year, and the diet of L. elliptica is fairly opportunistic, depending on the relative abundances of algae and detritus made available through primary production or advection. Additionally, the potential influence of changing ice cover on ecosystem trophic structure is complex.

Reduced $\mathrm{O}_{2}$ solubility in warmer oceans as well as increased stratification will increase the frequency of hypoxic events. Temperature tolerance thresholds in L. elliptica are dependent on oxygen availability (Pörtner et al., 2006), and the impacts of hypoxia are greater in older and larger individuals (Clark et al., 2013). Simultaneous hypoxia and temperature elevation could influence population age and subsequent population sizes as larger individuals are typically more fecund. Due to modelled impacts on reproductive potential and mortality rates at different life stages, L. elliptica may experience a $75 \%$ population reduction under end of century temperature and $\mathrm{pH}$ projections (Guy et al., 2014). Biological success or fitness is not measured by the number of individuals in an adult population, but rather by the population's capacity to propagate (Orr, 2009). In population genetics, the fitness of a population is largely based on the number of reproducing adults and recruiting larvae (Orr, 2009). Population analysis of L. elliptica suggests that a $5 \%$ increase in mortality rates in early life history stages would result in significant declines in population within the next 60 years (Guy et al., 2014). A species not reproducing and recruiting individuals at a rate that replaces or outnumbers the previous population cannot be considered successful. It is therefore important to consider reproductive success along with the responses of the whole organism in any study of the effects of ocean acidification and temperature. Additionally, in long lived species with deferred maturity, phenotypic plasticity and the ability to compensate for environmental stress in all life stages may be more important than genetic adaptation.

\subsection{Larval Responses to Climate Change}

Responses to environmental stressors vary greatly amongst species and taxonomic groups, as well as life stages (Kroeker et al., 2010, 2013a; Pereira et al., 2015). Larvae are the most vulnerable point of development in an organism's life history. This is due to the relatively small size of larvae, increasing the proportion of cells exposed to the external environment (Pechenik, 1999; Melzner et al., 2009). Additionally, adaptive mechanisms in adults may not be functional or present in larvae and embryos (Melzner et al., 2009; Waldbusser et al., 
2013). In more sessile species, planktonic larvae also may be the only opportunity to migrate away from stressful conditions and establish new populations. As early life history stages represent bottleneck points for populations, even small changes to the already high early mortality rates could have significant flow-on effects to later stages and the greater population (e.g. Parker et al., 2013; Guy et al., 2014).

The success of fertilisation and development under environmental stress is an important component of species' success and adaptive potential (Byrne, 2011). Genetic recombination may allow for the rise of tolerant phenotypes in responses to stress, however this is largely dependent on the phenotypic and genetic variation present within a population, as well as generation time (Sunday et al., 2011). Longer lived species, which generally reach sexual maturity at a later age (Ridgway et al., 2011), will be less able to adapt to stressors as long generation times reduce opportunities for genetic responses on short time frames.

\subsubsection{Observed impacts on early life stage survival and development rate}

Elevated temperatures and reduced $\mathrm{pH}$ may have impacts on development as early as gamete release and fertilisation, reducing fertilisation success or impairing viability (Kurihara and Shirayama, 2004; Byrne et al., 2009; Ellis et al., 2009; Parker et al., 2010; Pecorino et al., 2014). Temperature impacts on larval development success can be varied. For example, small elevations in temperature may reduce mortality rates in some mollusc larvae, as well as increase development rates (Davis et al., 2013; Dorey et al., 2013). Additionally, elevated temperatures may alleviate some of the negative effects of OA in urchin larvae (Byrne et al., 2011; Davis et al., 2013). In contrast, in an abalone and a sea urchin, moderate warming increased occurrences of abnormal development and thermotolerance was exceeded with only a $4^{\circ} \mathrm{C}$ elevation in temperature (Byrne et al., 2011). In bivalves, elevated temperatures increased mortality and sensitivity to other stressors, and reduced the accumulation of lipids, important in energy storage for metamorphosis (Talmage and Gobler, 2011).

Larval development rates are generally negatively impacted by reduced $\mathrm{pH}$, with larvae delaying metamorphosis or needing more time to reach equivalent life stages compared to those at ambient conditions (Talmage and Gobler, 2009; Davis et al., 2013; Gazeau et al., 2013). Reduced pH also increases occurrences of abnormal development in urchins (Byrne et al., 2013a; b), oysters (Parker et al., 2009; Parker et al., 2010) and abalone (Byrne et al., 2011). Compared to other invertebrate taxa, mollusc larvae are particularly sensitive to OA (Kroeker et al., 2010; Kroeker et al., 2013a). For example, increased mortality rates have 
been observed in pteropods (Gazeau et al., 2013), gastropods (Crim et al., 2011; Davis et al., 2013) and bivalves (Talmage and Gobler, 2009; Watson et al., 2009).

\subsubsection{Observed impacts on calcification and larval sizes}

While increased temperatures enhance growth in some larvae and may mitigate the effects of pH (Sheppard Brennand et al., 2010; Byrne et al., 2013a, b), species living near their thermal thresholds may experience reduced growth with further temperature elevation (Talmage and Gobler, 2011). Larval calcification may be particularly sensitive to OA due to high rates of calcification relative to body mass, indicating a larger metabolic burden to calcification (Thomsen et al., 2015). OA may increase the energetic cost of calcification, resulting in unshelled larvae (Crim et al., 2011), reduced calcium content (Miller et al., 2009) or shell dissolution (Watson et al., 2009; Talmage and Gobler, 2010). Calcification in the early stages of invertebrate development may be particularly sensitive not only due to the lack of regulatory mechanisms, but also due to the fact that they secrete more soluble forms of $\mathrm{CaCO}_{3}$ (e.g. in urchins and bivlaves; Weiss et al., 2002; Addadi et al., 2003).

OA may alter skeleton size, shape and morphology, as observed in urchin larvae which may have implications on larval feeding and swimming capacity (Matson et al., 2012; Davis et al., 2013). Altered and abnormal shell shapes have also been observed in gastropods (Ellis et al., 2009; Crim et al., 2011) and bivalves (Talmage and Gobler, 2010; Barros et al., 2013). Bivalve shells provide support for muscles and organs while hinges facilitate opening and closing, altered shell shapes may reduce larval movement and subsequent feeding and excretion (Talmage and Gobler, 2010; Andersen et al., 2013). OA also reduces calcification and shell integrity while causing simultaneous dissolution of existing structures; causing larvae to produce weaker, thinner shells (Watson et al., 2009; Gaylord et al., 2011). This would lead larvae to being more vulnerable to predation as well as crushing injuries at settlement (Talmage and Gobler, 2010).

Smaller shell sizes due to reduced calcification have been observed in marine molluscs including pteropods (Gazeau et al., 2013), abalone (Crim et al., 2011), mussels (Bechmann et al., 2011; Gaylord et al., 2011) and oysters (Miller et al., 2009; Parker et al., 2009; Watson et al., 2009; Barros et al., 2013). Smaller larvae observed under OA may be a result of delays in development due to the increased metabolic demands, or conversely may represent the sacrifice of somatic growth at the expense of the development of vital structure (Stumpp et al., 2011b; Matson et al., 2012). There are negative implications to either scenario. Larger 
larvae may have better success in settlement, and if reduced $\mathrm{pH}$ is creating smaller larvae at competency, it would likely indicate they are weaker and may be more susceptible to predation (Martel et al., 2014). Alternatively, delays in planktonic development would significantly reduce settlement success (Rodriguez et al., 1993). If reduced pH prolongs development periods, larvae will spend more time at development stages that are considered highly vulnerable to predation (Martel et al., 2014).

\subsubsection{Further implications for larvae}

The vulnerability of larvae may be dependent on life history strategy. Larvae fuel early development through maternally provided resources that are either sufficient for the development of an independently feeding larva (planktotrophy) or large enough to allow the larvae to bypass feeding stages and metamorphose into juveniles (lecithotrophy). Under OA, the increased metabolic costs of calcification would mean more energy is required to produce equivalent masses of $\mathrm{CaCO}_{3}$ as would be produced under ambient conditions (Thomsen et al., 2015). Impacts to metabolism may include changes to larval activity and heart rates or reductions in lipid availability (Ellis et al., 2009; Talmage and Gobler, 2011). Stress during development could place pressure on energetic reserves which may be limited in some larvae. This could occur by increased use of existing reserves or by the diversion of energetic resources to maintain cellular function under stress responses that alter metabolic rates (Stumpp et al., 2011b; Matson et al., 2012; Waldbusser et al., 2013).

Metamorphosis into juveniles is energetically demanding (Bayne, 1971). Larvae must be non-feeding during a portion of metamorphosis, as their feeding structures are being formed (Holland and Spencer, 1973; Lu et al., 1999). In planktotrophic species, lipids accumulated during development are relied on for successful metamorphosis, however, lecithotrophic larvae cannot replenish their energetic reserves. Increased usage during embryogenesis would mean reductions in the energetic pool available, preventing successful metamorphosis (although some lecithotrophic larvae may take up dissolved nutrients; Jaeckle and Manahan, 1989). Additionally, successful settlement of larvae may be sensitive to changes in environmental conditions, such as temperature or saturation state in the sediments. Changes in these cues may impact the timing of settling or metamorphosis, potentially before larvae reach competency (Rodriguez et al., 1993; Pechenik, 1999; Green et al., 2009, 2013). If larvae reach metamorphic competency faster with no significant depletion of energetic reserves, reserves may allow them to delay settlement until favourable conditions are met 
(Paulay and Meyer, 2006). Conversely, developmental delays may result in larvae that are unprepared for metamorphosis when they receive favourable cues (Stumpp et al., 2011b).

Larval survival and response to stressors may be further impacted by the conditions experienced by adults, through carry-over effects or transgenerational epigenetic inheritance (Miller et al., 2012; Parker et al., 2015). Offspring of oysters with prior exposure to high $p \mathrm{CO}_{2}$ conditions had lower rates of abnormality, faster development and faster shell growth compared to offspring of acclimated adults (Parker et al., 2015) and adverse effects of pH were absent in juvenile fish with parents exposed to similar conditions (Miller et al., 2012). Additionally, mothers may alter maternal investment based on local environment or conditions experienced during gametogenesis (Miller et al., 2012; Parker et al., 2013).

\subsubsection{Impacts of climate change stressors on Antarctic larvae}

Sensitivity to OA and warming has been observed in early life stages of Antarctic species. For example, increased temperature reduced viability of embryos in Odontaster meridionalis (Stanwell-Smith and Peck, 1998). In the echinoid Sterechinus neumayeri, increased temperature alone reduced egg viability, but enhanced fertilisation, and the combination of elevated temperatures and reduced $\mathrm{pH}$ reduced fertilisation (Stanwell-Smith and Peck, 1998; Ericson et al., 2012; Ho et al., 2013). Elevated temperature also increased late stage larval sizes in S. neumayeri, but negatively affected later development, up to the blastula stage (Ericson et al., 2012) and increased sensitivity to pH (Davis et al., 2013; Kapsenberg and Hofmann, 2014).

S. neumayeri is less sensitive to reduced $\mathrm{pH}$, compared to similar species from temperate and tropical regions (Clark et al., 2009; Kapsenberg and Hofmann, 2014). For example, larvae raised under very low $\mathrm{pH}$ had no degradation or malformation of fine skeletal structures (Clark et al., 2009). However, OA reduced fertilisation success at low sperm concentrations, and may increase polyspermy (Ericson et al., 2010; Sewell et al., 2013). Reduced $\mathrm{pH}$ also increased abnormal development in early larval stages of $S$. neumayeri (Ericson et al., 2012) and negatively impacted larval morphology and size (Clark et al., 2009; Yu et al., 2011; Davis et al., 2013).

Reduced $\mathrm{pH}$ also impaired fertilisation at low sperm concentrations in the Antarctic sea star Odontaster validus (Gonzalez-Bernat et al., 2013). O. validus larvae were also smaller and had higher rates of abnormality and mortality (Gonzalez-Bernat et al., 2013). Reduced 
$\mathrm{pH}$ had no impact on fertilisation success in the nemertean worm Parborlasia corrugatus and late stage larvae were only sensitive to very large pH reductions (Ericson et al., 2010).

Impacts of $\mathrm{pH}$ and temperature stress in other Antarctic species include decreased hatching success with reduced $\mathrm{pH}$ in Antarctic krill (Kurihara, 2008), and developmental delays with no increases in abnormality in the sub-Antarctic sea urchin Arbacia dufresnei (Catarino et al., 2012). In the Antarctic dragonfish, Gymnodraco acuticeps, increased $p \mathrm{CO}_{2}$ and temperature independently improved development, but when combined, embryos developed more slowly and had increased mortality (Flynn et al., 2015).

\subsection{Thesis Structure}

The responses of L. elliptica larvae and adults to environmental perturbations of elevated temperature and reduced $\mathrm{pH}$ were examined in a series of laboratory experiments. Chapters 2-5 of this thesis were written as independent papers prepared for publication, and therefore will be subject to a degree of repetition.

Chapter $2^{1}$ presents a study of patterns of larval development under ecologically relevant reduced $\mathrm{pH}$ and elevated temperature using a laboratory experiment. This assessed impacts on L. elliptica larval developmental success, including rates of mortality and abnormality and the timing of development stages.

Chapter 3 provides a closer analysis of the morphology and quality of the larvae from the Chapter 2 experiment using scanning electron microscope techniques. The impacts of $\mathrm{pH}$ and temperature were further assessed by comparing shell growth and quality at two points during larval shell development.

Chapter 4 concerned the energetics of lecithotrophic larval development. The utilisation of lipids, the lipid classes and relative importance of the classes were assessed through an analysis of the changes in the lipid content in development to the D-larval stage. Additionally, the potential metabolic cost of development under reduced $\mathrm{pH}$ and elevated

\footnotetext{
${ }^{1}$ This chapter was published in 2015 as follows:
}

Bylenga CH, Cummings VJ, Ryan KG (2015) Fertilisation and larval development in the Antarctic bivalve, Laternula elliptica, under reduced $\mathrm{pH}$ and elevated temperatures. Marine Ecology Progress Series 536:187-201 
temperature conditions was determined by comparing differences in total lipid and lipid class depletion, as well as oxygen consumption in late stage development.

Chapter 5 assessed adult feeding behaviour and biodeposition during short-term exposures to reduced $\mathrm{pH}$. The results and implications of Chapters 2-5 are synthesised and discussed in the sixth and final chapter.

This thesis and the experiments it describes were written, designed and performed by myself, while support and advice were received from my supervisors, Drs. Vonda Cummings and Ken Ryan. The published manuscript for Chapter 2 was written and prepared by myself, with comments and editing from my supervisors, the secondary authors, as well as three anonymous reviewers and Marine Ecology Progress Series editor Dr. James McClintock. In Chapter 3, assistance in the preparation of sample stubs for SEM analysis was provided by David Flynn. In Chapter 4, I performed lipid analysis in Dr. Mary Sewell's laboratory (University of Auckland), while the identification of the lipid classes by TLC was performed by Josefina Peters-Didier on samples prepared by myself. 


\section{Chapter 2}

\section{Fertilisation and larval development in the Antarctic bivalve, Laternula elliptica, under reduced $\mathrm{pH}$ and elevated temperature ${ }^{2}$}

\subsection{Introduction}

Since the industrial revolution, a $40 \%$ increase in atmospheric $\mathrm{CO}_{2}(>400 \mathrm{ppm})$ has resulted in large scale changes in global climate (IPCC, 2013; Tans and Keeling, 2015). Even under best-case mitigation scenarios further increases in atmospheric $\mathrm{CO}_{2}$ are projected (up to 450 ppm by 2100; Calvin et al., 2009; Fischedick et al., 2011). Radiative forcing due to increased greehouse gases results in increased energy uptake in global climate systems and subsequently, atmospheric temperatures are predicted to increase. Over $90 \%$ of the total energy increase observed in the climate system is stored in the oceans $(60 \%$ in the upper 700 $\mathrm{m}$ ), leading to warmer oceans (IPCC, 2013). Additionally, increased $\mathrm{CO}_{2}$ concentrations affect ocean chemistry through hydrolysis with seawater, which results in increased hydrogen ion $\left(\mathrm{H}^{+}\right)$concentrations and a subsequent drop in $\mathrm{pH}$ (Seibel and Walsh, 2003; Orr et al., 2005). Since measurements began, surface $\mathrm{pH}$ levels have reduced by approximately $0.1 \mathrm{pH}$ unit with up to a further 0.3 unit drop projected by the end of the century (IPCC, 2013). The increased $\left[\mathrm{H}^{+}\right]$is buffered by carbonate ions through the formation of bicarbonate, reducing the carbonate saturation state $(\Omega)$. As $\Omega$ decreases to undersaturation $(\Omega<1)$, dissolution of calcium carbonate $\left(\mathrm{CaCO}_{3}\right)$ occurs. As $\mathrm{CO}_{2}$ dissolves more readily in cold water, the effects of ocean acidification will be felt soonest in polar and/or deep regions (IPCC, 2013). Organisms using aragonite (a relatively unstable form of $\mathrm{CaCO}_{3}$ ) in shell formation may soon experience undersaturation in winter months in the Antarctic (McNeil et al., 2010).

Early life stages are important in the context of environmental stressors as sensitivity may affect species' persistence, success and adaptation (Byrne, 2011). Due to the high percentage of cells exposed to ocean conditions, invertebrate larvae may be more vulnerable to changes in ocean chemistry than to adults (Pechenik, 1999; Melzner et al., 2009). As oceanic $p \mathrm{CO}_{2}$ increases, diffusion of $\mathrm{CO}_{2}$ out of the cells becomes difficult. In adults, and some juveniles,

\footnotetext{
${ }^{2}$ This chapter is reproduced as it was published (Bylenga et al., 2015). The experimental concept, design, performance and data analysis was performed by myself. The manuscript was written by myself with comments and editing provided by Drs. Vonda Cummings and Ken Ryan, the secondary authors, as well as three anonymous reviewers and Marine Ecology Progress Series editor Dr. James McClintock.
} 
the $\mathrm{pH}$ gradient may be maintained either by increasing the metabolic rate or by switching to anaerobic metabolism. However, larvae have a limited capacity to regulate internal $\mathrm{pH}$ and ion transport systems (Melzner et al., 2009; Waldbusser et al., 2013).

Responses to temperature stress in invertebrate larvae are diverse and may include altered growth rates, increases in abnormal development and mortalities, as well as mitigation of $\mathrm{pH}$ effects (Byrne et al., 2011; Davis et al., 2013; Pecorino et al., 2014). The impacts of changes in $\mathrm{pH}$ and temperature on fertilisation vary in marine organisms, with many species being resistant to all but the most extreme conditions and others only showing negative impacts when stressors are combined (Byrne, 2011; Ericson et al., 2012; Gonzalez-Bernat et al., 2013). Furthermore, the observed effects of temperature and $\mathrm{pH}$ stressors on fertilisation may be dependent on sperm concentrations, population or experimental design (Reuter et al., 2011; Ho et al., 2013; Sewell et al., 2013). Other responses to temperature and pH stress include smaller larvae, reduced lipid content, reduced calcification and increased abnormal development (Talmage and Gobler, 2011; Nguyen et al., 2012; Andersen et al., 2013; Byrne et al., 2013a). Reduced pH can cause down-regulation of genes involved in skeletogenesis and metabolism in sea urchin larvae (O'Donnell et al., 2010), while reduced survivorship, particularly in later development stages, has been observed in mollusc larvae (Talmage and Gobler, 2009; Van Colen et al., 2012).

In bivalves, changes in shell development have occurred in response to ocean acidification and warming. These include reduced calcification, weakened shells, increased pitting, and changes in $\mathrm{CaCO}_{3}$ crystal structure (Watson et al., 2009; Beniash et al., 2010; Gaylord et al., 2011; Gobler and Talmage, 2013). Additionally, deformities in shell hinges and valve edges have occurred, which may significantly reduce larval survival by impairing feeding behaviour and mobility (Talmage and Gobler, 2010; Andersen et al., 2013; Gazeau et al., 2013; Parker et al., 2013).

The Antarctic geoduck, Laternula elliptica, is a deep burrowing bivalve with a circumpolar distribution. It occurs at depths from 0 to $360 \mathrm{~m}$, but is common between 5 and $30 \mathrm{~m}$ where densities of 50 to 170 ind. $\mathrm{m}^{-2}$ have been recorded (Powell, 1965; Hendler, 1982; Ahn, 1994; Cummings et al., 2011). Adult L. elliptica are temperature sensitive, with animals from the Antarctic Peninsula region having a reduced capacity for activities such as reburying at $2.5^{\circ} \mathrm{C}$ and exhibiting a complete loss of reburying capability at $5^{\circ} \mathrm{C}$ (Urban and Silva, 1998; Peck et al., 2002; Peck et al., 2004). Above $6^{\circ} \mathrm{C}$, increased oxygen consumption 
followed by a switch to anaerobic metabolism occurs, and prolonged exposure to temperatures exceeding $9^{\circ} \mathrm{C}$ is lethal (Heise et al., 2003; Peck et al., 2004). L. elliptica may be able to withstand small elevations in temperature by entering into low or anaerobic metabolic states, allowing for the conservation of energy until conditions become more favourable (Morley et al., 2007). Longer-term exposure to elevated temperatures suggests that adults have little or no capacity for acclimation, although their responses may be dependent on other factors such as season and food supply (Morley et al., 2012a, b).

The responses of L. elliptica to reductions in $\mathrm{pH}$ are less well studied. When exposed to low pH sea water, empty shells are prone to rapid dissolution (McClintock et al., 2009). Living L. elliptica adults exposed to low $\mathrm{pH}$ increased expression of the heat shock protein HSP70 and chitin synthase, an enzyme involved in shell formation (Cummings et al., 2011). Oxygen consumption also increased with decreased $\mathrm{pH}$, indicating a metabolic effect. Despite these changes in protein expression and metabolism, exposure to reduced $\mathrm{pH}$ did not result in mortality after 120 days (Cummings et al., 2011). Although the adults appear resilient (at least in the short term) to lowered $\mathrm{pH}$ and elevated temperatures on the order predicted for the end of this century, effects on early life history of this key bivalve are as yet unknown.

L. elliptica is a simultaneous hermaphrodite with seasonally and age dependent growth and gonad development (Ahn et al., 2003, Husmann et al., 2016). Larvae are large (220 $\mu \mathrm{m})$ and lecithotrophic (Pearse et al., 1985; Pearse et al., 1986). Spawning times vary with significant interannual variation (Ahn et al., 2003). Peak spawning occurs from late February to mid-May in McMurdo Sound (Ross Sea), and in late December through February on the Antarctic Peninsula with juveniles settling in the sediments in the following months (Ahn et al., 2000; Pearse et al., 1985; Pearse et al., 1986). The sensitivity of L. elliptica fertilisation and larval development to warming and acidification is addressed in this study. Fertilisation success and subsequent progression of development, abnormality and mortality are examined in the context of ecologically relevant elevated temperature and reduced $\mathrm{pH}$.

\subsection{Methods}

\subsubsection{Collection}

Adult L. elliptica (4.2-8.9 $\mathrm{cm}$ shell length) were collected from the McMurdo Station

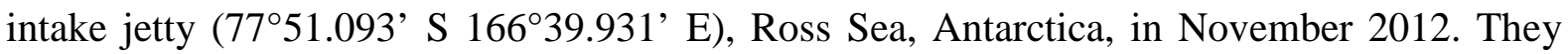


were transported to New Zealand, and held in flow-through tanks with filtered $(0.1 \mu \mathrm{m})$ seawater chilled to $-1.6^{\circ} \mathrm{C}$, at $\mathrm{pH} 7.98$ (ambient conditions in the Ross Sea at the time of collection), until March 2013. They were fed Shellfish Diet 1800 (Reed Aquaculture, USA), a liquid algal mix.

\subsubsection{Experiment Setup}

A combination of three $\mathrm{pH}$ and three temperature treatments were chosen to determine the effects of acidification and/or warming on fertilisation and subsequent embryonic and larval development. These included temperature and $\mathrm{pH}$ controls $\left(-1.6^{\circ} \mathrm{C}\right.$ and $\mathrm{pH} 7.98$, respectively). Projections of change in sea surface temperature and $\mathrm{pH}$ through to the end of the century were represented by two elevated temperatures $\left(-0.5\right.$ and $\left.0.4^{\circ} \mathrm{C}\right)$ and two reduced pHs (pH 7.80 and 7.65) (Table 2.1; Orr et al., 2005; IPCC, 2013). As a maximum of eight treatments were possible due to system logistical constraints, the combination of $0.4^{\circ} \mathrm{C}$ and pH 7.80 was not included.

\subsubsection{Temperature and $\mathrm{pH}$ Manipulation and Measurement}

Temperature and $\mathrm{pH}$ manipulations were performed in eight separate header tanks, which supplied the 48 treatment tanks through insulated lines. The $\mathrm{pH}$ in each header tank was manipulated through the diffusion of food grade $\mathrm{CO}_{2}$, and controlled using Omega $\mathrm{pH}$ controllers (Model PHCN-37-AI-230-03). Temperature was manipulated using $2000 \mathrm{~W}$ submersible heater elements that were controlled by Omega CN740 controllers connected to precision PT100 probes that also logged temperature (Table 2.1). Temperatures and $\mathrm{pH}$, on the total hydrogen scale, were monitored for each header tank 8 times per day using LabView ${ }^{\circledR}$ software. This automated system, detailed in McGraw et al. (2010), allows precise control by measuring $\mathrm{pH}$ spectrophotometrically and correcting for aberrations from target pHs (Table 2.1; McGraw et al., 2010; Cummings et al., 2011). Flow was maintained at

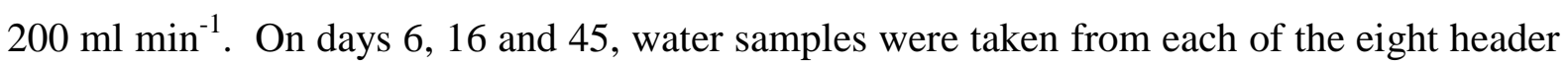
tanks and preserved with $\mathrm{HgCl}_{2}$ for analysis of dissolved inorganic carbon (DIC) and alkalinity $\left(\mathrm{A}_{\mathrm{T}}\right)$ (Table 2.1$)$. Saturation states of aragonite $\left(\Omega_{\mathrm{Ar}}\right)$ and calcite $\left(\Omega_{\mathrm{Ca}}\right)$ and partial pressure of $\mathrm{CO}_{2}\left(p \mathrm{CO}_{2}\right)$ at experimental temperatures and salinity were calculated from measured $\mathrm{pH}$ and $\mathrm{A}_{\mathrm{T}}$ using refitted equilibrium constants (Mehrbach et al., 1973; Dickson and Millero, 1987). Analytical methods follow those detailed in Cummings et al. (2011). 
Table 2.1. Seawater conditions for all experimental treatments. Average temperature $\left({ }^{\circ} \mathrm{C} ; n=360\right), \mathrm{pH}$ (measured on the total hydrogen scale; $n=360)$, total alkalinity $\left(A_{T} ; n=3\right)$ and dissolved inorganic carbon (DIC, $\mathrm{n}=3$ ), partial pressure of $\mathrm{CO}_{2}\left(p \mathrm{CO}_{2}\right)$ is calculated from $\mathrm{A}_{\mathrm{T}}$ and $\mathrm{pH}, \Omega_{\mathrm{Ar}}$ and $\Omega_{\mathrm{Ca}}$ are calculated from $\mathrm{A}_{\mathrm{T}}$ and $\mathrm{pH}$. Values presented are mean \pm standard error. Salinity was $34.2 \mathrm{psu}$.

\begin{tabular}{|ccccccc|}
\hline Temp $\left({ }^{\circ} \mathrm{C}\right)$ & $\mathrm{pH}$ & $\begin{array}{c}\mathrm{A}_{\mathrm{T}} \\
\left(\mu \mathrm{mol} \mathrm{kg}^{-1}\right)\end{array}$ & $\begin{array}{c}\mathrm{DIC} \\
\left.(\mu \mathrm{mol} \mathrm{kg})^{-1}\right)\end{array}$ & $\begin{array}{c}p \mathrm{CO}_{2} \\
(\mathrm{ppm})\end{array}$ & $\Omega_{\mathrm{Ar}}$ & $\Omega_{\mathrm{Ca}}$ \\
\hline$-1.6 \pm 0.01$ & $7.97 \pm 0.001$ & $2263.3 \pm 8.2$ & $2183.8 \pm 8.1$ & $350.1 \pm 1.3$ & $1.37 \pm 0.01$ & $2.18 \pm 0.01$ \\
& $7.79 \pm 0.001$ & $2260.3 \pm 8.9$ & $2233.0 \pm 4.0$ & $554.6 \pm 2.2$ & $0.92 \pm 0.01$ & $1.47 \pm 0.01$ \\
& $7.63 \pm 0.001$ & $2266.0 \pm 5.8$ & $2271.2 \pm 9.4$ & $823.3 \pm 2.1$ & $0.65 \pm 0.01$ & $1.04 \pm 0.01$ \\
$-0.5 \pm 0.01$ & $7.99 \pm 0.002$ & $2265.0 \pm 8.3$ & $2174.4 \pm 3.8$ & $367.2 \pm 1.4$ & $1.37 \pm 0.01$ & $2.19 \pm 0.01$ \\
& $7.80 \pm 0.001$ & $2264.8 \pm 6.2$ & $2254.0 \pm 22.4$ & $569.0 \pm 1.6$ & $0.95 \pm 0.01$ & $1.52 \pm 0.01$ \\
& $7.64 \pm 0.001$ & $2264.0 \pm 7.2$ & $2270.8 \pm 15.0$ & $835.6 \pm 2.7$ & $0.68 \pm 0.01$ & $1.08 \pm 0.01$ \\
$0.4 \pm 0.01$ & $7.99 \pm 0.001$ & $2260.0 \pm 8.4$ & $2173.8 \pm 5.8$ & $383.6 \pm 1.4$ & $1.38 \pm 0.01$ & $2.19 \pm 0.01$ \\
& $7.63 \pm 0.001$ & $2260.5 \pm 9.2$ & $2260.0 \pm 4.2$ & $893.0 \pm 3.7$ & $0.66 \pm 0.01$ & $1.06 \pm 0.01$ \\
\hline
\end{tabular}

\subsubsection{Gamete Collection and Fertilisation}

Eggs and sperm were collected from separate individuals to avoid self-fertilisation. The eggs were collected from 22 individuals by piercing the female portion of the gonad and using a Pasteur pipette to collect the eggs that flowed out. The eggs were pooled and the volume made up to $1.5 \mathrm{~L}$ with $-1.6^{\circ} \mathrm{C}$ seawater. Thirty $\mathrm{ml}$ of the egg solution (approximately 7,000 eggs) was added to a $400 \mathrm{ml}$ fertilisation container suspended in a $4 \mathrm{~L}$ insulated tank. Seawater at the experimental temperature flowed through the $4 \mathrm{~L}$ tanks, maintaining experimental temperatures in the fertilisation containers. Eggs were acclimatised to experimental conditions by adding seawater at the respective experimental temperature and $\mathrm{pH}$ to make up the volume within the fertilisation containers to $200 \mathrm{ml}$.

Twenty-four hours later, sperm were collected from 10 different individuals by cutting into the male portion of the gonad until sperm flowed out. A small sample of sperm collected from each bivalve was examined to determine motility. Sperm was pooled in a $1 \mathrm{~L}$ glass beaker, the volume topped to $500 \mathrm{ml}$ using $-1.6^{\circ} \mathrm{C}$ seawater and $10 \mathrm{ml}$ of sperm solution was added to each fertilisation container with eggs. Sperm concentration in the fertilisation containers was approximately $3 \times 10^{7}$ sperm ml$^{-1}$ (Powell et al., 2001). Once an hour, the water was gently agitated with a Pasteur pipette to ensure mixing. Four hours after the 
addition of the sperm, a sample of approximately 50 eggs was removed from each container using a Pasteur pipette and preserved in Carriker's solution for observations of fertilisation success as described below (Carriker, 1950). Following this sampling, the contents of the fertilisation containers were carefully emptied and rinsed into the $4 \mathrm{~L}$ tanks, through which seawater flowed at experimental conditions. The larvae were negatively buoyant and remained on the bottom of the tanks.

\subsubsection{Assessing Fertilisation and Larval Development}

Development was tracked over the following 45 days at varying intervals (hours to days), chosen to target particular embryonic and larval stages. Samples were collected at 4 and 6 hours post-fertilisation (PF) and every 1-2 days thereafter for 41 days. Sample points were chosen to reflect previous observations in ambient conditions of the first occurrence of each development stage in L. elliptica (pers. obs., Table 2.2). The larvae are negatively buoyant and remain encapsulated through to the D-larval stage (pers. obs., Ansell and Harvey, 1997). On each occasion, a sample of at least 50 eggs/embryos/larvae was removed from each replicate tank by running a Pasteur pipette along the bottom of the tank to ensure haphazard selection. Fertilisation success was determined after 4, 6, 24 and $48 \mathrm{~h}$. At these and the following sample points, embryos and larvae were classified into seven developmental stages using a stereomicroscope to assess the progression of development (Fig. 2.1). The percentages of fertilised larvae that were dead or abnormally developed were also determined. Larvae were considered abnormal if they displayed unusual cell development (e.g. Fig. $2.1 \mathrm{~g}, \mathrm{~h}$ ).

Table 2.2. Projected first observations of individual larval stages.

\begin{tabular}{|lc|}
\hline Sample Point & Stage (First observation) \\
\hline $4 \mathrm{~h}$ & 2-cell embryo \\
$24 \mathrm{~h}$ & 8-cell embryo \\
$48 \mathrm{~h}$ & 16-cell embryo \\
$4 \mathrm{~d}$ & Blastula \\
$10 \mathrm{~d}$ & Trochophore \\
$17 \mathrm{~d}$ & Veliger \\
$20 \mathrm{~d}$ & D-larvae \\
\hline
\end{tabular}



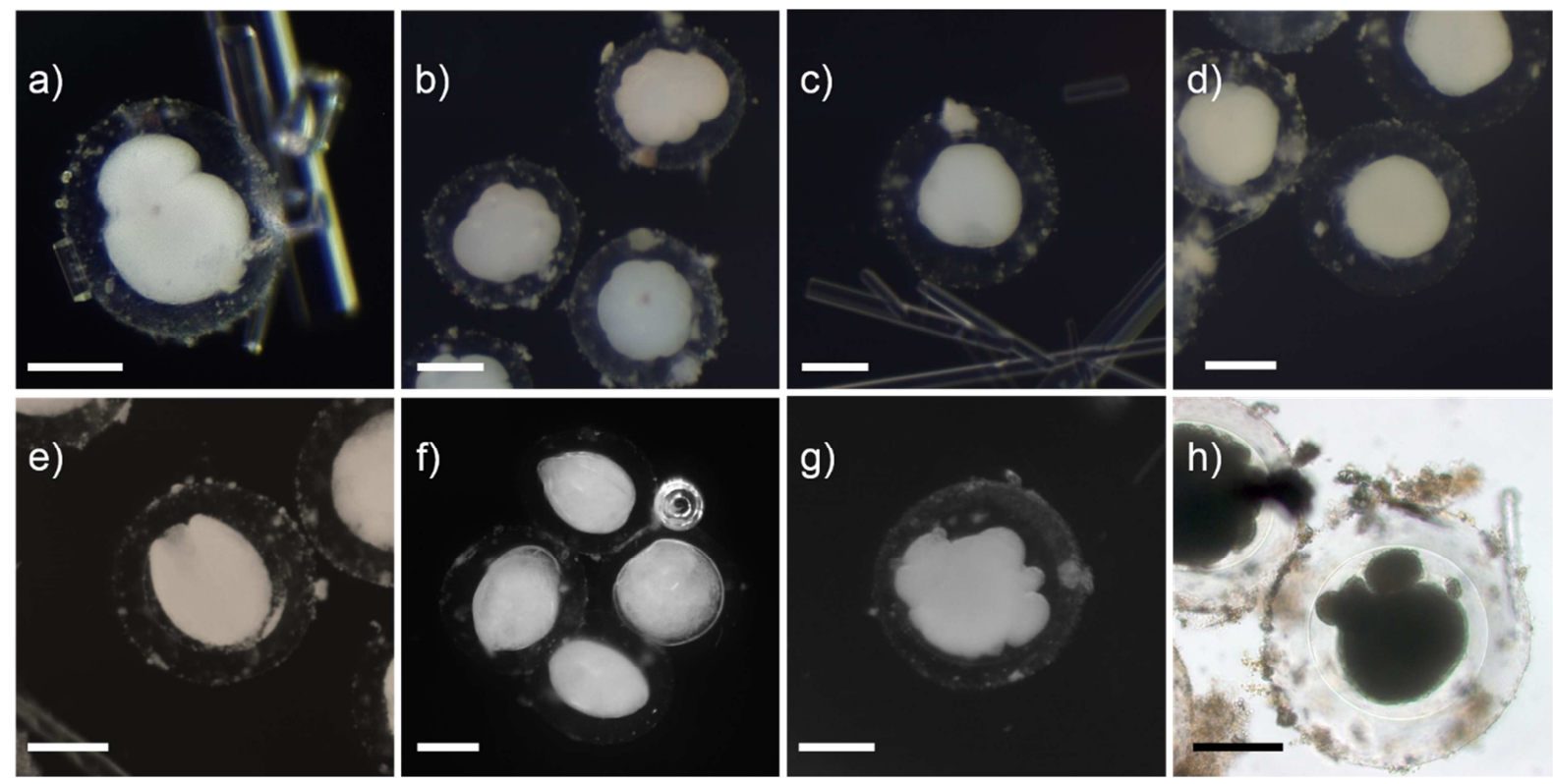

Fig. 2.1. Examples of embryos and larvae at the a) 2-cell ( $6 \mathrm{~h} \mathrm{PF})$, b) 16-cell ( $3 \mathrm{~d} P F)$, c) blastula (11 $\mathrm{d} P F), d$ ) trochophore (with cilia, $16 \mathrm{~d} P \mathrm{PF}$ ), e) veliger (25 d PF) and f) D-larvae developmental stages $(25 \mathrm{~d} P \mathrm{PF})$. Examples of abnormal development observed during the blastula stage (11 d PF) are shown in $\mathrm{g}$ ) and h). Imaged larvae were raised at control conditions. Scale bars $100 \mu \mathrm{m}$.

\subsubsection{Statistical Analysis}

All statistical analysis was performed using IBM SPSS Statistics, version 20. Normality of the data was verified using Shapiro-Wilk's test and equality of variances was confirmed using Levene's test. The relation of the developmental responses to $\mathrm{pH}$ and temperature was examined by fitting the data to a general linear model. Percent fertilisation, the individual developmental stages and percent abnormalities were used as dependent variables while $\mathrm{pH}$ and temperature, and $\Omega_{\mathrm{Ar}}$ at the later stages, were fixed factors, and a temperature $\times \mathrm{pH}$ interaction term was used. Where interactive effects were significant, or trended towards significance $(\mathrm{p}<0.100)$, individual between group $t$-tests were performed for temperature at each experimental $\mathrm{pH}$ and for $\mathrm{pH}$ at each experimental temperature. In order to reduce type-I errors, a Bonferroni correction was used to account for multiple measures $(\alpha=0.017)$ : only pvalues $<\alpha$ were considered significant. If the general linear model indicated overall individual statistical significance $(\mathrm{p}<0.050)$ of either temperature or $\mathrm{pH}$, a post-hoc Bonferroni multiple comparison test was performed to determine effects of $\mathrm{pH}$ averaged over temperature and temperature averaged over $\mathrm{pH}$, on larval stage percentages and abnormalities at each time point. 
Progression of development through the trochophore and D-larval stages was analysed using a repeated measures general linear model with temperature and $\mathrm{pH}$ (trochophore stage), or $\Omega_{\mathrm{Ar}}$ (D-larval stage), as fixed factors.

\subsection{Results}

Temperature and $\mathrm{pH}$ data are detailed in Table 2.1. $\Omega_{\mathrm{Ar}}$ was undersaturated at $\mathrm{pH} 7.80$ and 7.65, while $\Omega_{\mathrm{Ca}}$ remained above, but close to, undersaturation at $\mathrm{pH} 7.65$ (Table 2.1). All adults dissected had fully mature and ripe gonads with large numbers of eggs and sperm. Eggs ranged in size from 180 to $230 \mu \mathrm{m}$ and were encapsulated in a thick (30 $\mu \mathrm{m})$, slightly sticky membrane. Sperm were highly motile ( $99 \%)$ when activated with fresh seawater. Fertilised eggs often clumped and the sticky membranes collected algae and other debris. Abnormal development of larvae was observed at all stages in all treatments.

Table 2.3. (Opposite Page) General linear model results for a) fertilisation success, b) development progression and c) abnormal development by time post-fertilisation. Temperature, $\mathrm{pH}$ and a temperature $\times \mathrm{pH}$ interactive term were fixed factors. Bolded $\mathrm{p}$-values indicate significance where $\mathrm{p}<$ 0.050 . 


\begin{tabular}{|c|c|c|c|c|c|c|}
\hline & \multicolumn{2}{|c|}{ Temperature } & \multicolumn{2}{|c|}{$\mathrm{pH}$} & \multicolumn{2}{|c|}{ Temp. $\times \mathrm{pH}$} \\
\hline & $\mathrm{F}_{2,40}$ & $\mathrm{p}$ & $\mathrm{F}_{2,40}$ & $\mathrm{p}$ & $\mathrm{F}_{3,40}$ & $\mathrm{p}$ \\
\hline \multicolumn{7}{|c|}{ (a) Fertilisation } \\
\hline $4 \mathrm{~h}$ & 31.823 & $<0.001$ & 0.097 & 0.908 & 5.992 & 0.002 \\
\hline $6 \mathrm{~h}$ & 9.478 & $<0.001$ & 2.114 & 0.134 & 0.964 & 0.419 \\
\hline $24 \mathrm{~h}$ & 0.317 & 0.730 & 0.977 & 0.385 & 1.670 & 0.189 \\
\hline $48 \mathrm{~h}$ & 1.858 & 0.169 & 0.808 & 0.453 & 1.027 & 0.391 \\
\hline \multicolumn{7}{|c|}{ (b) Developmental progression } \\
\hline \multicolumn{7}{|c|}{ 2-Cell embryo } \\
\hline $4 \mathrm{~h}$ & 128.883 & $<0.001$ & 0.811 & 0.452 & 2.234 & 0.099 \\
\hline $6 \mathrm{~h}$ & 20.327 & $<0.001$ & 3.651 & 0.035 & 0.752 & 0.527 \\
\hline \multicolumn{7}{|c|}{ 8-Cell embryo } \\
\hline $24 \mathrm{~h}$ & 8.222 & 0.001 & 3.971 & 0.027 & 2.599 & 0.065 \\
\hline \multicolumn{7}{|c|}{ 16-Cell embryo } \\
\hline $48 \mathrm{~h}$ & 16.164 & $<0.001$ & 20.465 & $<0.001$ & 9.146 & $<0.001$ \\
\hline \multicolumn{7}{|c|}{ Trochophore } \\
\hline $15 \mathrm{~d}$ & 30.019 & $<0.001$ & 1.485 & 0.239 & 0.959 & 0.959 \\
\hline \multicolumn{7}{|c|}{ Veliger } \\
\hline $17 \mathrm{~d}$ & 352.473 & $<0.001$ & 12.186 & $<0.001$ & 6.412 & 0.001 \\
\hline $20 \mathrm{~d}$ & 470.430 & $<0.001$ & 0.752 & 0.478 & 2.314 & 0.090 \\
\hline \multicolumn{7}{|c|}{ D-Larvae } \\
\hline $17 \mathrm{~d}$ & 152.312 & $<0.001$ & 3.374 & 0.044 & 3.944 & 0.015 \\
\hline $18 \mathrm{~d}$ & 82.969 & $<0.001$ & 11.38 & $<0.001$ & 1.880 & $<0.001$ \\
\hline $20 \mathrm{~d}$ & 75.513 & $<0.001$ & 7.087 & 0.002 & 8.416 & $<0.001$ \\
\hline $22 \mathrm{~d}$ & 83.985 & $<0.001$ & 7.116 & 0.002 & 4.437 & 0.009 \\
\hline $24 \mathrm{~d}$ & 122.428 & $<0.001$ & 32.121 & $<0.001$ & 5.025 & 0.005 \\
\hline $27 \mathrm{~d}$ & 22.803 & $<0.001$ & 11.029 & $<0.001$ & 3.511 & 0.024 \\
\hline $29 \mathrm{~d}$ & 16.293 & $<0.001$ & 6.912 & 0.003 & 0.459 & 0.712 \\
\hline \multicolumn{7}{|c|}{ (c) Abnormal Development } \\
\hline $4 \mathrm{~h}$ & 2.298 & 0.114 & 0.543 & 0.585 & 5.511 & 0.003 \\
\hline $6 \mathrm{~h}$ & 2.910 & 0.066 & 2.103 & 0.135 & 7.472 & $<0.001$ \\
\hline $48 \mathrm{~h}$ & 2.582 & 0.088 & 1.624 & 0.210 & 0.593 & 0.623 \\
\hline $3 \mathrm{~d}$ & 0.070 & 0.933 & 0.508 & 0.605 & 0.354 & 0.786 \\
\hline $4 \mathrm{~d}$ & 1.207 & 0.310 & 0.352 & 0.705 & 3.030 & 0.040 \\
\hline $6 \mathrm{~d}$ & 0.489 & 0.619 & 1.240 & 0.301 & 6.295 & 0.001 \\
\hline $8 \mathrm{~d}$ & 19.455 & $<0.001$ & 1.749 & 0.187 & 3.855 & 0.016 \\
\hline $10 \mathrm{~d}$ & 4.027 & 0.026 & 1.647 & 0.205 & 0.247 & 0.863 \\
\hline $11 \mathrm{~d}$ & 7.656 & 0.002 & 0.183 & 0.834 & 1.439 & 0.246 \\
\hline $13 \mathrm{~d}$ & 3.719 & $\mathbf{0 . 0 3 3}$ & 0.160 & 0.853 & 0.151 & 0.929 \\
\hline $15 \mathrm{~d}$ & 3.841 & 0.030 & 1.611 & 0.212 & 0.672 & 0.574 \\
\hline $17 \mathrm{~d}$ & 2.390 & 0.105 & 0.478 & 0.624 & 0.280 & 0.840 \\
\hline $18 \mathrm{~d}$ & 2.276 & 0.116 & 0.422 & 0.659 & 0.450 & 0.750 \\
\hline $20 \mathrm{~d}$ & 1.948 & 0.156 & 1.605 & 0.214 & 0.133 & 0.940 \\
\hline $22 \mathrm{~d}$ & 0.620 & 0.543 & 0.636 & 0.535 & 0.562 & 0.643 \\
\hline $24 \mathrm{~d}$ & 4.460 & 0.018 & 1.393 & 0.260 & 0.552 & 0.650 \\
\hline $27 \mathrm{~d}$ & 3.709 & 0.033 & 0.331 & 0.720 & 0.158 & 0.924 \\
\hline $29 \mathrm{~d}$ & 0.784 & 0.463 & 0.375 & 0.689 & 0.377 & 0.770 \\
\hline $35 \mathrm{~d}$ & 3.597 & 0.037 & 0.449 & 0.641 & 0.161 & 0.922 \\
\hline $41 \mathrm{~d}$ & 5.568 & 0.007 & 2.341 & 0.109 & 0.097 & 0.961 \\
\hline
\end{tabular}




\subsubsection{Fertilisation Success and Early Embryonic Stages}

Fertilisation success reached a maximum of approximately $85 \%$ at $48 \mathrm{~h}$ PF (Fig. 2.2). A significant interactive effect of $\mathrm{pH}$ and temperature was observed in the first hours of fertilisation $(\mathrm{p}=0.002$; Table 2.3), with the impact of reduced $\mathrm{pH}$ on fertilisation success dependent on the incubation temperature. In the control temperature treatments, fertilisation was significantly lower at the control $\mathrm{pH}$ than at either of the two reduced $\mathrm{pH}$ levels $\left(\mathrm{t}_{(10)}=\right.$ 4.09, $\mathrm{p}=0.001$ and $\mathrm{t}_{(10)}=3.68, \mathrm{p}=0.002$, respectively; Fig. 2.2a). Conversely, at $0.4^{\circ} \mathrm{C}$, fertilisation was lower at $\mathrm{pH} 7.65$ compared to control $\left(\mathrm{t}_{(10)}=2.98, \mathrm{p}=0.006\right.$; Fig. 2a).

a)

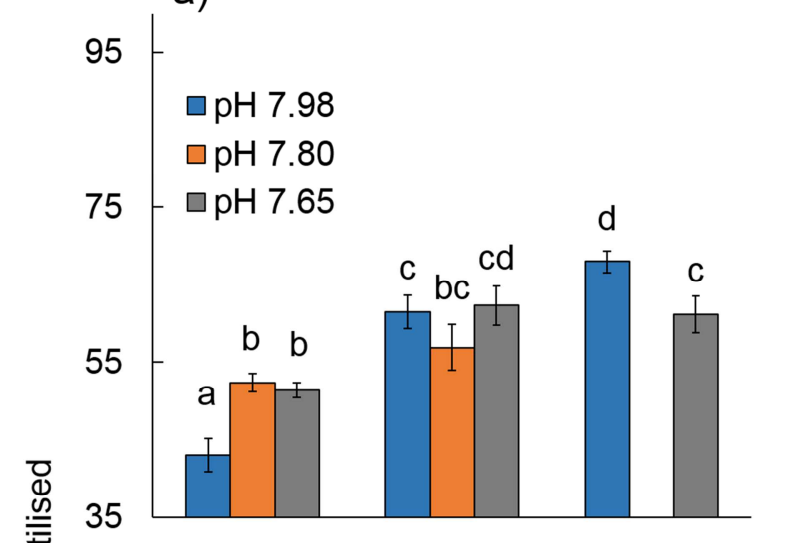

c)

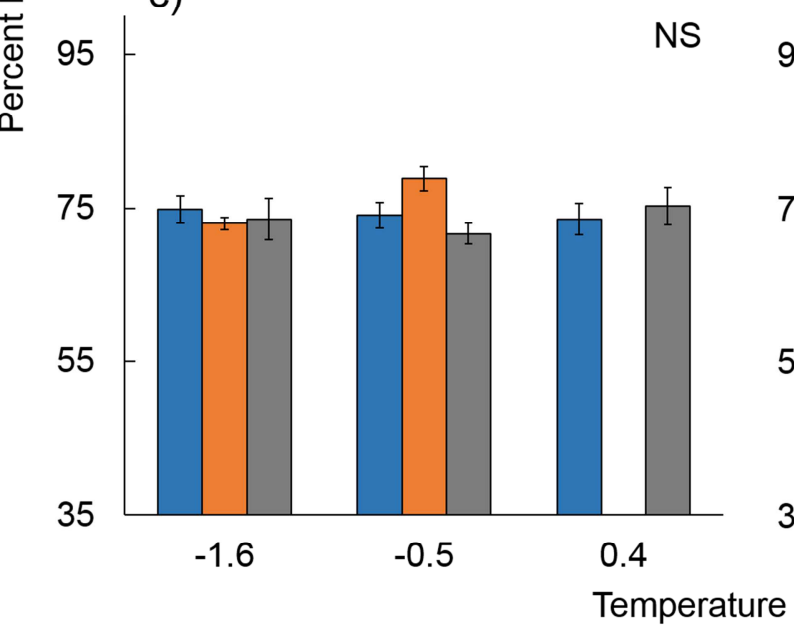

b)

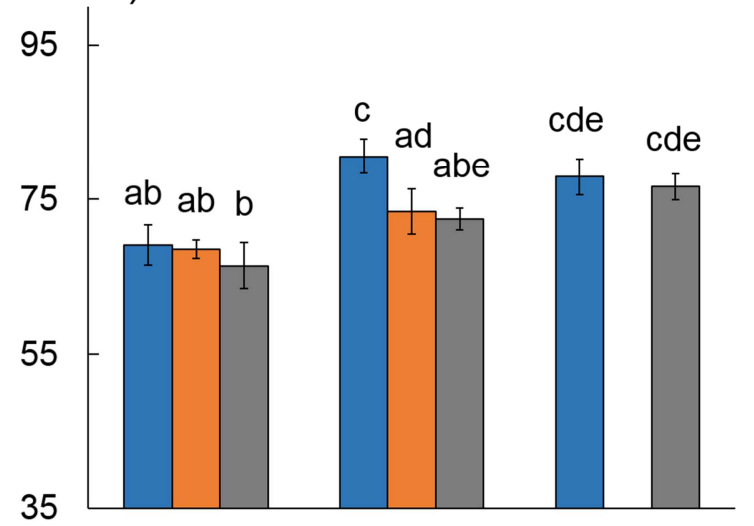

d)

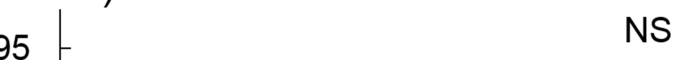

35

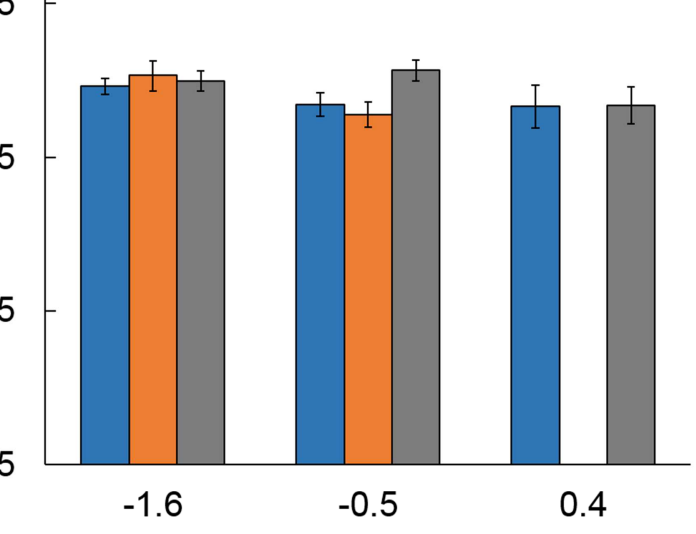

Fig. 2.2. Percentage of eggs fertilised at experimental temperatures and $\mathrm{pH}$ after a) 4 hours, b) 6 hours, c) 24 hours and d) 48 hours; error bars are standard error; letters indicate significance among treatments where $\mathrm{p}<\alpha$, treatments sharing the same letter are not significantly different; the temperature/pH combination of $-0.5^{\circ} \mathrm{C} / \mathrm{pH} 7.80$ was not used. $\mathrm{PF}=$ post-fertilisation, $\mathrm{NS}=$ no significance. 
Irrespective of $\mathrm{pH}$, temperature had an effect on fertilisation success that was dependent on the time PF. Four and six h PF, elevated temperature treatments had higher fertilisation success than those at the control temperature, regardless of $\mathrm{pH}$ treatment $(4 \mathrm{~h} \mathrm{PF}: \mathrm{p}<0.001$; Fig. 2a; 6 h PF: p < 0.001; Fig. 2.2b, Table 2.4). By 24 and 48 h PF, there were no individual or interactive effects of temperature treatment on fertilisation success $(\mathrm{p}>0.050$; Fig. 2.2c and d, respectively, Table 2.4).

Table 2.4. Development timing by treatment showing when at least $50 \%$ of the normally developing larvae were at a particular stage.

\begin{tabular}{|lcccccccc|}
\hline Stage & \multicolumn{7}{c|}{ Time of approximate $50 \%$ abundance } \\
Temp. $\left({ }^{\circ} \mathrm{C}\right):$ & -1.6 & -1.6 & -1.6 & -0.5 & -0.5 & -0.5 & 0.4 & 0.4 \\
pH: & 7.98 & 7.80 & 7.65 & 7.98 & 7.80 & 7.65 & 7.98 & 7.65 \\
\hline Fertilised & $4 \mathrm{~h}$ & $4 \mathrm{~h}$ & $4 \mathrm{~h}$ & $4 \mathrm{~h}$ & $4 \mathrm{~h}$ & $4 \mathrm{~h}$ & $4 \mathrm{~h}$ & $4 \mathrm{~h}$ \\
2-cell & $6 \mathrm{~h}$ & $6 \mathrm{~h}$ & $6 \mathrm{~h}$ & $4 \mathrm{~h}$ & $4 \mathrm{~h}$ & $6 \mathrm{~h}$ & $4 \mathrm{~h}$ & $4 \mathrm{~h}$ \\
8 -cell & $24 \mathrm{~h}$ & $24 \mathrm{~h}$ & $24 \mathrm{~h}$ & $24 \mathrm{~h}$ & $24 \mathrm{~h}$ & $24 \mathrm{~h}$ & $24 \mathrm{~h}$ & $24 \mathrm{~h}$ \\
16-cell & $48 \mathrm{~h}$ & $48 \mathrm{~h}$ & $48 \mathrm{~h}$ & $48 \mathrm{~h}$ & $48 \mathrm{~h}$ & $48 \mathrm{~h}$ & $48 \mathrm{~h}$ & $48 \mathrm{~h}$ \\
Blastula & $4 \mathrm{~d}$ & $4 \mathrm{~d}$ & $4 \mathrm{~d}$ & $4 \mathrm{~d}$ & $4 \mathrm{~d}$ & $4 \mathrm{~d}$ & $4 \mathrm{~d}$ & $4 \mathrm{~d}$ \\
Trochophore & $15 \mathrm{~d}$ & $15 \mathrm{~d}$ & $15 \mathrm{~d}$ & $15 \mathrm{~d}$ & $16 \mathrm{~d}$ & $15 \mathrm{~d}$ & $15 \mathrm{~d}$ & $15 \mathrm{~d}$ \\
Veliger & $22 \mathrm{~d}$ & $22 \mathrm{~d}$ & $22 \mathrm{~d}$ & $17 \mathrm{~d}$ & $17 \mathrm{~d}$ & $18 \mathrm{~d}$ & $17 \mathrm{~d}$ & $17 \mathrm{~d}$ \\
D-larvae & $24 \mathrm{~d}$ & $25 \mathrm{~d}$ & $26 \mathrm{~d}$ & $22 \mathrm{~d}$ & $22 \mathrm{~d}$ & $25 \mathrm{~d}$ & $18 \mathrm{~d}$ & $22 \mathrm{~d}$ \\
\hline
\end{tabular}

Progression of development through each stage was impacted by both elevated temperature and reduced $\mathrm{pH}$ (Tables 2.3 and 2.4). Temperature strongly influenced development to the 2-cell stage, 4 and 6 h PF. Significantly fewer 2-cell stage embryos were found at the control temperature compared to both elevated temperatures $(\mathrm{p}<0.002 ;$ Fig. $2.3 \mathrm{~b}$, Table 2.4). In the intermediate temperature treatment $\left(-0.5^{\circ} \mathrm{C}\right.$; Fig. $\left.2.3 \mathrm{a}\right), 4 \mathrm{~h}$ PF development was slower with reduced $\mathrm{pH}\left(\mathrm{t}_{(10)}=3.88, \mathrm{p}=0.002\right)$. At $6 \mathrm{~h} \mathrm{PF}$, there were fewer 2-cell stage embryos at the control $\mathrm{pH}$ compared to reduced $\mathrm{pH}(\mathrm{p}=0.035$; Fig. 2.3b, Table 2.3). Interactive effects were non-significant 6 h PF ( $p=0.527$; Table 2.3).

By $24 \mathrm{~h} \mathrm{PF}$, over $50 \%$ of individuals were at the 8-cell development stage in all treatments (Table 2.4, Fig. 2.3c). While there was no interactive effect of $\mathrm{pH}$ and temperature $(\mathrm{p}=0.065$; Table 2.3), both variables individually influenced development to the 8-cell stage (temperature: $\mathrm{p}<0.001 ; \mathrm{pH}: \mathrm{p}=0.027$; Table 2.3). Post-hoc tests revealed percentages in the 8cell stage were significantly higher at both elevated temperatures than at the control 
temperatures $\left(-0.5^{\circ} \mathrm{C}: \mathrm{p}=0.012 ; 0.4^{\circ} \mathrm{C}: \mathrm{p}=0.006\right.$; Fig. $\left.2.3 \mathrm{c}\right)$. Individuals raised at reduced $\mathrm{pH}$ had significantly higher percentages in the 8-cell stage compared to control $\mathrm{pH}\left(\mathrm{t}_{(10)}=\right.$ 2.52, p < 0.015; Fig. 2.3c).
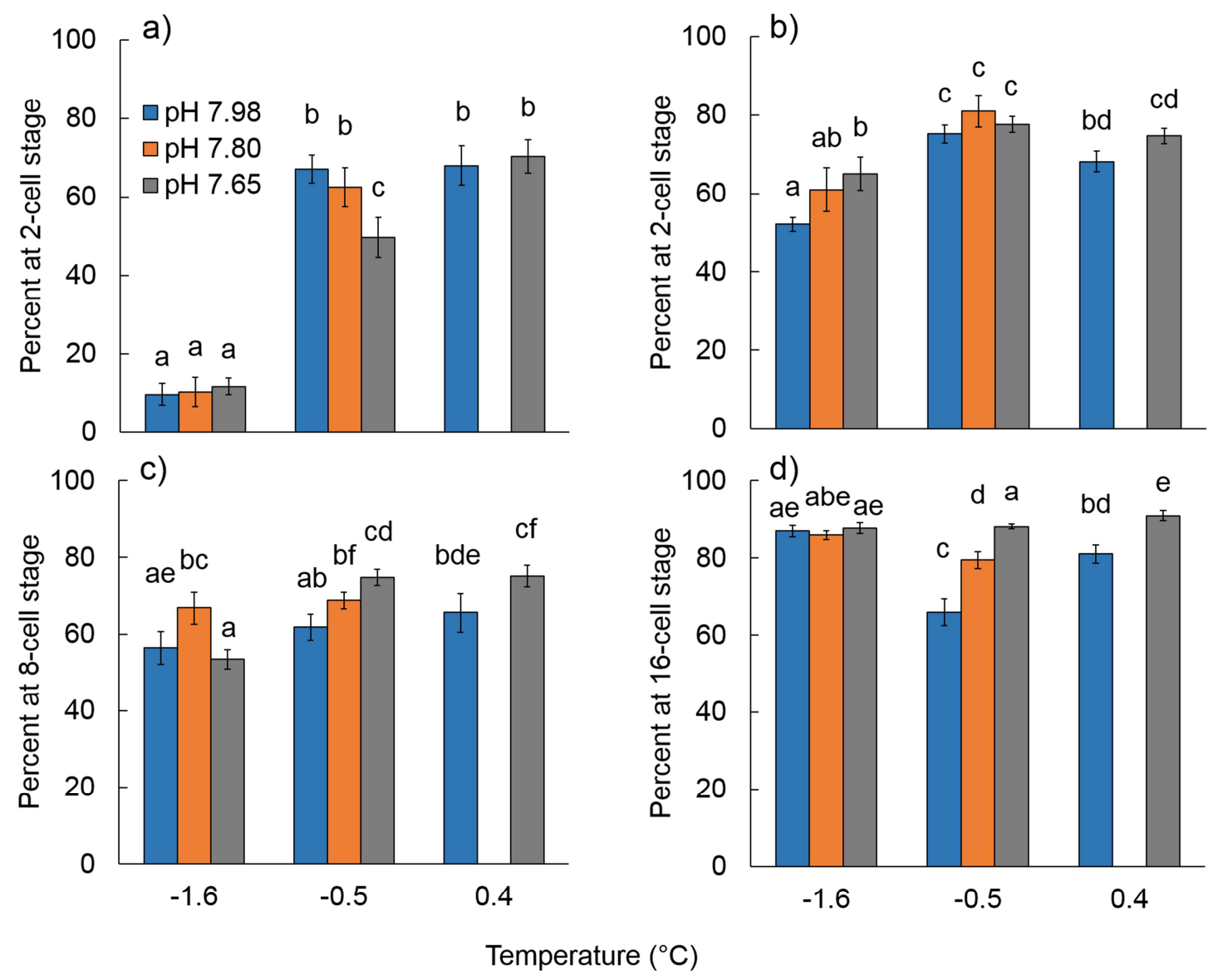

Fig. 2.3. Percentage of normally developing embryos at the a) 2-cell developmental stage at 4 hours and b) 6 hours PF, c) the 8-cell stage at 24 hours and d) the 16-cell stage at 48 hours at experimental temperatures and $\mathrm{pH}$; error bars are standard error; letters indicate significance as described in Fig. 2.2 ; the temperature $/ \mathrm{pH}$ combination of $-0.5^{\circ} \mathrm{C} / \mathrm{pH} 7.80$ was not used. $\mathrm{PF}=$ post-fertilisation, $\mathrm{NS}=$ no significance.

By $48 \mathrm{~h} \mathrm{PF}$, development had progressed to the 16-cell stage (Table 2.4, Fig. 2.3d). An effect of $\mathrm{pH}$ was observed only in the two elevated temperature treatments, where percentages at the 16-cell stage were significantly higher at reduced $\mathrm{pH}(\mathrm{p}<0.001$; Fig. 2.3d, Table 2.4).

By $3 \mathrm{~d}$ PF, development was entering the blastula stage, but percentages were low. By $4 \mathrm{~d}$ PF, all normally developing embryos had progressed to the blastula stage (Table 2.4). 
Development progression and abnormalities through the later blastula stage were not significantly impacted by temperature and/or $\mathrm{pH}$.

\subsubsection{Trochophore and Veliger Stage Development}

Development time to the trochophore stage was significantly affected by elevated temperature ( $\mathrm{p}<0.001$; Fig. 2.4, Table 2.3), with no individual or interactive effect of $\mathrm{pH}$. Trochophore larvae appeared first in the $0.4^{\circ} \mathrm{C}$ treatment at $11 \mathrm{~d} \mathrm{PF}$ and after $13 \mathrm{~d} \mathrm{PF}$ at $-0.5^{\circ} \mathrm{C}$. At the control temperature, only a very small percentage of trochophore larvae were noted $13 \mathrm{~d} \mathrm{PF}$, after which trochophore development quickly progressed. By $17 \mathrm{~d} \mathrm{PF}$, there were no significant differences among treatments.

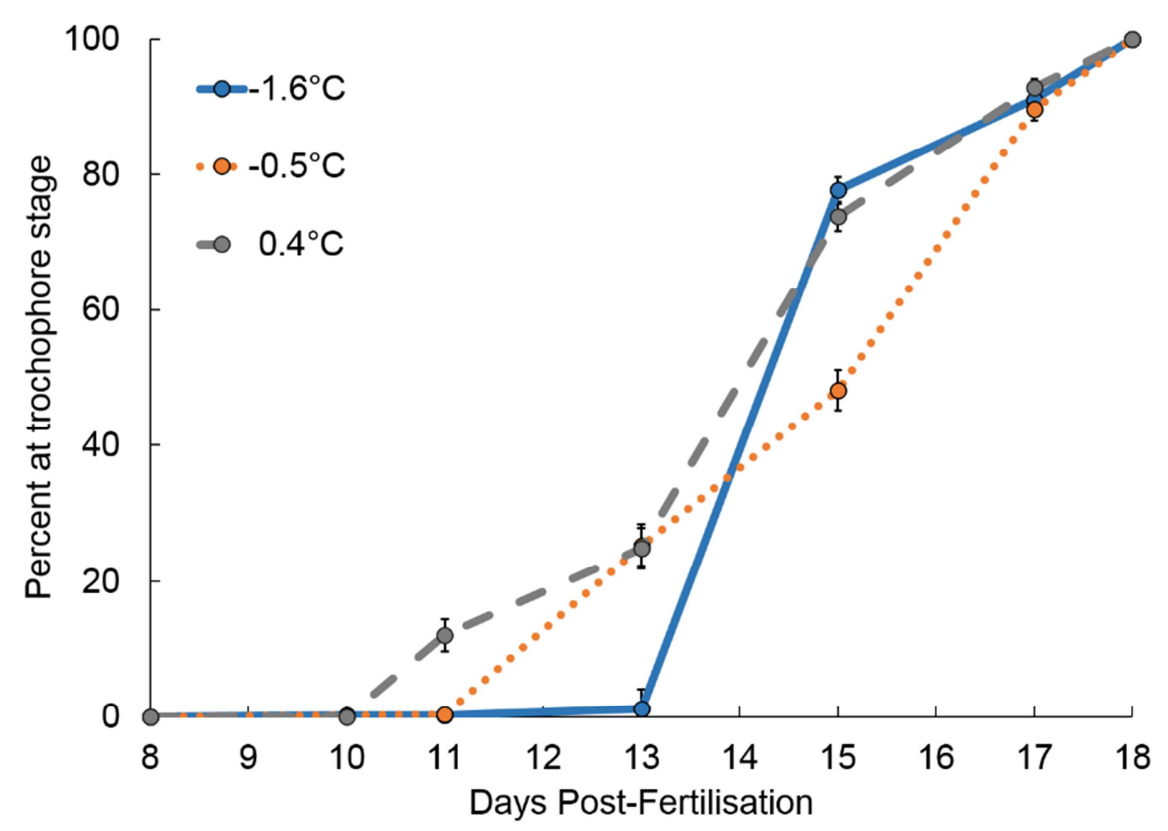

Fig. 2.4. Progression of normal larval development through the trochophore stage at each temperature, averaged over experimental $\mathrm{pH}$; error bars are standard error.

Timing of the veliger stage was significantly influenced by temperature and $\mathrm{pH}$ and an interaction term was detected $(\mathrm{p}=0.001$, in all cases; Table 2.3). The first of the veliger larvae appeared after $15 \mathrm{~d}$ in the elevated temperatures, compared to $17 \mathrm{~d}$ at the control temperature/pH and $20 \mathrm{~d}$ at the control temperature and $\mathrm{pH} 7.65$. By $17 \mathrm{~d} \mathrm{PF}$, only $9 \%$ of the developing larvae at the control temperature/pH were at the veliger stage compared to over $50 \%$ at $-0.5^{\circ} \mathrm{C}\left(\mathrm{t}_{(10)}=14.13, \mathrm{p}<0.001\right)$ and $80 \%$ at $0.4^{\circ} \mathrm{C}\left(\mathrm{t}_{(10)}=23.40, \mathrm{p}<0.001\right.$; Table 2.4, 
Fig. 2.5a). After $20 \mathrm{~d}$, this pattern of temperature dependence was still very evident as the percentage of veliger stage larvae in both elevated temperature treatments was $>90 \%$, significantly higher than levels at the control temperature $(<25 \%: \mathrm{p}<0.001$; Fig. $2.5 \mathrm{~b}$, Tables 2.3 and 2.4).

The effect of reduced $\mathrm{pH}$ on development to the veliger stage was dependent on the incubation temperature. At $-0.5^{\circ} \mathrm{C}, 17 \mathrm{~d} \mathrm{PF}$, significantly fewer larvae were observed in the reduced $\mathrm{pH}$ treatment $(\mathrm{pH} 7.65)$ compared to control $\left(\mathrm{t}_{(10)}=7.65, \mathrm{p}<0.001\right)$ and $\mathrm{pH} 7.80$ $\left(\mathrm{t}_{(10)}=7.60, \mathrm{p}<0.001\right.$; Fig. 2.5a). Conversely, $20 \mathrm{~d} \mathrm{PF}$ at $-1.6^{\circ} \mathrm{C}$, significantly more veligers were observed in the lowest $\mathrm{pH}$ treatment than in the control $\mathrm{pH}\left(\mathrm{t}_{(10)}=3.87, \mathrm{p}=0.002\right.$; Fig. $2.5 \mathrm{~b})$. There was no significant effect of $\mathrm{pH}$ at the highest temperature on either day $\left(\mathrm{t}_{(10)}=\right.$ 1.34, $\mathrm{p}=0.105$ and $\mathrm{t}_{(10)}=1.19, \mathrm{p}=0.130$; Fig. 2.5).

a)

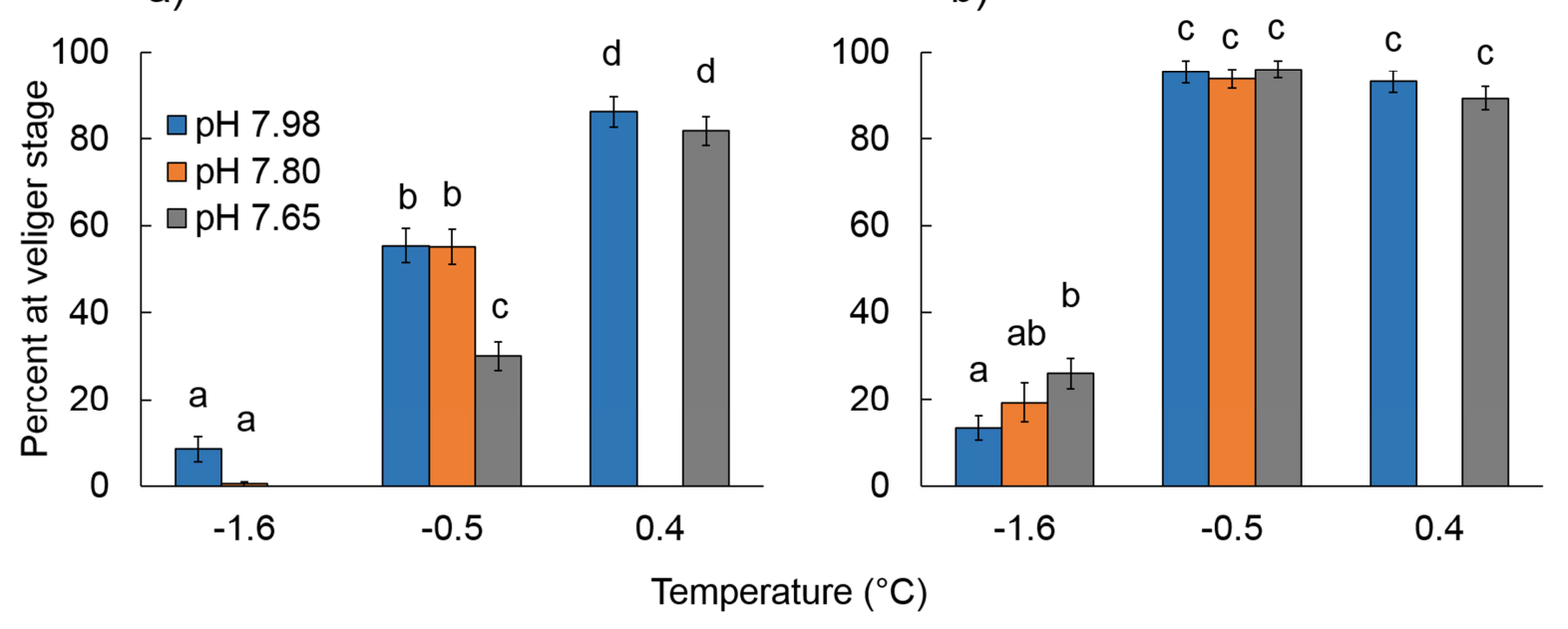

Fig. 2.5. Percentage of developing larvae at the veliger stage at a) 17 and b) 20 days PF; error bars are standard error; letters indicate significance as described in Fig. 2.2. The temperature/pH combination of $-0.5^{\circ} \mathrm{C} / \mathrm{pH} 7.80$ was not used. $\mathrm{PF}=$ post-fertilisation. 


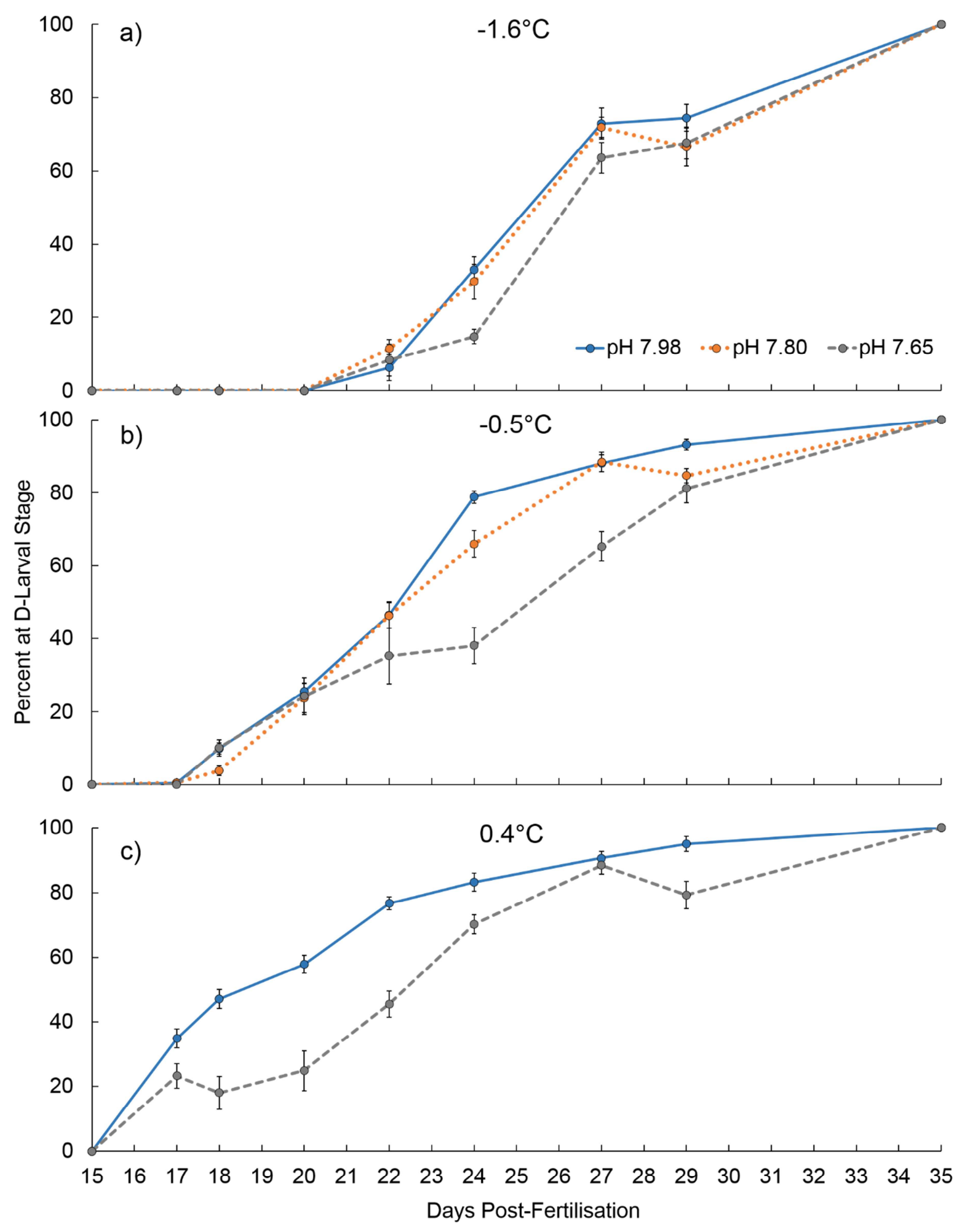

Fig. 2.6. Percentage of normally developing D-larvae raised at a) $-1.6^{\circ} \mathrm{C}$, b) $-0.5^{\circ} \mathrm{C}$ and c) $0.4^{\circ} \mathrm{C}$; error bars are standard error. 


\subsubsection{D-Larval Stage Development}

D-larvae first appeared at $17 \mathrm{~d} \mathrm{PF}$ in the $0.4^{\circ} \mathrm{C}$ and $-0.5^{\circ} \mathrm{C}$ treatments, and five days later in the control temperature treatments (Fig. 2.6). A significant interactive effect of $\mathrm{pH}$ and temperature on the progression of D-larvae development was observed from $17 \mathrm{~d}$ PF to $27 \mathrm{~d}$ PF. Development was slowest in the reduced $\mathrm{pH}$ treatments at all temperatures, with the longest delays occurring at elevated temperatures (Table 2.4). At each experimental temperature, $\mathrm{pH}$ had no effect on the first observance of D-larvae; however, the time needed for $50 \%$ of the normally developing larvae to reach the D-larval stage was increased at reduced $\mathrm{pH}$, an effect that was amplified at elevated temperatures (Table 2.3, Fig. 2.6). At the lowest $\mathrm{pH}$, larvae in the control temperature treatments were delayed 1-2 $\mathrm{d}_{\left(\mathrm{t}_{(10)}\right.}=4.83, \mathrm{p}<$ 0.001, Table 2.4, Fig. 2.6a), compared to 3 and $4 \mathrm{~d}$ at the midrange $\left(\mathrm{t}_{(10)}=10.73, \mathrm{p}<0.001\right.$, Table 2.4, Fig 2.6b) and highest temperatures $\left(\mathrm{t}_{(10)}=11.28, \mathrm{p}<0.001\right.$; Table 2.4, Fig. 2.6c), respectively. At $29 \mathrm{~d} \mathrm{PF}$, a pH effect independent of temperature was still evident, with Dlarvae development being significantly faster in all control $\mathrm{pH}$ treatments, compared to both reduced pHs ( $\mathrm{p}=0.003$; Fig. 2.6, Table 2.3).

Elevated temperatures accelerated development to the D-larval stage. This trend was apparent regardless of $\mathrm{pH}$ treatment (Fig. 6). At $17 \mathrm{~d} \mathrm{PF}$, less than $1 \%$ of the normally developing larvae in the mid-range temperature of $-0.5^{\circ} \mathrm{C}$ were D-larvae compared to $23 \%$ and $35 \%$ at $0.4^{\circ} \mathrm{C}$ ( $<<0.001$; Fig. 2.6b and c, Table 2.3). All normally developed larvae had reached the D-larval stage in all treatments by between 29 and $35 \mathrm{~d}$ PF.

\subsubsection{Abnormal Development}

Instances of abnormal development were influenced by both temperature and $\mathrm{pH}$ (Fig. 2.7). However, the effect of temperature and $\mathrm{pH}$ on abnormalities was largely dependent on larval stage. At $4 \mathrm{~h} \mathrm{PF}, 2-8 \%$ of fertilised and 2-cell stage embryos, on average, were abnormally developed, and by $6 \mathrm{~h}$ PF this number had increased slightly to 5-16\% (Fig. 2.7a, b). Despite these low occurrences, a significant interactive effect was observed between $\mathrm{pH}$ and temperature at both time points $(4 \mathrm{~h}: \mathrm{p}=0.003 ; 6 \mathrm{~h}: \mathrm{p}<0.001$; Table 2.3$)$. By $4 \mathrm{~h} \mathrm{PF}$, at the control temperature, significantly fewer abnormalities were observed in the control $\mathrm{pH}$ treatment compared to the reduced $\mathrm{pH}$ treatment $\left(\mathrm{pH}\right.$ 7.65: $\mathrm{t}_{(10)}=2.61, \mathrm{p}=0.013$; Fig. 2.7a). 


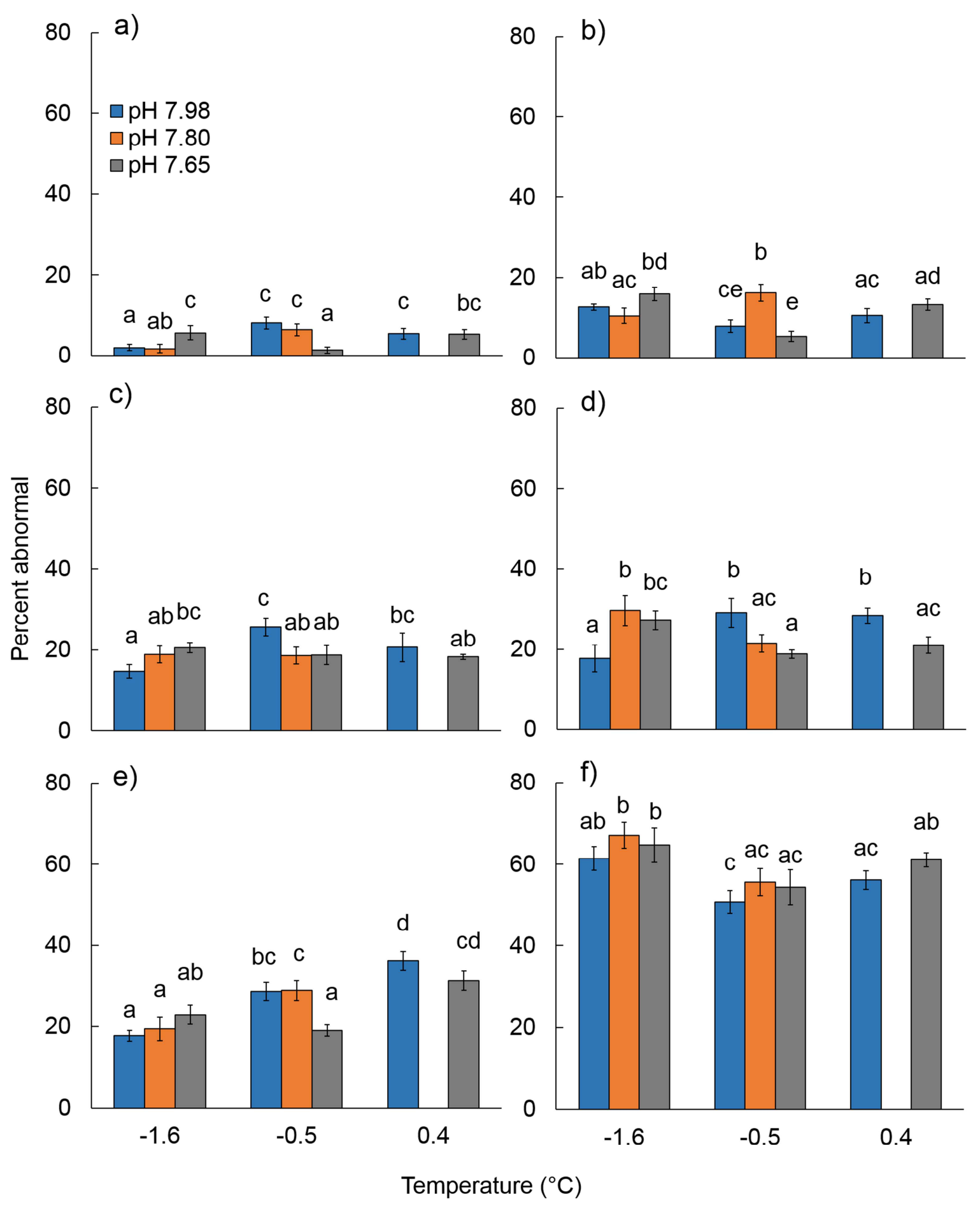

Fig. 2.7. Percentage of developing larvae that were abnormal at experimental temperatures and $\mathrm{pH}$ following fertilisation at a) 4 hours and b) 6 hours PF; during early developmental stages at c) 4 days PF, d) 6 days PF, and e) 8 days PF; and f) during D-larvae development 35 days PF; error bars are standard error; letters indicate significance as described in Fig. 2.2. The temperature/pH combination of $-0.5^{\circ} \mathrm{C} / \mathrm{pH} 7.80$ was not used. $\mathrm{PF}=$ post-fertilisation. 
By $6 \mathrm{~h} \mathrm{PF}$, abnormal development in response to elevated temperature and reduced $\mathrm{pH}$ was varied (Fig. 2.7b). At the control temperature, the reduced $\mathrm{pH}(\mathrm{pH} 7.65)$ increased abnormal development compared to the midrange $\mathrm{pH}\left(\mathrm{pH} 7.80 ; \mathrm{t}_{(10)}=3.07, \mathrm{p}=0.006\right)$. The highest occurrence of abnormality at $-0.5^{\circ} \mathrm{C}$ was observed with midrange $\mathrm{pH}\left(\mathrm{t}_{(10)}=6.15, \mathrm{p}<\right.$ 0.001; Fig. 2.7b).

A significant interactive effect of $\mathrm{pH}$ and temperature on the percentages of abnormally developing blastulas was observed 4, 6 and $8 \mathrm{~d}$ PF ( $\mathrm{p}=$ 0.040, 0.001 and 0.016, respectively; Fig. 2.7c-e, Table 2.3). Percentages were always lowest at the control temperature and $\mathrm{pH}$ $\left(-1.6^{\circ} \mathrm{C}, \mathrm{pH}\right.$ 7.98). Embryos from the control temperature treatments exhibited significantly higher abnormality percentages at reduced $\mathrm{pH}\left(4 \mathrm{~d} \mathrm{PF}: \mathrm{t}_{(10)}=2.49, \mathrm{p}=0.016\right.$, Fig. $2.7 \mathrm{c} ; 6 \mathrm{~d}$ PF: $\mathrm{t}_{(10)}=3.49, \mathrm{p}=0.003$; Fig. $2.7 \mathrm{~d}$ ). Although this trend was still evident at $8 \mathrm{~d} P F$, it was not statistically significant after Bonferroni correction $\left(\mathrm{t}_{(10)}=2.09, \mathrm{p}=0.031\right.$; Fig. 2.7e). Conversely, in the mid and high temperature treatments $\left(-0.5^{\circ} \mathrm{C}\right.$ and $\left.0.4^{\circ} \mathrm{C}\right)$, the highest abnormality percentages occurred at the control pH (Fig. $2.7 \mathrm{c}, \mathrm{d}$ ). At $-0.5^{\circ} \mathrm{C}$, both reduced $\mathrm{pH}$ treatments had fewer abnormally developing individuals 4 and $6 \mathrm{~d}$ PF compared to control $\mathrm{pH}\left(\mathrm{pH} 7.80: \mathrm{t}_{(10)}=3.12, \mathrm{p}=0.005\right.$ and $\mathrm{t}_{(10)}=3.01,0.007 ; \mathrm{pH} 7.65: \mathrm{t}_{(10)}=2.96, \mathrm{p}=0.007$ and $\mathrm{t}_{(10)}=3.79,0.002$, respectively). A similar pattern was noted in the $0.4^{\circ} \mathrm{C}$ treatment $6 \mathrm{~d} \mathrm{PF}$; higher occurrences of abnormality were observed at the control $\mathrm{pH}\left(\mathrm{t}_{(10)}=2.71, \mathrm{p}=0.011\right.$; Fig. 2.7d). By $8 \mathrm{~d} \mathrm{PF}$, at $-0.5^{\circ} \mathrm{C}$, the trend between control $\mathrm{pH}$ and $\mathrm{pH} 7.65$ was still significant $\left(\mathrm{t}_{(10)}=3.98, \mathrm{p}=0.001\right)$, but abundances of abnormalities had increased at $\mathrm{pH} 7.80$ to equal percentages at the control $\mathrm{pH}$ (Fig. 2.7e). At $0.4^{\circ} \mathrm{C}$, the differences in abnormal percentages due to $\mathrm{pH}$ were no longer significant after Bonferroni correction $\left(\mathrm{t}_{(10)}=1.97, \mathrm{p}=\right.$ 0.039; Fig. 2.7e).

Abnormalities were high in all treatments at the D-larval stage, ranging between $47 \%$ and $68 \%$ (Fig. 2.7f). No interactive effects were observed. Post-hoc tests revealed control temperature treatments had the highest percentages of abnormal larvae but differences were only significant against mid-range temperature treatments $(\mathrm{p}=0.042 ;$ Fig. $2.7 \mathrm{f})$. There were no differences in abnormality percentages at $-0.5^{\circ} \mathrm{C}$ and $0.4^{\circ} \mathrm{C}(35 \mathrm{~d} \mathrm{PF}$ : $\mathrm{p}=0.108)$. At all temperatures there were indications of negative impacts of reduced $\mathrm{pH}$ on D-larvae, however these were non-significant (Fig. 2.7f). Aragonite saturation state had no significant effect on abnormal development in D-larvae $(\mathrm{p}=1.000)$. 


\subsection{Discussion}

Our data shows for the first time that larval development in L. elliptica is influenced by reduced $\mathrm{pH}$ and elevated temperature. The observed effects vary with both developmental stage and with stressor combination. Where significant effects were detected, increased temperature had a consistently positive influence on development, regardless of $\mathrm{pH}$ level, resulting in greater initial fertilisation and faster development and reducing occurrences of abnormalities at later developmental stages. The effects of reduced $\mathrm{pH}$ were varied, promoting development during some stages while delaying it in others. Independent from experimental temperatures, reduced $\mathrm{pH}$ did not significantly impact occurrences of abnormal development. Interactive effects of $\mathrm{pH}$ and temperature on development varied with stage.

Fertilisation was high in all treatments, consistent with the highest rates reported in Powell et al. (2001). Overall, fertilisation in L. elliptica was robust against temperature and $\mathrm{pH}$ changes projected for the end of the century, both individually and in combination. However, the sperm concentrations in this experiment were within the optimal range (reported by Powell et al., 2001), and effects of temperature and $\mathrm{pH}$ stressors on fertilisation may be more evident at very low sperm concentrations (Reuter et al., 2011; Ho et al., 2013; Sewell et al., 2013), such as may be experienced in the wild. We noted higher fertilisation success at 4 and $6 \mathrm{~h}$ PF in the elevated temperature treatments. An initially high fertilisation success is potentially important because as time progresses past spawning, gametes may lose viability and local currents may dilute sperm concentrations. Consequently, the greater fertilisation success at elevated temperature observed for L. elliptica 4 and 6 h PF may help overcome such issues.

The tolerance and faster development through to the D-larval stage at elevated temperature observed here reflect observations of other Antarctic invertebrates where small increases in temperature had positive or neutral impacts until thermal tolerance thresholds were reached (Pearse et al., 1991; Stanwell-Smith and Peck, 1998; Ericson et al., 2012; Kapsenberg and Hofmann, 2014). The temperature tolerance thresholds in L. elliptica may be well above existing conditions in the southern Ross Sea (McMurdo Sound). Populations along the Antarctic Peninsula may experience higher summer temperatures (ranging from 0.5 to $1.5^{\circ} \mathrm{C}$ ), which are within and above the projected temperatures for the Ross Sea (Brey et al., 2011; Morley et al., 2012a). In adults, temperature tolerance limits are higher in Antarctic Peninsula compared to McMurdo Sound populations (Morley et al., 2012a). However, limits may be further influenced by animal size, oxygen saturation, exposure to additional stressors 
or acclimation to elevated temperatures (Pörtner et al., 2006; Peck et al., 2007a; Morley et al., 2012a; Morley et al., 2012b). In our study, the observed positive responses of L. elliptica larval development to temperatures up to $2^{\circ} \mathrm{C}$ above those currently found in McMurdo Sound also indicates some resilience, although the magnitude of the increase they can tolerate is unknown. Additionally, other stressors could further impact larval responses (e.g. reduced salinity, increased UV exposure). Exposure and acclimation of adults to adverse conditions can also influence tolerance of their offspring. For example, in the Antarctic sea urchin, Sterechinus neumayeri, long term (17 mo.) exposure of adults to reduced $\mathrm{pH}$ and elevated temperature improved larval performance, while 6 mo. exposure did not (Suckling et al., 2015). In this experiment, gametes were collected from adults developing in ambient $\mathrm{pH}$ and temperature conditions for the Ross Sea.

In late developmental stages, high percentages of abnormalities were observed in all treatments, although this was mitigated by elevated temperature. If the high occurrences observed here reflect abnormality rates in the wild, temperatures projected for the end of this century may result in larger populations at settlement due to fewer occurrences of abnormalities, as well as the reduction in time spent at stages vulnerable to predation. Warmer oceans may also alter temperature cues that initiate spawning or settling and metamorphosis, or may affect food availability during settlement by impacting the timing and magnitude of algal blooms (Clarke, 1982; Pechenik, 1999; Byrne, 2011; Ericson et al., 2012). Additionally, faster settlement could come with a potential trade-off of reduced larval dispersal and thus genetic connectivity (Pechenik, 1999). However, species with demersal larvae such as L. elliptica may rely on close proximity to other individuals for optimal spawning success, and decreased dispersal may even increase fertilisation success (Pechenik, 1999; Byers and Pringle, 2006; Byrne, 2011).

The effects of reduced $\mathrm{pH}$ on larval development were variable and largely dependent on larval stage and incubation temperature. In late stage larvae, delays from reduced $\mathrm{pH}$ were greater at elevated temperatures, however, larvae raised at high temperature and low $\mathrm{pH}$ developed faster than those raised in control conditions ( $22 \mathrm{cf} .25$ days to $50 \%$ abundance) due to the overall faster development rates at elevated temperature. This reflects observations in other species where the effects of reduced $\mathrm{pH}$ on development timing are mitigated by elevated temperature (Sheppard Brennand et al., 2010; Arnberg et al., 2013; Davis et al., 2013). In other species, $\mathrm{pH}$ effects are amplified by increased temperature (Talmage and 
Gobler, 2011; Pansch et al., 2012) or effects are fully independent (Parker et al., 2009; Parker et al., 2010).

In single stressor studies, developmental delays in sea urchin larvae in response to reduced $\mathrm{pH}$ have been attributed to the allocation of energetic resources away from growth and development in order to maintain cellular function and calcification (Stumpp et al., 2011b). Slight delays in development timing may negatively affect larvae by prolonging planktonic stages resulting in transport away from favourable settlement conditions or through prolonged exposure to predation or unfavourable conditions (Dupont et al., 2010; Stumpp et al., 2011b). Lecithotrophic larvae, such as those of L. elliptica, are dependent on maternally provided lipid stores during gametogenesis until hatching and settlement (Pearse et al., 1986).

Ocean acidification could prolong development, draining energy resources, although this may be mitigated by the faster development observed with elevated temperatures. Due to sufficient energetic resources, other encapsulated invertebrate larvae display an initial capacity for high calcification during early development even under acidified conditions (Timmins-Schiffman et al., 2013). Under ambient conditions, other Antarctic species have lipid stores in excess of what is needed for larval development, allowing for the development of larger juveniles (McClintock and Pearse, 1986). However, energetic reserves are limited and development delays, as well as environmental stress and subsequent metabolic responses, may increase the use of energy reserves to the point where available energy is insufficient for development (Pörtner, 2008; Dupont et al., 2010; Dorey et al., 2013). For example, reduced lipid content coinciding with prolonged development timing has been observed in bivalve larvae exposed to elevated $p \mathrm{CO}_{2}$ (Talmage and Gobler, 2011).

Incidences of abnormal development in D-larvae were not influenced by reductions in $\mathrm{pH}$. The constancy of abnormal development, even under reduced $\mathrm{pH}$, may be related to $L$. elliptica larval encapsulation. Larvae are encapsulated in a thick $(30 \mu \mathrm{m})$ gelatinous egg membrane, which may provide protection by buffering against external conditions, or conversely, create high $\mathrm{pCO}_{2}$ environments within the eggs (Ansell and Harvey, 1997; Pechenik, 1999). Encapsulated larvae of the gastropod Crepidula fornicata exhibit reduced calcification at reduced $\mathrm{pH}$, but abnormalities and differences in shell sizes indicate a much greater tolerance compared to other non-encapsulated mollusc larvae (Noisette et al., 2014). Egg cases of cuttlefish significantly limit gas diffusion creating a high intercapsular $p \mathrm{CO}_{2}$ as development progresses, even under ambient pH (Dorey et al., 2013). However, despite the 
reduced $\mathrm{pH}$, cuttlefish are able to begin calcification of their aragonite shells and continue calcification after hatching as juveniles (Melzner et al., 2009; Dorey et al., 2013). If a similar limitation of diffusion occurs in L. elliptica, larvae could be adapted to calcification under high $p \mathrm{CO}_{2}$.

The D-larval stage is not only a point of high calcification as the shell is formed, it is at a stage where isolation of calcifying surfaces may be more energetically demanding compared to later developmental stages (Waldbusser et al., 2013). Additionally, shell formation may be influenced by the availability and solubility of $\mathrm{CaCO}_{3}$. Aragonite was undersaturated $\left(\Omega_{\mathrm{Ar}}<\right.$ 1) at both reduced $\mathrm{pH}$ levels in our experiment (Table 2.1), indicating that the observed Dlarval developmental delay may be due to difficulties in shell maintenance. Closer examination of the D-larvae is required to assess treatment differences in shell formation and morphology.

Reduced calcification in D-larvae would result in smaller, weaker larval shells which would be more susceptible to crushing injury and predation upon settlement. The requirements for successful settlement and metamorphosis into juveniles in L. elliptica are unknown. In other bivalves, settlement success can be dependent on a number of factors including substrate suitability or sediment saturation state (Snelgrove et al., 1993; Green et al., 2009; Green et al., 2013). Protracted development times indicate that shell formation in juveniles may occur in winter months in the Ross Sea when aragonite saturation states, at $\Omega<$ 1 (McNeil and Matear, 2008), may be unfavourable for shell maintenance. Impacts of ocean acidification would likely persist past the D-larval stage, potentially impacting settlement cues and reducing survival and development of juveniles.

To conclude, fertilisation in L. elliptica was affected by elevated temperature and reduced $\mathrm{pH}$ during the first 4-6 h; after which fertilisation was high in all treatments and robust to temperature and $\mathrm{pH}$. No loss of gamete viability was observed. The observed influences of temperature and $\mathrm{pH}$ on development of the later veliger and D-larval stages suggest that future ocean warming may accelerate development to these stages, but that ocean acidification may limit this increase. Additionally, elevated temperatures reduced occurrences of abnormalities in D-larvae, while reduced $\mathrm{pH}$ ultimately had no effect. Despite no change in abnormalities, the slower development at reduced $\mathrm{pH}$ noted for this calcifying stage may indicate the diversion of energetic resources away from calcification/shell maintenance. Under continued exposure to these conditions, or in combination with other stressors, the 
negative effect of reduced $\mathrm{pH}$ on larvae may become significant through reduced shell growth rates, increased energy demands, or increased mortality rates. More work is required to investigate the links between developmental delays, energetic reserves, and shell morphology in order to determine the ecological relevance of these changes in terms of longer term larval success.

\section{Acknowledgements.}

I thank Rob Robbins and the USA dive team at McMurdo Station for L. elliptica collection and Antarctica New Zealand for their logistical support. I thank Neill Barr and Graeme Moss (National Institute of Water and Atmospheric Research, NIWA) for their continual support during set-up and maintenance of the experiment, Kim Currie and Judith Murdoch (NIWA/University of Otago Research Centre for Oceanography) for water chemistry analysis, Stefanie Menashe and Sonja Hempel (Victoria University of Wellington, VUW) for their valuable assistance in the lab, and Dalice Sim and Lisa Woods (VUW School of Mathematics, Statistics and Operations Research) for assistance and advice. This research was funded by VUW Grant 100241, the Victoria Doctoral Scholarship Fund, the Royal Society of New Zealand Marsden Fund NIW1101, and NIWA. 


\section{Chapter 3}

\section{Larval shell development in Laternula elliptica exposed to future climate change conditions}

\subsection{Introduction}

Human use of fossil fuels and other activities has resulted in a significant increase in greenhouse gas emissions. Since the industrial revolution, atmospheric concentrations of $\mathrm{CO}_{2}$ have risen by $40 \%$, to over $400 \mathrm{ppm}$ and are projected to rise to $450 \mathrm{ppm}$ by 2100 (IPCC, 2013; Tans and Keeling, 2015). In addition to warming brought on by greenhouse gases, increased partial pressure of $\mathrm{CO}_{2}\left(p \mathrm{CO}_{2}\right)$ can further impact marine environments where its uptake alters ocean chemistry. Carbon dioxide dissociates with seawater, resulting in an increase in $\left[\mathrm{H}^{+}\right]$and a subsequent drop in oceanic $\mathrm{pH}$, a process referred to as "ocean acidification" (OA). Oceanic $\mathrm{pH}$ has dropped by 0.1 units since measurements began, with further drops of over 0.3 units projected for the end of the century (IPCC, 2013). Excess $\left[\mathrm{H}^{+}\right]$ is buffered by free carbonate ions $\left(\mathrm{CO}_{3}{ }^{2-}\right)$, reducing their concentrations in seawater (Doney et al., 2009).

Ocean acidification may directly impact organisms through cellular acidosis and hypercapnia, while calcifiers may be further impacted by reduced saturation states $(\Omega)$ of calcium carbonate in seawater. The $\Omega$ is dependent on the relative concentrations of $\mathrm{Ca}^{2+}$ and $\mathrm{CO}_{3}{ }^{2-}$ (Doney et al., 2009; Steinacher et al., 2009):

$$
\Omega=\left[\mathrm{Ca}^{2+}\right]\left[\mathrm{CO}_{3}^{2-}\right] / K_{\mathrm{sp}}
$$

When undersaturation is reached $(\Omega<1)$, dissolution of biogenic carbonates is favoured. Due to differing stoichiometric solubility products $\left(K_{\mathrm{sp}}\right), \Omega$ varies among polymorphs of calcium carbonate (Doney et al., 2009). Aragonite, a carbonate polymorph, is projected to reach undersaturation as early as 2050 in polar waters, and even earlier in winter months in the Southern Ocean (Feely et al., 2004; Orr et al., 2005; McNeil and Matear, 2008). In addition to increased dissolution of established calcified structures, organisms may also experience difficulties in biomineralisation due to the reduced availability of $\mathrm{CO}_{3}{ }^{2-}$, which they may depend on for calcification (Fabry et al., 2008). However, this will only impact 
those that rely on seawater $\left[\mathrm{CO}_{3}{ }^{2-}\right]$; some organisms, including bivalves, instead use $\mathrm{HCO}_{3}{ }^{-}$ (Roleda et al., 2012; Thomsen et al., 2015).

Furthermore, increased $\left[\mathrm{CO}_{2}\right]$ may impact metabolism through alteration of the acid-base status (Michaelidis et al., 2005; Pecorino et al., 2014). Hypercapnia would place internal pH at disequilibrium with the seawater, meaning internal $\left[\mathrm{CO}_{2}\right]$ would need to increase relative to external conditions to favour $\mathrm{CO}_{2}$ diffusion out of the cell. Invertebrates may respond to reduced $\mathrm{pH}$ by actively regulating internal acid-base conditions through metabolic consumption or active transport of protons. However, these may only be short term solutions or may require regulatory systems not present in sessile species or ones that experience little natural variability (Pörtner, 2002a; Michaelidis et al., 2005; Pörtner, 2010). Bivalves may be particularly sensitive to OA due to their low capacity to regulate the acid-base balance of their haemolymph, especially at vulnerable early stages (Lindinger et al., 1984; Melzner et al., 2011; Waldbusser et al., 2013; Waldbusser et al., 2015). Alternatively, internal acidosis may be buffered by $\mathrm{HCO}_{3}{ }^{-}$, supplied through the dissolution of skeletal structures (Michaelidis et al., 2005; Wicks and Roberts, 2012). This may result in reduced rates of shell growth in calcifiers such as bivalves (e.g. Berge et al., 2006).

Laternula elliptica is a large, infaunal Antarctic bivalve that displays sensitivity to temperature and $\mathrm{pH}$ stressors. Increased temperatures limit energetic activities such as reburying, and impact metabolic rates, with prolonged thermal exposures resulting in mortality (Urban and Silva, 1998; Heise et al., 2003; Peck et al., 2004). In the larvae, increased temperatures result in faster development, and reduce occurrences of abnormalities, while reduced $\mathrm{pH}$ slows development, particularly at elevated temperature, with no change in survivorship (Bylenga et al., 2015). Under reduced pH, adults increase oxygen consumption, protein and chitin synthase gene expression, with no impacts on mortality (Cummings et al., 2011). Additionally, empty valves rapidly dissolve in acidified seawater (McClintock et al., 2009). However, the direct impacts of reduced $\mathrm{pH}$ on shell growth and integrity in live adults or larvae is unknown.

The adult shells of L. elliptica are nearly entirely aragonitic and grow to be as large as 117 mm (Barrera et al., 1994; Urban and Mercuri, 1998; Nehrke et al., 2012). The adult shell consists of two main layers, a thick outer homogenous granular layer and a thin inner nacreous layer (Sato-Okoshi and Okoshi, 2008; Sato-Okoshi and Okoshi, 2010). A thick periostracum covers most of the shell's outer surface. As sessile, infaunal organisms, shell 
integrity is important for withstanding crushing forces experienced during burial and ice movements. Adult shell development in L. elliptica displays a high level of phenotypic plasticity in response to environmental conditions, with shell morphology being linked to environmental disturbances (Harper et al., 2012). This may indicate a developmental response to environmental condition may exist in the larvae.

Exposure to reduced $\mathrm{pH}$ during larval shell formation may be of particular importance. The first calcification that occurs in many larvae is amorphous calcium carbonate (ACC) which, over time, converts to aragonite (Weiss et al., 2002; Addadi et al., 2003). ACC is highly soluble as it lacks a regular crystalline structure (Addadi et al., 2003; Wilt, 2005), indicating that early stages may be more vulnerable to dissolution than adult stages.

Reduced sizes in marine larvae, including bivalves are often observed in response to ocean acidification (e.g. Talmage and Gobler, 2011; Van Colen et al., 2012; Timmins-Schiffman et al., 2013). However, these smaller sizes often coincide with developmental delays, which suggests they are either a symptom of increased energetic costs associated with development or are due to reduced calcification (see Gaylord et al., 2011; Stumpp et al., 2011b). Calcification of bivalve larvae occurs in two distinct stages, one that corresponds with larval body size and the other with the rate of shell formation, offering an opportunity to address this question. Larval calcification begins at the trochophore stage when specialised ectodermal cells initiate shell formation (Carriker, 1996). These cells invaginate to form the shell gland, while the rest of the structure forms the periostracum (Eyster and Morse, 1984; Weiss et al., 2002; Barros et al., 2013). Calcification of prodissoconch I (PI, Fig. 3.1), the first larval shell, begins when the periostracum fully spans the epithelial surface. PI is complete when the new shell meets at the margins, completely enclosing the body, forming a straight-hinged D-shaped larva (Waller, 1981). Calcification then switches from the shell field to the mantle, beginning the development of prodissoconch II (PII, Fig. 3.1). During PII development shell deposition continues from the shell margins in conspicuous growth bands, as well as the inside of the shell, terminating at metamorphosis (Carriker, 1996; Kraeuter and Castagna, 2001). Therefore, PI correlates to the size of the larvae at competency, while PII corresponds to shell growth, and subsequently, the rate of calcification between PI and metamorphosis (Martel et al., 1995; Martel et al., 2014). 


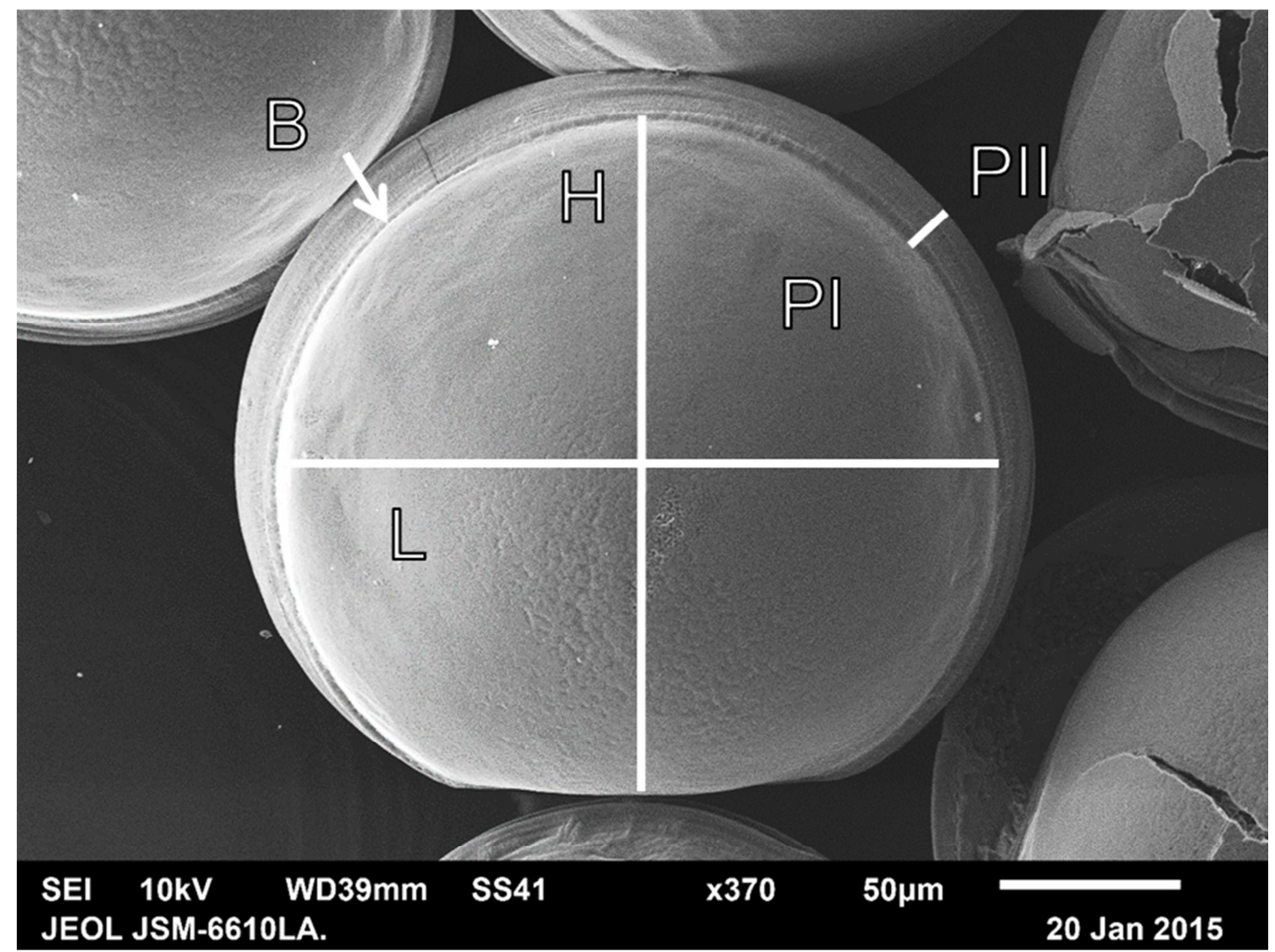

Fig. 3.1. SEM image of the shell of a L. elliptica D-shape larva, showing prodissoconch I (PI), the boundary between PI and PII (B) and the narrow band of prodissoconch II (PII). H and L indicate measurements of shell height and length, respectively of PI. Scale bar as indicated.

Calcification typically occurs in the extrapallial fluid, which is supersaturated with $\mathrm{CaCO}_{3}$. Bivalves may raise $\mathrm{pH}$ in the extrapallial fluid to aid the calcification process, possibly through active proton removal (McConnaughey and Gillikin, 2008). Under environmental stress there may be an increased energetic cost in maintaining calcification (Cohen et al., 2009). Additionally, ocean acidification is not the only stressor that may be experienced. Elevated temperatures may also influence species responses by increasing metabolic rates (Higgins et al., 2012), or by impacting survival, larval sizes and development (Byrne et al., 2011; Davis et al., 2013) and increasing development rates (Davis et al., 2013; Dorey et al., 2013). OA may increase sensitivity to other stressors (Mostofa et al., 2015; Przeslawski et al., 2015). Alternatively, exposures to other stressors may exacerbate or mitigate the effects of OA (Parker et al., 2009; Byrne et al., 2011; Parker et al., 2013; Pecorino et al., 2014). 
Reduced $\mathrm{pH}$ may impact more than shell size. Other effects include abnormal development of hinge and valve structure (Talmage and Gobler, 2010; Andersen et al., 2013), abnormal calcification (Watson et al., 2009), reduced shell integrity (Gaylord et al., 2011) and shell dissolution (Watson et al., 2009). Many bivalves rely heavily on shell structure to aid in feeding and mobility (Talmage and Gobler, 2010). Deformities in shell hinges and valve edges may significantly reduce larval survival, while reduced shell integrity would increase susceptibility to predation or crushing injuries (Talmage and Gobler, 2010; Gaylord et al., 2011; Andersen et al., 2013). In order to examine the impacts of future climate change on shell formation during early life history stages of L. elliptica, shell size and quality was assessed in larvae raised under ecologically relevant scenarios of elevated temperature and reduced $\mathrm{pH}$.

\subsection{Methods}

\subsubsection{Collection}

In November 2012, 32 adult Laternula elliptica were collected from the intake jetty at McMurdo Station $\left(7^{\circ} 51.093^{\prime}\right.$ S $166^{\circ} 39.931^{\prime}$ E), Ross Sea, Antarctica. They were transported to Wellington, New Zealand where they were held in free flowing filtered $(0.1 \mu \mathrm{m})$ seawater at $-1.6^{\circ} \mathrm{C}$ and $\mathrm{pH} 7.98$ (ambient conditions at the time of collection) until March 2013. They were fed a liquid algal mix (Shellfish Diet 1800, Reed Aquaculture, USA), 3 times per week.

\subsubsection{Experimental setup}

Larvae were raised under eight temperature/pH treatments in order to assess impacts of $\mathrm{OA}$ and warming on larval development (see Chapter 2). In addition to a temperature and $\mathrm{pH}$ control $\left(-1.6^{\circ} \mathrm{C}\right.$ and 7.98 , respectively), elevated temperatures of -0.5 and $0.4^{\circ} \mathrm{C}$ were chosen to reflect end of century projections for the Ross Sea (IPCC, 2013). Projections for $\mathrm{pH}$ were represented by two reduced $\mathrm{pH}$ treatments, 7.80 and 7.65 (IPCC, 2013; Orr et al., 2005). Logistical constraints allowed for a maximum of eight treatments, resulting in the temperature/pH combination $0.4^{\circ} \mathrm{C}$ and 7.80 not being used. Temperature and $\mathrm{pH}$ manipulations are detailed in Chapter 2 and Table 2.1.

\subsubsection{Microscopy}

Larvae were raised to the D-larvae stage, the first occurrence of a fully shelled larva in bivalves, as described in Chapter 2. Ninety-six hours after the point at which approximately 
$50 \%$ of the normally developing larvae in each treatment had reached the D-larvae stage (completing PI development); a sample of approximately 200 larvae was removed from each replicate and preserved in $90 \%$ ethanol.

Individual larvae from each treatment replicate $(n=4)$ were examined under a scanning electron microscope, (SEM: JEOL, JSM-6610LA, Japan) to determine sizes and shell morphology. Preserved larvae were rinsed with deionised water to remove as much of the ethanol as possible. Larvae were careful excised from each egg capsule using a scalpel blade under a dissecting microscope. Shelled larvae were then placed in a drop of deionised water on carbon tape on aluminium stubs ( 65 larvae per stub). The samples were air dried, and excess organic material was removed by plasma ashing for $30 \mathrm{~min}$, and stored in a vacuum desiccator until analysis. Samples were platinum coated $(10 \mathrm{~nm})$ and imaged.

Under SEM, D-larvae on each stub were counted and scored for instances of severe damage or malformation. Malformation counts included larvae that deviated from the expected D-shape and also included larvae that were uncalcified. From each sample, 10 intact larvae with a normal D-shape were then selected for analysis of shell size and quality of shell formation (magnification x350-500). The PI length (anterior to posterior) and height (hinge to ventral edge, see Fig. 1) were measured for each larva to assess body size at the onset of calcification. PII length measurements are typically taken as the length across the larval body, from edge to edge. This includes the length of PI and the new growth on PII. However, as variations in PI size would influence total PII length, we measured growth of PII from the terminal edge of PI to the new shell margin. This measurement was made at three standard points along the shell edge, and these values averaged to attain a single PII length for each individual and an estimate of shell growth.

Images were imported into ImageJ (version 1.47t) and each individual was further assessed for evidence of damage and malformation of the shell surface. On each image, the total pixel areas of shell malformation, cracking or pitting were determined and expressed as a percentage of the total shell area. Values of the 10 individuals from a particular replicate were averaged to obtain one value for each parameter for each replicate prior to statistical analysis. 


\subsubsection{Statistical Analysis}

All statistical analysis was performed using SPSS, version 22. Normality of the data was verified using Shapiro-Wilk's test and equality of variances was confirmed using Levene's test. Differences in shell size at PI and PII, as well as shell quality, were related to $\mathrm{pH}$ and temperature by fitting the data to a general linear model using $\mathrm{pH}$ and temperature as fixed factors, with a temperature $\times \mathrm{pH}$ interaction term. If the general linear model indicated overall individual statistical significance $(\mathrm{p}<0.05)$ of either temperature or $\mathrm{pH}$, a post-hoc Bonferroni multiple comparison test was performed to determine effects of $\mathrm{pH}$ averaged over temperature and temperature averaged over $\mathrm{pH}$, on larval shell sizes and quality. Where interactive effects approached significance $(\mathrm{p}<0.100)$, a one-way ANOVA was performed with treatment as a single factor.

\subsection{Results}

Calcification of PI and PII occurred in encapsulated larvae in all treatments, despite aragonite being undersaturated (Table 3.1) at both reduced $\mathrm{pH}$ levels. Fully shelled D-larvae at PI were capable of rotating within the egg capsule but development of PII caused the larval shell to press against the edges of the egg capsule, preventing later larvae from rotating (Fig. $3.2)$.

Table 3.1. Seawater conditions for all experimental treatments. Average temperature $\left({ }^{\circ} \mathrm{C} ; \mathrm{n}=360\right), \mathrm{pH}$ (measured on the total hydrogen scale; $\mathrm{n}=360$ ), partial pressure of $\mathrm{CO}_{2}\left(p \mathrm{CO}_{2}\right)$ is calculated from $\mathrm{A}_{\mathrm{T}}$ and $\mathrm{pH}, \Omega_{\mathrm{Ar}}$ is calculated from $\mathrm{A}_{\mathrm{T}}$ and $\mathrm{pH}$. Values presented are mean \pm standard error. Salinity was 34.2 psu. Further details are given in Chapter 2 Table 2.1.

\begin{tabular}{|cccc|}
\hline Temp $\left({ }^{\circ} \mathrm{C}\right)$ & $\mathrm{pH}$ & $p \mathrm{CO}_{2}(\mathrm{ppm})$ & $\Omega_{\mathrm{Ar}}$ \\
\hline$-1.6 \pm 0.01$ & $7.97 \pm 0.001$ & $350.1 \pm 1.3$ & $1.37 \pm 0.01$ \\
& $7.79 \pm 0.001$ & $554.6 \pm 2.2$ & $0.92 \pm 0.01$ \\
& $7.63 \pm 0.001$ & $823.3 \pm 2.1$ & $0.65 \pm 0.01$ \\
& & & \\
$-0.5 \pm 0.01$ & $7.99 \pm 0.002$ & $367.2 \pm 1.4$ & $1.37 \pm 0.01$ \\
& $7.80 \pm 0.001$ & $569.0 \pm 1.6$ & $0.95 \pm 0.01$ \\
& $7.64 \pm 0.001$ & $835.6 \pm 2.7$ & $0.68 \pm 0.01$ \\
$0.4 \pm 0.01$ & $7.99 \pm 0.001$ & $383.6 \pm 1.4$ & $1.38 \pm 0.01$ \\
& $7.63 \pm 0.001$ & $893.0 \pm 3.7$ & $0.66 \pm 0.01$ \\
\hline
\end{tabular}




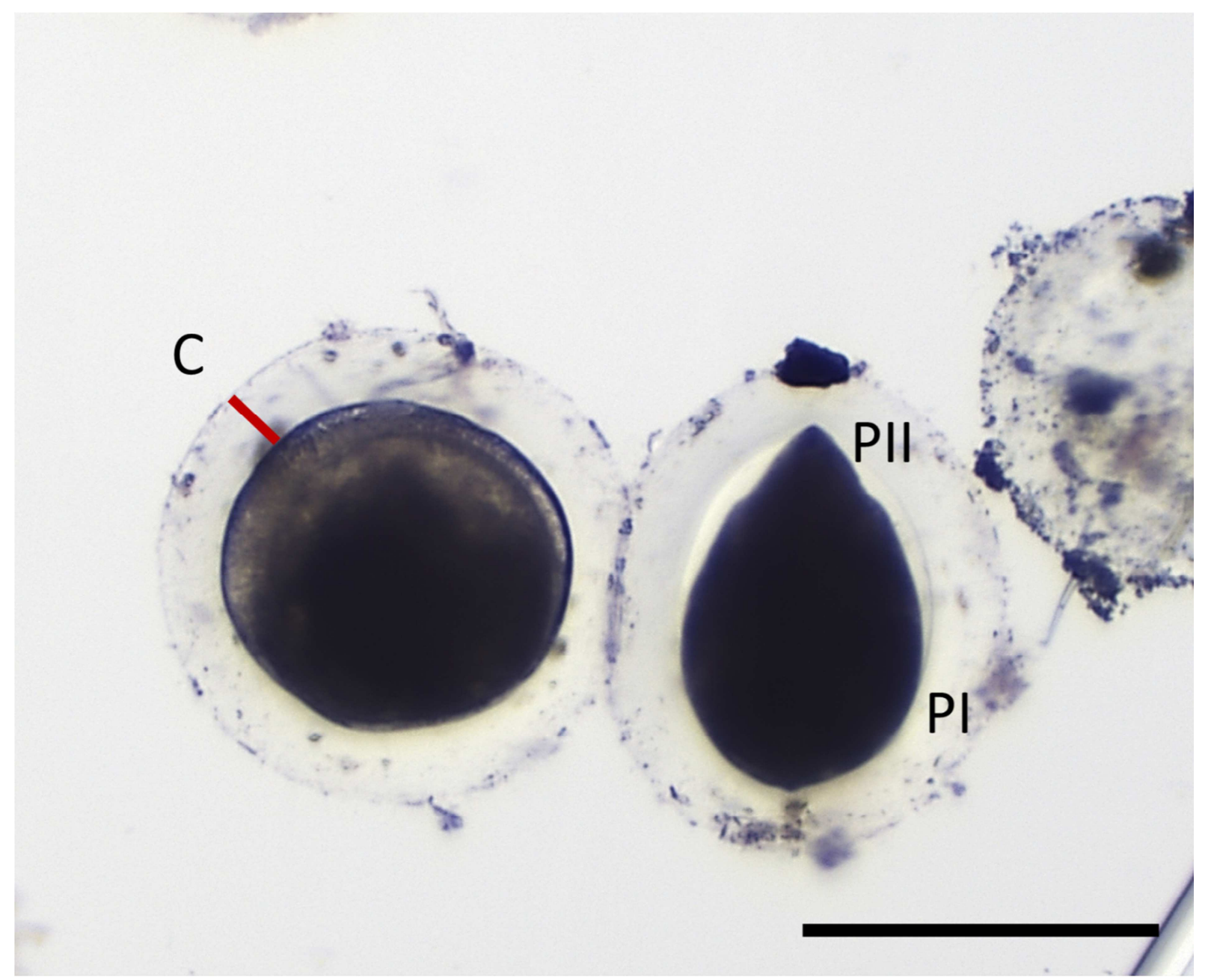

Fig. 3.2. D-larvae displaying encapsulated development of prodissoconch I and II (PI and PII). In the profile view of the larva on the right, note elongation of egg capsule due to PII growth. C indicates the thick gelatinous capsule in which the larvae develop. Scale bar $=200 \mu \mathrm{m}$. 
Table 3.2. Summary table of 2-way ANOVA for factors $\mathrm{pH}$ and temperature on shell measurements, shell shape and larval quality of D-larvae. Significant results in bold.

\begin{tabular}{|lcrrrrrr|}
\hline & \multicolumn{2}{c}{$\mathrm{pH}$} & \multicolumn{2}{c}{ Temperature } & \multicolumn{2}{c|}{ Temp. $\times \mathrm{pH}$} \\
& $\mathrm{F}_{2,215}$ & $\mathrm{p}$ & $\mathrm{F}_{2,215}$ & $\mathrm{p}$ & \multicolumn{1}{c|}{$\mathrm{F}_{3,215}$} & $\mathrm{p}$ \\
\hline Larval Quality & & & & & & \\
Malformation & $4.632^{\mathrm{a}}$ & $\mathbf{0 . 0 2 7}$ & $0.481^{\mathrm{a}}$ & 0.627 & $0.098^{\mathrm{b}}$ & 0.960 \\
Shell Quality & 75.521 & $<\mathbf{0 . 0 0 1}$ & 5.281 & $\mathbf{0 . 0 0 6}$ & 6.818 & $<\mathbf{0 . 0 0 1}$ \\
& & & & & & \\
Shell Measurements & & & & & & \\
PI Height & 1.318 & 0.270 & 4.290 & $\mathbf{0 . 0 1 5}$ & 3.009 & $\mathbf{0 . 0 3 1}$ \\
PI Length & 1.525 & 0.506 & 2.048 & 0.132 & 0.781 & 0.200 \\
PII Growth & 0.562 & 0.571 & 11.056 & $<\mathbf{0 . 0 0 1}$ & 5.146 & $\mathbf{0 . 0 0 2}$ \\
${ }^{\mathrm{a}}{ }^{\mathrm{F}}{ }_{2,15,}{ }^{\mathrm{b}}{ }^{\mathrm{F}}{ }_{3,15}$ & & & & & & \\
\hline
\end{tabular}

\subsubsection{Larval Shell Quality}

Damage appeared as heavy pitting and cracking in some shells (Fig. 3.3b-d, cf. with Fig. 3.3a, an example of a normally developing shell). Other forms of aberration included malformation of shell hinges (Fig. 3.3b, d and e) and shell edges (Fig. 3.3b-e). Additionally, Fig.3.3e shows an abnormal D-shaped larva (note the irregular outline of PI). Fig. 3.3f shows a highly aberrant shell as well as an unshelled larva. Shell quality analysis was only performed on the larvae that were used for the shell size measurements. Therefore, unshelled larvae and those with significant malformations or damage to the hinges or edges were excluded from the shell quality assessments. 

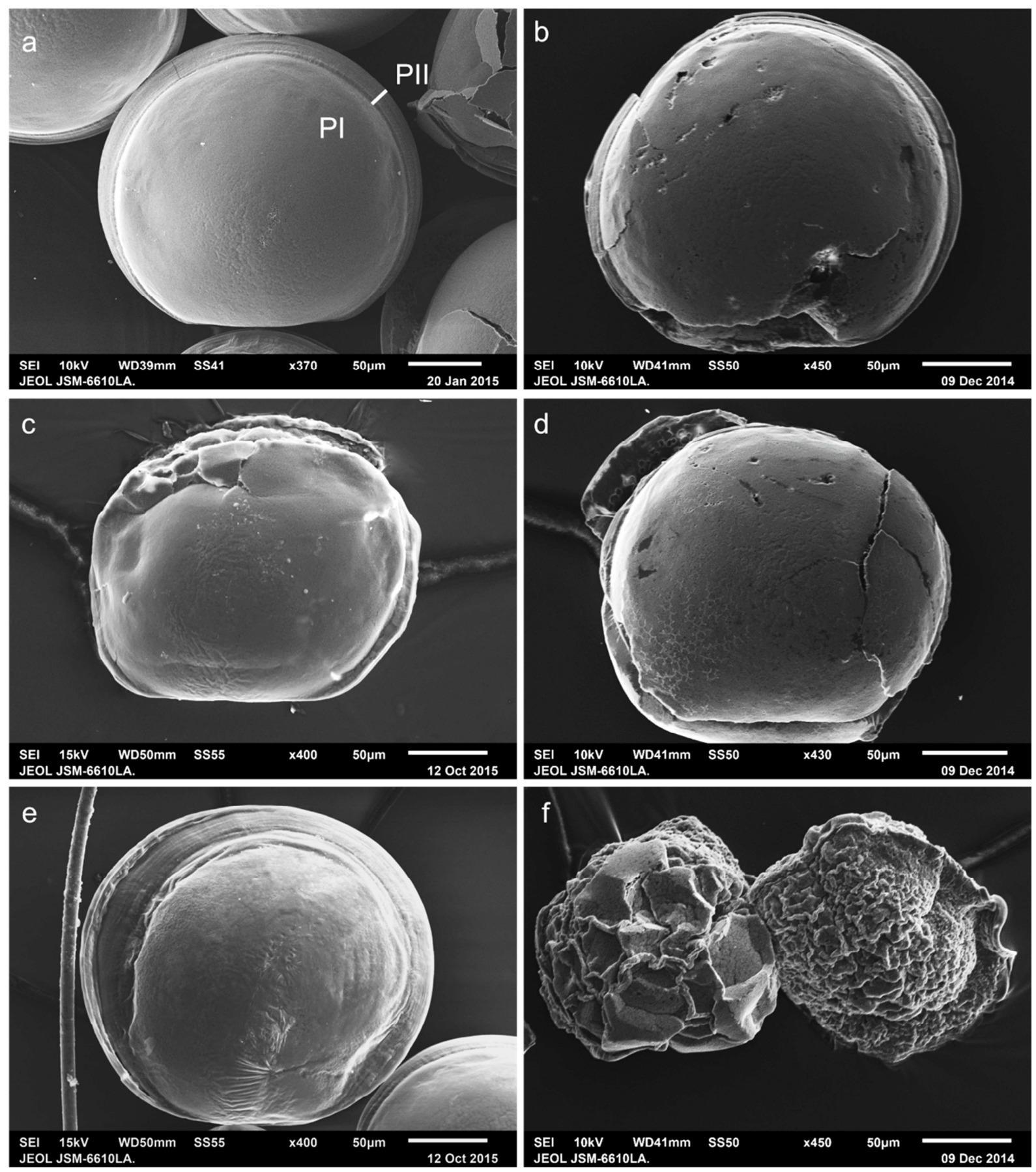

Fig. 3.3. SEM images of D-larvae from experimental treatments a) normal D-larvae from the control treatment ( $\mathrm{pH} 7.98$ and $\left.-1.6^{\circ} \mathrm{C}\right)$, and b-e) larvae from reduced $\mathrm{pH}$ treatments $(\mathrm{pH} 7.80$ and 7.65 at various temperatures) displaying pitting, cracking and/or malformation, f) extremely malformed and uncalcified larvae from the reduced $\mathrm{pH}$ treatment at $-1.6^{\circ} \mathrm{C}$. PI: prodissoconch I and PII: prodissoconch II, $50 \mu \mathrm{m}$ scale bars as indicated on each image. 
A significant effect of $\mathrm{pH}$ was observed on the proportion of larvae that had abnormal Dshapes or were uncalcified (Table 3.2, Fig. 3.4). Over $50 \%$ of the larvae developing at $\mathrm{pH}$ 7.80 and 7.65 were malformed compared to only $25-35 \%$ of those raised at the control $\mathrm{pH}$ (Fig. 3.4). Temperature did not affect the percentage of normally developed D-shaped larvae (Table 3.2).

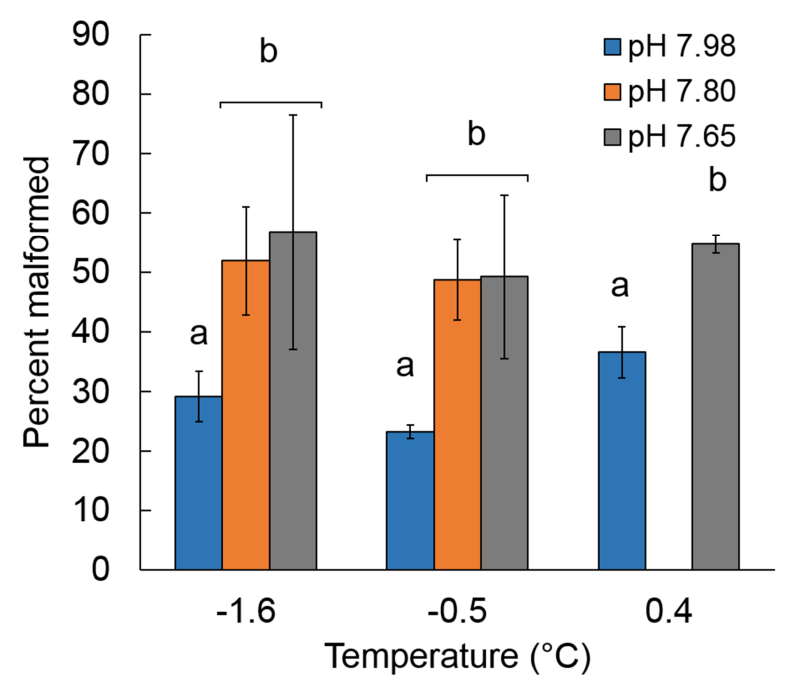

Fig. 3.4. Percentage of D-larvae in each treatment that were abnormally shaped, severely damaged or unshelled. The letters above the columns indicate significance at $\mathrm{p}<0.05$. The temperature/pH combination of $0.4^{\circ} \mathrm{C} / 7.80$ was not used, $\mathrm{n}=4$. Error bars are standard error.

In the larvae that were fully shelled and had normal D-shapes, damage to the shell surface covered 3.2 to $11.6 \%$ of the total area, and was influenced by reduced $\mathrm{pH}$ and elevated temperature. Shell damage increased with reduced $\mathrm{pH}$, while significantly more damage occurred at $\mathrm{pH} 7.65$ compared to those reared at the control pH (Table 3.2, Fig. 3.5). A significant temperature $\times \mathrm{pH}$ interaction was observed, whereas at $\mathrm{pH} 7.80$ and 7.65 elevated temperatures significantly reduced the extent of shell damage shell quality scores, but had no significant impact at the control $\mathrm{pH}$. An overall significant effect of temperature was also measured (Table 3.2), where shell damage was lower overall at -0.5 and $0.4^{\circ} \mathrm{C}$, with no significant differences between the two elevated temperatures. 


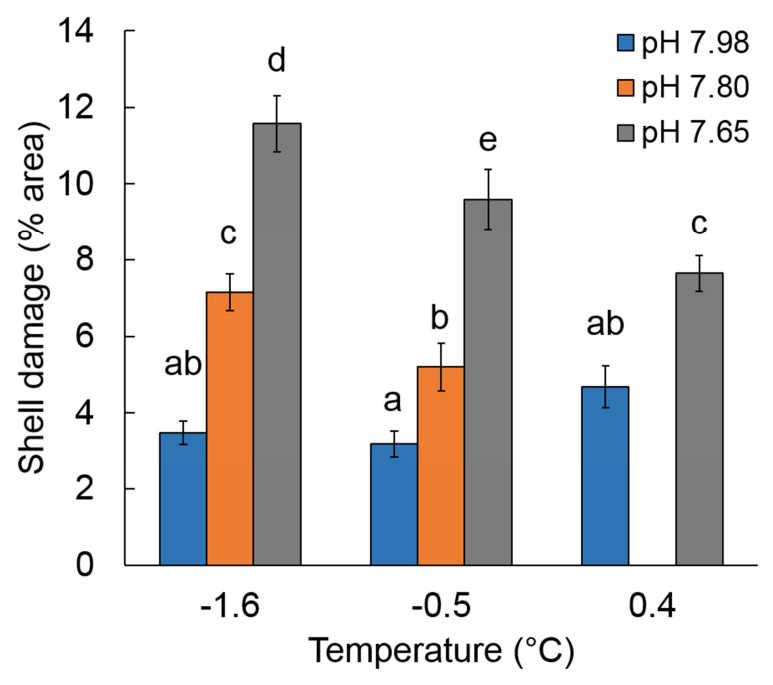

Fig. 3.5. Shell damage in normal D-shaped larvae from each treatment, where shell damage is equal to the percentage of the shell surface that is pitted, cracked or malformed. Letters indicate significance as in Fig. 3.4. The temperature/pH combination of $0.4^{\circ} \mathrm{C} / 7.80$ was not used, $\mathrm{n}=4$. Error bars are standard error.

\subsubsection{Shell Measurements}

\subsubsection{Prodissoconch I}

Larval shell heights at PI ranged between 173 and $180 \mu \mathrm{m}$, and lengths from 189 to 194 $\mu \mathrm{m}$ (Fig. 3.6). Reduced $\mathrm{pH}$ alone had no impact on height of PI, and therefore, larval size at the onset of calcification, but a significant interactive effect was observed, with the effects of pH 7.65 differing with treatment temperature (Table 3.2, Fig. 3.6a). Larval heights were smallest at $\mathrm{pH} 7.65$ at both -1.6 and $0.4^{\circ} \mathrm{C}$ (173.9 and $173.0 \mu \mathrm{m}$, respectively), which were significantly smaller than in larvae raised at $-0.5^{\circ} \mathrm{C}$ and $\mathrm{pH} 7.65(179.8 \mu \mathrm{m})$. An overall, independent effect of temperature was also observed with generally smaller shell heights in PI at $0.4^{\circ} \mathrm{C}$. Length of PI was not impacted by treatment (Table 3.2, Fig. 3.6b). 


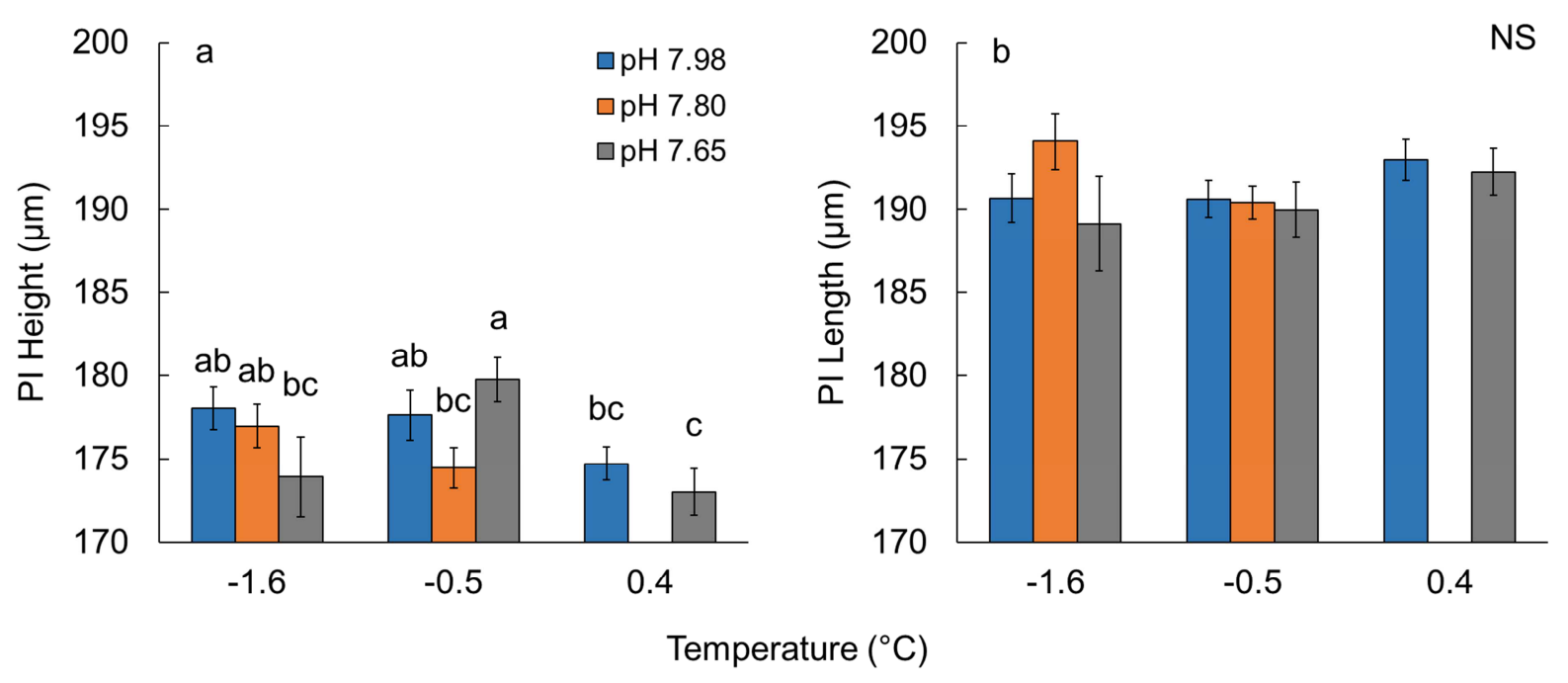

Fig. 3.6. Impacts of reduced $\mathrm{pH}$ and elevated temperatures on a) shell height and b) shell length on prodissoconch I (PI). Letters indicate significance as in Fig. 3.4. The temperature/pH combination of $0.4^{\circ} \mathrm{C} / 7.80$ was not used. NS $=$ no significant differences between treatments, $\mathrm{n}=4$. Error bars are standard error.

\subsubsection{Prodissoconch II}

During PII growth, larvae added $8.3-11.5 \mu \mathrm{m}$ of new shell. Temperature influenced this growth with elevated temperatures increasing the amount of new material at the shell edge (Table 3.2, Fig. 3.7). Interactive effects of $\mathrm{pH}$ and temperature were again observed on shell growth, with the effects of $\mathrm{pH}$ being dependent on the incubation temperature. The largest PII growth occurred in larvae raised at $\mathrm{pH} 7.65$ and $0.4^{\circ} \mathrm{C}$. Conversely, at the control temperature, reduced $\mathrm{pH}$ resulted in the smallest shell growth $\left(-1.6^{\circ} \mathrm{C}\right.$ and 7.65 , Fig. 3.7). There was no significant effect of $\mathrm{pH}$ on shell growth of PII. Total shell lengths (PI+PII) ranged between 205 and $215 \mu \mathrm{m}$, with the largest total lengths occurring at $\mathrm{pH} 7.65$ and $0.4^{\circ} \mathrm{C}$. 


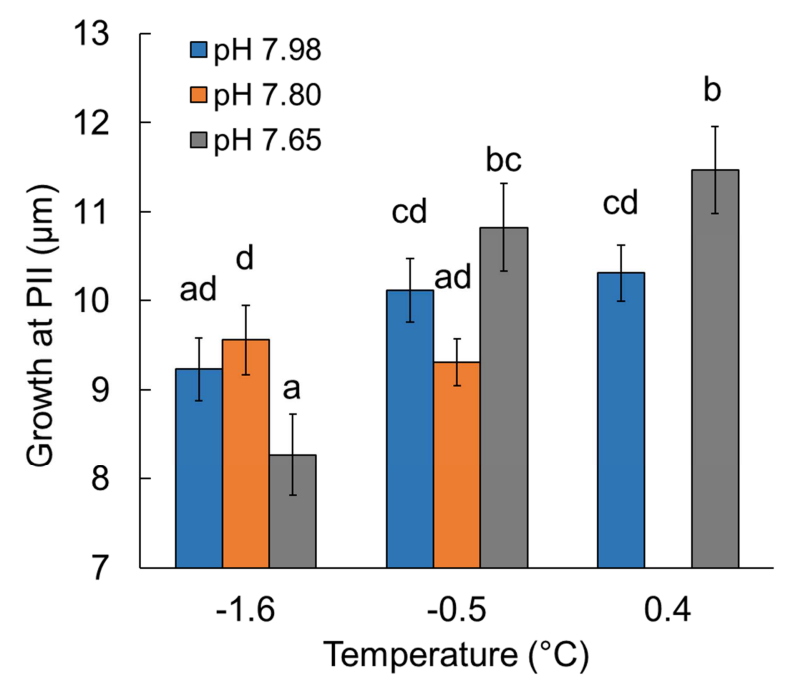

Fig. 3.7. Impacts of reduced $\mathrm{pH}$ and elevated temperatures on growth of prodissoconch II. Letters indicate significance as in Fig. 3.4. The temperature/pH combination of $0.4^{\circ} \mathrm{C} / 7.80$ was not used, $\mathrm{n}=$ 4. Error bars are standard error.

\subsection{Discussion}

Temperature and $\mathrm{pH}$ both affected shell development and quality in L. elliptica larvae. Impacts occurred on both PI, when larvae first become fully shelled and competent and PII, the point of shell elongation between competency and metamorphosis. Both factors influenced larval body size and shell growth. Larvae raised under elevated temperatures had smaller body sizes and displayed greater PII growth at equivalent larval stages compared to those at the control temperature treatments, while the impact of reduced $\mathrm{pH}$ was dependent on incubation temperature.

In Chapter 2, abnormality rates in these larvae were determined by performing a qualitative assessment of the overall larval shape using light microscopy. In Chapter 2 it was concluded that abnormality rates were high in all treatments, but not impacted by $\mathrm{pH}$, although a trend towards higher abnormalities was observed (Fig. 2.7f). It was suggested that larvae were robust to $\mathrm{OA}$, and that temperature had a much greater influence on larval development in this species. However, this study reveals that the effect of $\mathrm{pH}$ is significant and may have serious implications for later development stages. SEM analysis of the apparently normally developed D-larvae showed that larvae from reduced $\mathrm{pH}$ treatments had abnormal D-shapes, deformed shell edges and irregular hinges, cracked shell surfaces and some were even uncalcified (Fig. 3.3). Furthermore, pitting of the shell surface was observed on all larvae raised at $\mathrm{pH} 7.80$ and 7.65 , indicating dissolution due to the undersaturation of 
aragonite in both reduced $\mathrm{pH}$ treatments. Reduced $\mathrm{pH}$ (7.80 and 7.65) significantly increased the frequency of aberrations of shell edges and hinges, pitting and cracking. Elevated temperatures partially mitigated the damaging effects of reduced $\mathrm{pH}$. These results suggest that $\mathrm{pH}$ is in fact a major stressor in development for this species, with larval shells experiencing significant losses in quality, which could impair function or success.

These observations have important implications for OA research on larval development. Current methodology in many larval morphological investigations may inadvertently underestimate the damaging effects of $\mathrm{pH}$ exposure, which could lead to incorrect assumptions about stress responses. Due to small larval sizes, only severe abnormalities may be immediately obvious. The dissolution of shell surfaces, as well as damage to fine structures, may not be initially noticeable without SEM (see Green et al., 2009; Bednaršek et al., 2014; Müller et al., 2015). Sublethal damage such as this is notable as reduced shell integrity could drastically impair swimming (see Talmage and Gobler 2010; Andersen et al., 2013), and subsequently larval settlement and recruitment. Additionally, larvae may have experienced trade-offs in muscle and tissue development in order to maintain calcification, resulting in a weaker animal (Wood et al., 2008). During settlement in L. elliptica, juveniles must bury in sediments, and reduced muscle mass or altered shell shapes may increase the energetic cost of doing so. Furthermore, reduced shell integrity may hinder burial or expose soft tissues to damage, impacting successful settlement with negative flow-on effects to the population.

Repair to shell surfaces may be possible, however the process is slow and energetically demanding (Harper et al., 2012; Sleight et al., 2015). It is likely that the energetic costs of repairing such extensive damage to the shell would be high in larvae, even with extensive energetic reserves, particularly under OA. Weaker shells could lead to significantly reduced populations in more disturbed environments. Elevated temperatures may relieve some of the negative impacts of reduced $\mathrm{pH}$ on shell integrity, for example, at $\mathrm{pH} 7.65$, elevated temperatures reduced shell damage by $34 \%$. However, under these concurrent elevated temperature/reduced $\mathrm{pH}$ scenarios, shell damage was still $120 \%$ greater than in control conditions. Under projected warming and acidification, larvae will reach competency faster (Fig 2.6) and larval shells may grow to be larger (Fig. 3.7), but weakness in the calcified structures could reduce recruitment and significantly increase post-metamorphic mortalities and will likely overcome any potential benefits of larger juveniles. The effects of reduced pH will have a greater impact on larval survival than indicated in Chapter 2 and similar studies. It 
is unknown how dissolution and reduced integrity will influence survival in later stages and this is therefore an important direction for further research into the effects of reduced $\mathrm{pH}$ on larval development.

Shell development occurred at all reduced $\mathrm{pH}$ treatments despite undersaturation of aragonite, indicating calcification was not limited by saturation states. Calcification with undersaturation is not uncommon, in fact, many studies show calcification does occur (e.g. Miller et al., 2009; Ries et al., 2009), but that the extent and quality of the calcium carbonate is impacted (e.g. White et al., 2014; Pereira et al., 2015). While undersaturation in seawater would reduce $\mathrm{CO}_{3}{ }^{2-}$ availability and promote dissolution of established calcified structures, saturation states may not have directly impacted calcification of the L. elliptica larvae. These larvae would have still been able to calcify using bicarbonate from seawater, or made through the conversion of respiratory $\mathrm{CO}_{2}$ (Roleda et al., 2012; Thomsen et al., 2015), which may have increased in availability in elevated temperature treatments if metabolism was upregulated. Undersaturation does not create a distinct line between inability and ability to calcify, but rather increases the metabolic costs of calcification (Tunnicliffe et al., 2009; Thomsen and Melzner, 2010; Wicks and Roberts, 2012).

Despite not using seawater $\mathrm{CO}_{3}{ }^{2-}$ in biomineralisation, variations in calcification in bivalve larvae show a strong link to seawater $\Omega$ (Waldbusser et al., 2015). Calcification is still dependent on the $\mathrm{pH}$ and $\Omega$ at the site of calcification, maintained through the active pumping of ions in and out of the calcifying fluid (McConnaughey and Gillikin, 2008). Under OA, the cost of doing so would increase (Thomsen and Melzner, 2010; Wicks and Roberts, 2012). Additionally, established calcified structures would be at risk of dissolution. Shell growth did occur in the L. elliptica larvae at reduced $\mathrm{pH}$, however, the quality of the calcium carbonate structure was low. This is likely related to the energetic cost of maintaining shell growth which could also have serious implications for recruitment and survival. Larval shells appeared to be weaker, displaying an increased frequency of cracking and pitting as well as significant damage and malformation of shell hinges and edges. During growth of PII in bivalves, larvae do not add calcium carbonate only to the shell edges; they also thicken the shell by adding to the inside of the PI structure (Carriker, 1996). Under an increased energetic burden from maintaining calcification fluid $\mathrm{pH}$ and $\Omega$, calcification on PI may have been limited, resulting in thinner shells that were more prone to damage. 
The size of PI is typically correlated to egg size while PII size is dependent on the time between competency and metamorphosis (Waller, 1981; Martel et al., 1995; Martel et al., 2014). As metamorphosis would occur when the appropriate cues are received, the length of time spent on PII development, and therefore PII size, may vary between seasons and populations (Martel et al., 2014). Prodissoconch II is not always present in lecithotrophic species due to immediate settlement at competency (Ockelmann, 1965); however, it was present in L. elliptica larvae. As both PI and PII development occurred in encapsulated larvae in L. elliptica, PI may be more accurately linked to larval body size rather than egg size and PII size should be dependent on the length of time between a fully calcified D-larva (PI) and hatching. Shell length measurements were similar to those reported by Berkman et al. (1991), who determined PI/PII sizes from adult shells. Their measurements of PII ranged from 214$265 \mu \mathrm{m}$ compared to $205-215 \mu \mathrm{m}$ in this experiment, indicating the larvae analysed here might have been able to develop longer before hatching and metamorphosis.

The timing of development in L. elliptica is impacted by temperature and $\mathrm{pH}$ (Chaper 2 and Bylenga et al., 2015). Temperatures $2^{\circ} \mathrm{C}$ above ambient advanced development to the Dlarvae stage by up to 5 days, while reduced $\mathrm{pH}$ delayed development up to 4 days (Fig. 2.7 and Table 2.4 Bylenga et al., 2015). If larvae are developing faster they may be able to initiate calcification earlier, leading to fully calcified larvae of a smaller size, explaining the trend towards smaller PI heights at $+0.4^{\circ} \mathrm{C}$. While the differences in shell height at PI appear to correlate with differences in development timing due to temperature, they do not relate to the delays observed with reduced $\mathrm{pH}$. At $\mathrm{pH} 7.65$, there was a trend towards smaller PI larvae at $-1.6^{\circ} \mathrm{C}$ and $0.4^{\circ} \mathrm{C}$, while significantly larger larvae occurred at the intermediate temperature, $-0.5^{\circ} \mathrm{C}$. Possibly, this relates to an optimum temperature window for tolerance of $\mathrm{pH}$ stress, where temperatures around $-0.5^{\circ} \mathrm{C}$ increase metabolic rates, aiding in internal $\mathrm{pH}$ regulation and promoting larval growth. However at $0.4^{\circ} \mathrm{C}$, metabolic increases may have become insufficient to manage regulation at reduced $\mathrm{pH}$, and as these larvae approached critical temperatures, they may have diverted resources to activity other than growth.

Due to the observed differences in developmental timing, sampling time varied with treatment, dependent on the completion of PI development. This meant that while larvae were collected at different ages, they were at equivalent life history stages and had spent similar times in PII development. The measurements of PII therefore are a reflection of the rate of calcification. Under both elevated temperatures, shell growth on PII was greater than that of control temperatures, implying the larvae may have had higher rates of calcification. Larger 
larvae may reduce vulnerability in settled juveniles (Gosselin and Qian, 1997; Phillips and Gaines, 2002; Martel et al., 2014), indicating that recruitment in L. elliptica may be improved under future warming. However, the differences in total shell length were minor $(<5 \%$ increase in length). While the length of larvae at PII is not necessarily an indication of competency, size at settlement relates more to the time larvae take to find suitable habitat or receive settlement cues (see Martel et al., 2014). The faster development rates observed in $L$. elliptica may mean that more larvae settle on the receipt of settlement cues, potentially reducing time spent at this vulnerable life stage. The cues for settlement are unknown in $L$. elliptica. Beyond the time frame of this experiment, competent larvae may have continued PII growth while waiting for appropriate cues. Under elevated temperatures, larvae will either reach a larger size in a set development time resulting in larger juveniles, or they will have the potential to settle earlier. Both scenarios could have beneficial flow-on effects to the population through improved juvenile success.

Ocean acidification typically limits larval sizes in bivalves (see Parker et al., 2009; Watson et al., 2009; Parker et al., 2010; Jansson et al., 2013; White et al., 2013) largely due to increased shell dissolution and reduced calcification rates due to $\mathrm{CO}_{3}{ }^{2-}$ undersaturation (Waldbusser et al., 2015). This was only reflected in L. elliptica at the control temperature, where the smallest PII shells were observed at the lowest $\mathrm{pH}$ (where $\Omega_{\mathrm{Ar}}=0.65$, Table 3.1). Conversely, in the two elevated temperatures (where $\Omega_{\mathrm{Ar}}=0.68$ and 0.66, Table 3.1), the largest PII larvae were at pH 7.65 (Fig. 3.7). However, despite these larger sizes, these larvae still had significantly high levels of damage and malformation of shell surfaces (Fig. 3.4 and 3.5), which would overcome any benefit to a larger shell in settlement.

An increase in shell size in larvae in the highest stressed treatments may due to a hormetic response in which combined stressors crossed a tolerance threshold and activated repair mechanisms (e.g. Gooding et al., 2009). Alternatively, it may be related to the protected form of development used by L. elliptica larvae (Lucey et al., 2015). Increases in calcification at reduced $\mathrm{pH}$ have been observed in encapsulated cuttlefish (Gutowska et al., 2010; Dorey et al., 2013). In a gastropod with encapsulated development, $\mathrm{pH}$ impacts on growth were minor in comparison to non-encapsulated species (Noisette et al., 2014). Egg capsules act as diffusion barriers for respiratory $\mathrm{CO}_{2}$, and this indicates encapsulation may reduce extracellular pH during development, even under ambient conditions (Melzner et al., 2009). Despite the reduced $\mathrm{pH}$, calcification of aragonite structures still occurs, indicating ion regulatory mechanisms may exist in these species (Melzner et al., 2009; Dorey et al., 2013). 
While ion regulatory mechanisms would allow for continued calcification in L. elliptica, they may not fully protect larvae from the effects of ocean acidification. Bivalves may have a reduced capacity for ion and acid-base regulation, as active control in these areas is related to metabolic capacity which would be limited in animals with sessile life stages (Seibel and Walsh, 2001, 2003; Melzner et al., 2009; Parker et al., 2013).

\subsubsection{Conclusions}

Elevated temperatures and reduced $\mathrm{pH}$ influenced larval shell development in L. elliptica. Elevated temperatures improved larval shell quality and increased PII sizes as well as accelerated development (Chapter 2, Bylenga et al., 2015). While reduced $\mathrm{pH}$ increased larval shell sizes at elevated temperature, it slowed development to the D-larval stage (Bylenga et al., 2015). The results presented in Chapter 2 suggested $\mathrm{pH}$ had no significant influence on larval abnormalities; however, these observations were limited by methodology. Detailed analysis of the shell using SEM here showed that reduced $\mathrm{pH}$ significantly increased occurrences of malformed larvae, produced fewer larvae with a normal D-shape, and increased shell pitting and cracking in these D-larvae by as much as $230 \%$. This indicates larvae may be in poor condition at settlement, which would reduce juvenile recruitment and overall survival. Under future ocean conditions, slightly larger larvae may be observed at elevated temperatures and reduced $\mathrm{pH}(<5 \%$ increase in length), which could improve settlement in L. elliptica. However, the overall impacts on larval shell quality and integrity due to reduced $\mathrm{pH}$ would likely overshadow any beneficial results, due to reduced survival in settlement and recruitment, limiting populations of this prevalent Antarctic species.

\section{Acknowledgements}

I thank Rob Robbins and the USA dive team at McMurdo Station for L. elliptica collection and Antarctica New Zealand for their logistical support. I thank Neill Barr and Graeme Moss (National Institute of Water and Atmospheric Research, NIWA) for their continual support during set-up and maintenance of the experiment, Kim Currie and Judith Murdoch (NIWA/University of Otago Research Centre for Oceanography) for water chemistry analysis, Stefanie Menashe and Sonja Hempel (Victoria University of Wellington, VUW) for their valuable assistance in the lab, and Dalice Sim and Lisa Woods (VUW School of Mathematics, Statistics and Operations Research) for their assistance and advice. I also thank David Flynn (VUW School of Chemical and Physical Sciences) for his assistance with SEM. This research was funded by VUW Grant 100241, the Victoria Doctoral Scholarship Fund, the Royal Society of New Zealand Marsden Fund NIW1101, and NIWA. 


\section{Chapter 4}

\section{Lipid use in the lecithotrophic larvae of Laternula elliptica under $\mathrm{pH}$ and temperature stress}

\subsection{Introduction}

Mortality in early development is often associated with environmental fluctuations during embryogenesis and metamorphosis (Lu et al., 1999). Successful development is largely dependent on stored energy and the ability to form feeding structures before these reserves are depleted. In invertebrate larvae there are two basic development modes, lecithotrophy and planktotrophy, which are differentiated by the amount of maternal investment and whether or not the larvae are able to feed (Jaeckle and Manahan, 1989). In either case, eggs must carry enough energy and structural components to develop into independently feeding larvae or juveniles (Prowse et al., 2009).

Planktotrophic larvae have a feeding stage. Endogenous resources support their development until larval feeding structures are formed, after which the larvae rely on remaining egg reserves (facultative feeding) and exogenous energy to support metamorphosis to juvenile stages (Miner et al., 2005; Pernet et al., 2006; Byrne et al., 2008a; Byrne et al., 2008b). Metamorphosis may be delayed until energetic reserves are high enough to support it (Lucas et al., 1986). This results in relatively long development times during which the larvae are exposed to risks such as predation, starvation and disease (Prowse et al., 2009).

Lecithotrophic larvae lack a feeding stage, relying on maternally-derived egg nutrients for embryonic development and metamorphosis. Therefore, there are maternal trade-offs of energetic input and fecundity, with mothers producing low numbers of nutrient rich eggs, compared to the high numbers of nutritionally poor eggs in planktotrophic developers (Prowse et al., 2009; Moran et al., 2013). As lecithotrophic larvae do not require exogenous food sources, time spent in vulnerable larval stages prior to development to the juvenile stage is reduced compared to planktotrophic larvae (Wicks and Roberts, 2012). Consequently, with fewer egg numbers, lecithotrophic larvae may have greater success in terms of juveniles produced per parent (Prowse et al., 2009). Lecithotrophy also allows development during low productive seasons, producing competent feeding juveniles at the onset of phytoplankton blooms (Lee et al., 2006; Pearse et al., 1991). The cost of initial investment from the parent is 
high, and eggs may only be supplied with the amount of energy required to develop to an independently feeding state under the natural historic range of environmental conditions experienced by the population.

The main constituents providing energy and structural components for the larvae are lipids, proteins and carbohydrates. Lipids provide the densest form of energy, having more energy per gram compared to either carbohydrates or protein (Lee et al., 2006; Parrish, 2013). Since relative concentrations of lipids, proteins and carbohydrates vary with species and each component has different energetic densities $\left(\mathrm{J} \mathrm{g}^{-1}\right)$, there may be significant variation in the energy available in eggs of similar size (DeFreese and Clark, 1983; McAlister and Moran, 2012). Compositionally, lecithotrophic eggs generally have higher lipid:protein ratios than those from planktotrophs (Villinski et al., 2002; Falkner et al., 2006; Byrne et al., 2008b; Falkner et al., 2015). In echinoderms with contrasting modes of development, lecithotroph lipid density is often greater and energetic lipids account for a greater proportion of the total lipid content compared to planktotrophic species (Falkner et al., 2006; Falkner et al., 2015). Lipid content can be partially correlated with larval growth, where it may be a major energy reserve in some species (Holland and Spencer, 1973).

Lipids are used both energetically and structurally with major energetic lipid classes including triacylglycerol (TAG), diacylglycerol ethers (DAGE), phospholipid (PL) and wax esters (WE) (Lee et al., 2006). Of particular note is TAG, an energetic lipid common in animal tissues that is often involved in larval development (Allen, 1976; Fraser, 1989; Lee et al., 2006; Prowse et al., 2008). TAG is often favoured for short term energy provision, due to its ability to be quickly hydrolysed (Lee et al., 2006).

Wax esters are another primary energetic lipid in animal tissues, and are commonly a dominant class in species at high latitudes (Lee et al., 2006). WE often serve as long term energy providers that can be stored for energy provision during metamorphosis and postmetamorphic development, as they may not be as quickly hydrolysed as TAG (Lee et al., 2006; Prowse et al., 2009; Falkner et al., 2015). They also play roles in buoyancy control, being more buoyant than TAG due to their capacity for thermal expansion and their compressibility properties (Lee et al., 2006; Pond and Tarling, 2011; Falkner et al., 2015).

DAGE is a major energetic lipid in some species, particularly in lecithotrophic echinoderms (Lee et al., 2006; Prowse et al., 2009). Similar to WE, DAGE are long term energy providers that are used in early and post juvenile development and may have a role in 
buoyancy control (Falkner et al., 2015). Increases in free diacylglycerol (DAG) may also be observed during development (Tocher et al., 1985). DAG is a by-product of cellular signalling pathways and possibly of the hydrolysis of TAG (Berridge, 1984; Canavoso and Wells, 2000).

PL is a structural lipid, and will often accumulate during development due to cellular growth (Pernet et al., 2006; Meyer et al., 2007). As it is a key component of membranes, per cell abundances of PL may give an indication of larval condition and nutritional state (Lee et al., 2006; Meyer et al., 2007). However, PL may also be used energetically in larval development, dependent on species. For example, in stone and king crabs, significant depletion of PL occurs during development, indicating its use as an energetic source (Kattner et al., 2003). In euphausiids, PL is the primary energetic lipid in eggs (Lee et al., 2006). Cholesterols (ST) are another common structural lipid class. As ST content is typically proportional to larval size, it can be used as a proxy in standardising lipid use to larval size during development (Fraser, 1989).

Stress during development could place pressure on energetic reserves due, for example, to increases in metabolic rates under elevated temperatures (Pörtner, 2002b). Many species' specialisations or adaptations are related to temperature thresholds (Pörtner, 2002a), but warming temperature is not the only climate change related issue. As $p \mathrm{CO}_{2}$ increases in the atmosphere, and subsequently in seawater, hydrolysis of $\mathrm{CO}_{2}$ increases concentrations of hydrogen ions $\left(\mathrm{H}^{+}\right)$, subsequently reducing $\mathrm{pH}$, commonly referred to as 'ocean acidification' (OA). Due to the high solubility of $\mathrm{CO}_{2}$ in cold water, $\mathrm{OA}$ is expected to be first observed at high latitudes (IPCC, 2013). OA may exacerbate response to thermal stress, narrowing windows of thermal tolerance (Pörtner, 2008; Pörtner and Farrell, 2008). Additionally, carbonate ions become limited as they are used in buffering excess hydrogen ions. Some calcifying organisms rely on carbonate ions in seawater in order to calcify, and reduced availability may increase the energetic demands of shell and skeleton production. Additionally, even if an organism is not dependent on carbonate availability to calcify (see Roleda et al., 2012), established calcium carbonate structures are at risk of dissolution at low concentrations (saturation states, $\Omega$ ).

Increased $p \mathrm{CO}_{2}$ can have further impacts by affecting metabolism through altered acidbase regulation (e.g. Pecorino et al., 2014). As external $p \mathrm{CO}_{2}$ increases, cellular $p \mathrm{CO}_{2}$ increases due to diffusion across cell walls. This results in a build-up of internal $\mathrm{CO}_{2}$ as well 
as extracellular acidosis which can be mitigated by active ion transport, metabolic production, consumption of protons and passive buffering. Potentially, all of these are at the expense of calcified structures (Michaelidis et al., 2005; Comeau et al., 2012b; Wicks and Roberts, 2012). An organism that cannot compensate for acidosis may experience metabolic suppression, respiratory stress, reduced metabolic scope, loss of consciousness and even death (Michaelidis et al., 2005; Wicks and Roberts, 2012). Some authors (Pörtner, 2002a; Pörtner, 2010) have suggested species may not be as well adapted to changing $\mathrm{pH}$ as to changing temperature, as there may be less natural variability in the former in some of these species' habitats. This may not limit adaptions in Antarctic species as phytoplankton blooms in the Ross Sea drive considerable variability in $\mathrm{pH}$ on seasonal scales, although daily variation in coastal zones may be smaller (Hofmann et al., 2011; Matson et al., 2014; McNeil et al., 2010).

Bivalves may have a reduced capacity for active ion and acid-base regulation due to their sessile life stages (Pörtner, 2010; Parker et al., 2013). In mussels, decreased oxygen consumption was observed with hypercapnia, indicating reduced metabolism (Michaelidis et al., 2005). Larvae may be more vulnerable, as they may lack mechanisms for acid-base regulation that may be present in adults (Parker et al., 2013; Pecorino et al., 2014). Importantly, increases in external stressors may initiate stress responses that alter metabolic rates or result in the diversion of energetic resources to maintain cellular function, potentially reducing reserves (Stumpp et al., 2011b; Waldbusser et al., 2013). In the one study to date directly quantifying the impacts of elevated $p \mathrm{CO}_{2}$ on the use of lipids in larval development, no change was observed in echinoderm larvae, however there were indications of reduced growth with equivalent lipid use (Matson et al., 2012).

The developmental rate of the lecithotrophic larvae of the Antarctic clam, Laternula elliptica is altered in response to temperature and $\mathrm{pH}$ stressors. For example, under elevated temperatures, larvae developed faster, while under reduced $\mathrm{pH}$, development slowed (Chapter 2 and Bylenga et al., 2015). However, little is known about the energetics of their development even under normal conditions. During normal development at high latitudes metabolic rates are generally lower in cold climates, which may reduce energy requirements (Pearse et al., 1986). Large energetic reserves allow for increased development times or extended periods of dormancy such as observed in L. elliptica (Peck et al., 2007b). However, developmental delays observed under climate change conditions may be a symptom of 
increased metabolic stress and/or increased demand on energetic resources, which could have significant flow-on effects to later life stages if these resources are depleted.

Metamorphosis into juveniles is energetically demanding. Larvae must be non-feeding during the portion of metamorphosis when their feeding structures are being formed (Holland and Spencer, 1973; Lu et al., 1999). Lipids account for a large portion of the energetic expenditure during metamorphosis (Holland and Spencer, 1973; Lu et al., 1999). In planktotrophic species, lipids accumulated during development are required for successful metamorphosis. However, lecithotrophic larvae have finite energy reserves that sustain development and metamorphosis. Increased usage during embryogenesis could mean reductions in the available energetic pool, preventing successful metamorphosis (although some lecithotrophic larvae have the capacity to take up dissolved nutrients; Jaeckle and Manahan, 1989). L. elliptica do not have the capacity to move to more favourable habitats under environmental stress. Furthermore, their long generation times will limit their ability to respond to a rapidly changing climate through genetic adaptation. Additionally, most bivalves have a low capacity to regulate acid-base balances, particularly in larval stages (Lindinger et al., 1984; Melzner et al., 2011; Waldbusser et al., 2013; Walbusser et al., 2015). Species persistence will be determined both by the dispersal capacity of the larvae as well as their ability to withstand environmental stress.

Reproduction in L. elliptica has been observed in the Ross Sea from late February to midMay (Pearse et al., 1986; Bosch and Pearse, 1988) and in the laboratory as late as June and July (Bylenga, pers. obs.). In the months following spawning, larvae develop into aragonite shelled juveniles that settle in the sediments (Pearse et al., 1985; Pearse et al., 1986). Following their summer maxima during phytoplankton blooms, $\mathrm{pH}$ and aragonite saturation state $\left(\Omega_{\text {Ar }}\right)$ both begin to fall, reaching 7.94 and 1.04 respectively, in May 2013 (cf. 8.17 and 1.79 in January) at Cape Evans. for example (Kapsenberg et al., 2015). This raises concerns about the impacts of OA on these larvae as $\Omega_{\mathrm{Ar}}$ is already approaching undersaturation during spawning and settlement times in the Ross Sea. Under OA conditions, empty shells of adult L. elliptica rapidly dissolve (McClintock et al., 2009). However, the impacts of OA on calcification in live adults and larvae are unstudied. Under future OA scenarios, the metabolic costs of larval development may increase in order to maintain calcification or cause a prioritisation of energetic resources to maintain other cellular function, subsequently reducing calcification. Alternatively, acidosis and the lack of compensatory mechanisms may result in metabolic suppression. 
It is unknown how metabolic rates in L. elliptica larvae would be impacted by elevated temperatures or reduced $\mathrm{pH}$. Larvae may increase the use of lipids to support development under stress, which may impact the finite energetic reserves in lecithotrophic larvae. Additionally, the changes in L. elliptica developmental timing observed in Chapter 2 may suggest an increase in metabolic rate, but this would be limited by energy reserves in larvae. Increased demand on lipid reserves in support of faster development or in maintaining cellular function could significantly impact lipid reserves needed for subsequent metamorphosis.

In this study, I investigated larval energetics and metabolism during development from fertilisation to the shelled D-larval stage under ambient conditions. I analysed the differences between the total lipid pools, as well as the different lipid class components, at $48 \mathrm{~h}$ postfertilisation and in D-stage larvae to determine lipid use during development. Additionally, I raised the larvae under reduced $\mathrm{pH}$ and elevated temperature conditions to see how these stressors influenced the use of total lipids and classes during development. Respiratory responses to these stressors were also assessed by measuring the changes in oxygen consumption in D-stage larvae.

\subsection{Methods}

\subsubsection{Collection}

Adult L. elliptica (6.5-9.7 cm shell length) were collected from Granite Harbour, Ross Sea, Antarctica $\left(77^{\circ} 00.963^{\prime} S, 162^{\circ} 52.607\right)$ in November 2014 . They were transported to Wellington, New Zealand and held in tanks with free flowing $\left(250 \mathrm{ml} \mathrm{min}{ }^{-1}\right)$, filtered $(0.1$ $\mu \mathrm{m})$ seawater chilled to $-1.7^{\circ} \mathrm{C}$, at $\mathrm{pH} 8.00$ in a temperature controlled room, until March 2015. They were fed a liquid algal mix (Shellfish Diet 1800, Reed Mariculture, USA), 3 days per week during this period.

\subsubsection{Experimental treatments}

Larvae were fertilised and raised to the D-larvae stage under a combination of four temperature and two $\mathrm{pH}$ treatments ( 8 treatments). Ambient conditions in the Ross Sea were represented by the control conditions of $-1.7^{\circ} \mathrm{C}$ and $\mathrm{pH} 8.00$. Two elevated temperatures were chosen to represent projections for sea surface change through to the end of the century $(-0.5$ and $0.5^{\circ} \mathrm{C}$, IPCC, 2013), and a further elevated temperature $\left(1.5^{\circ} \mathrm{C}\right)$, based on "business as 
usual" end-of-century projections $\left(+3^{\circ} \mathrm{C}\right.$ RCP8.5, IPCC, 2013) was chosen to examine temperature tolerance limits in larvae. Projections for end-of-century $\mathrm{pH}$ conditions were represented by the reduced $\mathrm{pH}$ treatment, 7.65 (Orr et al., 2005; IPCC, 2013).

\subsubsection{Temperature and $\mathrm{pH}$ manipulation and measurement}

Wellington Harbour seawater was chilled to $-1.7^{\circ} \mathrm{C}$ with further temperature and $\mathrm{pH}$ manipulations occurring in 8 separate header tanks that supplied 64 insulated $4 \mathrm{~L}$ treatment tanks through insulated lines ( $\mathrm{n}=8$ replicates of each treatment). Temperature was elevated to experimental conditions using $500 \mathrm{~W}$ submersible heaters. $\mathrm{pH}$ was manipulated using diffusion of food grade $\mathrm{CO}_{2}$ through $0.5 \mathrm{~mm}$ (4 mm diameter) silicone tubing. Temperature and $\mathrm{pH}$ were controlled remotely by a LabView ${ }^{\circledR}$ server communicating with Jumo dTrans $\mathrm{pH} 02$ controllers via a MOBUS serial interface. Temperature and $\mathrm{pH}$ were continuously logged (5 min intervals) using PT100 temperature probes and Sensorex S150C pH probes, and additional checks of $\mathrm{pH}$ were made spectrophotometrically. Flow was maintained at 100 $\mathrm{ml} \min ^{-1}$. On days 1, 21 and 31, water samples were taken from each treatment and preserved with $\mathrm{HgCl}_{2}$ for analysis of dissolved organic carbon (DIC) and alkalinity $\left(\mathrm{A}_{\mathrm{T}}\right)$. Aragonite $\left(\Omega_{\mathrm{Ar}}\right)$ and calcite $\left(\Omega_{\mathrm{Ca}}\right)$ saturation states and partial pressure of $\mathrm{CO}_{2}\left(p \mathrm{CO}_{2}\right)$ at the experimental temperatures and salinities were calculated from the measured values of $\mathrm{pH}$ and $\mathrm{A}_{\mathrm{T}}$ using refitted Mehrbach constants (Mehrbach et al., 1973; Dickson and Millero, 1987). Analytical methods followed those detailed in Cummings et al. (2011). Seawater conditions for each treatment are summarised in Table 4.1.

\subsubsection{Gamete collection and fertilisation}

Prior to gamete collection, in order to avoid self-fertilisation, 74 individuals were designated egg donors and 32 were set aside for sperm collection. The ovary was dissected and eggs were collected using a Pasteur pipette. Eggs were pooled and the volume was topped up to $1.4 \mathrm{~L}$ with $-1.7^{\circ} \mathrm{C}$ seawater at the control $\mathrm{pH}$. Twenty $\mathrm{ml}$ of the egg solution was added to each of the $4 \mathrm{~L}$ tanks containing seawater at experimental conditions, equating to approximately 50,000 eggs per tank. Water flow was maintained through the tanks $(100 \mathrm{ml}$ $\min ^{-1}$ ) to ensure eggs were acclimated to experimental conditions prior to fertilisation. The depth of the tank, along with the demersal nature of the eggs, ensured that water flow could be maintained with no loss of gametes. 
Twenty-four hours later, sperm was collected by cutting into the testis and collecting the sperm using a Pasteur pipette. The sperm was pooled and the volume made up to $1 \mathrm{~L}$ as above. Ten $\mathrm{ml}$ of the sperm solution was added to each tank. The seawater was gently mixed to ensure even distribution of the sperm across the eggs. A $1 \mathrm{ml}$ subsample was removed from the egg and sperm solutions to determine egg and sperm counts. Additionally, gametes were examined microscopically for condition and size (eggs) as well as motility (sperm). Fertilisation success was checked at $48 \mathrm{~h}$. Larvae were held in the tanks for $45 \mathrm{~d}$ in freeflowing seawater $\left(100 \mathrm{ml} \mathrm{min}^{-1}\right)$ at experimental conditions.

Forty-eight hours post-fertilisation (PF), approximately 500 developing larvae were sampled from each replicate and placed in Eppendorf tubes. The seawater was carefully removed and the samples frozen at $-80^{\circ} \mathrm{C}$ for later analysis of the lipids available for the developing larvae. Development in the remaining larvae was allowed to continue to the Dlarvae stage. Due to temperature and $\mathrm{pH}$ impacts on development timing, each treatment was closely monitored around the expected time of the first occurrence of D-larvae (approximately 15 d; see Chapter 2 and Bylenga et al., 2015). Each day, subsamples were removed from each replicate to assess development progression. The time when $50 \%$ of the normally developing larvae were at the D-larvae stage was noted (Table 4.2). Five days following this timepoint, samples of approximately 500 D-larvae were removed from each replicate and placed in Eppendorf tubes. The seawater was carefully removed and the samples frozen at $-80^{\circ} \mathrm{C}$ for lipid analysis. Multiple samples were collected as above from control condition replicates to be used for the identification of the lipid classes present in $L$. elliptica larvae. Ten days following the point at which $50 \%$ D-larvae were found in each treatment, approximately 1000 larvae were removed from 4 replicates per treatment for respiration measurements (described below).

\subsubsection{Lipid analysis}

Four replicates of each treatment from both $48 \mathrm{~h}$ and D-larval stages were processed to determine the composition of energetic and structural lipids in the larvae. Lipids were extracted from the frozen larval tissue using a chloroform/methanol method adapted by Sewell (2005) from Holland and Gabbott (1971) with changes as detailed below. Methanol and chloroform from the LiChrosolv ${ }^{\circledR}$ Hypergrade for LC-MS range (Merck Millipore) were used in extractions. Following preliminary TLC lipid class analysis (see below) that indicated the presence of WE, cetyl alcohol was used as a replacement internal standard (15 $\mu 1$ of $3 \mathrm{mg}$ 
$\mathrm{ml}^{-1}$ chloroform) to determine recovery in lipid quantification samples, as ketone may be hidden by large WE peaks, making quantification difficult (Parrish, 1987). Lipid extracts in chloroform were stored at $-20^{\circ} \mathrm{C}$ for a maximum of $48 \mathrm{~h}$ before analysis.

Thin layer chromatography (TLC) was used to aid the identification of neutral lipid classes, based on their relative mobility on TLC plates against lipid standards. Using glass capillaries, lipid extracts were placed in $3 \mu \mathrm{l}$ aliquots in $2 \mathrm{~mm}$ narrow bands onto aluminiumbacked TLC plates (Reveleris, Grace) alongside prepared lipid standards: aliphatic hydrocarbon (AH), methyl ester (ME), WE, DAGE, a TAG/ME/WE standard, a $\mathrm{ME} / \mathrm{AH} / \mathrm{TAG} /$ free fatty acid (FFA)/ST and a TAG/FFA standard. Plates were developed in preconditioned TLC tanks containing a hexane/diethyl ether/acetic acid (90:10:1 v/v/v) neutral solvent system (Bergelson, 1980). Plates were sprayed in a primuline solution (5 mg in $100 \mathrm{ml}$ acetone/water, 80:20 v/v), which is a biological stain, and viewed under ultraviolet light. Lipid bands were identified by their relative mobility on the TLC plate compared to the lipid standards.

Lipids were quantified using an Iatroscan Mark $\mathrm{V}^{\text {new }}$ Thin Layer Chromatography/Flame Ionization Detection system (TLC/FID), and silica gel S-III Chromarods as described in Sewell (2005), with modifications as detailed below. Air flow was $2000 \mathrm{ml} \mathrm{min}^{-1}$ and hydrogen was set to $160 \mathrm{ml} \mathrm{min}^{-1}$. Instrument grade $\mathrm{N}_{2}$ gas was used to dry samples before they were resuspended in $20 \mu \mathrm{l}$ chloroform, using a positive displacement pipette (Gilson, Microman, USA). Following cleaning of the chromarods, $2 \mu 1$ of sample was applied to each chromarod. Lipids were separated along the chromarods in a two stage development system (Parrish, 1987, 1999) resulting in two chromatograms per chromarod. Chromarods were first developed in a hexane/diethyl ether/formic acid solution (98.95:1:0.05 v/v/v) for $22 \mathrm{~min}$, followed by $5 \mathrm{~min}$ in a humidity chamber before further development for $16 \mathrm{~min}$. Chromarods were dried in the Iatroscan for 5 min before a $30 \mathrm{~s}$ partial scan was used to burn from the solvent front and manually stopped following the WE peak. Following a 5 min incubation in the humidity chamber, the chromarods were developed for $27 \mathrm{~min}$ in a more polar hexane/diethyl ether/formic acid solution (79:20:1 v/v). Chromarods were dried in the Iatroscan for $5 \mathrm{~min}$ and scanned on full scan from the solvent front to the origin. A SESChromstar PC-board was used to collect data and SES-Chromstar version 4.10 was used to record and quantify chromatograms (SES Analysesysteme). Lipid classes were quantified by quadratic regression from multilevel lipid calibration curves using lipid standards as in Sewell (2005). Standards represented energetic neutral lipids [i.e., aliphatic hydrocarbon 
$(\mathrm{AH})$, wax ester (WE), triacylglycerol (TAG), free fatty acids (FFA) and diacylglycerol (DAG)]; the structural neutral lipid cholesterol (ST) and also, the structural polar lipids [i.e., acetone mobile polar lipids (AMPL) and phospholipids (PL)]. Total lipid content was determined from the sum of the lipid classes in each sample. Total energetic and structural lipids, as well as ratios of energetic:structural lipids, TAG:ST and TAG:PL were also calculated.

\subsubsection{Respiration measurements}

Approximately 1,000 larvae from four replicates of each treatment were placed in separate $25 \mathrm{ml}$ glass vials filled with seawater at experimental temperature and $\mathrm{pH}$. Vials were precalibrated using a two point calibration system with water vapour saturated air and $0 \%$ oxygen saturated seawater (deoxygenated using saturated sodium sulphite). The vials were sealed and checked for trapped air bubbles. Oxygen saturation measurements were made with a non-invasive fibre optic oxygen microsensor system (PreSens, Germany) using microoptodes placed in each vial. The sealed vials were placed in a water bath at the appropriate experimental temperature and measurements of oxygen saturation were made every hour for 6-8 h. Oxygen saturation was not allowed to fall below 50\%. Preliminary respiration trials had been performed on concentrations of larvae ranging from 100-1000 ind. vial ${ }^{-1}$ for a range of 1-8 $\mathrm{h}$, in order to determine appropriate larval numbers and measurement times necessary to detect oxygen consumption. Two vials containing only seawater at experimental conditions were also analysed for each treatment. Oxygen consumption was measured as the difference between initial and final measurements and was expressed as pmol $\mathrm{O}_{2} \mathrm{~h}^{-1}$ ind. $^{-1}$.

The relationship between temperature and changes in respiration rates was examined by determining the $\mathrm{Q}_{10}$ value for the change in respiration rate between each experimental increase in temperature at each $\mathrm{pH}$ (see Davenport, 1992). $\mathrm{Q}_{10}$ is a tool to describe temperature compensation by comparing rate changes in metabolic responses in response to temperature elevations, extrapolated to $10^{\circ} \mathrm{C}$ differences. A $\mathrm{Q}_{10}$ value $<1$ indicates higher metabolic rates at lower temperatures, $\mathrm{Q}_{10} \approx 1$ indicates perfect compensation, $\mathrm{Q}_{10}>1$ and < 2 indicates partial elevation of rates with some compensation. $\mathrm{A} \mathrm{Q}_{10} \approx 2$ indicates no compensation, and the rate change is explained by the temperature change. $\mathrm{Q}_{10}>2$ indicates responses are greater than can be explained by the temperature elevation, indicating a stress response. 


\subsubsection{Statistical analysis}

Statistical tests were performed to assess the changes in lipid reserve compositions during development, as well as the impacts of reduced $\mathrm{pH}$ and elevated temperatures on lipid use and oxygen consumption. All statistical analysis was performed using SPSS, version 22. Normality of the data was verified using Shapiro-Wilk's test and equality of variances was confirmed using Levene's test. Lipid content at fertilisation, lipid depletion by the D-larval stage, respiration and the relation of the responses to $\mathrm{pH}$ and temperature were examined by fitting the data to a general linear model. When comparing the impacts of stressors on lipid content, lipid depletion and respiration, $\mathrm{pH}$ and temperature were fixed factors, and a temperature $\times \mathrm{pH}$ interaction term was used.

Depletion of total lipid content, total energetic and structural lipid content and individual lipid class content in development to the D-larval was analysed using development stage as a fixed factor. When analysing the impacts of $\mathrm{pH}$ and temperature at $2 \mathrm{~d} \mathrm{PF}$, total lipid content, total energetic and structural lipid contents, individual class content as well as ratios of energetic:structural lipid, TAG:ST and TAG:PL were used as dependent variables. In Dlarvae, percent depletion in total lipid content, total energetic and structural lipid content and individual class content were used as dependent variables. In respiration trials, respiration rate was used as a dependent variable.

Where the general linear model indicated overall individual statistical significance $(\mathrm{p}<$ 0.050) of either temperature or $\mathrm{pH}$, a post-hoc Bonferroni multiple comparison test was performed to determine effects of temperature averaged over $\mathrm{pH}$ or $\mathrm{pH}$ averaged over temperature respectively. Where interactive effects approached significance $(p<0.100)$, a one-way ANOVA was performed with treatment as a single factor, in order to determine differences between each treatment.

\subsection{Results}

Temperature, $\mathrm{pH}$ and carbonate chemistry data for the duration of the experiment are detailed in Table 4.1. $\Omega_{\mathrm{Ar}}$ and $\Omega_{\mathrm{Ca}}$ were undersaturated at $\mathrm{pH} 7.65$ at all temperatures, but remained at or above saturation at the control $\mathrm{pH}$ (Table 4.1). 
Table 4.1. Seawater conditions for each experimental treatment. Average temperature $\left({ }^{\circ} \mathrm{C} ; \mathrm{n}=\right.$ $22,765) ; \mathrm{pH}$ (measured on the total hydrogen scale; $\mathrm{n}=22,765)$; total alkalinity $\left(\mathrm{A}_{\mathrm{T}} ; \mathrm{n}=3\right)$; dissolved inorganic carbon (DIC, $\mathrm{n}=3$ ), aragonite and calcite saturation states $\left(\Omega_{\mathrm{Ar}}\right.$ and $\Omega_{\mathrm{Ca}}$, respectively) and partial pressure of $\mathrm{CO}_{2}\left(p \mathrm{CO}_{2}\right)$ are calculated from $\mathrm{A}_{\mathrm{T}}$ and $\mathrm{pH}$. All values are mean $\pm \mathrm{SE}$. Salinity was 34.7 psu.

\begin{tabular}{|ccccccc|}
\hline $\begin{array}{c}\text { Temp } \\
\left({ }^{\circ} \mathrm{C}\right)\end{array}$ & $\mathrm{pH}$ & $\begin{array}{c}\mathrm{A}_{\mathrm{T}} \\
\left(\mu \mathrm{mol} \mathrm{kg}{ }^{-1}\right)\end{array}$ & $\begin{array}{c}\mathrm{DIC} \\
\left(\mu \mathrm{mol} \mathrm{kg}{ }^{-1}\right)\end{array}$ & $\begin{array}{c}p \mathrm{CO}_{2} \\
(\mathrm{ppm})\end{array}$ & $\Omega_{\mathrm{Ar}}$ & $\Omega_{\mathrm{Ca}}$ \\
\hline$-1.7 \pm 0.01$ & $8.00 \pm 0.001$ & $2290.0 \pm 7.3$ & $2211.7 \pm 6.3$ & $482.3 \pm 16.7$ & $1.08 \pm 0.04$ & $1.72 \pm 0.06$ \\
& $7.64 \pm 0.001$ & $2290.0 \pm 6.4$ & $2306.6 \pm 7.0$ & $1074.8 \pm 6.4$ & $0.53 \pm 0.00$ & $0.85 \pm 0.00$ \\
$-0.5 \pm 0.01$ & $7.99 \pm 0.001$ & $2290.1 \pm 6.8$ & $2199.2 \pm 4.9$ & $460.3 \pm 4.9$ & $1.18 \pm 0.02$ & $1.87 \pm 0.03$ \\
& $7.65 \pm 0.001$ & $2290.4 \pm 6.7$ & $2293.4 \pm 5.5$ & $999.0 \pm 8.6$ & $0.59 \pm 0.01$ & $0.94 \pm 0.01$ \\
$0.5 \pm 0.01$ & $7.99 \pm 0.001$ & $2290.7 \pm 6.6$ & $2198.0 \pm 9.6$ & $476.3 \pm 24.0$ & $1.20 \pm 0.05$ & $1.91 \pm 0.08$ \\
& $7.66 \pm 0.001$ & $2290.2 \pm 6.9$ & $2288.6 \pm 6.2$ & $1002.8 \pm 5.5$ & $0.62 \pm 0.01$ & $0.98 \pm 0.01$ \\
$1.5 \pm 0.01$ & $7.99 \pm 0.001$ & $2290.7 \pm 6.8$ & $2193.1 \pm 8.5$ & $478.6 \pm 18.1$ & $1.24 \pm 0.04$ & $1.97 \pm 0.06$ \\
& $7.65 \pm 0.001$ & $2288.8 \pm 6.2$ & $2293.5 \pm 7.4$ & $1104.0 \pm 34.0$ & $0.59 \pm 0.02$ & $0.95 \pm 0.03$ \\
\hline
\end{tabular}

Fertilisation success ranged from 73-81\%, and was similar across all treatments. D-larvae first appeared at $17 \mathrm{~d} \mathrm{PF}$ at treatment temperatures of 0.5 and $1.5^{\circ} \mathrm{C}$ and at $21 \mathrm{~d}$ at the control temperature (Table 4.2). Across all treatments, 50\% abundance of D-larvae was reached 5-6 d following their first observance (Table 4.2). A developmental delay due to reduced $\mathrm{pH}$ was only observed at $-1.7^{\circ} \mathrm{C}$ (Table 4.2$)$.

Table 4.2. Days post-fertilisation of first observations of D-larvae by treatment, the point of $50 \%$ abundance and the day of sampling for lipid and respiration analysis (5 and $10 \mathrm{~d}$ after 50\% abundance, respectively).

\begin{tabular}{|cccccc|}
\hline & & \multicolumn{4}{c|}{ Days Post Fertilisation } \\
\cline { 3 - 6 } Temperature $\left({ }^{\circ} \mathrm{C}\right)$ & $\mathrm{pH}$ & $\begin{array}{c}\text { First } \\
\text { Observance }\end{array}$ & $\begin{array}{c}50 \% \\
\text { Abundance }\end{array}$ & $\begin{array}{c}\text { Lipid } \\
\text { Analysis }\end{array}$ & $\begin{array}{c}\text { Respiration } \\
\text { Analysis }\end{array}$ \\
\hline-1.7 & 8.00 & 21 & 26 & 31 & 36 \\
& 7.65 & 22 & 28 & 33 & 38 \\
-0.5 & 8.00 & 19 & 24 & 29 & 34 \\
& 7.65 & 19 & 24 & 29 & 34 \\
0.5 & 8.00 & 17 & 22 & 27 & 32 \\
& 7.65 & 17 & 22 & 27 & 32 \\
1.5 & 8.00 & 17 & 23 & 28 & 33 \\
& 7.65 & 17 & 23 & 28 & 33 \\
\hline
\end{tabular}




\subsubsection{Lipid Analysis}

\subsubsection{Lipid Reserve Composition}

Newly fertilised eggs contained approximately 200 ng total lipids per individual egg, although large variations in lipid content were observed (Appendix 1). Eight lipid classes were identified in the eggs and developing larvae (Fig. 4.1, Tables 4.3 and Appendix 1). The energetic lipids AH, WE, TAG and DAG accounted for $70 \%$ of the total lipid content. The remainder were the structural lipids ST, acetone mobile polar lipids (AMPL) and PL.

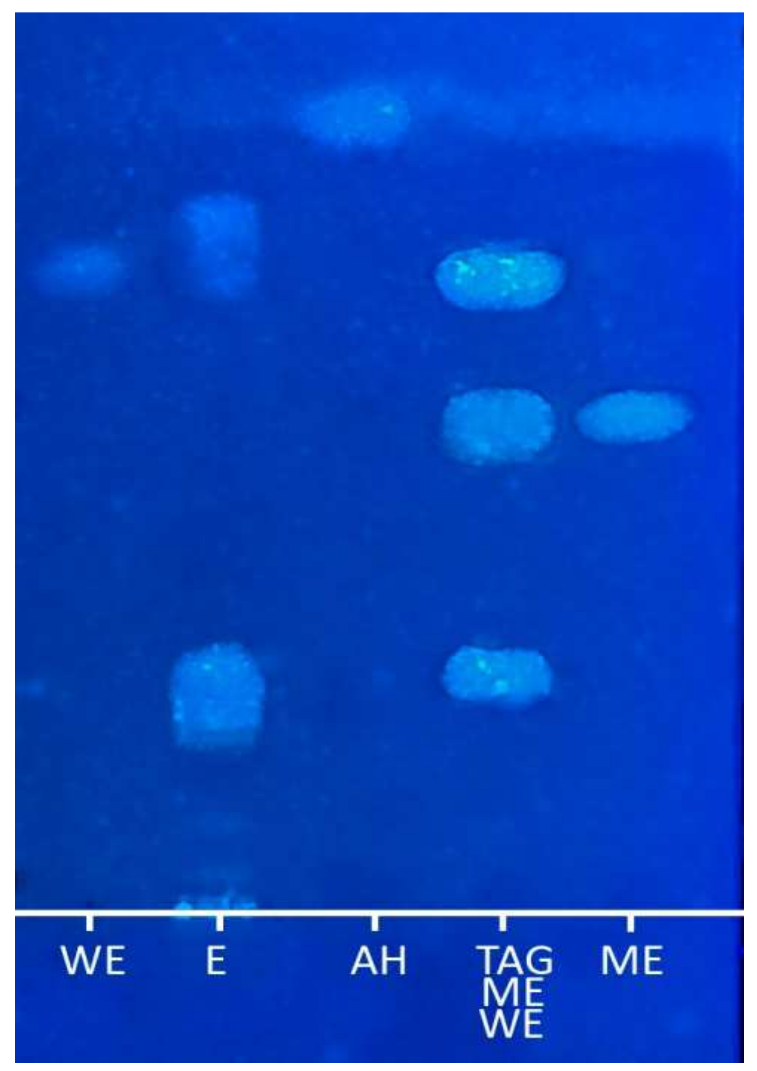

Fig. 4.1. Example of the TLC plates used for identification of neutral lipid classes in sample extracts (E) against standards of WE, AH, ME and a TAG, ME and WE standard.

\subsubsection{Embryos 2 days Post-Fertilisation}

In embryos $2 \mathrm{~d}$ PF, TAG was the dominant lipid class in embryos with $64 \%$ of the total content, followed by PL (24\%, Table 4.3). DAG was found in only trace amounts $(<0.1 \%)$ and was not present in all samples. In embryos $2 \mathrm{~d} \mathrm{PF}$, no significant effects of temperature and/or $\mathrm{pH}$ were observed on total lipids, concentrations of any of the lipid classes, or percent of total lipids ( $p>0.050$, Appendix 2). TLC identified the presence of free fatty acids (FFA), 
however, separation of TAG and FFA peaks using Iatroscan TLC/FID can be difficult if either is present in large amounts (Parrish, 1987), as occurred here with TAG. As FFA peaks were obscured by TAG, TAG should be considered a measure of TAG and FFA content. However, it will be referred to as TAG.

Table 4.3. Summary of lipid content and ratios in embryos of Laternula elliptica from the control treatments $\left(-1.7^{\circ} \mathrm{C}\right.$ and $\left.\mathrm{pH} 8.00\right), 2 \mathrm{~d} \mathrm{PF}(\mathrm{n}=8, \sim 500$ larvae ea.) and in D-larvae from control treatments, $31 \mathrm{~d}$ PF ( $\mathrm{n}=4$, 500 larvae ea.), determined by Iatroscan TLC/FID. Data are mean \pm SE. Total lipids: sum of all lipid classes, energetic lipids $=$ AH + WE + TAG + DAG, structural lipids $=$ ST +AMPL + PL. nd = not detectable. For a detailed summary of all treatments see Appendix 1.

\begin{tabular}{|lrrrr|}
\hline & Embryo & & D-Larvae & \\
& $\begin{array}{l}\text { Amount per } \\
\text { embryo (ng) }\end{array}$ & $\begin{array}{l}\text { \% of Total } \\
\text { lipid }\end{array}$ & $\begin{array}{l}\text { Amount per } \\
\text { larvae (ng) }\end{array}$ & $\begin{array}{l}\text { \% of Total } \\
\text { lipid }\end{array}$ \\
\hline Total Lipids & & & & \\
Energetic Lipids: & $197.47 \pm 14.60$ & & $151.26 \pm 2.40$ & \\
TAG & & & & \\
WE & $126.66 \pm 9.64$ & $64.13 \pm 0.91$ & $95.20 \pm 1.00$ & $62.95 \pm 0.42$ \\
AH & $6.85 \pm 0.43$ & $3.48 \pm 0.04$ & $6.39 \pm 0.28$ & $4.23 \pm 0.20$ \\
DAG & $2.46 \pm 0.24$ & $1.24 \pm 0.06$ & $2.33 \pm 0.25$ & $1.53 \pm 0.15$ \\
Total & nd & nd & $4.41 \pm 0.88$ & $2.91 \pm 0.58$ \\
Structural Lipids: & $136.56 \pm 10.02$ & $69.18 \pm 1.03$ & $108.32 \pm 1.83$ & $71.62 \pm 0.78$ \\
PL & $46.46 \pm 4.08$ & $23.52 \pm 1.13$ & $29.96 \pm 2.11$ & $19.79 \pm 1.3$ \\
AMPL & $10.04 \pm 0.85$ & $5.26 \pm 0.12$ & $9.10 \pm 1.01$ & $6.02 \pm 0.69$ \\
ST & $4.06 \pm 0.44$ & $2.04 \pm 0.07$ & $3.89 \pm 0.40$ & $2.56 \pm 0.23$ \\
Total & $60.92 \pm 5.12$ & $30.82 \pm 1.03$ & $42.94 \pm 1.50$ & $28.38 \pm 0.78$ \\
Ratios & & & & \\
Energetic:Structural & $2.25 \pm 0.11$ & & $2.53 \pm 0.10$ & \\
TAG:ST & $31.49 \pm 0.87$ & & $25.12 \pm 2.07$ & \\
TAG:PL & $2.75 \pm 0.17$ & & $3.22 \pm 0.25$ & \\
\hline
\end{tabular}

\subsubsection{D-larval stage}

Total lipid content in D-larvae ranged from $136.4-188.3 \mathrm{ng}$ larva $^{-1}$. TAG dominated the lipid classes, averaging $63 \%$ of the total lipid content, followed by PL at 20\% (Appendix 1). 


\subsection{Lipid Depletion}

In development to the D-larval stage, over $45 \mathrm{ng}$ of total lipid per larva was used, a depletion of nearly $25 \%$ of that available at $2 \mathrm{~d}$ PF (Table 4.3 and 4.4). Depletion of total lipid content between $2 \mathrm{~d}$ PF and 27-33 d PF ranged from $9.3 \pm 6.3 \%$ depletion in the low $\mathrm{pH} /$ control temperature treatment to $33.4 \pm 1.1 \%$ depletion in the low $\mathrm{pH} / 0.5^{\circ} \mathrm{C}$ treatment (Fig. 4.2a). Significant reductions occurred in energetic and structural lipids (9.4-45.9\% and 10.0-24.9\%, respectively; Fig. 4.2b and c), and also TAG and PL (12.1-35.8\% and 21.5$49.9 \%$, respectively), indicating these were the primary lipids used during development (Fig. 4.2d and e, Appendix 1). Increases were observed in DAG while non-significant depletion was observed in AH, ST, and AMPL. Overall losses in both energetic and structural lipid classes were largely due to significant depletion of TAG and PL, respectively (energetic: 6.5$31.3 \%$ and structural: $15.9-38 \%$, Fig. $4.2 \mathrm{~b}$ and c).

Table 4.4. Summary of one-way ANOVA for difference in lipid content and classes between embryos $2 \mathrm{~d}$ PF and D-larvae 27-31 d PF (as described in Table 4.3) with development stage as an independent factor for D-larval lipid content at the control $\mathrm{pH}$ and temperature. Significant results in bold.

\begin{tabular}{|lrr|}
\hline Lipid & \multicolumn{1}{c|}{$\mathrm{F}_{(3,23)}$} & \multicolumn{1}{c|}{$\mathrm{p}$} \\
\hline Total Lipids & 16.198 & $<\mathbf{0 . 0 0 1}$ \\
TAG & 16.098 & $<\mathbf{0 . 0 0 1}$ \\
WE & 1.568 & 0.219 \\
AH & 0.835 & 0.362 \\
DAG & 133.489 & $<\mathbf{0 . 0 0 1}$ \\
PL & 20.475 & $<\mathbf{0 . 0 0 1}$ \\
AMPL & 1.967 & 0.170 \\
ST & 0.466 & 0.500 \\
& & \\
Energetic & 11.348 & $\mathbf{0 . 0 0 2}$ \\
Structural & 19.729 & $<\mathbf{0 . 0 0 1}$ \\
& & \\
Energetic:Structural & 2.621 & 0.115 \\
TAG:ST & 18.896 & $<\mathbf{0 . 0 0 1}$ \\
TAG:PL & 4.363 & $\mathbf{0 . 0 4 5}$ \\
\hline
\end{tabular}


The amount of depletion in the different lipid classes during development to D-larvae was influenced by temperature (Fig. 4.2; Table 4.5), and this trend was driven largely by the high retention in the reduced $\mathrm{pH} / \mathrm{control}$ temperature treatment. Post-hoc tests showed a significantly higher percentage of the overall D-larval lipid pool was depleted in elevated temperature treatments $\left(-0.5^{\circ} \mathrm{C}: \mathrm{p}=0.034,0.5^{\circ} \mathrm{C}: \mathrm{p}=0.003\right.$ and $1.5^{\circ} \mathrm{C}: \mathrm{p}=0.014$, cf. with $-1.7^{\circ} \mathrm{C}$; Fig. 4.2a). Elevated temperatures also increased percent depletion of energetic and structural lipids during development (Fig. 4.2b and c). An independent effect of temperature on percent depletion of TAG and PL was observed, with post-hoc tests showing greater depletion of TAG in elevated temperature treatments compared to control conditions $\left(-0.5^{\circ} \mathrm{C}\right.$ : $\mathrm{p}=0.001,0.5^{\circ} \mathrm{C}: \mathrm{p}=0.002$ and $1.5^{\circ} \mathrm{C}: \mathrm{p}=0.010$, cf. with $-1.7^{\circ} \mathrm{C}$; Fig. 4.2d). In PL, greater depletion occurred at the highest temperature, and this was significantly different from the control and the $-0.5^{\circ} \mathrm{C}$ temperatures $(\mathrm{p}=0.016$ and 0.019 , respectively, Fig. $4.2 \mathrm{e})$.

Table 4.5. Summary table of 2 -way ANOVA for factors $\mathrm{pH}$ and temperature on percent depletion of lipid content and classes (as described in Table 4.3) and ratios in D-larval stage Laternula elliptica. Significant results in bold.

\begin{tabular}{|lcccccc|}
\hline & \multicolumn{2}{c}{$\mathrm{pH}$} & \multicolumn{2}{c}{ Temperature } & \multicolumn{2}{c|}{ Temp. $\times \mathrm{pH}$} \\
Lipid & $\mathrm{F}_{1,23}$ & $\mathrm{p}$ & $\mathrm{F}_{3,23}$ & $\mathrm{p}$ & $\mathrm{F}_{3,23}$ & $\mathrm{p}$ \\
\hline Total Lipids & 0.641 & 0.432 & 3.239 & $\mathbf{0 . 0 1 6}$ & 0.264 & 0.074 \\
AH & 1.529 & 0.229 & 1.432 & 0.259 & 0.373 & 0.773 \\
WE & 1.111 & 0.303 & 1.541 & 0.231 & 1.185 & 0.337 \\
TAG & 0.412 & 0.513 & 5.439 & $\mathbf{0 . 0 0 6}$ & 2.570 & 0.079 \\
ST & 0.001 & 0.989 & 1.010 & 0.406 & 0.169 & 0.916 \\
AMPL & 3.642 & 0.069 & 0.361 & 0.782 & 1.899 & 0.158 \\
PL & 2.219 & 0.150 & 3.407 & $\mathbf{0 . 0 3 5}$ & 0.761 & 0.527 \\
& & & & & & \\
Energetic & 0.339 & 0.566 & 4.171 & $\mathbf{0 . 0 1 7}$ & 2.343 & 0.100 \\
Structural & 0.948 & 0.340 & 3.770 & $\mathbf{0 . 0 2 5}$ & 1.816 & 0.172 \\
& & & & & & \\
Energetic:Structural & 0.601 & 0.446 & 4.560 & $\mathbf{0 . 0 1 2}$ & 1.835 & 0.169 \\
TAG:ST & 0.584 & 0.453 & 1.934 & 0.152 & 0.901 & 0.456 \\
TAG:PL & 0.183 & 0.189 & 4.189 & $\mathbf{0 . 0 1 0}$ & 0.948 & 0.434 \\
\hline
\end{tabular}



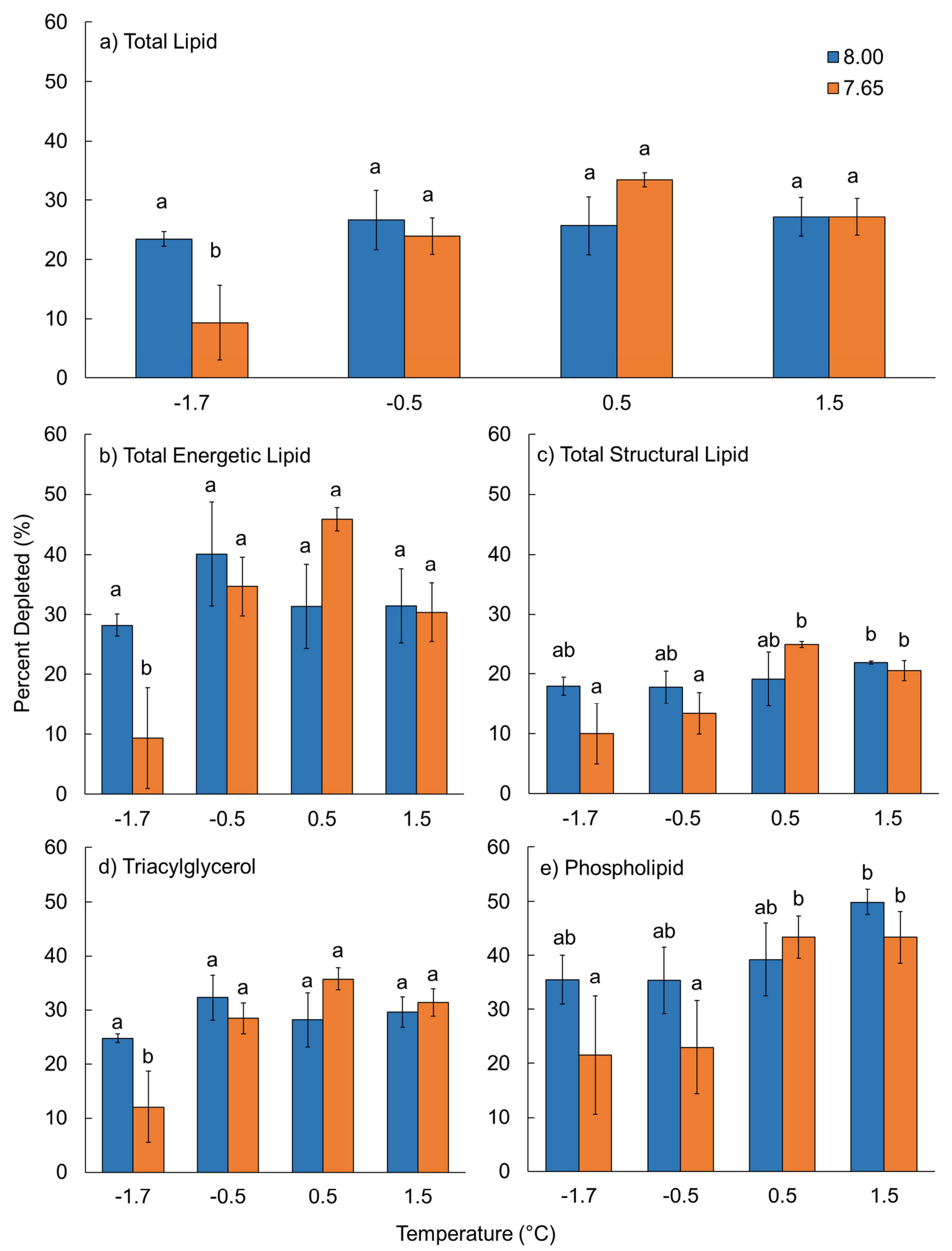

Fig. 4.2. Percent depletion during early development from 2 days PF to D-larvae stage in a) total lipids, b) energetic lipids, c) structural lipid, d) TAG and e) PL. The letters above the columns indicate significance at $\mathrm{p}<0.05, \mathrm{n}=4$ per treatment. Error bars are standard error. 
Reduced $\mathrm{pH}$ did not influence lipid use in development to the D-larval stage. The data suggested an interactive effect of $\mathrm{pH}$ and temperature where larvae at low $\mathrm{pH}$ had similar lipid depletion to control, except those at $-1.7^{\circ} \mathrm{C}$. Larvae in the $\mathrm{pH} 7.65$ and $-1.7^{\circ} \mathrm{C}$ treatment used considerably less total lipids ( $\sim 60 \%$ less) and TAG ( $\sim 50 \%$ less) compared to all other treatments. Variation in depletion between replicates and this interactive effect was not significant. Percent depletion between embryos and D-larvae was not measured for DAG, as it was below the limit of detection in some treatments $2 \mathrm{~d}$ PF. Depletion in other lipid classes was low, highly variable and not influenced by $\mathrm{pH}$ or temperature (Appendix 1).

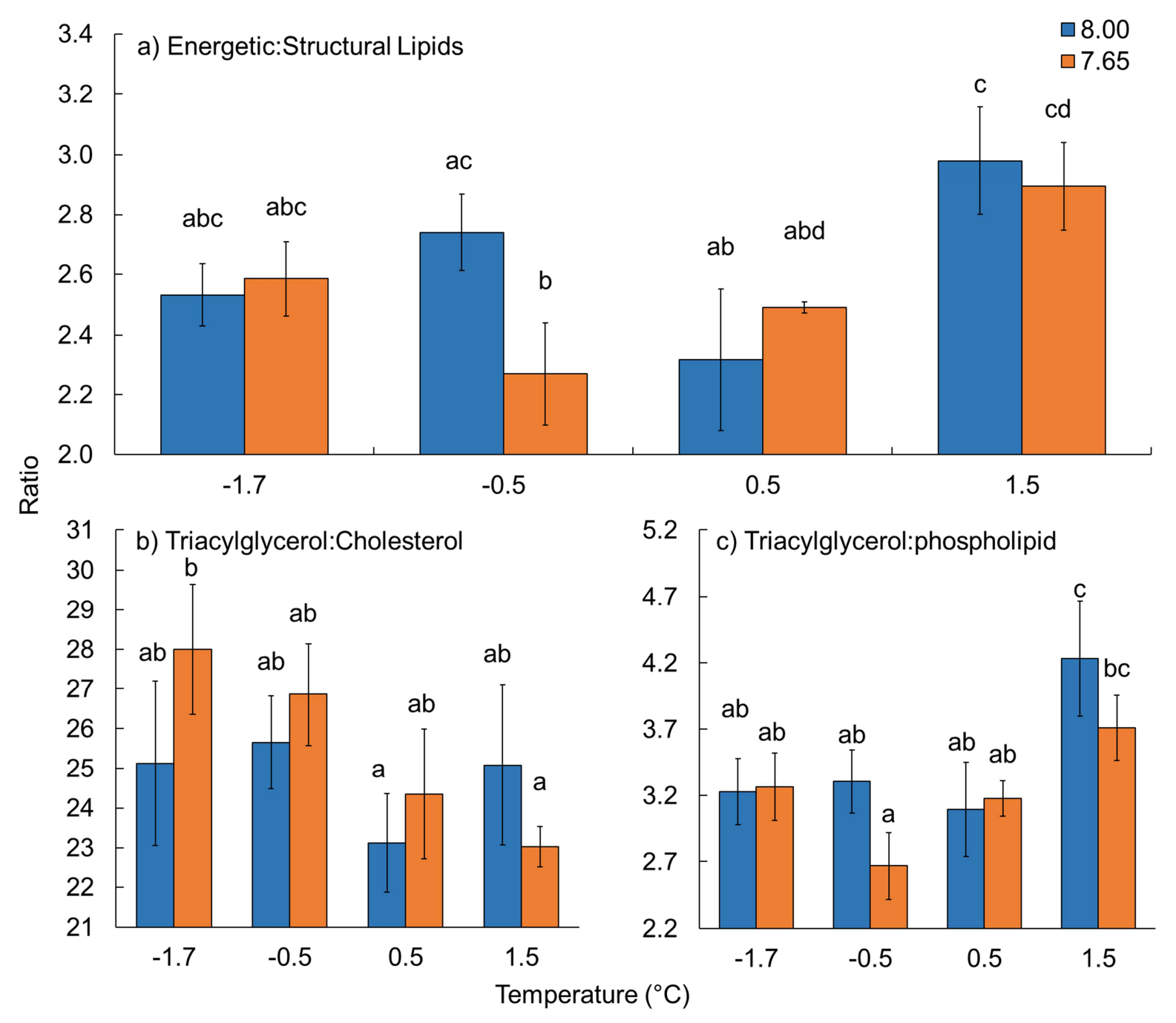

Fig. 4.3. Lipid ratios in D-larvae a) Ratio of energetic lipid to structural lipid classes, b) Ratio of total triacylglycerol to cholesterol content and c) Ratio of total triacylglycerol to phospholipid content. The letters indicate significance as in Fig. 4.2, $\mathrm{n}=4$. Error bars are standard error. 


\subsection{Lipid Ratios in D-Larvae}

D-larvae contained 2-3 times more energetic lipids than structural lipids, and this was similar to the ratio in embryos (Fig. 4.3a; Tables 4.3 and 4.4). During development to the Dlarval stage, the TAG:ST ratio decreased while the TAG:PL ratio increased (Tables 4.3 and 4.4).

Temperature, but not $\mathrm{pH}$, influenced ratios in D-larvae. Elevated temperatures lowered the ratio of energetic to structural lipids (Table 4.5, Fig. 4.3a). A trend was observed in the TAG:ST ratio, where it was reduced by elevated temperatures (Table 4.5, Fig. 4.3b). Ratios were significantly higher at the reduced $\mathrm{pH} / \mathrm{control}$ temperature compared to the $\mathrm{pH}$ $8.00 / 0.5^{\circ} \mathrm{C}$ and $\mathrm{pH} 7.65 / 1.5^{\circ} \mathrm{C}$ treatments. In contrast, the ratio of TAG to PL was higher at elevated temperature (Table 4.5, Fig. $4.4 \mathrm{c}$ ). At $1.5^{\circ} \mathrm{C}$ and $\mathrm{pH} 8.00$, the TAG:PL ratio was significantly higher than those under all other temperatures, regardless of $\mathrm{pH}\left(-1.7^{\circ} \mathrm{C}: \mathrm{p}=\right.$ $0.016,-0.5^{\circ} \mathrm{C}: \mathrm{p}=0.002$ and $0.5^{\circ} \mathrm{C}: \mathrm{p}=0.006$; Fig. $\left.4.3 \mathrm{c}\right)$.

\subsubsection{Respiration}

Elevated temperatures increased respiration rates in larvae above those in control temperature treatments (Table 4.6, Fig. 4.4). Respiration rates reached a maximum of 204.6 pmol $\mathrm{O}_{2} \mathrm{~h}^{-1}$ ind $^{-1}$ at $0.5^{\circ} \mathrm{C}$, compared to $130.9 \mathrm{pmol} \mathrm{O}_{2} \mathrm{~h}^{-1}$ ind $^{-1}$ at control conditions (Fig. 4.4). The high $\mathrm{Q}_{10}$ values for the -1.7 to $0.5^{\circ} \mathrm{C}$ range indicated a significant metabolic response to this temperature elevation, while $\mathrm{Q}_{10}$ values for the -0.5 to $0.5^{\circ} \mathrm{C}$ and 0.5 to $1.5^{\circ} \mathrm{C}$ ranges showed a lack of compensation to further temperature elevations (Table 4.7).

Table 4.6. Summary table of 2-way ANOVA for factors $\mathrm{pH}$ and temperature on respiration in Dlarval stage Laternula elliptica. Significant results in bold.

\begin{tabular}{|cccccc|}
\hline \multicolumn{2}{c}{$\mathrm{pH}$} & \multicolumn{3}{c|}{ Temperature } & \multicolumn{2}{c|}{ Temp. $\times \mathrm{pH}$} \\
$\mathrm{F}_{1,24}$ & $\mathrm{p}$ & $\mathrm{F}_{3,24}$ & $\mathrm{p}$ & $\mathrm{F}_{3,24}$ & $\mathrm{p}$ \\
\hline 1.060 & 0.313 & 3.157 & $\mathbf{0 . 0 4 3}$ & 0.837 & 0.487 \\
\hline
\end{tabular}




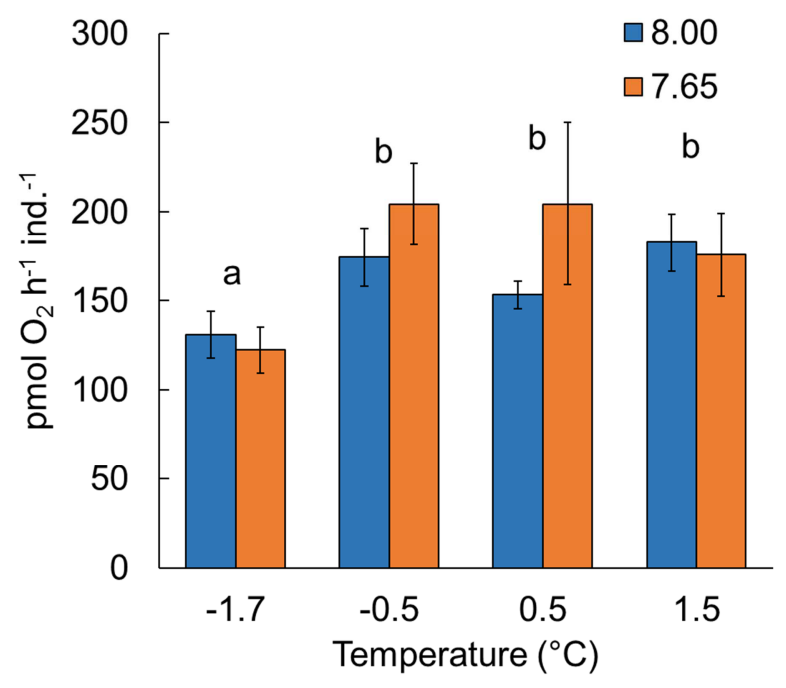

Fig. 4.4. Oxygen consumption in D-larvae. The letters indicate significance as in Fig. 4.2, $n=4$. Error bars are standard error.

Table 4.7. $\mathrm{Q}_{10}$ values for the changes in respiration rates observed with successive temperatures elevations at each experimental $\mathrm{pH}$.

\begin{tabular}{|lcc|}
\hline Temperature range & $\mathrm{Q}_{10}$ at experimental $\mathrm{pH}$ \\
$\left({ }^{\circ} \mathrm{C}\right)$ & 8.00 & 7.65 \\
\hline-1.7 to -0.5 & 10.90 & 72.00 \\
-0.5 to 0.5 & 0.28 & 1.02 \\
0.5 to 1.5 & 5.76 & 0.22 \\
\hline
\end{tabular}

Despite $\mathrm{pH}$ having no independent or interactive impact on respiration rate (Table 4.6), $\mathrm{Q}_{10}$ values showed a stronger impact of elevated temperature at reduced $\mathrm{pH}$ treatments (Table 4.7). At $\mathrm{pH}$ 8.00, an initial high rate of change in respiration was observed when temperature was raised from -1.7 to $-0.5^{\circ} \mathrm{C}$ (Fig. 4.5, Table 4.7). Under reduced $\mathrm{pH}$, the change in respiration rate between -1.7 and $-0.5^{\circ} \mathrm{C}$ was even greater compared to the change observed at the control pH (Fig. 4.4).

\subsection{Discussion}

\subsubsection{Development}

Elevated temperatures accelerated development to the D-larval stage, with the fastest rates occurring at $0.5^{\circ} \mathrm{C}$ (Table 4.2). Larvae at $1.5^{\circ} \mathrm{C}$ reached the D-larval stage a day later than those at $0.5^{\circ} \mathrm{C}$, suggesting that the limit for accelerated development under elevated temperature likely falls within this range. Compared to previous observations (Chapter 2), 
these larvae reached the $50 \%$ abundance point two days later, however the pattern of acceleration with temperature was equivalent (Table 2.4 and 4.2). Contrary to my previous observations (in Chapter 2), $\mathrm{pH}$ only had a delaying effect on larval development to the Dlarvae stage at the control temperature (Table 4.2).

\subsubsection{Lipid utilisation by L. elliptica larvae}

Energetic lipids accounted for $70 \%$ of the total lipid content in L. elliptica larvae. These were made up primarily of TAG, with WE as a small, but notable portion. There was nearly three times as much TAG as the next abundant class, the structural phospholipids, which accounted for over $20 \%$ of the total lipid content. Both energetic and structural lipids were used during development. Dominance of these lipid classes in L. elliptica eggs was measured by Ahn et al. (2000) using HPLC and TLC. However, TAG content accounted for only $24.4 \%$ of the total lipids in their study, compared to the $64.1 \%$ found in this experiment in larvae $2 \mathrm{~d}$ PF. Methodologies used by Ahn et al. (2000) differed from this experiment both in how eggs were collected and how lipids were measured. Additionally, the adult source populations differed (Antarctic Peninsula vs. Ross Sea). Energy per egg can differ significantly within species, varying with factors such as the type and availability of food for adults during gametogenesis, or population, genetics, temperature and other abiotic factors (DeFreese and Clark, 1983).

Of the four energetic lipid classes found, only TAG displayed significant depletion during development from embryos to the D-larvae stage. As TAG accounted for the largest proportion of the total lipid pool, it is likely that TAG is the main energetic source for larval development in L. elliptica. TAG is a common energetic storage lipid in animals (Allen, 1976; Holmer, 1989) and is the primary energetic lipid class in many invertebrate larvae, including those of echinoderms (Falkner et al., 2006; Byrne et al., 2008a; Byrne et al. 2008b; Falkner et al., 2015), crustaceans (e.g. Kattner et al., 2003) and molluscs (e.g. Holland and Spencer, 1973; Moran and Manahan, 2003; Pernet et al., 2003a). Despite its use in development, significantly large amounts of TAG remained at the D-larval stage (approximately $75 \%$ of the concentration at $2 \mathrm{~d} \mathrm{PF}$ ). This suggests the large remaining reserves could provide energy for these non-feeding larvae waiting for settlement cues. In a laboratory setting, L. elliptica larvae remained encapsulated for 18 mo. (Peck et al., 2007b) with no observations of hatching or settlement. The authors suggested that protracted development allows larvae to wait for favourable conditions for settlement. A sizeable 
remaining lipid reserve, of the magnitude observed here, coupled with low metabolic rates typical in cold climate animals (Pearse et al., 1986), would allow for a long period of encapsulation in the absence of appropriate cues. Additionally, TAG may also be an important reserve in metamorphosis.

Wax esters are another primary energetic lipid in animal tissues. They are often the dominant class in species at high latitudes (Lee et al., 2006), as well as in lecithotrophic larvae (Falkner et al., 2015), and are considered important in metamorphosis and postmetamorphic development (Villinski et al., 2002). WE were found in the larvae of L. elliptica in this study, although the amount present was small in comparison to TAG ( 4\% WE vs. $64 \%$ TAG). WE concentrations showed minimal change during development, suggesting that they too may be a reserve for later metamorphosis and settlement, stages which were not examined in this experiment. The WE reserve was smaller than might have been expected in a polar lecithotroph. Wax esters are a source of buoyancy control and large reserves in marine larvae may aid in dispersal (Villinski et al., 2002; Lee et al., 2006; Pond and Tarling, 2011). The small amounts in L. elliptica may encourage larval retention and recruitment within areas favourable to settlement.

Significant depletion was also observed in PL, which may indicate it too was used as an energy source. Despite being classified as a structural lipid class, PL can be used energetically in development or during periods of starvation (Holland, 1978; Kattner et al., 2003; Pernet et al., 2003b; Kattner et al., 2006) and is known to be used as a storage lipid in high latitude euphausiids (Lee et al., 2006). When PL is used solely as a structural lipid in development, its content remains constant or increases, due to its use in larval body structure (see Pernet et al., 2006; Lee et al., 2006; Meyer et al., 2007; Byrne et al., 2008a). Despite the use of PL during development, reserves were not fully exhausted. Around $65 \%$ of the available PL in $2 \mathrm{~d}$ old larvae remained available to D-larvae. However, it is unclear how much of this reserve would remain available energetically, as a portion of the remaining PL would be performing a structural function.

\subsubsection{Impacts of pH and temperature on lipid use}

There was no impact of the various temperature and $\mathrm{pH}$ treatments on lipid content and individual lipid class content during the earliest stages of embryogenesis ( $2 \mathrm{~d} P F)$. Results of my previous work on L. elliptica larvae have shown that, in the first $48 \mathrm{~h}$ development rates are slower at elevated temperatures (to $0.5^{\circ} \mathrm{C}$ ), and faster at low $\mathrm{pH}$ (Chapter 2 and Bylenga 
et al., 2015). This was not reflected in lipid use, although any differences may have been hidden in the variation seen between treatments. However, development at this very early stage may not be energetically costly. In urchin larvae, the use of energetic lipids was negligible in early development stages (early cleavage to hatching), higher levels of maternally provided lipids were used in the development of the feeding larvae (Byrne et al., 2008a).

While there was an indication of a significant overall effect of elevated temperature on $L$. elliptica lipid use, the significance was only due to the observation of reduced depletion in a single treatment $\left(\mathrm{pH} 7.65 /-1.7^{\circ} \mathrm{C}\right)$. The trend of increased lipid use at elevated temperatures was not significant against the control due to measured variations, although it was still apparent. Additionally, even with a trend towards greater lipid use at elevated temperature, large reserves remained in larvae at all treatments (65-75\% of the original lipid pool).

Changes in development rate in response to temperature and $\mathrm{pH}$ change are not uncommon (e.g. Sheppard Brennand et al., 2010; Stumpp et al., 2011b), although how these changes are reflected in energy use is largely unknown. Faster development rates observed in this experiment were not supported by increases in lipid use. Therefore, at elevated temperatures, larvae reached competency faster with large remaining reserves. Through lecithotrophy, lipids can provide larvae with sufficient reserves to sustain development through periods of low primary production, generating competent larvae at the onset of spring blooms (Lee et al., 2006). It is unknown how elevated temperatures will impact food availability and feeding behaviour in adults, which in turn would influence larval provisioning. Adults undergoing gametogenesis at elevated temperatures and/or reduced $\mathrm{pH}$, may provide larvae with better resources for survival or initiate changes in gene expression (Miller et al., 2012; Parker et al., 2015). However, under current provisioning, elevated temperatures may improve populations of L. elliptica through the production of larvae ready for metamorphosis at a faster rate, with no great trade-off in energy expenditure.

An animal's response to OA may be dependent on its capacity to regulate acid-base status (Pörtner, 2002a; Michaelidis et al., 2005), which in larvae may be metabolically demanding or limited (Melzner et al., 2009). Additionally, the costs may be greater in calcifiers as they will need to regulate saturation states at the site of calcification (McConnaughey and Gillikin, 2008), which may also incur metbolic costs (Tunnicliffe et al., 2009; Thomsen et al., 2010; Wicks and Roberts, 2012). Other costs may come from active processes surrounding the 
provision of substrates for calcification, such as moving seawater carbonate into the cell against concentration gradients under low saturation or by the conversion of respiratory $\mathrm{CO}_{2}$ into bicarbonate (Roleda et al., 2012). Organisms may respond by either reducing calcification rates or by increasing the use of energy.

Potential energetic costs for development have been inferred through the analysis of changes in growth rates (Thomsen and Melzner, 2010; Stumpp et al., 2011b), calcification (Thomsen and Melzner, 2010), metabolic rates (Thomsen and Melzner, 2010; Nakamura et al., 2011), gene expression (Todgham and Hofmann, 2009; O'Donnell et al., 2010; Stumpp et al., 2011a), and the regulation of proteins (Wong et al., 2011). Despite these observations, this is only the second study I am aware of to perform a detailed biochemical analysis on the energetic reserves in larvae affected by OA (see also Matson et al., 2012). In this experiment, only larvae from the reduced $\mathrm{pH}$ treatment at the control temperature displayed a significant change in lipid use. These larvae developed more slowly and used significantly less TAG in development to the D-larvae stage compared to that in all other treatments. Additionally, these larvae used less PL compared to larvae at $1.5^{\circ} \mathrm{C}$. These results imply that reduced $\mathrm{pH}$ lowered energetic costs at the control temperatures and had no effect in larvae at elevated temperatures. Therefore larvae at reduced $\mathrm{pH}$ reached equivalent life stages with little or reduced impact on lipid reserves.

Biochemical analysis of larval urchins raised under high $\mathrm{pCO}_{2}$ conditions showed no change in lipid use at set times PF, but the larvae had reduced growth (Matson et al., 2012). The authors suggested the urchin larvae were not altering the use of the energy they had available, but rather growing less under the same energy use. L. elliptica larvae may be continuing development through the diversion of resources away from energetically expensive activities such as calcification or later shell growth. Reductions in the energy spent in these areas could result in smaller and weaker larvae at competency. There are indications that this may be the case; under reduced $\mathrm{pH}$, the larval shells of L. elliptica have high occurrences of malformation, pitting and cracking (see Chapter 3).

Increases in metabolic rates have been used as an indicator of a greater energetic cost to development under stress (e.g. Stumpp et al., 2011b). Overall, respiration rates increased at elevated temperatures, while they did not change with reduced $\mathrm{pH}$. These rates reflected the impacts of temperature on development rate in L. elliptica. Respiration was significantly higher in the larvae that reached $50 \%$ abundance in the D-larvae stage in $22-24 \mathrm{~d}$ relative to 
those that took 26-28 d. While the increased respiration indicates a higher metabolic rate at elevated temperatures, this did not appear to have an added energetic cost, at least in the use of lipids.

$\mathrm{Q}_{10}$ results from this study suggest that a thermal tolerance point for L. elliptica larvae was reached, possibly around $-0.5^{\circ} \mathrm{C}$. Following an initial increase when temperatures were raised from -1.7 to $-0.5^{\circ} \mathrm{C}$, respiration rates remained steady upon further temperature elevation, indicating maximum respiration rates were reached. It is likely that oxygen delivery systems in polar species will be optimal between the average high and lows found in the organism's environment, and that a less variable environment will have restricted tolerance limits. Limits of thermal tolerance are also linked with respiration and organismal capacity to supply oxygen demand. A decrease in aerobic scope points to an approach towards thermal limits, indicated by falling internal $\mathrm{O}_{2}$ levels or decreased ventilation followed by a critical threshold where anaerobic metabolism begins (Pörtner, 2002a, b). Thermal sensitivity is usually first observed as limitations in species with high organisational complexity, so that less complex organisms tend to have higher thermal tolerances. Thermal limitation is progressive, affecting processes first and flowing downwards: from systemic to cellular to molecular levels (Pörtner, 2002a).

The lack of change in larval respiration rates as well as no increased lipid use with reduced $\mathrm{pH}$ suggests that these larvae are not upregulating metabolism to support the increased costs of calcifying under OA. Larvae may instead be reducing calcification, which would lead to smaller, weaker shells (see Chapter 3). However, it is possible that reduced $\mathrm{pH}$ causes a switch in energetic pathways, supporting metabolism with a different energetic source, such as protein which fuels adult metabolism (Brockington, 2001; Ahn et al., 2003). Proteins typically are another major energy component in invertebrate eggs (Holland and Spencer, 1973; Labarta et al., 1999; Falkner et al., 2015), although their use in development and relative proportions varies with species. Protein concentrations in L. elliptica larvae are unknown.

The larvae of L. elliptica have the capacity to defer metamorphosis and settlement and remain encapsulated for extensive periods of time (+18 mo; Peck et al., 2007b). During this time, larvae would be able to continue growth while waiting for settlement cues. The sizable lipid reserves observed here would likely be able to support long encapsulation times, particularly if the larvae do not perform additional shell and somatic growth in this period, 
reserving this energy for basic functioning. Additionally, remaining reserves may carry over through metamorphosis, providing an alternative resource for juveniles guarding against starvation or food limitation (Thiyagarajan et al., 2005). However, the higher metabolic rates and some of the trends toward higher lipid use at elevated temperatures could strain energetic resources and could impair later development. Smaller remaining reserves would reduce larval capacity to defer settlement in the absence of cues. Supporting the increased rates of metabolism may become difficult if malformed and weak shells (see Chapter 3) impair feeding capacity in juveniles. Projections to 2100 suggest these larvae will not be negatively impacted by ocean warming and acidification. While they may be approaching thermal tolerance limits, a temperature change of $+3^{\circ} \mathrm{C}$ would not significantly tax energetic resources and may result in larvae prepared for metamorphosis sooner than under ambient conditions.

\subsubsection{Conclusions}

The lecithotrophic larvae of L. elliptica rely on large reserves of TAG and PL to develop to the D-larvae stage. Despite considerable depletion of both of these lipid classes during development, significant reserves remained for metamorphosis, suggesting these larvae are well provisioned, even for long periods of encapsulation in the absence of settlement cues. In contrast to other polar species, WE comprised only a small portion $(<5 \%)$ of the total lipids in L. elliptica larvae.

These larvae showed resilience to projected ocean changes. An elevation in metabolic rate, indicated by increased $\mathrm{O}_{2}$ consumption, coincided with observations of $\mathrm{pH}$ and temperature impacts on development rates in this species (Bylenga et al., 2015). However, increased metabolic rates did not come at great energetic cost. Changes in development rates were not reflected in significant changes in the lipids required to reach equivalent points of development, although the impacts of these stressors on other energetic reserves in larvae (protein, carbohydrates) are still unknown. Carry over effects may last over generations. Larvae of L. elliptica are well provisioned and will likely experience little energetic cost in development under end of century temperature and $\mathrm{pH}$ projections. 


\section{Acknowledgements}

I thank the NIWA dive team (Scott Edhouse, David Bremner, Peter Marriott, Peter Notman and Andrew Lohrer) for L. elliptica collection and Antarctica New Zealand for their logistical support. This research was funded by VUW Grant 100241, the Victoria Doctoral Scholarship Fund, The ARC Endowed Development Fund, the Royal Society of New Zealand Marsden Fund NIW1101, and the National Institute of Water and Atmospheric Research (NIWA). Mary Sewell (University of Auckland, UofA) is thanked for the use of her laboratory, equipment and training. Josefina Peters-Didier (UofA) is thanked for her help in training as well as providing the TLC analysis. I also thank Neill Barr and Graeme Moss (NIWA) for their continual support during set-up and maintenance of the experiment, Lisa Northcote and Mark Gall (NIWA) for providing the lab space and equipment used for respiration measurements. Kim Currie and Judith Murdoch (NIWA/University of Otago Research Centre for Oceanography) are thanked for the water chemistry analysis. Sonja Hempel (Victoria University of Wellington, VUW) is thanked for her valuable assistance in the lab, and Dalice Sim and Lisa Woods (VUW School of Mathematics, Statistics and Operations Research) for their assistance and advice. 


\section{Chapter 5}

\section{Ocean acidification does not impact biodeposition by the Antarctic bivalve Laternula elliptica}

\subsection{Introduction}

Ocean acidification (OA) is an important stressor in molluscs. OA occurs through increased uptake of $\mathrm{CO}_{2}$ by the oceans, resulting in an increase in hydrogen ion concentrations, and a subsequent reduction in ocean $\mathrm{pH}$. Excess hydrogen can be removed through buffering by carbonate, which in turn reduces its availability for processes such as biological calcification. Thus, as OA increases, calcifiers may experience increased difficulty in shell formation as well as dissolution or degradation of existing calcium carbonate structures. OA may also have further impacts through altering immune responses, changing metabolism and interfering with acid-base pathways, as well as reducing reproduction and survival (Parker et al., 2013).

In calcifying organisms, research and concern about OA is often related to growth, or the maintenance and production of calcified structures. However, there are also metabolic effects that may result in a change in feeding behaviour in some species. Research into the impacts of acidification on feeding behaviour in bivalves typically focuses mostly on acidification from eutrophication, sewage and acid soils outflows (see Pynnönen and Huebner, 1995; Dove and Sammut, 2007), as well as industrial discharges and mining waste (see Loosanoff and Tommers, 1947; Bamber, 1987; Bamber, 1990; Loayza-Muro and Elías-Letts, 2007), situations that involve short term exposures to drastically low $\mathrm{pH}(\sim 5.5)$ and that often coincide with toxic metal exposure. In these cases, tissue degradation and necrosis occurred along with abnormal filtering behaviour including shell gaping or prolonged closure, diminished biodeposit production, increased mucous production and decreased filtration rates (Bamber, 1987; Bamber, 1990; Pynnönen and Huebner, 1995; Dove and Sammut, 2007; Loayza-Muro and Elías-Letts, 2007).

Few studies have examined feeding behaviour under $\mathrm{pH}$ stress from elevated $\left[\mathrm{CO}_{2}\right]$. Some invertebrate species show no direct impacts on behaviour or feeding rates (e.g. Marchant et al., 2010; Arnberg et al., 2013). In some bivalves, however, long term exposure to low pH 
reduced food clearance rates and absorption efficiency, as well as diminished oxygen consumption and increased ammonia excretion (Fernández-Reiriz et al., 2011; Navarro et al., 2013). However, in closely related species, reduced $\mathrm{pH}$ resulted in losses of organic tissue mass with no changes in ingestion and clearance rates (Fernández-Reiriz et al., 2011). Abalone larvae altered their particle selection in favour of smaller food particle sizes, and reduced ingestion and clearance rates (Vargas et al., 2013).

Higher routine metabolic rates occur with OA, meaning that increased energetic costs may be associated with reduced pH (Parker et al., 2013). These increases in metabolic rates may result in changes to energy allocation, redirecting energy at the expense of non-vital processes (Melzner et al., 2011). This indicates that food availability too could influence responses to OA. This has been observed in mussels, where increased shell dissolution occurred under combined stressors of reduced food and OA (Melzner et al., 2011).

Primary production in the Antarctic is seasonal with large variations due to differences in light conditions, sea-ice cover and currents. Additionally, productive seasons in the Antarctic may be quite short (Kang et al., 1997; Ahn et al., 2003). Some ice-covered, shallow water regions are classified as phytoplankton impoverished despite having highly productive benthic communities (Ahn et al., 1993; Norkko et al., 2005a). Suspension feeders in these communities may be opportunistic, using both advected material and resuspended benthic microalgae for food (Peck et al., 2005; Tatián et al., 2008).

Sedimentation is the process by which organic and inorganic particles suspended in the water column are deposited to the benthos. This process is enhanced through biodeposition, where suspension feeding organisms bind particulate matter and expel it as faeces and pseudofaeces, substantially increasing organic and nutrient content in surrounding sediments (Kautsky and Evans, 1987; Jaramillo et al., 1992; Norkko et al., 2001). Due to this benthicpelagic coupling, benthic communities are enhanced in the presence of biodepositors (Norkko et al., 2001). The extent of biodeposition is related to the abundance of suspension feeding organisms, their distributions and their feeding behaviour (Jaramillo et al., 1992). Suspension feeders generally ingest particles from the water column; particles that are not selected for consumption are bound in mucous and rejected as pseudofaeces, while particles that are utilised are digested and the remains deposited as faeces (Levinton, 1972). Suspension feeders may alter rates of filtration, ingestion or rejection as well as change particle handling times and selection efficiency in response to environmental conditions in order to maximise 
the energetic gain from feeding (Bayne, 1998). Changes in particle selection in response to stress or increased metabolic demands could alter inorganic and organic content of pseudofaeces and faeces. Feeding and biodeposition rates may be impacted by factors such as sediment loads (Hawkins et al., 1996; Safi et al., 2007), temperature (Jaramillo et al., 1992), salinity (Navarro, 1988; Jaramillo et al., 1992), hypoxia (Norkko et al., 2005b), and the presence of toxic species (Hégaret et al., 2007), as well as variations in the amount and quality of food (Bayne et al., 1988; Lauringson et al., 2007).

The suspension feeding clam, Laternula elliptica, plays an important role in Antarctic benthic-pelagic coupling (Ahn, 1993; Ahn et al., 1993). Sedimentation of organic matter increases in the presence of L. elliptica, with deposition of organic carbon measured around $95 \mathrm{mg} \mathrm{C} \mathrm{m} \mathrm{d}^{-1}$, a value comparable to Mytilus edulis in temperate waters (Ahn, 1993). Consequently, L. elliptica increases the amount of organic carbon available for deposit feeders in sediments (Ahn et al., 1993).

L. elliptica feeds on particles suspended in the water column, which in winter months are limited due to lack of primary production or sediment resuspension in fast-ice covered seas (Brockington, 2001; Tatián et al., 2008). They are able to utilise a variety of particle types and sizes, including macroalgal fragments, although the importance of different food sources may be site-specific (Norkko et al., 2007; Tatián et al., 2008). Energy budgets vary with season, with somatic growth occurring primarily in summer months. During winter, feeding and metabolic activity are reduced and the animal survives on energy stored primarily in muscle tissue (Ahn and Shim, 1998; Brockington, 2001). Gonad development may remain constant across seasons, although peak gametogenesis is linked to chlorophyll $\alpha$ abundance (Kang et al., 2009). Their capacity for entering a low metabolic state allows L. elliptica to withstand unfavourable conditions. However, this requires that the animal be able to make up energy reserves upon return to favourable conditions. It is unknown whether L. elliptica has the capacity to enter low metabolic states in response to other stressors. Larger animals reduce respiration rates, and presumably filtration rates, under increased sediment loads (Philipp et al., 2011), but the influence of other stressors on biodeposition rates in L. elliptica are unknown.

Exposure to OA results in rapid dissolution of empty shells in L. elliptica (McClintock et al., 2009); while in live adults exposure increases expression of chitin synthase and heat shock proteins and elevates oxygen consumption (Cummings et al., 2011). In addition to 
impacts on the shell, living under reduced $\mathrm{pH}$ would also expose tissues to unfavourable conditions, which could lead to an increased cost of maintaining homeostasis. Under such conditions, adults could increase food uptake, resulting in changes to pseudofaeces and faeces production as well as their inorganic and organic contents. Alternatively, adults could divert energy from areas of lesser importance such as fuelling somatic growth and gonad development. The larvae of L. elliptica are lecithotrophic, meaning they rely on maternally provided energetic reserves in the egg to fuel larval development through to metamorphosis. Changes in feeding behaviour could be indications of increased energetic demand, pointing to potential flow on effects to eggs and larvae. Success of juveniles can be directly linked to nutritional supply (Emlet and Sadro, 2006); this indicates that reduced nutritional states in adults could carry over to vulnerable early juvenile stages. Larvae experience high mortality rates $(60 \%)$ and altered development timing in response to both elevated temperature and reduced $\mathrm{pH}$, individually and in combination (Chapter 2, Bylenga et al., 2015). As they are important biodepositors, changes in feeding behaviour under these conditions could also have negative flow on effects to the benthic community. For example, reductions in deposited carbon through altered feeding rates would impact the available energy for associated deposit feeding organisms. In this study, feeding behaviour of L. elliptica under OA was examined by comparing biodeposit production and organic composition of faeces and pseudofaeces across a range of reduced $\mathrm{pH}$ levels.

\subsection{Methods}

On 31 October 2013, 48 L. elliptica were collected from a depth of $14.2 \mathrm{~m}$ in loose gravel sediments at Cape Evans $\left(-77.635258^{\circ} \mathrm{S} 166.414382^{\circ} \mathrm{E}\right)$. They were hung in a catch bag under the sea ice until they were used in the experiments 7-15 d later. Two separate experiments were conducted to assess biodeposition following 48 and $96 \mathrm{~h}$ exposure to reduced $\mathrm{pH}$. Both experiments were carried out at Cape Evans in a tent on the sea ice. Experimental tanks were isolated from the ice by an insulated floor and padding.

The first experiment was initiated on 7 November 2013, when clams were placed into insulated experimental tanks in free flowing seawater $(50 \mathrm{ml} / \mathrm{min})$. The clams were acclimated to the tanks at the control $\mathrm{pH}(\sim \mathrm{pH} 8.05)$ for two hours. Seawater $\mathrm{pH}$ was slowly lowered over the following $6 \mathrm{~h}$ to experimental $\mathrm{pH}$ levels 7.78, representative of end of century projections (Caldeira and Wickett, 2003; IPCC, 2013), and further reduced pH of 7.54 in order to further assess responses to low $\mathrm{pH}$, using diffusion of food grade $\mathrm{CO}_{2}$ into 
two supply tanks. A third tank supplied seawater at ambient $\mathrm{pH}$ as a control. No temperature manipulation was performed; therefore, all treatments were at ambient temperature (around $\left.1.9^{\circ} \mathrm{C}\right)$.

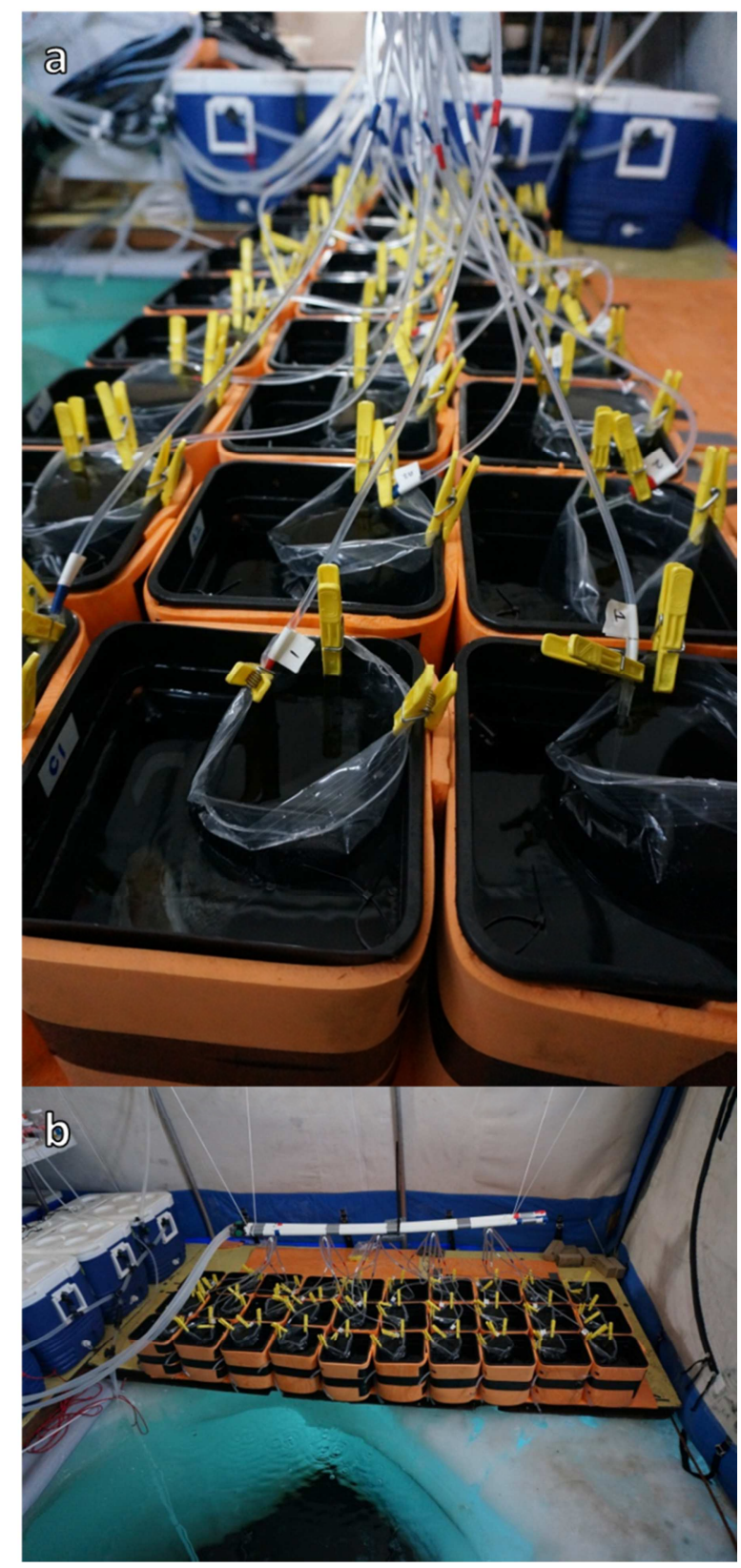

Fig. 5.1. Set up for biodeposition experiment. $\mathrm{pH}$ was manipulated in the blue supply tanks visible in the background in a, and experimental seawater was delivered to the 30 insulated tanks via the line suspended above the tanks in $b$.

Thirty $2 \mathrm{~L}$ experimental tanks were used, 10 for each treatment $\mathrm{pH}$ (Fig. 5.1). Prior to the experiment, a 1 litre plastic bag was placed in each bucket and the flow was directed into it to 
fill it up until it flowed over into the tank (Fig. 5.1 a). The tanks were placed in a randomised block design to account for any possible effects of temperature gradients from the nearby door and dive hole. The set of tanks was covered in black plastic sheeting to help mimic low light conditions under the ice. The shell length of each clam was determined before placing them on the bottom of the experimental tank (one ind. per tank, $n=8$ per treatment). Two tanks with plastic bags were left empty at each $\mathrm{pH}$ to provide a control for the passive settlement of organic and inorganic particulate matter due to natural sedimentation. Three to five times per day, the plastic sheeting was raised to feed the clams and to make observations of behaviour in L. elliptica, such as siphon position and movement.

When the target $\mathrm{pH}$ was reached, clams were removed from the bottom of their tanks and placed in their respective plastic bags. The shape of the plastic bag allowed the clams to maintain a natural upright body position in order to minimise animal stress. The $48 \mathrm{~h}$ experimental period was then initiated. Twice a day during this time, the flow was stopped for $30 \mathrm{~min}$ to feed the clams $0.5 \mathrm{ml}$ of a mixed algal solution, created from concentrating scrapings from under the ice. As empty tanks were used to control for the passive settlement of particles outside of biodeposition, the algal mix was added to all tanks. After 48 hours, water flow was turned off and clams were removed. The bag was sealed and the contents were allowed to settle. Before filtration a qualitative assessment of the shape, size and colour of the pseudofaeces and faeces was made. Deposits from both experiments were filtered onto preweighed $47 \mathrm{~mm}$ precombusted Whatman $\mathrm{GF} / \mathrm{C}$ filters for measurements of total biodeposits and passive settlement and kept frozen until analysis was performed in Wellington, New Zealand.

Experiment 2 was initiated on 15 November, with 24 new individuals. Methods followed those described above for Experiment 1, with two exceptions. Firstly, once the pH had been lowered, L. elliptica were acclimated to experimental conditions for 48 hours prior to the collection of biodeposits. Secondly, faeces and pseudofaeces were collected separately. Clams were fed during acclimation, also as described above. The clams were then placed in the plastic bags and biodeposits were allowed to collect for 48 hours following the acclimation period. In order to assess potential impacts of $\mathrm{pH}$ on food rejection, pseudofaeces were separated using a Pasteur pipette and filtered separately from the faeces and any remaining settled particles (referred to collectively as faecal deposits). 
Filters were dried for 24 hours at $60^{\circ} \mathrm{C}$, weighed and then combusted at $450^{\circ} \mathrm{C}$ for 3 hours to determine ash-free dry weight (AFDW). Dry weights (DWs) of passive settlement and deposit samples were determined by subtracting the initial filter weight from the weight after being dried for 24 hours. Biodeposition in Experiment 1 was determined by the DW of total deposits produced in 24 hours, corrected for total as well as inorganic and organic content of passive settlement (mg ind. ${ }^{-1} \mathrm{~d}^{-1}$ ). In Experiment 2, total deposits were calculated by adding the DW of pseudofaecal and faecal content. Organic content in both experiments was determined using the differences between AFDW and DW. Rates of pseudofaeces production and the organic content of deposits were expressed as mg ind ${ }^{-1} \mathrm{~d}^{-1}$; and organic content was also expressed as percentage of total DW. Due to the separate collection of faeces and pseudofaeces, only total deposits in Experiment 2 samples were corrected for passive settlement. As biodeposit production in L. elliptica is linked to animal weight (Ahn et al., 1993) and limitations of field work prevented accurate weighing of the clams, deposit weights were normalised to shell length.

\subsubsection{Statistical analysis}

All statistical analysis was performed using SPSS, version 22. Normality of the data was verified using Shapiro-Wilk's test and equality of variance was confirmed using Levene's test. The impacts of $\mathrm{pH}$ on total biodeposits (Experiment 1 and 2), pseudofaecal and faecal production (Experiment 2), as well as the organic components of each were compared by one-way ANOVA with $\mathrm{pH}$ as a single factor.

\subsection{Results}

\subsubsection{Behaviour}

Clams ranged in size from 63.3 - $93.6 \mathrm{~mm}$, averaging $82.9 \mathrm{~mm}$ in Experiment 1 and 75.1 $\mathrm{mm}$ in Experiment 2. The shape of the bag which held the clam allowed individuals to maintain an upright position, reflecting their natural orientation in sediments. Siphons remained partially to fully extended and the foot was often observed extending from the bottom of the shell. Feeding behaviour was not constant. Clams regularly had their siphons closed, but not for extended periods of time (>2 h). No differences in behaviour were observed in individuals between treatments. 
Pseudofaeces and faeces were ejected simultaneously and were slightly sticky, often adhering to the siphon or shell. Individuals were carefully rinsed with filtered seawater into the tanks to ensure collection of all deposits. In reduced $\mathrm{pH}$ treatments in both experiments, an apparent increase in mucous production was observed, with pseudofaeces appearing larger and more translucent.

\subsubsection{Deposition}

Total deposition in both experiments was greater than passive settlement (up to $2.3 \mathrm{x}$ ). However, the net deposition rates differed between Experiment 1 and 2 (average 4.4 and 21.6 $m g$ ind ${ }^{-1} \mathrm{~d}^{-1}$ above passive settlement, respectively). Passive settlement was similar between experiments and did not vary with treatment $\mathrm{pH}\left(\sim 16.3 \pm 0.3 \mathrm{mg} \mathrm{d}^{-1}\right.$; comprising $12.5 \pm 0.1$ and $3.9 \pm 0.2 \mathrm{mg} \mathrm{d}^{-1}$ inorganic and organic content, respectively). When adjusted for wet weight using average values from Ahn (1993), daily deposition rates in Experiments 1 and 2 were $0.26-0.53 \mathrm{mg} \cdot \mathrm{g}$ wet $\mathrm{wt}^{-1} \cdot \mathrm{d}^{-1}$.

\subsubsection{Experiment 1}

In Experiment 1, deposition by L. elliptica was 3.64-4.87 $\mathrm{mg}^{\text {ind }}{ }^{-1} \mathrm{~d}^{-1}$, when corrected for passive settlement (Fig. 5.2). Inorganic content accounted for a greater percentage of the biodeposits (70-75\%) and $\mathrm{pH}$ had no effect on uncorrected or length-corrected total deposits, inorganic or organic content (Table 5.1).

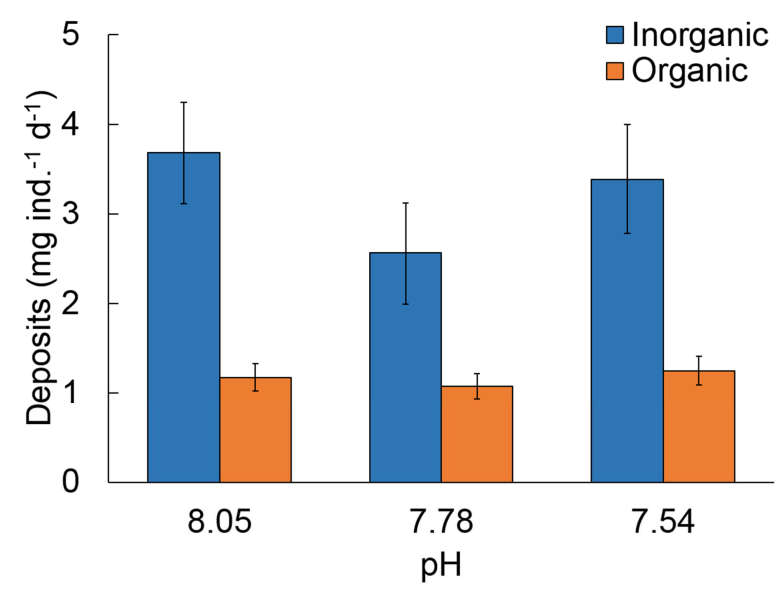

Fig. 5.2. Average organic and inorganic content of individual daily deposition at experimental $\mathrm{pH}$ in Experiment 1, corrected for passive settlement. Error bars are standard error. 
Table 5.1. Results of one-way ANOVA on the effect of $\mathrm{pH}$ on biodeposition in Experiment 1, including results corrected for shell length.

\begin{tabular}{|lcc|}
\hline & $\mathrm{F}_{2,21}$ & $\mathrm{p}$ \\
\hline Total deposits & 0.758 & 0.481 \\
Organic content & 0.293 & 0.749 \\
Inorganic content & 0.884 & 0.428 \\
Percent organic & 0.889 & 0.426 \\
& & \\
Length Corrected: & & \\
Total deposits & 1.553 & 0.235 \\
Organic content & 0.378 & 0.690 \\
Inorganic content & 1.844 & 0.183 \\
\hline
\end{tabular}

\subsubsection{Experiment 2}

Biodeposition was much higher in Experiment 2, ranging between 21.2 and $22.1 \mathrm{mg}$ ind. ${ }^{-1}$ $\mathrm{d}^{-1}$ above passive settlement in control tanks. Pseudofaeces accounted for approximately $45 \%$ of the total deposits, with no effect of $\mathrm{pH}$ on total deposits, pseudofaeces or faecal deposits (Table 5.2). Approximately $30 \%$ of pseudofaeces and faecal deposits were organic material and organic content was not significantly impacted by $\mathrm{pH}$ (Fig. 5.3, Table 5.2). Additionally, no significant difference was found between treatments when deposits and organic content were corrected for shell length.

Table 5.2. Results of one-way ANOVA on the effect of $\mathrm{pH}$ on total deposition, faecal content and pseudofaecal content in Experiment 2.

\begin{tabular}{|lcc|ccccc|}
\hline & \multicolumn{3}{c}{ Total deposits } & \multicolumn{2}{c|}{$\begin{array}{c}\text { Non- } \\
\text { pseudofaeces }\end{array}$} & \multicolumn{2}{c|}{ Pseudofaeces } \\
& $\mathrm{F}_{2,21}$ & $\mathrm{p}$ & $\mathrm{F}_{2,21}$ & $\mathrm{p}$ & $\mathrm{F}_{2,21}$ & $\mathrm{p}$ \\
\hline Total deposits & 0.146 & 0.865 & 0.021 & 0.979 & 0.691 & 0.512 \\
Organic content & 0.128 & 0.881 & 0.019 & 0.981 & 0.496 & 0.616 \\
Inorganic content & 0.144 & 0.867 & 0.020 & 0.980 & 0.839 & 0.446 \\
Percent organic & 0.067 & 0.935 & 0.011 & 0.989 & 1.043 & 0.370 \\
Length Corrected: & & & & & & \\
Total content & 0.691 & 0.512 & 0.364 & 0.699 & 0.952 & 0.402 \\
Organic content & 0.687 & 0.514 & 0.240 & 0.789 & 1.180 & 0.327 \\
Inorganic content & 0.644 & 0.535 & 0.362 & 0.700 & 0.889 & 0.426 \\
\hline
\end{tabular}



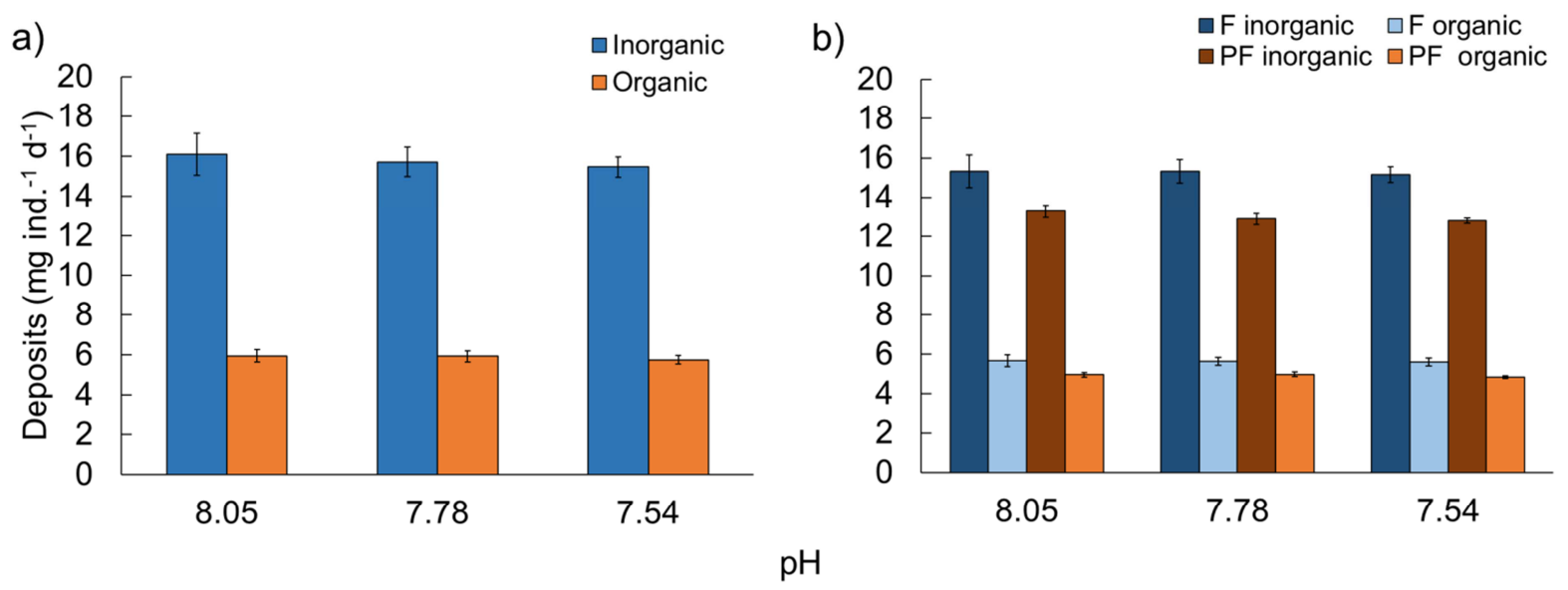

Fig. 5.3. a) Total organic and inorganic deposition, corrected for passive settlement and b) average individual daily deposition at experimental $\mathrm{pH}$ in Experiment 2 separated by inorganic and organic content of faecal and pseudofaecal deposits. Error bars are standard error.

\subsection{Discussion}

The presence of a single adult L. elliptica increased deposition of material from the water column above passive settlement, demonstrating their importance in benthic-pelagic coupling and sedimentation. Short term exposure to reduced $\mathrm{pH}$ did not influence feeding behaviour or the amount or the characteristics of biodeposits. Animal wet weights were not measured in this experiment; however when deposition rates were adjusted using average wet weight values from Ahn (1993), deposition was within the low end of the range of their daily rates (i.e. $0.26-0.53 \mathrm{mg} \cdot \mathrm{g}$ wet $\mathrm{wt}^{-1} \cdot \mathrm{d}^{-1}$ vs. $0.26-2.17 \mathrm{mg} \cdot \mathrm{g}$ wet $\mathrm{wt}^{-1} \cdot \mathrm{d}^{-1}$ in Ahn 1993). As $L$. elliptica has the capacity to enter a near hibernation state under low food concentrations (Brockington, 2001), clams were well fed to ensure sufficient biodeposit collection. Biodeposition in this experiment may have been influenced more by food availability than by the external seawater conditions. Under ideal food conditions, impacts of stressors may be reduced or overridden (Norkko et al., 2005b; Melzner et al., 2011).

Stress responses may be dependent on other factors such as age, size class and source population. For example, under various stressors small, young L. elliptica showed lower stress responses to tissue and shell damage, had lower accumulation of metals and cellular waste products, and also displayed a greater capacity for reburial and other energetically intense actions under stress compared to older and larger adults (Clark et al., 2013; Husmann 
et al., 2011; Husmann et al., 2012). Respiration in animals from different source populations on King George Island on the Antarctic Peninsula showed various responses to increased sediment loads in the water column which reflected sediment influx in the source areas (Philipp et al., 2011). Animals grown in a more variable environment (in terms of sediment load, salinity, temperature, food supply etc.) may also show a greater capacity to respond to and withstand a changing environment, reflecting the importance of experience in defining tolerance limits (Pörtner, 2010).

In 2011, daily variation at Cape Evans reached as high as $0.090 \mathrm{pH}$ units and seasonal variation was 0.3 units in 2012 and 2013 (see Matson et al., 2011; Matson et al., 2014; Kapsenberg et al., 2015). However, the lowest $\mathrm{pH}$ measurements occurred in winter months (Kapsenberg et al., 2015), when feeding activity in L. elliptica would be minimal or cease altogether (Brockington, 2001). Although the $\mathrm{pH}$ in my experiments was lower than that observed at Cape Evans, the natural variation at the site may indicate an adaptive capacity in the adults, allowing them to withstand short term stresses (maximum exposure time to low pH was $4 \mathrm{~d}$ in Experiment 2). While L. elliptica may be adapted to short term exposure, longer term exposure may have a metabolic cost. For example, under reduced $\mathrm{pH}$, increased heat shock protein levels and chitin synthase gene expression (after $21 \mathrm{~d}$ ) as well as increased oxygen consumption (after 120 d) were observed in L. elliptica (Cummings et al., 2011). It is possible that the increased metabolic costs associated with these observed changes could increase energetic demand over time, resulting in changing feeding behaviours with prolonged exposure.

The energy to support added metabolic costs may come from increased food intake, internal reserves, or the diversion of energy away from less important activities, such as gametogenesis. Here I show that in the very short term, L. elliptica do not change feeding behaviour to support these additional demands. Adults may be tolerating $\mathrm{pH}$ in the short term or else they are supporting increased metabolic demand by diverting resources, which could have consequences for individual growth or larval provisioning. However, longer term exposure in the adults is necessary to fully understand these implications.

In these experiments, qualitative differences in pseudofaeces were observed, being less compact and more translucent under reduced $\mathrm{pH}$. Other studies have shown increased mucus production in molluscs in response to reduced $\mathrm{pH}$ (Loayza-Muro and Elías-Letts, 2007). Additionally, stress may result in changes in particle selection (Safi et al., 2007; Vargas et al., 
2013). Increased mucous production could hide changes in particle selection when only organic content is measured. The observed differences in pseudofaeces colouration in Experiment 2 could be an indication of changes in particle selection and/or mucous production. If L. elliptica were rejecting fewer particles under low $\mathrm{pH}$, and simultaneously increasing mucous production, overall organic content may have remained similar between treatments. Ashing provides a measure of organic content in a sample, but it does not allow differentiation of carbon sources, and therefore differences in organic carbon contributions from mucous and phytoplankton would not have been measured. Closer examination and comparison of species abundances and particle sizes in pseudofaeces and faeces would allow clarification of feeding behaviours such as ingestion/rejection rates, and indicate whether changes in particle selection occur under lower $\mathrm{pH}$.

A difference in total biodeposition was observed between Experiments 1 and 2. In the first experiment, $\mathrm{pH}$ was lowered over 6 hours prior to the experiment start and clams were fed at the start of the experiment. In the second experiment, the clams were held in the tanks at experimental $\mathrm{pH}$ for $48 \mathrm{~h}$ prior to the start of the experiment and were fed during this time. Food may reside in the gut of L. elliptica in excess of $15 \mathrm{~h}$ (Tatián et al., 2008). The clams in Experiment 1 may have had a period of relatively low food intake by having been stored under the ice prior to the start of the experiment and the reduced deposition may be due to clams filling empty stomachs before beginning deposition.

\subsubsection{Conclusions}

L. elliptica significantly enhanced their environment through the provision of nutrients and organic deposits above natural sedimentation. Total deposition is dependent on variables such as feeding duration, season and organic content. Despite $\mathrm{pH}$ impacting respiration rates in another experiment (Cummings et al., 2011), pH did not affect deposition or feeding behaviour, at least in the short term with high food availability. However, changes in particle selection may have occurred, as indicated by qualitative differences in pseudofaecal appearances at low $\mathrm{pH}$. This indicates that L. elliptica adults may be able to withstand projected conditions for the Antarctic, continuing to provide adequate reserves for their lecithotrophic larvae as well as conserving suitable reserves for dormancy in winter months and maintaining their role as significant biodepositors in the Antarctic. However, longer term assessment of feeding behaviour would need to be performed to see if rates are impacted by metabolic changes observed under longer term exposure. 


\section{Acknowledgements}

I thank the NIWA dive team (Scott Edhouse, David Bremner, Peter Marriott, Peter Notman and Andrew Lohrer) for L. elliptica collection and Antarctica New Zealand for their logistical support. This research was funded by VUW Grant 100241, the Victoria Doctoral Scholarship Fund, The ARC Endowed Development Fund, the Royal Society of New Zealand Marsden Fund NIW1101, and NIWA. I also thank Neill Barr (National Institute of Water and Atmospheric Research, NIWA) for his continual support during set-up and maintenance of the experiment. Lisa Northcote is thanked for providing her lab and equipment for the dry weight analysis 


\section{Chapter 6}

\section{Discussion}

\subsection{Introduction}

Anthropogenic activities are having a significant impact on the environment, changing temperatures and ocean chemistry at an unprecedented rate (IPCC, 2013). Rapidly changing ocean conditions have significant implications for species survival, particularly in regions more sensitive to these changes, such as the Southern Ocean. Previously, adults of the Antarctic clam, Laternula elliptica, have been demonstrated to be sensitive to two of these stressors, ocean acidification and warming (see Cummings et al., 2011; Hempel, 2016), however, impacts on early life history stages are unknown. In order to address this knowledge gap, larval development in L. elliptica was analysed in a series of laboratory experiments, in which larvae were raised under elevated temperature conditions $\left(-0.5\right.$ to $\left.+1.5^{\circ} \mathrm{C}\right)$ and/or reduced $\mathrm{pH}$ (7.80 to 7.65), representative of changes in their environment projected for the end of the century. The observed differences in development and abnormality rates, larval sizes and metabolism between larvae raised at the control $\mathrm{pH}$ and temperature ( 8.00 and $1.7^{\circ} \mathrm{C}$, respectively), and those elevated temperatures and reduced $\mathrm{pH}$ are summarised in Table 6.1.

Table 6.1. (Opposite page). Summary of the experimental results on the effects of elevated temperature and reduced $\mathrm{pH}$ on development and nutrition in L. elliptica compared to the control temperature and $\mathrm{pH}$ treatment $\left(-1.6 /-1.7^{\circ} \mathrm{C}\right.$ and $\sim 8.00$, respectively). $\uparrow$ and $\downarrow$ indicate significant increases and decreases, respectively, in fertilisation success, larval development, abnormalities, respiration rates and sizes or lipid use, where significance is $p<0.05$. Double arrows indicate $p<$ $0.001, \mathrm{~ns}=$ no significance. Green arrows indicate an effect that would likely be beneficial and red indicates detrimental effects. Blank spaces, apart from those at control conditions, indicate treatments

where the effect was not assessed. ${ }^{*}$ includes 2,8 and 16-cell stages. ${ }^{* *}$ includes blastula, trochophore and veliger stages. ${ }^{* * *}$ Low $\mathrm{pH}$ value for biodeposition was 7.54. 


\begin{tabular}{|c|c|c|c|c|c|c|}
\hline & \multicolumn{4}{|c|}{ Experimental Temperature $\left({ }^{\circ} \mathrm{C}\right)$} & \multirow[b]{2}{*}{ Parameter } & \multirow[b]{2}{*}{ Chapter } \\
\hline $\mathrm{pH}$ & $\begin{array}{l}-1.7 /-1.6 \\
\text { (Control) }\end{array}$ & -0.5 & $0.4 / 0.5$ & 1.5 & & \\
\hline \multirow{14}{*}{$\begin{array}{c}\sim 8.00 \\
\text { (Control) }\end{array}$} & & $\uparrow \uparrow$ & $\uparrow \uparrow$ & & Fertilisation (4-6 h) & 2 \\
\hline & & $\uparrow \uparrow$ & $\uparrow \uparrow$ & & Early development (to $48 \mathrm{~h}$ ) & 2 \\
\hline & & $\uparrow \uparrow$ & $\uparrow \uparrow$ & & Early development $(2-20 \mathrm{~d}){ }^{* *}$ & 2 \\
\hline & & $\uparrow \uparrow$ & $\uparrow \uparrow$ & & D-larval development & 2 \\
\hline & & $\uparrow \uparrow$ & $\uparrow \uparrow$ & $\uparrow \uparrow$ & D-larval development & 4 \\
\hline & & $\uparrow \uparrow$ & $\uparrow \uparrow$ & & Early abnormality rate (to $6 \mathrm{~d}$ ) & 2 \\
\hline & & $\downarrow$ & $\mathrm{ns}$ & & D-larval abnormality rate & 2 \\
\hline & & $\mathrm{ns}$ & ns & & PI size (larval body) & 3 \\
\hline & & $\mathrm{ns}$ & $\mathrm{ns}$ & & PII size (shell growth) & 3 \\
\hline & & ns & ns & & Shell malformation & 3 \\
\hline & & ns & ns & & Shell abnormalities & 3 \\
\hline & & $\mathrm{ns}$ & ns & ns & Lipid depletion (Total, TAG) & 4 \\
\hline & & $\uparrow$ & $\uparrow$ & $\uparrow$ & Respiration & 4 \\
\hline & & & & & Biodeposition $^{* * *}$ & 5 \\
\hline \multirow{14}{*}{$7.80 / 7.78$} & $\uparrow \uparrow$ & $\uparrow \uparrow$ & & & Fertilisation (4-6 h) & 2 \\
\hline & $\mathrm{ns}$ & $\uparrow \uparrow$ & & & Early development (to $48 \mathrm{~h}$ ) & 2 \\
\hline & $\mathrm{ns}$ & $\uparrow \uparrow$ & & & Early development $(2-20 \mathrm{~d}){ }^{* *}$ & 2 \\
\hline & $\downarrow$ & $\uparrow$ & & & D-larval development & 2 \\
\hline & & & & & D-larval development & 4 \\
\hline & $\uparrow$ & $\mathrm{ns}$ & & & Early abnormality rate (to $6 \mathrm{~d}$ ) & 2 \\
\hline & ns & $\mathrm{ns}$ & & & D-larval abnormality rate & 2 \\
\hline & $\mathrm{ns}$ & ns & & & PI size (larval body) & 3 \\
\hline & $\mathrm{ns}$ & ns & & & PII size (shell growth) & 3 \\
\hline & $\uparrow$ & $\uparrow$ & & & Shell malformation & 3 \\
\hline & $\uparrow \uparrow$ & $\uparrow \uparrow$ & & & Shell abnormalities & 3 \\
\hline & & & & & Lipid depletion (Total, TAG) & 4 \\
\hline & & & & & Respiration & 4 \\
\hline & $\mathrm{ns}$ & & & & Biodeposition $^{* * *}$ & 5 \\
\hline \multirow{14}{*}{7.65} & $\overline{\uparrow \uparrow}$ & $\uparrow \uparrow$ & $\uparrow \uparrow$ & & Fertilisation $(4-6 \mathrm{~h})$ & 2 \\
\hline & ns & $\uparrow \uparrow$ & $\uparrow \uparrow \uparrow$ & & Early development (to $48 \mathrm{~h}$ ) & 2 \\
\hline & $\uparrow$ & $\uparrow \uparrow$ & $\uparrow \uparrow$ & & Early development $(2-20 \mathrm{~d}){ }^{* *}$ & 2 \\
\hline & $\downarrow \downarrow$ & $\downarrow$ & $\uparrow \uparrow$ & & D-larval development & 2 \\
\hline & $\downarrow \downarrow$ & $\uparrow \uparrow$ & $\uparrow \uparrow$ & $\uparrow \uparrow$ & D-larval development & 4 \\
\hline & $\uparrow$ & $\mathrm{ns}$ & ns & & Early abnormality rate $(6 \mathrm{~d})$ & 2 \\
\hline & $\mathrm{ns}$ & ns & $\mathrm{ns}$ & & D-larval abnormality rate & 2 \\
\hline & $\mathrm{ns}$ & $\mathrm{ns}$ & $\downarrow$ & & PI size (larval body) & 3 \\
\hline & $\mathrm{ns}$ & $\uparrow$ & $\uparrow \uparrow$ & & PII size (shell growth) & 3 \\
\hline & $\uparrow$ & $\uparrow$ & $\uparrow$ & & Shell malformation & 3 \\
\hline & $\uparrow \uparrow$ & $\uparrow \uparrow$ & $\uparrow \uparrow$ & & Shell abnormalities & 3 \\
\hline & $\downarrow$ & $\mathrm{ns}$ & $\mathrm{ns}$ & $\mathrm{ns}$ & Lipid depletion (Total, TAG) & 4 \\
\hline & $\mathrm{ns}$ & $\uparrow$ & $\uparrow$ & $\uparrow$ & Respiration & 4 \\
\hline & ns & & & & Biodeposition $^{* * *}$ & 5 \\
\hline
\end{tabular}




\subsection{Synthesis}

Chapter 2 describes changes in fertilisation success, progression of embryonic and larval development, occurrences of abnormalities and larval survival under reduced $\mathrm{pH}$ and elevated temperature. Further impacts of these stressors on larval quality and development were analysed in Chapter 3 by evaluating changes in shell growth and the quality of calcified structures using scanning electron microscopy. Chapter 4 examined both the use of energetic reserves by larvae and their metabolic responses to climate change stressors during development. Chapter 5 examined the impacts of ocean acidification on feeding behaviour and biodeposition in adult clams. A synthesis of the results of these experiments is presented here, followed by a discussion of their implications for future populations of L. elliptica.

\subsubsection{Fertilisation}

Fertilisation in invertebrates is generally robust to warming and acidification (reviewed in Byrne, 2011). In the Chapter 2 experiments, elevated temperature improved fertilisation rate relative to control conditions at both 4 and 6 hours (Table 6.1). At these higher temperatures, reduced $\mathrm{pH}$ impaired fertilisation compared to levels at the control $\mathrm{pH}$. However, even under $\mathrm{pH}$ stress, fertilisation success was still higher in elevated temperature treatments compared to rates at control temperatures (Table 6.1). This indicates projected ocean changes might improve fertilisation success, even with $\mathrm{pH}$ stress. By $48 \mathrm{~h}$ fertilisation was high in all treatments and robust to the temperature and $\mathrm{pH}$ treatment conditions. No loss of gamete viability was observed with either stressor.

Fertilisation studies made in a laboratory can be difficult to interpret as results may differ with experimental method (Byrne, 2011). Significant variation is often observed between experiments on the same species (e.g. Havenhand and Schlegel, 2009; Parker et al., 2010). There are many variables that can influence measurements of fertilisation success, such as population differences, parental age and gamete output, experimental method, gamete concentrations, sperm residence time, etc. (Byrne, 2011). The fertilisation in the Chapter 2 study occurred under optimum sperm and egg concentrations (Powell et al., 2001), which are unlikely to occur in the wild. The higher fertilisation rates observed in the first few hours following spawning may significantly increase the number of fertilised eggs at elevated temperature and reduced $\mathrm{pH}$, before sperm concentrations are diluted, subsequently increasing the numbers of developing larvae. 


\subsubsection{Development timing}

Not only will elevated temperatures potentially increase larval populations through enhanced fertilisation, the developing larvae will reach competency faster. Elevated temperatures accelerated development rates in my experiments (Table 6.1), an effect that was noticed as early as 4 hours post-fertilisation (PF) at the 2-cell stage. In addition to reaching the first developmental stage earlier, these larvae maintained a faster rate of development through successive development stages (Table 6.1). By the D-larvae stage, $\mathrm{a}+2^{\circ} \mathrm{C}$ change in temperature resulted in fully shelled larvae developing 5-6 days sooner compared to those at the control temperature, equating to a $20-25 \%$ increase in development rate.

The impacts of $\mathrm{pH}$ were more variable and highlighted the necessity of assessing the impacts of stressors at multiple developmental stages. Reduced $\mathrm{pH}$ largely accelerated development up until the trochophore stage, first seen around 10 days PF, which is the point in bivalve development where calcification begins (Waller, 1981; Weiss et al., 2002). This stage marked a turning point where the effects of $\mathrm{pH}$ started to become negative. Reduced $\mathrm{pH}$ significantly slowed development by the D-larvae stage, relative to control $\mathrm{pH}$, with the effect dependent on the incubation temperature (Table 6.1). For example, at control temperatures, the delay was $1-2 \mathrm{~d}$, but at $0.4^{\circ} \mathrm{C}$, the delay was $4 \mathrm{~d}$. However, due to the overall faster development at elevated temperatures, larvae at $\mathrm{pH} 7.65$ and $0.4^{\circ} \mathrm{C}$ still developed faster than those at control conditions (Table 6.1). The observed influences of temperature and $\mathrm{pH}$ on development of the later veliger and D-larval stages suggest that future ocean warming may accelerate development to these stages, but that ocean acidification may limit the extent of this increase. However SEM data (discussed below) indicates that settlement and juvenile survival may be impaired by extensive shell damage at reduced $\mathrm{pH}$

Larval stages are among the most vulnerable life stages, and any change in rates of mortality or development could have significant flow-on effects for the population (e.g. Parker et al., 2013; Guy et al., 2014). The lack of developed protective structures and mechanisms, exposure to adverse conditions and predation all significantly reduce the proportion of spawned gametes that survive to become settled juveniles (Martel et al., 2014; Pecorino et al., 2014; Przeslawski et al., 2015). Faster rates of development would mean protective and regulatory structures would be formed sooner, potentially reducing vulnerability and allowing for responses to external stressors. 
Elevated temperatures are not likely to occur without concomitant reductions in $\mathrm{pH}$, therefore it is important to consider the impacts of simultaneous reduced $\mathrm{pH}$ and elevated temperature. Despite the delaying influence $\mathrm{pH}$ had on the development of D-larvae, at elevated temperatures, the influence of $\mathrm{pH}$ was minor in comparison to the overall faster development rates observed with elevated temperature alone. Larvae in the most extreme treatment $\left(\mathrm{pH} 7.65\right.$ and $\left.0.4^{\circ} \mathrm{C}\right)$ still reached competency before the larvae at control conditions. However, even within a species, responses to stressors may be quite varied.

Variable responses to reduced $\mathrm{pH}$ have also been observed between populations of Mytilus edulis. In populations from the North Sea, shell dissolution and significant reductions in calcification were observed with elevated $p \mathrm{CO}_{2}$ (Gazeau et al., 2007). In contrast, M. edulis from a Baltic Sea upwelling region maintained calcification, somatic growth and juvenile recruitment at much higher $p \mathrm{CO}_{2}$ levels (Thomsen et al., 2010) and individuals from the American Atlantic coast experienced no change in calcification following exposure to elevated $p \mathrm{CO}_{2}$ (Ries et al., 2009). The naturally higher $p \mathrm{CO}_{2}$ experienced in the upwelling zone may have allowed for acclimation within the population, leading to higher resilience. Differential responses to stress in adult L. elliptica have been observed in populations that experience contrasting conditions. For example, acute thermal limits and individual performance at elevated temperatures were greater in individuals from locations with higher summer maximum temperatures (Morley et al., 2009). Additionally, in the Ross Sea, antioxidant defences were upregulated and oxidative stress was greater in populations from a more polluted environment (Lister et al., 2015).

In the present studies, differences in developmental timing were observed between larvae from the Chapter 2 experiment compared to those from Chapter 4. Experimental conditions were similar between these chapters, eggs were fertilised under reduced $\mathrm{pH}$ (7.80 and 7.65 in Chapter 2, pH 7.65 in Chapter 4) and elevated temperatures $\left(-0.5\right.$ and $0.4^{\circ} \mathrm{C}$ in Chapter 2 and $-0.5,0.5$, and $1.5^{\circ} \mathrm{C}$ in Chapter 4$)$, and larvae were raised under these conditions to the Dlarvae stage. In the Chapter 4 experiment, no delay was observed in any of the reduced $\mathrm{pH}$ treatments at elevated temperatures (up to $1.5^{\circ} \mathrm{C}$ ), while those at control temperature were delayed by close to $2 \mathrm{~d}$. The adult L. elliptica that supplied the larvae for the two experiments were sourced in different years (2012 vs. 2014) and from different populations (McMurdo Jetty vs. Granite Harbour). Adult condition and experience during gametogenesis can influence larval performance through the alteration of energetic provisioning or by 
transgenerational epigenetic inheritance (Sunday et al., 2011; Miller et al., 2012; Parker et al., 2013; Parker et al., 2015). For example, in oysters, prior exposure to reduced $\mathrm{pH}$ led to lower rates of abnormality, faster development, faster shell growth and increased heart rate in following generations (Parker et al., 2012; Parker et al., 2015). Similar responses are observed in other marine species (e.g. Foo et al., 2012; Miller et al., 2012; Vehmaa et al., 2012), although prior exposure may exacerbate negative responses (see Dupont et al., 2013). The variable responses observed between the experiments may indicate that $L$. elliptica larval sensitivity to reduced $\mathrm{pH}$ may be linked to different environmental conditions experienced by the parents.

No long term data sets exist detailing conditions at Granite Harbour. However, Kapsenberg et al. (2015) compared conditions at McMurdo Jetty to Cape Evans. Short term measurements of $\mathrm{pH}$ made at Cape Evans and Granite Harbour from the same time (November) in different years (2013 and 2014, respectively) indicate these locations are similar, but $\mathrm{pH}$ is slightly lower at Granite Harbour compared to Cape Evans (approximately 7.99 vs. 8.04, respectively; Cummings, Pers. Comm.). McMurdo Jetty has small short term variations in $\mathrm{pH}$, and seasonal averages are higher compared to conditions at Cape Evans (8.15 vs. 8.05, respectively, Kapsenberg et al., 2015). If $\mathrm{pH}$ variability at Granite Harbour is similar to that at Cape Evans, the adults used for the Chapter 4 lipid analysis may have been better adapted for reduced and variable $\mathrm{pH}$ conditions compared to those from the McMurdo Jetty. This may have allowed larvae to respond better to the low $\mathrm{pH}$ conditions in Chapter 4. However, the data from Granite Harbour are from a limited time scale and a different year from Cape Evans data, more data would be needed to make an accurate comparison of the conditions experienced by the different populations.

Small changes to developmental timing could have significant flow on effects to the size of population at settlement. Larvae reach competency at the D-larvae stage. At this critical point, they can begin metamorphosis and settle in the sediments as juveniles. Under elevated temperature, larvae will reach competency sooner, with two positive implications: faster settlement or greater growth. Early competency means larvae will be able to complete metamorphosis and settlement sooner upon the receipt of appropriate cues. This would reduce the time in which larvae might be carried away from favourable settlement locations due to currents, promoting the retention of larvae. Additionally, larvae would spend less time in life stages where they are vulnerable to predation, thereby increasing the overall population 
of juveniles (Lamare and Barker, 1999; Prowse et al., 2009). Alternatively, larvae would be able to delay metamorphosis and spend more time in larval somatic and shell growth, allowing for the development of larger juveniles, which could increase their survivorship (Gosselin and Qian, 1996; Emlet and Hoegh-Guldberg, 1997; Emlet and Sadro, 2006; Martel et al., 2014).

Settlement in invertebrate larvae is typically dependent on external cues (Martel et al., 2014; Wicks and Roberts, 2012). These cues may be physical, chemical or interactive, triggered by the presence of specific predators or prey, substrata and/or biofilms (Hadfield and Paul, 2001). Additionally, within a species, cues for settlement may differ from those for metamorphosis (Hadfield and Paul, 2001). Cues may be influenced by the same conditions that influence larval development in L. elliptica, therefore, even if larvae reach competency sooner, there is no guarantee the larvae will receive the appropriate cues to initiate metamorphosis and settlement. L. elliptica larvae are non-feeding, and are unable to replenish any reserves before metamorphosis. If cues are missing, larvae may be able to wait, but this time will be limited by the available energetic reserve. The observed impacts of reduced $\mathrm{pH}$ and temperature on energetic reserves and larval sizes are further discussed below. However, if cues are not affected in this species, the faster development indicates that L. elliptica populations could possibly increase under projected elevated temperatures.

\subsubsection{Abnormalities and mortalities}

Abnormal development was observed in all life history stages studied. Abnormalities included altered larval body shapes, which would likely result in larvae not progressing on to successive developmental stages, or larval mortality. Four hours PF, abnormality rates of the embryos ranged between 2-8\%, and by $6 \mathrm{~d} \mathrm{PF}$ had increased to $18-30 \%$. Temperature and $\mathrm{pH}$ did not individually influence abnormality rates in the first $6 \mathrm{~d}$, but an interactive effect was observed with reduced $\mathrm{pH}$ increasing abnormalities at $-1.6^{\circ} \mathrm{C}$ but reducing them at $-0.5^{\circ} \mathrm{C}$. By the D-larvae stage, abnormality rates were high in all treatments.

The elevated temperature of $-0.5^{\circ} \mathrm{C}$ reduced occurrences of abnormalities in the D-larval stage (Table 6.1). Due to the difficulty of observing details of the larval shell under light microscopy, observations of abnormal development in the D-larvae in Chapter 2 were limited to those that presented obvious malformation or had not progressed past previous stages (e.g. "ab" and "vel" in Fig. 6.1a). Abnormalities were more frequent in reduced $\mathrm{pH}$ treatments at 
each temperature, however, this effect was not statistically significant due to large variability between treatments, which indicated that future warmer oceans might increase D-larvae numbers with little impact of concurrent reduced $\mathrm{pH}$ (to 7.65).

While the effects of $\mathrm{pH}$ on abnormal development were non-significant in Chapter 2, closer examination of shell quality and morphology under SEM revealed significant negative effects. D-larvae from reduced $\mathrm{pH}$ treatments that appeared to be fully shelled under light microscopy (e.g. "D" in Fig. 6.1a) were sometimes uncalcified and a significant portion of them had abnormal D-shapes, deformed shell edges and irregular hinges (Fig. 6.1b-d). Furthermore, of the larvae that had normal D-shapes, significantly more displayed high amounts of shell damage when raised under reduced $\mathrm{pH}$ (Table 6.1). Undersaturation of aragonite in both reduced $\mathrm{pH}$ treatments likely led to the dissolution of shell surfaces, resulting in the increased pitting that was observed. Elevated temperature did not impact shell morphology (Table 6.1), but it did have a slight mitigating effect on reduced $\mathrm{pH}$. These results suggest that OA will be major concern for these developing larvae, as larval shells will experience a significant loss of quality, which could impair function or success.

Apparently normal larvae may actually be severely damaged by $\mathrm{pH}$. Abnormalities and dissolution of calcified structures are difficult to observe without SEM. This may lead to incorrect interpretations of stress responses. In Chapter 2, abnormalities were judged solely on the apparent overall shape of the larva, and it was suggested that larvae were largely robust to reduced $\mathrm{pH}$, particularly in the context of beneficial effects of elevated temperatures. However, Chapter 3 revealed significant flaws in shell structure that would have serious implications for settlement and survival. In order to avoid an underestimation of the impacts of $\mathrm{pH}$, future studies on larval development will need to pay close attention to calcified structures. 


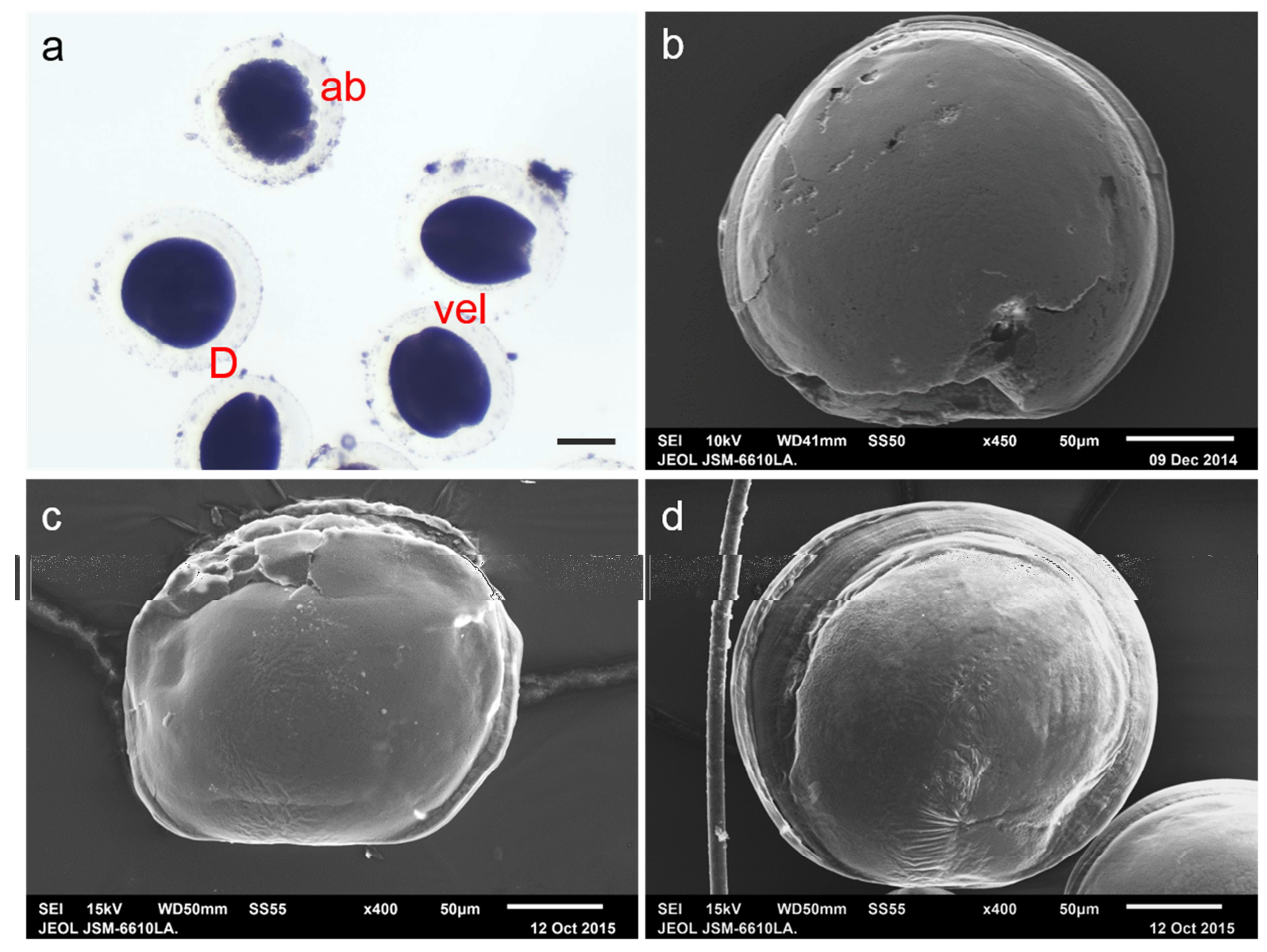

Fig. 6.1. Images of larvae from the Chapter 2 and 3 experiments, taken using (a) light microscopy and (b-d) SEM. (a) shows a D-larvae (D), late stage veligers (vel) and an extreme example of abnormal development (ab); (b-d) are examples of D-larvae that were counted as "normally developed" under light microscopy, but that SEM examination in Chapter 3 revealed were in fact malformed. Scale bar $=100 \mu$ in $(\mathrm{a}),(\mathrm{b}-\mathrm{d})$ as indicated.

Larval morphology and shell integrity may have a large influence on survival (Talmage and Gobler, 2010; Gaylord et al., 2011). In species with planktonic feeding stages, reduced shell integrity in structure, or in the hinge or edges may impair feeding or swimming capacity (Talmage and Gobler, 2010; Waldbusser et al., 2015). Adult L. elliptica may not be heavily reliant on structural integrity as they are sessile. However, impaired swimming may reduce the capacity of juveniles to select suitable substrate on which to settle. Additionally, as infaunal organisms, they must bury in sediments as part of the settlement process. L. elliptica is found in a large variety of sediment types ranging from coarse gravel to mud. Altered shell shape may influence the sediment types in which juveniles are able to settle and burrow, while reduced shell integrity may increase mortality at settlement. 
The impacts of exposure to reduced $\mathrm{pH}$ will likely mean reduced larval and juvenile populations due to malformed and/or weaker calcified structures. Simultaneous exposure to elevated temperatures will improve shell condition and reduce abnormal development. However, unlike the observed impacts on development timing, the benefits of elevated temperatures will not overcome the costs of reduced $\mathrm{pH}$. The increased frequency of cracking on larval shells at reduced $\mathrm{pH}$ is a symptom of a larger problem. The larvae are encapsulated in a thick gel capsule that should offer protection for the developing larvae. Larvae raised under reduced $\mathrm{pH}$ had higher occurrences of shell cracking. This implies that they have weaker shell structure and may be prone to damage in settlement. While there are no crushing predators in Antarctica, shell strength is an important component of individual survival in $L$. elliptica. The shells of bivalves may also offer protection against bacterial invasion, and significant cracking and damage may leave larvae and juveniles vulnerable to infection (Husmann et al., 2011; Harper et al., 2012).

In molluscs, larval shells are not lost in metamorphosis, but are incorporated instead into the juvenile and adult shells (Weiss et al., 2002) Consequently, any damage sustained in larval development will carry-over to later stages. Repair of damage is possible in adults that sustain crushing injuries suffered during physical disturbances (e.g. from icebergs Harper et al., 2012). However, the repair process in L. elliptica is slow and may be limited (Sleight et al., 2015) and extensive damage, as seen here in larval shells may be too energetically demanding to repair. Additionally, under ocean acidification, reduced $\mathrm{pH}$ will not only affect larval stages. Juveniles and adults will be subject to the same conditions, possibly experiencing similar reductions in shell quality and may not be able to repair damage. Under future ocean conditions, shell damage sustained during larval development may significantly reduce recruitment leading to significant population declines, particularly in more disturbed habitats. It must also be considered that these experiments were carried out in a laboratory setting where developing larvae were largely protected. Natural mortality rates would likely be even higher in the wild as larvae would be exposed to predation, advection and other stressors. Climate change related stressors may place added strain upon already vulnerable life stages (Gazeau et al., 2013; Parker et al., 2013).

\subsubsection{Larval sizes}

Elevated temperatures and reduced $\mathrm{pH}$ not only influenced the rate of development and the quality of calcified structures, they also impacted larval body sizes and shell growth (Table 
6.1, Chapter 3). Larval sizes often affected by stressors, however, it is not clear whether the size differences are related to developmental delays or reduced growth (Gaylord et al., 2011; Stumpp et al., 2011b). When comparing larval sizes at set times PF, developmental delays may indicate smaller larvae sizes. However, reduced growth would only be apparent when comparing larvae at equivalent life history stages, independent of the time PF. In L. elliptica, the answer to whether larvae are smaller or just delayed lies somewhere in the middle.

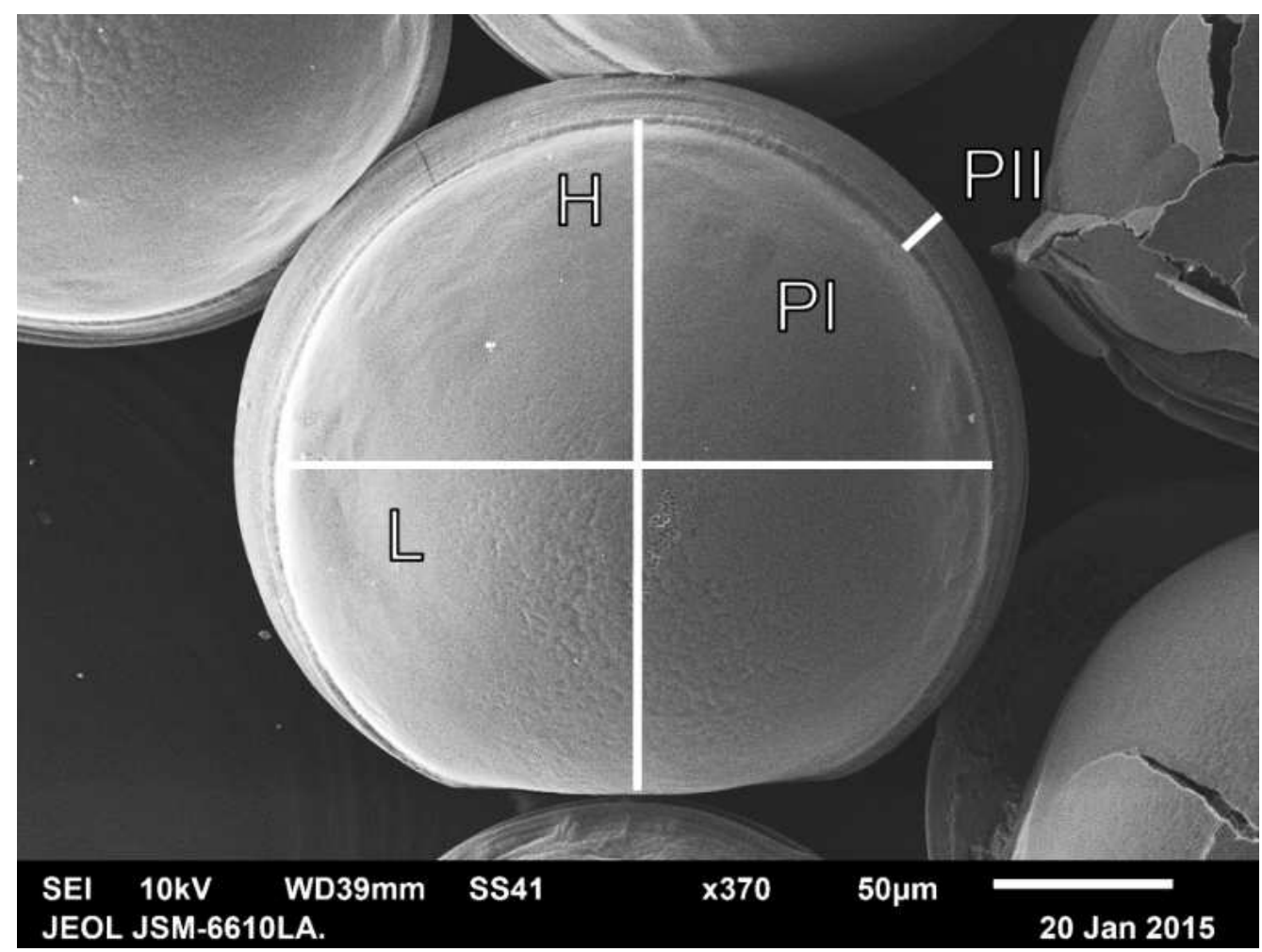

Fig. 6.2. SEM image of a normal D-shape larva, showing prodissoconch I (PI) and the narrow band of prodissoconch II (PII). H and L indicate measurements of shell height and length, respectively of PI.

The two-staged development of bivalve shells allows for the measurement of different aspects of larval growth: body size and shell formation. The first part of shell development is the formation of prodissoconch I (PI, Fig. 6.2). Calcification is initiated by the shell field, specialised ectodermal cells that later form the shell gland and periostracum (Eyster and Morse, 1984). The development of the larval shell begins in the trochophore stage at the onset of calcification, and PI is complete when the shell meets at the margins and the body is completely enclosed forming a D-shaped straight hinged larvae. From this point the 
formation of prodissoconch II (PII, Fig. 6.2) begins. At this stage, shell formation switches from the shell field to the mantle, and calcium carbonate is laid in thin bands along the newly formed shell edges. The larvae will also add calcium carbonate to the inside of the shell, thickening it (Carriker, 1996). PI height and length measurements correspond to the size of the larvae at competency, while the width of new shell in PII corresponds to shell growth, and subsequently, the rate of calcification between PI and metamorphosis (Martel et al., 1995; Martel et al., 2014).

Larval body sizes (PI) as well as shell growth (PII) were influenced by both reduced $\mathrm{pH}$ and elevated temperatures (Table 6.1). In PI development, under elevated temperature, larvae had significantly smaller shell heights and therefore larval body sizes, compared to those at the control temperature. Incubation temperature did not impact PI length. These smaller larvae at elevated temperature are contrary to expectation. Generally, larger larvae sizes are an indication of greater health or quality (Gosselin and Qian, 1996; Martel et al., 2014). Faster growth rates had already been observed with elevated temperature in Chapter 2, indicating that the larvae were reaching the fully shelled D-larvae stage sooner. This would mean that the larvae were finishing the formation of PI at an earlier age PF. Larvae may have had less time in which to perform cell growth during PI development, becoming fully shelled at a smaller size.

The temperature dependent impact of $\mathrm{pH}$ on PI development is harder to interpret (Table 6.1). At -1.6 and $0.4^{\circ} \mathrm{C}$, smaller shell heights were observed at reduced $\mathrm{pH}$. Conversely, the largest shell heights were observed at $\mathrm{pH} 7.65$ and $-0.5^{\circ} \mathrm{C}$. This variable response may be related to the energetic costs of calcification. Calcification is dependent on an organism's capacity to maintain $\mathrm{pH}$ at the site of calcification. Under ocean acidification, internal $\mathrm{pH}$ can be regulated through the removal of protons using ion transport mechanisms or through buffering using bicarbonate (McConnaughey and Gillikin, 2008). Bivalves are capable of forming bicarbonate through the energetic conversion of respiratory $\mathrm{CO}_{2}$ (Roleda et al., 2012). Under elevated temperatures, respiration increased in L. elliptica larvae (see below, Table 6.1). This may have supported a higher metabolism, leading to a greater production of bicarbonate, improving buffering and allowing greater cell growth. However, a lack of change in respiration rate at temperatures elevated above $-0.5^{\circ} \mathrm{C}$ (i.e., 0.5 and $1.5^{\circ} \mathrm{C}$, Chapter 4) indicates that metabolism may be limited. Additionally, increased metabolic demands at the higher temperatures may have resulted in the smaller larvae seen at $0.4^{\circ} \mathrm{C}$, as energetic 
resources may have been used to build vital larval structures and not for further body growth. This indicates that smaller sizes may also be expected above $0.4^{\circ} \mathrm{C}$.

Elevated temperature increased the amount of shell growth performed at PII, while the influence of $\mathrm{pH}$ was once again dependent on the incubation temperature. At the control temperature, significantly less shell material was deposited at reduced $\mathrm{pH}$. Unlike the larval body growth at PI, which increased under reduced $\mathrm{pH}$ only at $-0.5^{\circ} \mathrm{C}$, increased growth of PII was observed at both elevated temperatures (i.e. -0.5 and $0.4^{\circ} \mathrm{C}$ ) with reduced $\mathrm{pH}$. This is likely related to the patterns of development described in Chapter 2. Larvae raised in elevated temperature treatments reached the D-larvae stage sooner, meaning they could have more time to continue calcification before settlement, if settlement cues are not received, resulting in larger PII growth. This increase could have positive implications for L. elliptica populations, as a larger size at metamorphosis may give an advantage in settlement (Martel et al., 2014; Phillips and Gaines, 2002). Larger shells may reduce the vulnerability to predation, as well as give the larvae a competitive advantage for prime settlement areas. Additionally, as PII growth occurs on the inner shell layers as well as along the shell edge, more time spent in PII growth will mean larval shells may be thicker and more resistant to crushing fractures during burial.

Reduced $\mathrm{pH}$ had a variable effect on shell growth at PII, apparently limiting shell growth at the control temperature, but not at the elevated temperatures. If increased respiration and metabolic limits under reduced $\mathrm{pH}$ and elevated temperatures noted in Chapter 4 (see below) explain the pattern of growth in PI, they may also explain the effect at PII. While size at PI relates more to larval body growth, PII may relate to calcification rates. Factors limiting cell growth at elevated temperature may not have had an influence on the ability to calcify. The larvae may have continued growing larger shells at reduced $\mathrm{pH}$ and elevated temperatures due to the increased production of bicarbonate with higher respiration rates. Interestingly, not only was shell growth greater at reduced $\mathrm{pH}$ at both elevated temperatures, greater shell growth occurred at pH 7.65 compared to 7.80 (Table 6.1). If increased buffering aided calcification at high temperatures, it would be expected that shell formation would be similar, not greater. Perhaps a hormetic response occurred, where the increased and combined stressors ( $\mathrm{pH} 7.65$ and $0.4^{\circ} \mathrm{C}$ ) crossed a threshold, triggering a repair mechanism that was not activated under less stressful conditions. However, responses such as these are energetically 
demanding and may come at costs to the developing larvae, such as losses in tissue mass or reductions in energetic reserves.

\subsubsection{Larval energetics}

The energetics of larval development in L. elliptica were analysed in Chapter 4, focusing on the use of lipid reserves in development to the D-larval stage, as well as how these reserves were impacted by reduced $\mathrm{pH}$ and elevated temperature. Eggs contained around 200 ng of lipids, which were dominated by the energetic lipid triacylglycerol (TAG) and the structural phospholipid (PL). TAG accounted for nearly $65 \%$ of the total lipid content. Also present were wax esters, aliphatic hydrocarbons, diacylglycerol, cholesterol, acetone mobile polar lipids and free fatty acids.

Depletion of lipids over time was partially dependent on the incubation temperature. In development to the D-larval stage, a trend towards higher depletion was observed at elevated temperatures. Surprisingly, the lowest lipid depletion was observed in larvae developing under reduced $\mathrm{pH}$ at control temperatures (Table 6.1). However, the differences in lipid use between treatments were minor and considerable reserves remained under all experimental $\mathrm{pH}$ and temperatures. Larvae developing under elevated temperatures reached the D-larval stage sooner compared to those at control temperatures (Chapter 2) and achieved greater shell growth (Chapter 3). Larvae that reach greater sizes at equivalent age may be expending more energy to complete equivalent growth. Metamorphosis is energetically demanding and if reserves are depleted before competency is reached, larvae will not be able to complete metamorphosis. However, there was little or no added energetic cost to maintain these faster development rates (Chapter 4). This indicates that the larvae may have reached competency sooner, with no increase in lipid use.

In development to the D-larvae stage, around $25 \%$ of the total lipid pool was depleted ( 45 $\mu \mathrm{g}$ ), largely due to changes in PL and TAG content. The relative size of the original TAG lipid pool also declined significantly, indicating that it was the primary lipid used in larval development in L. elliptica. This was not unexpected, as TAG is a common storage lipid used by many marine invertebrates in larval development (Holmer, 1989; Kattner et al., 2003; Moran and Manahan, 2003; Falkner et al., 2015). Despite its classification as structural lipid class, the significant depletion of PL during development indicated it was used energetically in development (Kattner et al., 2003; Pernet et al., 2003b; Pernet et al., 2006). Similar to 
TAG, more than half of the original PL reserve remained at the D-larvae stage, indicating that it may also be a significant reserve for metamorphosis. However, it is unknown what proportion of the remaining reserve is available to be used energetically as PL is an important component of cell membranes (Fraser et al., 1988; Lee et al., 2006), some of the measured PL would have been performing a structural function in the larvae.

The small size of the wax ester pool in L. elliptica was unexpected, as it is commonly a dominant energetic lipid class in high latitude species (Lee et al., 2006). Wax esters are also important for metamorphosis and post-metamorphic development (Villinski et al., 2002). The size of the wax ester reserve did not change during development, indicating it may still be important later for metamorphosis.

The high proportion of the TAG and PL reserves that remained at the D-larval stage was surprising. However, these may be important for later metamorphosis (Holland and Spencer, 1973; Rodriguez et al., 1993). When larvae reach competency, they may delay metamorphosis in the absence of cues for settlement or in favour of searching for more suitable settlement sites (Pernet et al., 2003b). During this time, larvae would be able to use energetic reserves and continue shell development, resulting in larger larvae at settlement (Martel et al., 2014). The large reserves remaining in D-larvae in L. elliptica observed in this experiment, would allow for long periods of encapsulation, which have been observed in this species (see Peck et al., 2007a) in the absence of appropriate settlement cues. Additionally, large remaining reserves could benefit juvenile survival as they may be able to use remaining reserves once settled to prevent starvation under food limitation (Thiyagarajan et al., 2005), as well as to increase early growth rates (Emlet and Hoegh-Guldberg, 1997; Prowse et al., 2008). The large energetic reserves in L. elliptica eggs and larvae may flow on to benefit later life stages.

The large size of the remaining lipid pool in stressed larvae does not mean there are no added energetic or metabolic costs for the developmental changes observed under reduced $\mathrm{pH}$ and elevated temperatures in L. elliptica. Differing growth responses in larvae may have implications for the allocation of energy during development. Larvae that reach equivalent life stages at different sizes may be diverting energy away from somatic growth to processes of more immediate concern, such as mechanisms required for survival. Rather than significantly increasing lipid use, the larvae could have maintained a faster rate of development through the diversion of resources at the expense of other energetically costly 
activities, or may have used other energetic sources such as protein or carbohydrates, which are also common in marine larvae (Falkner et al., 2015; Holland and Spencer, 1973; Labarta et al., 1999). Larval body sizes (PI in Chapter 3) were smaller at elevated temperature. Possibly, the faster development was at the cost of reduced tissue growth. Reductions in the energy spent in these areas could result in smaller and weaker larvae at competency. However, when comparing lipid use to shell development in PII larvae, both shell growth and quality were improved under elevated temperature. If energy was diverted to aid in faster development at elevated temperature, it was not at the expense of shell growth.

A metabolic cost to development under elevated temperature may be shown by the observed changes in respiration rates (Chapter 4). Larval metabolic rates increased in response to small elevations in temperature (i.e. from $-1.7^{\circ} \mathrm{C}$ to $-0.5^{\circ} \mathrm{C}$ ). However, tolerance thresholds were low, as there was no further significant increase in rate after $-0.5^{\circ} \mathrm{C}$. This suggests early life history stages in L. elliptica may not be tolerant to future warming above $0.5^{\circ} \mathrm{C}$ (i.e. at 0.5 or $1.5^{\circ}$ ). At higher temperatures, oxygen delivery systems may be limited, which could impair function. During development, larvae rely on maternally provided energetic stores and therefore experience no added energetic costs in food capture. If this temperature sensitivity continues into the juvenile stages, once the larvae settle and can no longer rely on energetic reserves, activities such as calcification or later shell growth could be significantly reduced. The increase in respiration rate at elevated temperature appeared to be greater among reduced $\mathrm{pH}$ treatments, although the effect was not statistically significant.

Additionally, there may have been an energetic cost of calcification at reduced $\mathrm{pH}$. In early larval development in L. elliptica, before the onset of calcification, larvae appeared to benefit from reduced $\mathrm{pH}$, developing faster (Chapter 2). However, as soon as shell development started at the trochophore stage, developmental delays set in. This may have been related to the cost of maintaining $\mathrm{pH}$ at the site of calcification through the formation of bicarbonate or the removal of $\mathrm{H}^{+}$, or to the diversion of energetic resources away from calcification/shell maintenance (Roleda et al., 2012; Wicks and Roberts, 2012; Thomsen et al., 2015). Under OA, calcification may become energetically costly and an organism must respond by either reducing calcification or increasing the energetic input. The strategy for calcification in the larvae of L. elliptica is likely the former. Larval energy use showed no significant increase with reduced $\mathrm{pH}$ (Chapter 4), but shells in D-larvae developing under reduced $\mathrm{pH}$ were weaker and prone to breakage (Chapter 3). Additionally, larval body and 
shell shape were negatively impacted. Some of the damage observed may have been directly related to the dissolution of calcium carbonate due to the undersaturation of aragonite in reduced $\mathrm{pH}$ treatments, as pitting of the shell was observed. However, the fragility of the shell indicates that overall calcification was reduced, possibly resulting in a thinner shell, in addition to the observed dissolution. This implies that, despite the large energetic reserves available in the eggs of L. elliptica, larvae may respond to OA by reducing calcification rather than increasing the lipid use.

\subsubsection{Biodeposition}

Through lecithotrophy, adult invertebrates can prepare larvae for development in regions of seasonal or poor food supply by providing a sufficient reserve to sustain development through to competency (Lee et al., 2006). However, the nutrient supply in the egg may be dependent on the conditions experienced by the adult. Under stress, adults may need to increase energy intake to support higher metabolic rates (Parker et al., 2013). They may do this by altering feeding behaviours such as particle selection, or rates of ingestion, digestion and filtration (Bayne, 1998; Vargas et al., 2013). Alternatively, high metabolism may be supported by diverting energy to maintain critical function at the expense of growth or gametogenesis (Melzner et al., 2011). It is unknown how ocean change conditions will impact food availability and feeding behaviour in adult L. elliptica, which in turn would determine larval provisioning.

Reduced $\mathrm{pH}$ had no effect on the amount of biodeposits produced, the amounts of pseudofaeces and faeces, nor the organic components of any of the deposits (Chapter 5, Table 6.1). However, the pseudofaeces from the reduced $\mathrm{pH}$ treatments appeared larger and more translucent. Larval gastropods altered selection behaviours in response to reduced $\mathrm{pH}$, favouring smaller particles sizes that may have made handling easier (Vargas et al., 2013). In L. elliptica, an increased ingestion of particles in order to support higher metabolic rates would mean less food particles were being rejected in the pseudofaeces. Additionally, observations of increased mucous production have been made in suspension feeding bivalves exposed to very low $\mathrm{pH}$ ( $\mathrm{pH} 4$ and 5; Loayza-Muro and Elías-Letts, 2007). If a similar response occurred in L. elliptica, alongside reduced particle rejection, the large translucent appearance and constant organic weights may be explained by simultaneously higher mucous and lower particle content. 
Changes in metabolic rates have been observed in adults of this species in response to longer term exposure to reduced $\mathrm{pH}$ (Cummings et al., 2011), but rates following short term exposure are unknown. The lack of response in biodeposition to reduced $\mathrm{pH}$ indicates that if higher metabolic rates occur during short term exposure, the adults are not altering feeding behaviours to supply an increased energetic demand. This could indicate that adults tolerate reduced $\mathrm{pH}$ in the short term, with no change in metabolic rates. Alternatively, they may be supporting an increase in metabolic demand by diverting resources. If this behaviour continued with longer exposure to $\mathrm{pH}$ stress, this could impact reproduction and subsequent population growth, either by reducing the number of gametes produced by an individual or reducing the energetic reserves provided in the eggs. While reserves were sufficient for larval growth under stress in well supplied larvae, parental stress or $\mathrm{pH}$ exposure could reduce the overall reserve. However, longer term exposure to reduced $\mathrm{pH}$ in the adults is necessary to see if changes in feeding behaviour occur alongside changing metabolic responses, and how this could impact larval provisioning.

\subsection{Future Directions}

Through this series of experiments, a basic understanding has been developed of the responses of L. elliptica larvae to environmental stress. However, there are still significant gaps in understanding how future populations will be impacted. As previously mentioned, any positive, negative or neutral impacts of temperature or $\mathrm{pH}$ stress experienced by the larvae will flow-on to later stages during metamorphosis and settlement, and to the greater population. There is no information surrounding settlement in this species, except that juveniles appear in sediments in the months following spawning (Bosch and Pearse, 1988). In order to gain a better understanding of how changes in larval development timing and energy use will flow on to the later life stages, we will need to know what triggers metamorphosis in this species, and how those cues may be impacted by stressors. The determination of biological cues may be difficult, particularly if they are a combination of interactive factors such as temperature, substrate conditions, bacterial biofilms and biochemical cues from predators or prey (Hadfield and Paul, 2001; Bowden, 2005). Information on settlement cues in other Laternulid or Antarctic benthic species is limited, making it difficult to infer what cues in L. elliptica may be. Bacteria may play a strong role in settlement cues for soft sediment dwelling invertebrate species (Hadfield and Paul, 2001). By studying local conditions, such as phytoplankton species and abundances, sediment saturation states and 
bacterial content, and localised temperature around the time juveniles begin appearing in the sediments in different populations, potential cues may be determined or eliminated. These potential cues could then be tested on L. elliptica D-larvae in a laboratory setting.

While reduced $\mathrm{pH}$ and elevated temperatures are important stressors to consider in the context of larval development in high latitude molluscs, these are not the only stressors larvae would face. Larvae may also experience alterations in salinity, sea ice extent, water column stratification, oxygen saturation, and water circulation (Arrigo and Thomas, 2004; Doney et al., 2012; IPCC, 2013). In addition to these climate change related stressors, early life stages may also experience high rates of mortality due to predation, UV exposure, low nutrition, disease, internal defects or the inability to find suitable settlement sites (Gosselin and Qian, 1997; Lamare and Barker, 1999; Pedersen et al., 2008). Natural mortality rates in larvae and juveniles may be significantly high in marine invertebrates (Gosselin and Qian, 1997). Larvae in these experiments were raised under relatively ideal conditions, in order to isolate effects from reduced $\mathrm{pH}$ and elevated temperature. Gaining a better understanding of the natural larval mortality rates for this species, or what proportion of spawned gametes successfully settle, would allow for a better interpretation of how negative effects will impact the greater population (Guy et al., 2014).

Additionally, more work is needed to understand how future ocean changes will impact larval development and recruitment in this species. For instance, lipids are not the only important component of larval energetics. Protein is a major energetic reserve in adult $L$. elliptica (Brockington, 2001; Ahn et al., 2003), and it is often a major reserve in the larvae of other species as it may be used to build functional body structures (Labarta et al., 1999; Byrne et al., 2008a; Byrne et al., 2008b; Prowse et al., 2008; Falkner et al., 2015). In some bivalves, protein is an important energy source in later larval development, particularly in metamorphosis (Labarta et al., 1999; Lu et al., 1999). The importance of protein and its use in the larval development of L. elliptica is unknown. However, larvae from the same experiment as that used for the lipid extraction in Chapter 4 were set aside for analysis. Whether proteins form an important part of larval energetic stores alongside lipids, and whether they have similar responses to stress will be considered in a future study in 2016.

Acclimation periods are not necessarily a concern in fertilisation and larval development studies as larvae do not experience an abrupt change in external condition when fertilised under experimental conditions. However, these experiments are unable to account for 
maternal experience during gametogenesis. Shifts in tolerance beyond natural thresholds requires genetic adaptation (Pörtner 2010). The conditions experienced during gametogenesis may influence larval responses to stressors (Sunday et al., 2011; Parker et al., 2015). Gametes in these experiments were sourced from adults that performed gametogenesis in the wild under current ambient environmental conditions, which may have influenced the observed effects on larvae in these experiments. For example, adults of invertebrate species that are well fed during gametogenesis may provide larvae with better reserves, or may produce greater gamete numbers (Minor and Scheibling, 1997; Poorbagher et al., 2010). Alternatively, exposing adults to stressful conditions led to improved responses in subsequent generations in fish (Miller et al., 2009; Schade et al., 2014), copepods (Vehmaa et al., 2012) and oysters (Parker et al., 2012; Parker et al., 2015). A similar effect may have been responsible for some of the observed differences in L. elliptica development. It would be interesting to see how maternal experience in L. elliptica influences stress responses in their larvae. By exposing recently spawned L. elliptica to $\mathrm{pH}$ and temperature stress, as well as different food regimes for a full gametogenic cycle this may be better understood. Carry-over effects could be observed by examining egg numbers, energetic provisioning and subsequent larval development under stress.

Variations between adult populations of L. elliptica have been observed, such as altered shell thickness dependent on local ice movements (Harper et al., 2012), higher levels of oxidative stress in regions with greater anthropogenic impacts (Lister et al., 2005), as well as differences in thermal tolerance, suggesting adaptive potential within this species (Morley et al., 2012a, Waller et al., 2016). Since the environmental conditions typically experienced by an individual influences tolerance to stressors (Pörtner, 2002a), differences in the baseline conditions between sites may have influenced larval performance through adaptation by the adults. Performing the same experiments on larvae from adults from different populations, collected around the same time would help determine how population experience may influence larval tolerances. Different responses may give a better indication of the future of the species as recruitment from more variable environments could aid species persistence under climate change conditions.

\subsection{Conclusions}

Survival of a species under stressful conditions is not determined solely by resistance in the individual adult, but rather the ability of the species to persist under pressure. In order to 
survive unfavourable conditions, species must outlast, move away from or adapt to detrimental conditions (Peck 2005). Adaptation occurs through genetic recombination in reproduction and allows an organism to expand or shift its ideal range of physiological conditions to fit around the changed environment (Peck, 2005). Genetic recombination allows the rise of tolerant phenotypes in responses to stress, however this is largely dependent on the phenotypic and genetic variation present within a population, as well as generation time (Sunday et al., 2011). Long term responses to climate change conditions will be dependent on adaptive potential, which may be limited in organisms from historically stable environments or with long generation times relative to the rate of environmental change (Pörtner, 2010; Matson et al., 2012; Kelly and Hofmann, 2013). A species that cannot produce or fertilise gametes or recruit larvae under adversity will not be able to adapt to unfavourable environmental conditions. Therefore, the development of phenotypes tolerant to projected climate conditions will be partly dependent on larval responses to these conditions.

Under elevated temperature alone, improvements in population size could be expected in L. elliptica. Higher initial fertilisation, faster development rates with no real change in lipid use, as well as reductions in abnormalities indicate that larger numbers of larvae will be competent sooner after fertilisation. Larvae will be able to either settle faster, reducing time spent in vulnerable larval stages or they will be able to use remaining reserves to spend more time growing, resulting in larger sizes of the juveniles at settlement, which could reduce juvenile mortality. However, this would be dependent on the scale of the warming. Respiration rates indicate that temperature tolerance thresholds in the larvae are low, particularly compared to adults. Following an initial increase in respiration rate with a temperature elevation to $-0.5^{\circ} \mathrm{C}$ from ambient, $\left(-1.6^{\circ} \mathrm{C}\right)$, larvae appeared to be unable to compensate for further elevations in temperature. There appears to be an optimum temperature around $-0.5^{\circ} \mathrm{C}$. At this point the development rates were faster, and abnormalities and shell quality scores were better than larvae at control or higher temperatures.

Faster development may better prepare larvae for settlement; however, the impacts of reduced $\mathrm{pH}$ may overwhelm the positive implications of elevated temperature. Reduced shell integrity and larval sizes could have significant implications for population survival. At $\mathrm{pH}$ 7.65 , at both elevated temperatures in the Chapter 2 experiment $\left(-0.5\right.$ and $\left.0.4^{\circ} \mathrm{C}\right)$, initial fertilisation rates were higher, development was faster and PII shell growth was greater compared to larvae in control conditions ( $\mathrm{pH} 7.98$ and $-1.6^{\circ} \mathrm{C}$ ). These results alone would indicate an overall benefit to development in L. elliptica under future ocean conditions with 
greater numbers of larger larvae reaching competency sooner. However, there are indications that the larvae may be disadvantaged. Larval sizes at PI were smaller compared to those at control conditions. While larvae did not alter the use of energetic reserves in responses, the smaller size may indicate that under stressful conditions, less larval body development occurs with similar lipid use. Additionally, larvae from the stressed treatments had higher occurrences of shell malformation and abnormalities as well as reduced shell integrity. Reduced shell integrity could significantly influence mortality rates in settlement.

Maternal provisioning in the larvae is sufficient for development up to metamorphosis; however, after metamorphosis juveniles are reliant on their ability to capture available food. Large reserves may have supported metabolic changes in development, resulting in faster growth and larger shells, but the energetic demands of maintaining alternative pathways may not be supported in juveniles.

Overall, impacts of reduced $\mathrm{pH}$ and elevated temperatures on the larvae of L. elliptica were sub-lethal. However, the observed effects will have considerable consequence for later life stages. Exposure to reduced $\mathrm{pH}$ and elevated temperatures does not end when larvae metamorphose and settle. At higher temperatures, juveniles may experience metabolic depression. Energetic activities such as food selection may not be supported, leading to reduced condition and somatic growth and even mortalities. The reduced larval condition observed with $\mathrm{pH}$ stress would lead to reduced populations of juveniles with weak and malformed shells. Even with slightly larger larval numbers and faster development, an overall population decline would occur as juveniles fail in settlement, which could have significant connotations for the benthic environments in which they are prevalent. 


\section{References}

Addadi, L., Raz, S., Weiner, S., 2003. Taking advantage of disorder: amorphous calcium carbonate and its roles in biomineralization. Advanced Materials 15, 959-970.

Ahn, I.-Y., 1993. Enhanced particle flux through the biodeposition by the Antarctic suspension-feeding bivalve Laternula elliptica in Marian Cove, King George Island. Journal of Experimental Marine Biology and Ecology 171, 75-90.

Ahn, I.-Y., 1994. Ecology of the Antarctic bivalve Laternula elliptica (King and Broderip) in Collins Harbor, King George Island: Benthic environment and an adaptive strategy. Memoirs of National Institute of Polar Research. Special issue 50, 1-10.

Ahn, I.-Y., Kang, J.-S., Kang, S.-H., 1993. Primary food sources for shallow-water benthic fauna in Marian Cove, King George Island during an austral summer. Korean Journal of Polar Research 4, 67-72.

Ahn, I.-Y., Kang, J., Kim, K.-W., 2001. The effect of body size on metal accumulations in the bivalve Laternula elliptica. Antarctic Science 13, 355-362.

Ahn, I.-Y., Shim, J.H., 1998. Summer metabolism of the Antarctic clam, Laternula elliptica (King and Broderip) in Maxwell Bay, King George Island and its implications. Journal of Experimental Marine Biology and Ecology 224, 253-264.

Ahn, I.-Y., Surh, J., Park, Y.-G., Kwon, H., Choi, K.-S., Kang, S.-H., Choi, H.J., Kim, K.-W., Chung, H., 2003. Growth and seasonal energetics of the Antarctic bivalve Laternula elliptica from King George Island, Antarctica. Marine Ecology Progress Series 257, 99-110.

Ahn, I.-Y., Woong Cho, K., Choi, K.-S., Seo, Y., Shin, J., 2000. Lipid content and composition of the Antarctic lamellibranch, Laternula elliptica (King \& Broderip) (Anomalodesmata: Laternulidae), in King George Island during an austral summer. Polar Biology 23, 24-33.

Allen, W., 1976. Biochemical aspects of lipid storage and utilization in animals. American Zoologist 16, 631-647.

Andersen, S., Grefsrud, E.S., Harboe, T., 2013. Effect of increased $p \mathrm{CO}_{2}$ on early shell development in great scallop (Pecten maximus Lamarck) larvae. Biogeosciences Discussions 10, 3281-3310.

Ansell, A.D., Harvey, R., 1997. Protected larval development in the Antarctic bivalve Laternula elliptica (King and Broderip) (Anomalodesmata: Laternulidae). Journal of Molluscan Studies 63, 109-111.

Ansell, A.D., Rhodes, M.C., 1997. Unusual capabilities for surface movement in a normally deep-burrowed Antarctic bivalve. Journal of Molluscan Studies 63, 109-111.

Arnberg, M., Calosi, P., Spicer, J.I., Tandberg, A.H.S., Nilsen, M., Westerlund, S., Bechmann, R.K., 2013. Elevated temperature elicits greater effects than decreased $\mathrm{pH}$ on the 
development, feeding and metabolism of northern shrimp (Pandalus borealis) larvae. Marine Biology 160, 2037-2048.

Arrigo, K.R., Thomas, D.N., 2004. Large scale importance of sea ice biology in the Southern Ocean. Antarctic Science 16, 471-486.

Bamber, R., 1990. The effects of acidic seawater on three species of lamellibranch mollusc. Journal of Experimental Marine Biology and Ecology 143, 181-191.

Bamber, R.N., 1987. The effects of acidic sea water on young carpet-shell clams Venerupis decussata (L.) (Mollusca: Veneracea). Journal of Experimental Marine Biology and Ecology 108, 241-260.

Barrera, E., Tevesz, M.J.S., Carter, J.G., McCall, P.L., 1994. Oxygen and carbon isotopic composition and shell microstructure of the bivalve Laternula elliptica from Antarctica. PALAIOS 9, 275-287.

Barros, P., Sobral, P., Range, P., Chícharo, L., Matias, D., 2013. Effects of sea-water acidification on fertilization and larval development of the oyster Crassostrea gigas. Journal of Experimental Marine Biology and Ecology 440, 200-206.

Bayne, B., 1971. Some morphological changes that occur at the metamorphosis of the larvae of Mytilus edulis. Fourth European Marine Biology Symposium, 259-280.

Bayne, B., 1998. The physiology of suspension feeding by bivalve molluscs: an introduction to the Plymouth "TROPHEE" workshop. Journal of Experimental Marine Biology and Ecology 219, 1-19.

Bayne, B., Hawkins, A., Navarro, E., 1988. Feeding and digestion in suspension-feeding bivalve molluscs: the relevance of physiological compensations. American Zoologist 28, 147159.

Bechmann, R.K., Taban, I.C., Westerlund, S., Godal, B.F., Arnberg, M., Vingen, S., Ingvarsdottir, A., Baussant, T., 2011. Effects of ocean acidification on early life stages of shrimp (Pandalus borealis) and mussel (Mytilus edulis). Journal of Toxicology and Environmental Health, Part A 74, 424-438.

Bednaršek, N., Tarling, G.A., Bakker, D.C., Fielding, S., Feely, R.A., 2014. Dissolution dominating calcification process in polar pteropods close to the point of aragonite undersaturation. PLOS ONE 9, e109183

Beniash, E., Ivanina, A.V., Lieb, N.S., Kurochkin, I., Sokolova, I.M., 2010. Elevated level of carbon dioxide affects metabolism and shell formation in oysters Crassostrea virginica. Marine Ecology Progress Series 419, 95-108.

Berge, J.A., Bjerkeng, B., Pettersen, O., Schaanning, M.T., Øxnevad, S., 2006. Effects of increased sea water concentrations of $\mathrm{CO}_{2}$ on growth of the bivalve Mytilus edulis L. Chemosphere 62, 681-687.

Bergelson, L.D., 1980. Lipid Biochemical Preperations. Elsevier/North Holland Biomedical Press, Amsterdam. 
Berkman, P.A., Waller, T.R., Alexander, S.P., 1991. Unprotected larval development in the Antarctic scallop Adamussium colbecki (Mollusca: Bivalvia: Pectinidae). Antarctic Science 3, 151-157.

Berridge, M.J., 1984. Inositol trisphosphate and diacylglycerol as second messengers. Biochemical Journal 220, 345.

Bigatti, G., Penchaszadeh, P., Mercuri, G., 2001. Aspects of the gonadal cycle in the Antarctic bivalve Laternula elliptica. Journal of Shellfish Research 20, 283-287.

Bosch, I., Pearse, J., 1988. Seasonal pelagic development and juvenile recruitment of the bivalve Laternula elliptica in McMurdo Sound, Antarctica. American Zoologist 28, A89A89.

Bowden, D.A., 2005. Seasonality of recruitment in Antarctic sessile marine benthos. Marine Ecology Progress Series 297, 101-118.

Brey, T., Voigt, M., Jenkins, K., Ahn, I.-Y., 2011. The bivalve Laternula elliptica at King George Island - A biological recorder of climate forcing in the West Antarctic Peninsula region. Journal of Marine Systems 88, 542-552.

Brockington, S., 2001. The seasonal energetics of the Antarctic bivalve Laternula elliptica (King and Broderip) at Rothera Point, Adelaide Island. Polar Biology 24, 523-530.

Byers, J.E., Pringle, J.M., 2006. Going against the flow: retention, range limits and invasions in advective environments. Marine Ecology Progress Series 313, 27-41.

Bylenga, C.H., Cummings, V.J., Ryan, K.G., 2015. Fertilisation and larval development in the Antarctic bivalve, Laternula elliptica, under reduced $\mathrm{pH}$ and elevated temperatures. Marine Ecology Progress Series 536, 187-201.

Byrne, M., 2011. Impact of ocean warming and ocean acidification on marine invertebrate life history stages: Vulnerabilities and potential for persistence in a changing ocean. Oceanography and Marine Biology: An Annual Review 49, 1-42.

Byrne, M., Ho, M., Selvakumaraswamy, P., Nguyen, H.D., Dworjanyn, S.A., Davis, A.R., 2009. Temperature, but not $\mathrm{pH}$, compromises sea urchin fertilization and early development under near-future climate change scenarios. Proceedings of the Royal Society B: Biological Sciences 276, 1883-1888.

Byrne, M., Ho, M., Wong, E., Soars, N.A., Selvakumaraswamy, P., Shepard-Brennand, H., Dworjanyn, S.A., Davis, A.R., 2011. Unshelled abalone and corrupted urchins: development of marine calcifiers in a changing ocean. Proceedings of the Royal Society B: Biological Sciences 278, 2376-2383.

Byrne, M., Ho, M.A., Koleits, L., Price, C., King, C.K., Virtue, P., Tilbrook, B., Lamare, M., 2013a. Vulnerability of the calcifying larval stage of the Antarctic sea urchin Sterechinus neumayeri to near-future ocean acidification and warming. Global Change Biology 19, 22642275. 
Byrne, M., Lamare, M., Winter, D., Dworjanyn, S.A., Uthicke, S., 2013b. The stunting effect of a high $\mathrm{CO}_{2}$ ocean on calcification and development in sea urchin larvae, a synthesis from the tropics to the poles. Philosophical Transactions of the Royal Society B 368, 20120439

Byrne, M., Prowse, T., Sewell, M., Dworjanyn, S., Williamson, J., Vaitilingon, D., 2008a. Maternal provisioning for larvae and larval provisioning for juveniles in the toxopneustid sea urchin Tripneustes gratilla. Marine Biology 155, 473-482.

Byrne, M., Sewell, M., Prowse, T., 2008b. Nutritional ecology of sea urchin larvae: influence of endogenous and exogenous nutrition on echinopluteal growth and phenotypic plasticity in Tripneustes gratilla. Functional Ecology 22, 643-648.

Caldeira, K., Wickett, M.E., 2003. Oceanography: anthropogenic carbon and ocean pH. Nature 425, 365-365.

Calvin, K., Edmonds, J., Bond-Lamberty, B., Clarke, L., Kim, S.H., Kyle, P., Smith, S.J., Thomson, A., Wise, M., 2009. 2.6: Limiting climate change to $450 \mathrm{ppm} \mathrm{CO}_{2}$ equivalent in the 21st century. Energy Economics 31, Supplement 2, S107-S120.

Canavoso, L.E., Wells, M.A., 2000. Metabolic pathways for diacylglycerol biosynthesis and release in the midgut of larval Manduca sexta. Insect biochemistry and molecular biology 30, $1173-1180$.

Carriker, M.R., 1950. Killing and Preservation of Bivalve Larvae in Fluids. The Nautilus 64, 14-17.

Carriker, M.R., 1996. The shell and ligament, in: Kennedy, V.S., Newell, R.I.E., Eble, A.F. (Eds.), The Eastern Oyster: Crassostrea virginica. Maryland Sea Grant, pp. 75-168.

Catarino, A.I., De Ridder, C., Gonzalez, M., Gallardo, P., Dubois, P., 2012. Sea urchin Arbacia dufresnei (Blainville 1825) larvae response to ocean acidification. Polar Biology 35, 455-461.

Clark, D., Lamare, M., Barker, M., 2009. Response of sea urchin pluteus larvae (Echinodermata: Echinoidea) to reduced seawater $\mathrm{pH}$ : a comparison among a tropical, temperate, and a polar species. Marine Biology 156, 1125-1137.

Clark, M., Fraser, K., Peck, L., 2008. Antarctic marine molluscs do have an HSP70 heat shock response. Cell Stress and Chaperones 13, 39-49.

Clark, M., Thorne, M., Burns, G., Peck, L., 2016. Age-related thermal response: the cellular resilience of juveniles. Cell Stress and Chaperones, 21 (75-85).

Clark, M.S., Husmann, G., Thorne, M.A., Burns, G., Truebano, M., Peck, L.S., Abele, D., Philipp, E.E., 2013. Hypoxia impacts large adults first: consequences in a warming world. Global Change Biology 19, 2251-2263.

Clarke, A., 1982. Temperature and embryonic development in polar marine invertebrates. International Journal of Invertebrate Reproduction 5, 71-82.

Cohen, A.L., McCorkle, D.C., de Putron, S., Gaetani, G.A., Rose, K.A., 2009. Morphological and compositional changes in the skeletons of new coral recruits reared in acidified seawater: 
Insights into the biomineralization response to ocean acidification. Geochemistry, Geophysics, Geosystems 10, Q07005.

Comeau, S., Alliouane, S., Gattuso, J., 2012a. Effects of ocean acidification on overwintering juvenile Arctic pteropods Limacina helicina. Marine Ecology Progress Series 456, 279-284.

Comeau, S., Gattuso, J.-P., Nisumaa, A.-M., Orr, J., 2012b. Impact of aragonite saturation state changes on migratory pteropods. Proceedings of the Royal Society of London B: Biological Sciences 279, 732-738.

Crim, R.N., Sunday, J.M., Harley, C.D., 2011. Elevated seawater $\mathrm{CO}_{2}$ concentrations impair larval development and reduce larval survival in endangered northern abalone (Haliotis kamtschatkana). Journal of Experimental Marine Biology and Ecology 400, 272-277.

Cummings, V., Hewitt, J., Van Rooyen, A., Currie, K., Beard, S., Thrush, S., Norkko, J., Barr, N., Heath, P., Halliday, N.J., Sedcole, R., Gomez, A., McGraw, C., Metcalf, V., 2011. Ocean acidification at high latitudes: potential effects on functioning of the Antarctic bivalve Laternula elliptica. PLoS ONE 6, e16069.

Davenport, J., 1992. Animal life at low temperature, 1 ed. Springer Science \& Business Media.

Davis, A.R., Coleman, D., Broad, A., Byrne, M., Dworjanyn, S.A., Przeslawski, R., 2013. Complex responses of intertidal molluscan embryos to a warming and acidifying ocean in the presence of UV radiation. PLOS ONE 8, e55939.

DeFreese, D.E., Clark, K.B., 1983. Analysis of reproductive energetics of Florida Opisthobranchia (Mollusca: Gastropoda). International Journal of Invertebrate Reproduction 6, 1-10.

Dickson, A., Millero, F., 1987. A comparison of the equilibrium constants for the dissociation of carbonic acid in seawater media. Deep Sea Research Part A. Oceanographic Research Papers 34, 1733-1743.

Doney, S.C., Fabry, V.J., Feely, R.A., Kleypas, J.A., 2009. Ocean acidification: the other $\mathrm{CO}_{2}$ problem. Annual Review of Marine Science 1, 169-192.

Doney, S.C., Ruckelshaus, M., Duffy, J.E., Barry, J.P., Chan, F., English, C.A., Galindo, H.M., Grebmeier, J.M., Hollowed, A.B., Knowlton, N., 2012. Climate change impacts on marine ecosystems. Annual Review of Marine Science 4, 11-37.

Dorey, N., Melzner, F., Martin, S., Oberhänsli, F., Teyssié, J.-L., Bustamante, P., Gattuso, J.P., Lacoue-Labarthe, T., 2013. Ocean acidification and temperature rise: effects on calcification during early development of the cuttlefish Sepia officinalis. Marine Biology 160, 2007-2022.

Dove, M.C., Sammut, J., 2007. Histological and feeding response of Sydney rock oysters, Saccostrea glomerata, to acid sulfate soil outflows. Journal of Shellfish Research 26, 509518. 
Dupont, S., Dorey, N., Stumpp, M., Melzner, F., Thorndyke, M., 2013. Long-term and translife-cycle effects of exposure to ocean acidification in the green sea urchin Strongylocentrotus droebachiensis. Marine Biology 160, 1835-1843.

Dupont, S., Lundve, B., Thorndyke, M., 2010. Near future ocean acidification increases growth rate of the lecithotrophic larvae and juveniles of the sea star Crossaster papposus. Journal of Experimental Zoology Part B: Molecular and Developmental Evolution 314, 382389.

Ellis, R.P., Bersey, J., Rundle, S.D., Hall-Spencer, J.M., Spicer, J.I., 2009. Subtle but significant effects of $\mathrm{CO}_{2}$ acidified seawater on embryos of the intertidal snail, Littorina obtusata. Aquatic Biology 5, 41-48.

Emlet, R.B., Hoegh-Guldberg, O., 1997. Effects of egg size on postlarval performance: experimental evidence from a sea urchin. Evolution 51, 141-152.

Emlet, R.B., Sadro, S.S., 2006. Linking stages of life history: how larval quality translates into juvenile performance for an intertidal barnacle (Balanus glandula). Integrative and Comparative Biology 46, 334-346.

Ericson, J.A., Ho, M.A., Miskelly, A., King, C.K., Virtue, P., Tilbrook, B., Byrne, M., 2012. Combined effects of two ocean change stressors, warming and acidification, on fertilization and early development of the Antarctic echinoid Sterechinus neumayeri. Polar Biology 35, $1027-1034$.

Ericson, J.A., Lamare, M.D., Morley, S.A., Barker, M.F., 2010. The response of two ecologically important Antarctic invertebrates (Sterechinus neumayeri and Parborlasia corrugatus) to reduced seawater $\mathrm{pH}$ : effects on fertilisation and embryonic development. Marine Biology 157, 2689-2702.

Eyster, L.S., Morse, M.P., 1984. Early shell formation during molluscan embryogenesis, with new studies on the surf clam, Spisula solidissima. American Zoologist 24, 871-882.

Fabry, V.J., Seibel, B.A., Feely, R.A., Orr, J.C., 2008. Impacts of ocean acidification on marine fauna and ecosystem processes. ICES Journal of Marine Science: Journal du Conseil 65, 414-432.

Falkner, I., Byrne, M., Sewell, M.A., 2006. Maternal provisioning in Ophionereis fasciata and $O$. schayeri: brittle stars with contrasting modes of development. The Biological Bulletin 211, 204-207.

Falkner, I., Sewell, M.A., Byrne, M., 2015. Evolution of maternal provisioning in ophiuroid echinoderms: characterisation of egg composition in planktotrophic and lecithotrophic developers. Marine Ecology Progress Series 525, 1-13.

Feely, R.A., Sabine, C.L., Lee, K., Berelson, W., Kleypas, J., Fabry, V.J., Millero, F.J., 2004. Impact of anthropogenic $\mathrm{CO}_{2}$ on the $\mathrm{CaCO}_{3}$ system in the oceans. Science 305, 362-366.

Fernández-Reiriz, M.J., Range, P., Álvarez-Salgado, X.A., Labarta, U., 2011. Physiological energetics of juvenile clams Ruditapes decussatus in a high $\mathrm{CO}_{2}$ coastal ocean. Marine Ecology Progress Series 433, 97-105. 
Fischedick, M., Schaeffer, R., Adedoyin, A., Akai, M., Bruckner, T., Clarke, L., Krey, V., Savolainen, I., Teske, S., Ürge-Vorsatz, D., Wright, R., 2011. Mitigation Potential and Costs, in: Edenhofer, O., Pichs-Madruga, R., Sokona, Y., Seyboth, K., Kadner, S., Zwickel, T., Eickemeier, P., Hansen, G., Schlömer, S., von Stechow, C. (Eds.), Renewable Energy Sources and Climate Change Mitigation: Special Report of the Intergovernmental Panel on Climate Change. Cambridge University Press, Cambridge, United Kingdom and New York, NY, USA, pp. 791-864.

Flynn, E.E., Bjelde, B.E., Miller, N.A., Todgham, A.E., 2015. Ocean acidification exerts negative effects during warming conditions in a developing Antarctic fish. Conservation Physiology 3, cov033.

Foo, S.A., Dworjanyn, S.A., Poore, A.G., Byrne, M., 2012. Adaptive capacity of the habitat modifying sea urchin Centrostephanus rodgersii to ocean warming and ocean acidification: performance of early embryos. PLoS ONE 7, e42497-e42497.

Fraser, A., Gamble, J., Sargent, J., 1988. Changes in lipid content, lipid class composition and fatty acid composition of developing eggs and unfed larvae of cod (Gadus morhua). Marine Biology 99, 307-313.

Fraser, A.J., 1989. Triacylglycerol content as a condition index for fish, bivalve, and crustacean larvae. Canadian Journal of Fisheries and Aquatic Sciences 46, 1868-1873.

Gaylord, B., Hill, T.M., Sanford, E., Lenz, E.A., Jacobs, L.A., Sato, K.N., Russell, A.D., Hettinger, A., 2011. Functional impacts of ocean acidification in an ecologically critical foundation species. Journal of Experimental Biology 214, 2586-2594.

Gazeau, F., Parker, L.M., Comeau, S., Gattuso, J.-P., O’Connor, W.A., Martin, S., Pörtner, H.-O., Ross, P.M., 2013. Impacts of ocean acidification on marine shelled molluscs. Marine Biology 160, 2207-2245.

Gazeau, F., Quiblier, C., Jansen, J.M., Gattuso, J.P., Middelburg, J.J., Heip, C.H., 2007. Impact of elevated $\mathrm{CO}_{2}$ on shellfish calcification. Geophysical Research Letters 34, L07603.

Gobler, C., Talmage, S., 2013. Short-and long-term consequences of larval stage exposure to constantly and ephemerally elevated carbon dioxide for marine bivalve populations. Biogeosciences 10, 2241-2253.

Gonzalez-Bernat, M.J., Lamare, M., Barker, M., 2013. Effects of reduced seawater pH on fertilisation, embryogenesis and larval development in the Antarctic seastar Odontaster validus. Polar Biology 36, 235-247.

Gooding, R.A., Harley, C.D., Tang, E., 2009. Elevated water temperature and carbon dioxide concentration increase the growth of a keystone echinoderm. Proceedings of the National Academy of Sciences 106, 9316-9321.

Gosselin, L., Qian, P.-Y., 1996. Early post-settlement mortality of an intertidal barnacle: a critical period for survival. Marine Ecology Progress Series 135, 69-75.

Gosselin, L.A., Qian, P.-Y., 1997. Juvenile mortality in benthic marine invertebrates. Marine Ecology Progress Series 146, 265-282. 
Green, M.A., Waldbusser, G.G., Hubazc, L., Cathcart, E., Hall, J., 2013. Carbonate mineral saturation state as the recruitment cue for settling bivalves in marine muds. Estuaries and coasts 36, 18-27.

Green, M.A., Waldbusser, G.G., Reilly, S.L., Emerson, K., 2009. Death by dissolution: sediment saturation state as a mortality factor for juvenile bivalves. Limnology and Oceanography 54, 1037-1047.

Gutowska, M.A., Melzner, F., Pörtner, H.O., Meier, S., 2010. Cuttlebone calcification increases during exposure to elevated seawater $p \mathrm{CO}_{2}$ in the cephalopod Sepia officinalis. Marine Biology 157, 1653-1663.

Guy, C.I., Cummings, V.J., Lohrer, A.M., Gamito, S., Thrush, S.F., 2014. Population trajectories for the Antarctic bivalve Laternula elliptica: identifying demographic bottlenecks in differing environmental futures. Polar Biology 37, 541-553.

Hadfield, M.G., Paul, V.J., 2001. Natural chemical cues for settlement and metamorphosis of marine invertebrate larvae, in: McClintock, J.B., Baker, B. (Eds.), Marine Chemical Ecology. CRC Press, Boca Raton, FL, pp. 431-461.

Hall-Spencer, J.M., Rodolfo-Metalpa, R., Martin, S., Ransome, E., Fine, M., Turner, S.M., Rowley, S.J., Tedesco, D., Buia, M.-C., 2008. Volcanic carbon dioxide vents show ecosystem effects of ocean acidification. Nature 454, 96-99.

Hammer, K.M., Kristiansen, E., Zachariassen, K.E., 2011. Physiological effects of hypercapnia in the deep-sea bivalve Acesta excavata (Fabricius, 1779)(Bivalvia; Limidae). Mar Environ Res 72, 135-142.

Hardy, P., 1972. Biomass estimates for some shallow-water infaunal communities at Signy Island, South Orkney Islands. British Antarctic Survey Bulletin 31, 93-106.

Harper, E.M., Clark, M.S., Hoffman, J.I., Philipp, E.E., Peck, L.S., Morley, S.A., 2012. Iceberg scour and shell damage in the Antarctic bivalve Laternula elliptica. PLoS ONE 7, e46341.

Havenhand, J., Schlegel, P., 2009. Near-future levels of ocean acidification do not affect sperm motility and fertilization kinetics in the oyster Crassostrea gigas. Biogeosciences $\mathbf{6}$, 3009-3015.

Hawkins, A., Smith, R., Bayne, B., Heral, M., 1996. Novel observations underlying the fast growth of suspension-feeding shellfish in turbid environments: Mytilus edulis. Marine Ecology Progress Series 131, 179-190.

Hégaret, H., Wikfors, G.H., Shumway, S.E., 2007. Diverse feeding responses of five species of bivalve mollusc when exposed to three species of harmful algae. Journal of Shellfish Research 26, 549-559.

Heise, K., Puntarulo, S., Pörtner, H.O., Abele, D., 2003. Production of reactive oxygen species by isolated mitochondria of the Antarctic bivalve Laternula elliptica (King and Broderip) under heat stress. Comparative Biochemistry and Physiology Part C: Toxicology \& Pharmacology 134, 79-90. 
Hempel, S.M.E., 2016. The functional response of the Antarctic bivalve, Laternula elliptica to ocean warming and acidification. Master's Thesis, School of Biological Sciences. Victoria University of Wellington.

Hendler, G., 1982. Laternula elliptica. Smithsonian National Museum of Natural History Antarctic Invertebrates Collection.

Higgins, F.A., Bates, A.E., Lamare, M.D., 2012. Heat tolerance, behavioural temperature selection and temperature-dependent respiration in larval Octopus huttoni. Journal of Thermal Biology 37, 83-88.

Ho, M.A., Price, C., King, C.K., Virtue, P., Byrne, M., 2013. Effects of ocean warming and acidification on fertilization in the Antarctic echinoid Sterechinus neumayeri across a range of sperm concentrations. Marine Environmental Research 90, 136-141.

Hofmann, G.E., Smith, J.E., Johnson, K.S., Send, U., Levin, L.A., Micheli, F., Paytan, A., Price, N.N., Peterson, B., Takeshita, Y., 2011. High-frequency dynamics of ocean pH: a multi-ecosystem comparison. PLoS ONE 6, e28983.

Holland, D., 1978. Lipid reserves and energy metabolism in the larvae of benthic marine invertebrates. Biochemical and Biophysical Perspectives in Marine Biology 4, 85-123.

Holland, D., Gabbott, P., 1971. A micro-analytical scheme for the determination of protein, carbohydrate, lipid and RNA levels in marine invertebrate larvae. Journal of the Marine Biological Association of the United Kingdom 51, 659-668.

Holland, D., Spencer, B., 1973. Biochemical changes in fed and starved oysters, Ostrea edulis L. during larval development, metamorphosis and early spat growth. Journal of the Marine Biological Association of the United Kingdom 53, 287-298.

Holmer, G., 1989. Triacylglycerols, in: Ackman, R.G. (Ed.), Marine biogenic lipids, fats and oils. CRC Press, Boca Raton, FL, pp. 139-174.

Houghton, J., Ding, Y., Griggs, D., Noguer, M., Van der Linden, P., Dai, X., Maskell, K., Johnson, C., 2001. IPCC 2001: Climate Change 2001. The Climate change Contribution of Working Group I to the Third Assessment Report of the Intergovemmental Panel on Climate Change 159.

Husmann, G., Abele, D., Monien, D., Monien, P., Kriews, M., Philipp, E., 2012. The influence of sedimentation on metal accumulation and cellular oxidative stress markers in the Antarctic bivalve Laternula elliptica. Estuarine, Coastal and Shelf Science 111, 48-59.

Husmann, G., Phillip, E., Abele, D., 2016. Seasonal proliferation rates and the capacity to express genes involved in cell cycling and maintenance in response to seasonal and experimental food shortage in Laternula elliptica from King George Island. Marine Environemntal Resarch 118, 57-68.

Husmann, G., Philipp, E., Rosenstiel, P., Vazquez, S., Abele, D., 2011. Immune response of the Antarctic bivalve Laternula elliptica to physical stress and microbial exposure. Journal of Experimental Marine Biology and Ecology 398, 83-90. 
IGBP, IOC, SCOR, 2013. Ocean Acidification Summary for Policymakers-Third Symposium on the Ocean in a High- $\mathrm{CO}_{2}$ World. International Geosphere-Biosphere Programme. Stockolm, Sweden.

Iglesias-Rodriguez, M.D., Halloran, P.R., Rickaby, R.E., Hall, I.R., Colmenero-Hidalgo, E., Gittins, J.R., Green, D.R., Tyrrell, T., Gibbs, S.J., von Dassow, P., 2008. Phytoplankton calcification in a high- $\mathrm{CO}_{2}$ world. Science 320, 336-340.

IPCC, 2013. Climate Change 2013: The Physical Science Basis. Contribution of Working Group I to the Fifth Assessment Report of the Intergovernmental Panel on Climate Change, in: Stocker, T.F., Qin, D., Plattner, G.K., Tignor, M., Allen, S.K., Boschung, J., Nauels, A., Xia, Y., Bex, V., Midgley, P.M. (Eds.), Cambridge, United Kingdom and New York, NY, USA, p. 1535.

Jaeckle, W.B., Manahan, D.T., 1989. Growth and energy imbalance during the development of a lecithotrophic molluscan larva (Haliotis rufescens). The Biological Bulletin 177, 237246.

Jansson, A., Norkko, J., Norkko, A., 2013. Effects of reduced pH on Macoma balthica larvae from a system with naturally fluctuating $\mathrm{pH}$-dynamics. PLoS ONE 8, e68198.

Jaramillo, E., Bertran, C., Bravo, A., 1992. Mussel biodeposition in an estuary in southern Chile. Marine Ecology Progress Series 82, 85-94.

Kang, D.-H., Ahn, I.-Y., Choi, K.-S., 2003. Quantitative assessment of reproductive condition of the Antarctic clam, Laternula elliptica (King \& Broderip), using image analysis. Invertebrate Reproduction \& Development 44, 71-78.

Kang, D.-H., Ahn, I.-Y., Choi, K.-S., 2009. The annual reproductive pattern of the Antarctic clam, Laternula elliptica from Marian Cove, King George Island. Polar Biology 32, 517-528.

Kang, S.-H., Kang, J.-S., Chung, K.-H., Lee, M.-Y., Lee, B.-Y., Chung, H., Kim, Y., Kim, D.-Y., 1997. Seasonal variation of nearshore Antarctic microalgae and environmental factors in Marian Cove, King George Island, 1996. Korean Journal of Polar Research 8, 9-27.

Kapsenberg, L., Hofmann, G.E., 2014. Signals of resilience to ocean change: high thermal tolerance of early stage Antarctic sea urchins (Sterechinus neumayeri) reared under presentday and future $p \mathrm{CO}_{2}$ and temperature. Polar Biology 37, 967-980.

Kapsenberg, L., Kelley, A.L., Shaw, E.C., Martz, T.R., Hofmann, G.E., 2015. Near-shore Antarctic $\mathrm{pH}$ variability has implications for the design of ocean acidification experiments. Scientific Reports 5, 9628.

Kattner, G., Graeve, M., Calcagno, J.A., Lovrich, G.A., Thatje, S., Anger, K., 2003. Lipid, fatty acid and protein utilization during lecithotrophic larval development of Lithodes santolla (Molina) and Paralomis granulosa (Jacquinot). Journal of Experimental Marine Biology and Ecology 292, 61-74.

Kautsky, N., Evans, S., 1987. Role of biodeposition by Mytilus edulis in the ciculation of matter and nutrients in a Baltic coastal ecosystim. Marine Ecology Progress Series 38, 201212. 
Kelly, M.W., Hofmann, G.E., 2013. Adaptation and the physiology of ocean acidification. Functional Ecology 27, 980-990.

Kraeuter, J.N., Castagna, M., 2001. Biology of the Hard Clam. Elsevier.

Kroeker, K.J., Kordas, R.L., Crim, R., Hendriks, I.E., Ramajo, L., Singh, G.S., Duarte, C.M., Gattuso, J.P., 2013a. Impacts of ocean acidification on marine organisms: quantifying sensitivities and interaction with warming. Global Change Biology 19, 1884-1896.

Kroeker, K.J., Kordas, R.L., Crim, R.N., Singh, G.G., 2010. Meta-analysis reveals negative yet variable effects of ocean acidification on marine organisms. Ecology Letters 13, 14191434.

Kroeker, K.J., Micheli, F., Gambi, M.C., 2013b. Ocean acidification causes ecosystem shifts via altered competitive interactions. Nature Climate Change 3, 156-159.

Kroeker, K.J., Micheli, F., Gambi, M.C., Martz, T.R., 2011. Divergent ecosystem responses within a benthic marine community to ocean acidification. Proceedings of the National Academy of Sciences 108, 14515-14520.

Kurihara, H., 2008. Effects of $\mathrm{CO}_{2}$-driven ocean acidification on the early developmental stages of invertebrates. Marine Ecology Progress Series 373, 275-284.

Kurihara, H., Shirayama, Y., 2004. Effects of increased atmospheric $\mathrm{CO}_{2}$ on sea urchin early development. Marine Ecology Progress Series 274, 161-169.

Labarta, U., Fernández-Reiriz, M.J., Pérez-Camacho, A., 1999. Energy, biochemical substrates and growth in the larval development, metamorphosis and postlarvae of Ostrea edulis (L.). Journal of Experimental Marine Biology and Ecology 238, 225-242.

Lamare, M.D., Barker, M.F., 1999. In situ estimates of larval development and mortality in the New Zealand sea urchin Evechinus chloroticus (Echinodermata: Echinoidea). Marine Ecology Progress Series 180, 197-211.

Lauringson, V., Mälton, E., Kotta, J., Kangur, K., Orav-Kotta, H., Kotta, I., 2007. Environmental factors influencing the biodeposition of the suspension feeding bivalve Dreissena polymorpha (Pallas): Comparison of brackish and freshwater populations. Estuarine, Coastal and Shelf Science 75, 459-467.

Lee, R.F., Hagen, W., Kattner, G., 2006. Lipid storage in marine zooplankton. Marine Ecology Progress Series 307, 273-306.

Levinton, J., 1972. Stability and trophic structure in deposit-feeding and suspension-feeding communities. American Naturalist 106, 472-486.

Lindinger, M.I., Lauren, D.J., McDonald, D.G., 1984. Acid-base balance in the sea mussel, Mytilus edulis. III: Effects of environmental hypercapnia on intra-and extracellular acid-base balance. Marine Biology Letters 5, 371-381.

Lister, K.N., Lamare, M.D., Burritt, D.J., 2015. Oxidative damage and antioxidant defence parameters in the Antarctic bivalve Laternula elliptica as biomarkers for pollution impacts. Polar Biology 38, 1741-1752. 
Loayza-Muro, R., Elías-Letts, R., 2007. Responses of the mussel Anodontites trapesialis (Unionidae) to environmental stressors: effect of $\mathrm{pH}$, temperature and metals on filtration rate. Environmental Pollution 149, 209-215.

Loosanoff, V.L., Tommers, F., 1947. Effect of low $\mathrm{pH}$ upon rate of water pumping of oysters, Ostrea virginica. The Anatomical Record 99, 668-669.

Lu, Y.T., Blake, N.J., Torres, J.J., 1999. Biochemical utilization during embryogenesis and metamorphosis in the bay scallop, Argopecten irradians concentricus (Say). Journal of Shellfish Research 18, 425-429.

Lucas, A., Chebab-Chalabi, L., Beninger, P., 1986. Variation of relative organic matter in Mytilus edulis L. larvae and postlarvae. Journal of Experimental Marine Biology and Ecology 95, 99-103.

Lucey, N.M., Lombardi, C., DeMarchi, L., Schulze, A., Gambi, M.C., Calosi, P., 2015. To brood or not to brood: Are marine invertebrates that protect their offspring more resilient to ocean acidification? Scientific Reports 5, 12009.

Lüthi, D., Le Floch, M., Bereiter, B., Blunier, T., Barnola, J.-M., Siegenthaler, U., Raynaud, D., Jouzel, J., Fischer, H., Kawamura, K., 2008. High-resolution carbon dioxide concentration record 650,000-800,000 years before present. Nature 453, 379-382.

Marchant, H.K., Calosi, P., Spicer, J.I., 2010. Short-term exposure to hypercapnia does not compromise feeding, acid-base balance or respiration of Patella vulgata but surprisingly is accompanied by radula damage. Journal of the Marine Biological Association of the United Kingdom 90, 1379-1384.

Martel, A., Hynes, T.M., Buckland-Nicks, J., 1995. Prodissoconch morphology, planktonic shell growth, and size at metamorphosis in Dreissena polymorpha. Canadian Journal of Zoology 73, 1835-1844.

Martel, A.L., Tremblay, R., Toupoint, N., Olivier, F., Myrand, B., 2014. Veliger size at metamorphosis and temporal variability in prodissoconch II morphometry in the blue mussel (Mytilus edulis): Potential impact on recruitment. Journal of Shellfish Research 33, 443-455.

Matson, P.G., Martz, T.R., Hofmann, G.E., 2011. High-frequency observations of pH under Antarctic sea ice in the southern Ross Sea. Antarctic Science 23, 607-613.

Matson, P.G., Pauline, C.Y., Sewell, M.A., Hofmann, G.E., 2012. Development under elevated $p \mathrm{CO}_{2}$ conditions does not affect lipid utilization and protein content in early lifehistory stages of the purple sea urchin, Strongylocentrotus purpuratus. The Biological Bulletin 223, 312-327.

Matson, P.G., Washburn, L., Martz, T.R., Hofmann, G.E., 2014. Abiotic versus biotic drivers of ocean $\mathrm{pH}$ variation under fast sea ice in McMurdo Sound, Antarctica. PLoS ONE 9, e107239.

McAlister, J.S., Moran, A.L., 2012. Relationships among egg size, composition, and energy: a comparative study of geminate sea urchins. PLOS ONE 7, e41599. 
McClintock, J.B., Angus, R.A., McDonald, M.R., Amsler, C.D., Catledge, S.A., Vohra, Y.K., 2009. Rapid dissolution of shells of weakly calcified Antarctic benthic macroorganisms indicates high vulnerability to ocean acidification. Antarctic Science 21, 449-456.

McClintock, J.B., Pearse, J.S., 1986. Organic and energetic content of eggs and juveniles of Antarctic echinoids and asterids with lecithotrophic development. Comparative Biochemistry and Physiology Part A: Physiology 85, 341-345.

McConnaughey, T.A., Gillikin, D.P., 2008. Carbon isotopes in mollusk shell carbonates. Geo-Marine Letters 28, 287-299.

McGraw, C.M., Cornwall, C.E., Reid, M.R., Currie, K.I., Hepburn, C.D., Boyd, P., Hurd, C.L., Hunter, K.A., 2010. An automated pH-controlled culture system for laboratory-based ocean acidification experiments. Limnology and Oceanography Methods 8, 686-694.

McNeil, B.I., Matear, R.J., 2008. Southern Ocean acidification: A tipping point at 450-ppm atmospheric $\mathrm{CO}_{2}$. Proceedings of the National Acadamy of Sciences U.S.A. 105, 1886018864.

McNeil, B.I., Tagliabue, A., Sweeney, C., 2010. A multi-decadal delay in the onset of corrosive 'acidified' waters in the Ross Sea of Antarctica due to strong air-sea $\mathrm{CO}_{2}$ disequilibrium. Geophysical Research Letters 37, L19607.

Mehrbach, C., Culberson, C., Hawley, J., Pytkowicx, R., 1973. Measurement of the apparent dissociation constants of carbonic acid in seawater at atmospheric pressure. Limnology and Oceanography 18, 897-907.

Melatunan, S., Calosi, P., Rundle, S.D., Widdicombe, S., Moody, A.J., 2013. Effects of ocean acidification and elevated temperature on shell plasticity and its energetic basis in an intertidal gastropod. Marine Ecology Progress Series 472, 155-168.

Melzner, F., Gutowska, M.A., Langenbuch, M., Dupont, S., Lucassen, M., Thorndyke, M.C., Bleich, M., Pörtner, H.O., 2009. Physiological basis for high $\mathrm{CO}_{2}$ tolerance in marine ectothermic animals: pre-adaptation through lifestyle and ontogeny? Biogeosciences 6, 23132331.

Melzner, F., Stange, P., Trübenbach, K., Thomsen, J., Casties, I., Panknin, U., Gorb, S.N., Gutowska, M.A., 2011. Food supply and seawater $p \mathrm{CO}_{2}$ impact calcification and internal shell dissolution in the blue mussel Mytilus edulis. PLOS ONE 6, e24223.

Meyer, E., Green, A., Moore, M., Manahan, D., 2007. Food availability and physiological state of sea urchin larvae (Strongylocentrotus purpuratus). Marine Biology 152, 179-191.

Michaelidis, B., Ouzounis, C., Paleras, A., Pörtner, H.O., 2005. Effects of long-term moderate hypercapnia on acid-base balance and growth rate in marine mussels Mytilus galloprovincialis. Marine Ecology Progress Series 293, 109-118.

Miller, A.W., Reynolds, A.C., Sobrino, C., Riedel, G.F., 2009. Shellfish face uncertain future in high $\mathrm{CO}_{2}$ world: Influence of acidification on oyster larvae calcification and growth in estuaries. PLOS ONE 4, e5661. 
Miller, G.M., Watson, S.-A., Donelson, J.M., McCormick, M.I., Munday, P.L., 2012. Parental environment mediates impacts of increased carbon dioxide on a coral reef fish. Nature Climate Change 2, 858-861.

Miner, B.G., McEdward, L.A., McEdward, L.R., 2005. The relationship between egg size and the duration of the facultative feeding period in marine invertebrate larvae. Journal of Experimental Marine Biology and Ecology 321, 135-144.

Minor, M., Scheibling, R.E., 1997. Effects of food ration and feeding regime on growth and reproduction of the sea urchin Strongylocentrotus droebachiensis. Marine Biology 129, 159167.

Moran, A., McAlister, J., Whitehill, E., 2013. Eggs as energy: revisiting the scaling of egg size and energetic content among echinoderms. The Biological Bulletin 224, 184-191.

Moran, A.L., Manahan, D.T., 2003. Energy metabolism during larval development of green and white abalone, Haliotis fulgens and H. sorenseni. The Biological Bulletin 204, 270-277.

Morley, S., Bates, A., Lamare, M., Richard, J., Nguyen, K., Brown, J., Peck, L., 2014. Rates of warming and the global sensitivity of shallow water marine invertebrates to elevated temperature. Journal of the Marine Biological Association of the United Kingdom , 1-7.

Morley, S., Martin, S., Bates, A., Clark, M., Ericson, J., Lamare, M., Peck, L., 2012a. Spatial and temporal variation in the heat tolerance limits of two abundant Southern Ocean invertebrates. Marine Ecology Progress Series 450, 81-92.

Morley, S., Peck, L., Miller, A., Pörtner, H., 2007. Hypoxia tolerance associated with activity reduction is a key adaptation for Laternula elliptica seasonal energetics. Oecologia 153, 2936.

Morley, S.A., Hirse, T., Thorne, M.A., Pörtner, H.O., Peck, L.S., 2012b. Physiological plasticity, long term resistance or acclimation to temperature, in the Antarctic bivalve, Laternula elliptica. Comparative Biochemistry and Physiology Part A: Molecular \& Integrative Physiology 162, 16-21.

Morley, S.A., Tan, K.S., Day, R.W., Martin, S.M., Pörtner, H.-O., Peck, L.S., 2009. Thermal dependency of burrowing in three species within the bivalve genus Laternula: a latitudinal comparison. Marine Biology 156, 1977-1984.

Mostofa, K., Liu, C., Zhai, W., Minella, M., Vione, D., Gao, K., Minakata, D., Arakaki, T., Yoshioka, T., Hayakawa, K., 2015. Reviews and Syntheses: Ocean acidification and its potential impacts on marine ecosystems. Biogeosciences Discussions 12.

Müller, M.N., Trull, T.W., Hallegraeff, G.M., 2015. Differing responses of three Southern Ocean Emiliania huxleyi ecotypes to changing seawater carbonate chemistry. Mar. Ecol. Prog. Ser 531, 81-90.

Nakamura, M., Ohki, S., Suzuki, A., Sakai, K., 2011. Coral larvae under ocean acidification: survival, metabolism, and metamorphosis. PLOS ONE 6, e14521-e14521. 
Navarro, J.M., 1988. The effects of salinity on the physiological ecology of Choromytilus chorus (Molina, 1782) (Bivalvia: Mytilidae). Journal of Experimental Marine Biology and Ecology 122, 19-33.

Navarro, J.M., Torres, R., Acuña, K., Duarte, C., Manriquez, P.H., Lardies, M., Lagos, N.A., Vargas, C., Aguilera, V., 2013. Impact of medium-term exposure to elevated $p \mathrm{CO}_{2}$ levels on the physiological energetics of the mussel Mytilus chilensis. Chemosphere 90, 1242-1248.

Nehrke, G., Poigner, H., Wilhelms-Dick, D., Brey, T., Abele, D., 2012. Coexistence of three calcium carbonate polymorphs in the shell of the Antarctic clam Laternula elliptica. Geochemistry, Geophysics, Geosystems 13.

Nguyen, H.D., Doo, S.S., Soars, N.A., Byrne, M., 2012. Noncalcifying larvae in a changing ocean: warming, not acidification/hypercapnia, is the dominant stressor on development of the sea star Meridiastra calcar. Global Change Biology 18, 2466-2476.

Noisette, F., Comtet, T., Legrand, E., Bordeyne, F., Davoult, D., Martin, S., 2014. Does encapsulation protect embryos from the effects of ocean acidification? The example of Crepidula fornicata. PLoS ONE 9, e93021.

Norkko, A., Hewitt, J.E., Thrush, S.F., Funnell, T., 2001. Benthic-pelagic coupling and suspension-feeding bivalves: Linking site-specific sediment flux and biodeposition to benthic community structure. Limnology and Oceanography 46, 2067-2072.

Norkko, A., Thrush, S., Cummings, V., Gibbs, M., Andrew, N., Norkko, J., Schwarz, A.-M., 2007. Trophic structure of coastal Antarctic food webs associated with changes in sea ice and food supply. Ecology 88, 2810-2820.

Norkko, J., Norkko, A., Thrush, S., Cummings, V., 2005a. Detecting growth under environmental extremes: spatial and temporal patterns in nucleic acid ratios in two Antarctic bivalves. Journal of Experimental Marine Biology and Ecology 326, 144-156.

Norkko, J., Pilditch, C., Thrush, S., Wells, R., 2005b. Effects of food availability and hypoxia on bivalves: the value of using multiple parameters to measure bivalve condition in environmental studies. Marine Ecology Progress Series 298, 205-218.

O'Donnell, M.J., Todgham, A.E., Sewell, M.A., Hammond, L., Ruggiero, K., Fangue, N.A., Zippay, M.L., Hofmann, G.E., 2010. Ocean acidification alters skeletogenesis and gene expression in larval sea urchins. Marine Ecology Progress Series 398, 157-171.

Ockelmann, K.W., 1965. Developmental types in marine bivalves and their distribution along the Atlantic coast of Europe. Marine Biological Laboratory.

Orr, H.A., 2009. Fitness and its role in evolutionary genetics. Nature Reviews Genetics 10, 531-539.

Orr, J.C., Fabry, V.J., Aumont, O., Bopp, L., Doney, S.C., Feely, R.A., Gnanadesikan, A., Gruber, N., Ishida, A., Joos, F., Key, R.M., Lindsay, K., Maier-Reimer, E., Matear, R., Monfray, P., Mouchet, A., Najjar, R.G., Plattner, G.-K., Rodgers, K.B., Sabine, C.L., Sarmiento, J.L., Schlitzer, R., Slater, R.D., Totterdell, I.J., Weirig, M.-F., Yamanaka, Y., Yool, A., 2005. Anthropogenic ocean acidification over the twenty-first century and its impact on calcifying organisms. Nature 437, 681-686. 
Pansch, C., Nasrolahi, A., Appelhans, Y.S., Wahl, M., 2012. Impacts of ocean warming and acidification on the larval development of the barnacle Amphibalanus improvisus. Journal of Experimental Marine Biology and Ecology 420, 48-55.

Park, H., Ahn, I.-Y., Lee, H.E., 2007. Expression of heat shock protein 70 in the thermally stressed Antarctic clam Laternula elliptica. Cell Stress \& Chaperones 12, 275.

Parker, L., Ross, P., O'Connor, W., 2010. Comparing the effect of elevated $p \mathrm{CO}_{2}$ and temperature on the fertilization and early development of two species of oysters. Marine Biology 157, 2435-2452.

Parker, L.M., O’Connor, W.A., Raftos, D.A., Pörtner, H.-O., Ross, P.M., 2015. Persistence of positive carryover effects in the oyster, Saccostrea glomerata, following transgenerational exposure to ocean acidification. PLOS ONE 10, e0132276.

Parker, L.M., Ross, P.M., O'Connor, W.A., 2009. The effect of ocean acidification and temperature on the fertilization and embryonic development of the Sydney rock oyster Saccostrea glomerata (Gould 1850). Global Change Biology 15, 2123-2136.

Parker, L.M., Ross, P.M., O'Connor, W.A., Borysko, L., Raftos, D.A., Pörtner, H.O., 2012. Adult exposure influences offspring response to ocean acidification in oysters. Global Change Biology 18, 82-92.

Parker, L.M., Ross, P.M., O'Connor, W.A., Pörtner, H.O., Scanes, E., Wright, J.M., 2013. Predicting the response of molluscs to the impact of ocean acidification. Biology 2, 651-692.

Parrish, C.C., 1987. Separation of aquatic lipid classes by chromarod thin-layer chromatography with measurement by latroscan flame ionization detection. Canadian Journal of Fisheries and Aquatic Sciences 44, 722-731.

Parrish, C.C., 1999. Determination of total lipid, lipid classes, and fatty acids in aquatic samples, Lipids in freshwater ecosystems. Springer, pp. 4-20.

Parrish, C.C., 2013. Lipids in marine ecosystems. ISRN Oceanography 2013604045.

Paulay, G., Meyer, C., 2006. Dispersal and divergence across the greatest ocean region: do larvae matter? Integrative and Comparative Biology 46, 269-281.

Pearse, J.S., Bosch, I., McClintock, J.B., 1985. Contrasting modes of reproduction by common shallow-water Antarctic invertebrates. Antarctic Journal 19, 138-139.

Pearse, J.S., Bosch, I., McClintock, J.B., Marinovic, B., Britton, R., 1986. Contrasting tempos of reproduction by shallow-water animals in McMurdo Sound, Antarctica. Antarctic Journal 21, 182-184.

Pearse, J.S., McClintock, J.B., Bosch, I., 1991. Reproduction of Antarctic benthic marine invertebrates: tempos, modes, and timing. American Zoologist 31, 65-80.

Pechenik, J.A., 1999. On the advantages and disadvantages of larval stages in benthic marine invertebrate life cycles. Marine Ecology Progress Series 177, 269-297. 
Peck L.S., 2005. Prospects for survival in the Southern Ocean: vulnerability of benthic species to climate change. Antarctic Science 17, 497-507.

Peck, L.S., Barnes, D.K.A., Willmott, J., 2005. Responses to extreme seasonality in food supply: diet plasticity in Antarctic brachiopods. Marine Biology 147, 453-463.

Peck, L.S., Conway, L.Z., 2000. The myth of metabolic cold adaptation: oxygen consumption in stenothermal Antarctic bivalves. Geological Society, London, Special Publications 177, 441-450.

Peck, L.S., Morley, S.A., Pörtner, H.-O., Clark, M.S., 2007a. Thermal limits of burrowing capacity are linked to oxygen availability and size in the Antarctic clam Laternula elliptica. Oecologia 154, 479-484.

Peck, L.S., Pörtner, H.O., Hardewig, I., 2002. Metabolic demand, oxygen supply, and critical temperatures in the Antarctic bivalve Laternula elliptica. Physiological and Biochemical Zoology 75, 123-133.

Peck, L.S., Powell, D.K., Tyler, P.A., 2007b. Very slow development in two Antarctic bivalve molluscs, the infaunal clam Laternula elliptica and the scallop Adamussium colbecki. Marine Biology 150, 1191-1197.

Peck, L.S., Webb, K.E., Bailey, D.M., 2004. Extreme sensitivity of biological function to temperature in Antarctic marine species. Functional Ecology 18, 625-630.

Peck, V.L., Tarling, G.A., Manno, C., Harper, E.M., Tynan, E., 2016. Outer organic layer and internal repair mechanism protects pteropod Limacina helicina from ocean acidification. Deep Sea Research Part II: Topical Studies in Oceanography 127, 41-52.

Pecorino, D., Barker, M.F., Dworjanyn, S.A., Byrne, M., Lamare, M.D., 2014. Impacts of near future sea surface $\mathrm{pH}$ and temperature conditions on fertilisation and embryonic development in Centrostephanus rodgersii from northern New Zealand and northern New South Wales, Australia. Marine Biology 161, 101-110.

Pedersen, T.M., Hansen, J.L., Josefson, A.B., Hansen, B.W., 2008. Mortality through ontogeny of soft-bottom marine invertebrates with planktonic larvae. Journal of Marine Systems 73, 185-207.

Pereira, A.M., Range, P., Campoy, A., Oliveira, A.P., Joaquim, S., Matias, D., Chícharo, L., Gaspar, M.B., 2015. Larval hatching and development of the wedge shell (Donax trunculus L.) under increased $\mathrm{CO}_{2}$ in southern Portugal. Regional Environmental Change 16, 855-864.

Pernet, F., Bricelj, V.M., Cartier, S., 2006. Lipid class dynamics during larval ontogeny of sea scallops, Placopecten magellanicus, in relation to metamorphic success and response to antibiotics. Journal of Experimental Marine Biology and Ecology 329, 265-280.

Pernet, F., Tremblay, R., Bourget, E., 2003a. Biochemical indicator of sea scallop (Placopecten magellanicus) quality based on lipid class composition. Part I: Broodstock conditioning and young larvae performance. Journal of Shellfish Research 22, 365-376. 
Pernet, F., Tremblay, R., Bourget, E., 2003b. Biochemical indicator of sea scallop (Placopecten magellanicus) quality based on lipid class composition. Part II: Larval growth, competency and settlement. Journal of Shellfish Research 22, 377-388.

Philipp, E., Brey, T., Pörtner, H.-O., Abele, D., 2005. Chronological and physiological ageing in a polar and a temperate mud clam. Mechanisms of ageing and Development 126, 598-609.

Philipp, E.E., Husmann, G., Abele, D., 2011. The impact of sediment deposition and iceberg scour on the Antarctic soft shell clam Laternula elliptica at King George Island, Antarctica. Antarctic Science 23, 127-138.

Phillips, N.E., Gaines, S.D., 2002. Spatial and temporal variability in size at settlement of intertidal mytilid mussels from around Pt. Conception, California. Invertebrate Reproduction \& Development 41, 171-177.

Pond, D.W., Tarling, G.A., 2011. Phase transitions of wax esters adjust buoyancy in diapausing Calanoides acutus. Limnology and Oceanography 56, 1310-1318.

Poorbagher, H., Lamare, M.D., Barker, M.F., Rayment, W., 2010. Relative importance of parental diet versus larval nutrition on development and phenotypic plasticity of Pseudechinus huttoni larvae (Echinodermata: Echinoidea). Marine Biology Research 6, 302314.

Pörtner, H.-O., 2002a. Climate variations and the physiological basis of temperature dependent biogeography: systemic to molecular hierarchy of thermal tolerance in animals. Comparative Biochemistry and Physiology Part A: Molecular \& Integrative Physiology 132, 739-761.

Pörtner, H.-O., 2002b. Physiological basis of temperature-dependent biogeography: tradeoffs in muscle design and performance in polar ectotherms. Journal of Experimental Biology 205, 2217-2230.

Pörtner, H.-O., 2008. Ecosystem effects of ocean acidification in times of ocean warming: a physiologist's view. Marine Ecology Progress Series 373, 203-217.

Pörtner, H.-O., 2010. Oxygen- and capacity-limitation of thermal tolerance: a matrix for integrating climate-related stressor effects in marine ecosystems. Journal of Experimental Biology 213, 881-893.

Pörtner, H.-O., Farrell, A.P., 2008. Physiology and climate change. Science 322, 690-692.

Pörtner, H.O., Peck, L.S., Hirse, T., 2006. Hyperoxia alleviates thermal stress in the Antarctic bivalve, Laternula elliptica: evidence for oxygen limited thermal tolerance. Polar Biology 29, 688-693.

Powell, A.W.B., 1965. Mollusca of Antarctic and Subantarctic Seas, in: van Oye, P., van Mieghem, J. (Eds.), Biogeography and Ecology in Antarctica. W. Junk, The Hague, Netherlands, pp. 333-380.

Powell, D.K., Tyler, P.A., Peck, L.S., 2001. Effect of sperm concentration and sperm ageing on fertilisation success in the Antarctic soft-shelled clam Laternula elliptica and the Antarctic limpet Nacella concinna. Marine Ecology Progress Series 215, 191-200. 
Prowse, T., Sewell, M., Byrne, M., 2008. Fuels for development: evolution of maternal provisioning in asterinid sea stars. Marine Biology 153, 337-349.

Prowse, T.A., Falkner, I., Sewell, M.A., Byrne, M., 2009. Long-term storage lipids and developmental evolution in echinoderms. Evolutionary Ecology Research 11, 1069-1083.

Przeslawski, R., Byrne, M., Mellin, C., 2015. A review and meta-analysis of the effects of multiple abiotic stressors on marine embryos and larvae. Global Change Biology 21, 21222140.

Pynnönen, K.S., Huebner, J., 1995. Effects of episodic low pH exposure on the valve movements of the freshwater bivalve Anodonta cygnea L. Water Research 29, 2579-2582.

Ralph, R., Maxwell, J., 1977. Growth of two Antarctic lamellibranchs: Adamussium colbecki and Laternula elliptica. Marine Biology 42, 171-175.

Range, P., Ben-Hamadou, R., Pilo, D., 2012. Seawater acidification by $\mathrm{CO}_{2}$ in a coastal lagoon environment: Effects on life history traits of juvenile mussels Mytilus galloprovincialis.Journal of Experimental Marine Biology and Ecology 424, 89-98

Range, P., Chícharo, M., Ben-Hamadou, R., Piló, D., Matias, D., Joaquim, S., Oliveira, A., Chícharo, L., 2011. Calcification, growth and mortality of juvenile clams Ruditapes decussatus under increased $p \mathrm{CO}_{2}$ and reduced $\mathrm{pH}$ : Variable responses to ocean acidification at local scales? Journal of Experimental Marine Biology and Ecology 396, 177-184.

Raven, J., Caldeira, K., Elderfield, H., Hoegh-Guldberg, O., Liss, P., Riebesell, U., Shepherd, J., Turley, C., Watson, A., 2005. Ocean acidification due to increasing atmospheric carbon dioxide. The Royal Society.

Reuter, K.E., Lotterhos, K.E., Crim, R.N., Thompson, C.A., Harley, C.D., 2011. Elevated $p \mathrm{CO}_{2}$ increases sperm limitation and risk of polyspermy in the red sea urchin Strongylocentrotus franciscanus. Global Change Biology 17, 163-171.

Ridgway, I.D., Richardson, C.A., Austad, S.N., 2011. Maximum Shell Size, Growth Rate, and Maturation Age Correlate With Longevity in Bivalve Molluscs. The Journals of Gerontology Series A: Biological Sciences and Medical Sciences 66A, 183-190.

Riebesell, U., Zondervan, I., Rost, B., Tortell, P.D., Zeebe, R.E., Morel, F.M., 2000. Reduced calcification of marine plankton in response to increased atmospheric $\mathrm{CO}_{2}$. Nature 407, 364367.

Ries, J.B., Cohen, A.L., McCorkle, D.C., 2009. Marine calcifiers exhibit mixed responses to $\mathrm{CO}_{2}$-induced ocean acidification. Geology 37, 1131-1134.

Rodriguez, S.R., Ojeda, F.P., Inestrosa, N.C., 1993. Settlement of benthic marine invertebrates. Marine Ecology Progress Series 97, 193-207.

Roleda, M.Y., Boyd, P.W., Hurd, C.L., 2012. Before ocean acidification: calcifier chemistry lessons. Journal of Phycology 48, 840-843. 
Sabine, C.L., Feely, R.A., Gruber, N., Key, R.M., Lee, K., Bullister, J.L., Wanninkhof, R., Wong, C., Wallace, D.W., Tilbrook, B., 2004. The oceanic sink for anthropogenic $\mathrm{CO}_{2}$. Science 305, 367-371.

Safi, K.A., Hewitt, J.E., Talman, S.G., 2007. The effect of high inorganic seston loads on prey selection by the suspension-feeding bivalve, Atrina zelandica. Journal of Experimental Marine Biology and Ecology 344, 136-148.

Sahade, R., Lagger, C., Torre, L., Momo, F., Monien, P., Schloss, I., Barnes, D.K., Servetto, N., Tarantelli, S., Tatián, M., 2015. Climate change and glacier retreat drive shifts in an Antarctic benthic ecosystem. Science Advances 1, e1500050.

Sato-Okoshi, W., Okoshi, K., 2008. Characteristics of shell microstructure and growth analysis of the Antarctic bivalve Laternula elliptica from Lützow-Holm Bay, Antarctica. Polar Biology 31, 131-138.

Sato-Okoshi, W., Okoshi, K., Sasaki, H., Akiha, F., 2010. Shell structure characteristics of pelagic and benthic molluscs from Antarctic waters. Polar Science 4, 257-261.

Schade, F.M., Clemmesen, C., Wegner, K.M., 2014. Within-and transgenerational effects of ocean acidification on life history of marine three-spined stickleback (Gasterosteus aculeatus). Marine Biology 161, 1667-1676.

Seibel, B.A., Walsh, P.J., 2001. Potential impacts of $\mathrm{CO}_{2}$ injection on deep-sea biota. Science 294, 319-320.

Seibel, B.A., Walsh, P.J., 2003. Biological impacts of deep-sea carbon dioxide injection inferred from indices of physiological performance. Journal of Experimental Biology 206, 641-650.

Sewell, M.A., 2005. Utilization of lipids during early development of the sea urchin Evechinus chloroticus. Marine Ecology Progress Series 304, 133-142.

Sewell, M.A., Millar, R.B., Yu, P.C., Kapsenberg, L., Hofmann, G.E., 2013. Ocean acidification and fertilization in the Antarctic sea urchin Sterechinus neumayeri: the importance of polyspermy. Environmental Science \& Technology 48, 713-722.

Sheppard Brennand, H., Soars, N., Dworjanyn, S.A., Davis, A.R., Byrne, M., 2010. Impact of ocean warming and ocean acidification on larval development and calcification in the sea urchin Tripneustes gratilla. PLoS ONE 5, e11372.

Sleight, V.A., Thorne, M.A., Peck, L.S., Clark, M.S., 2015. Transcriptomic response to shell damage in the Antarctic clam, Laternula elliptica: Time scales and spatial localisation. Marine Genomics 20, 45-55.

Snelgrove, P.V.R., Butman, C.A., Grassle, J.P., 1993. Hydrodynamic enhancement of larval settlement in the bivalve Mulinia lateralis (Say) and the polychaete Capitella sp. I in microdepositional environments. Journal of Experimental Marine Biology and Ecology 168, 71-109. 
Stanwell-Smith, D., Peck, L.S., 1998. Temperature and embryonic development in relation to spawning and field occurrence of larvae of three Antarctic echinoderms. Biological Bulletin 194, 44-52.

Steinacher, M., Joos, F., Frolicher, T., Plattner, G.-K., Doney, S.C., 2009. Imminent ocean acidification in the Arctic projected with the NCAR global coupled carbon cycle-climate model. Biogeosciences 6, 515-533

Stumpp, M., Dupont, S., Thorndyke, M., Melzner, F., 2011a. $\mathrm{CO}_{2}$ induced seawater acidification impacts sea urchin larval development II: Gene expression patterns in pluteus larvae. Comparative Biochemistry and Physiology Part A: Molecular \& Integrative Physiology 160, 320-330.

Stumpp, M., Wren, J., Melzner, F., Thorndyke, M., Dupont, S., 2011b. $\mathrm{CO}_{2}$ induced seawater acidification impacts sea urchin larval development I: Elevated metabolic rates decrease scope for growth and induce developmental delay. Comparative Biochemistry and Physiology Part A: Molecular \& Integrative Physiology 160, 331-340.

Styf, H.K., Nilsson Sköld, H., Eriksson, S.P., 2013. Embryonic response to long-term exposure of the marine crustacean Nephrops norvegicus to ocean acidification and elevated temperature. Ecology and Evolution 3, 5055-5065.

Suckling, C.C., Clark, M.S., Richard, J., Morley, S.A., Thorne, M.A., Harper, E.M., Peck, L.S., 2015. Adult acclimation to combined temperature and $\mathrm{pH}$ stressors significantly enhances reproductive outcomes compared to short-term exposures. Journal of Animal Ecology 84, 773-784.

Sunday, J.M., Crim, R.N., Harley, C.D., Hart, M.W., 2011. Quantifying rates of evolutionary adaptation in response to ocean acidification. PLOS ONE 6, e22881-e22881.

Talmage, S.C., Gobler, C.J., 2009. The effects of elevated carbon dioxide concentrations on the metamorphosis, size, and survival of larval hard clams (Mercenaria mercenaria), bay scallops (Argopecten irradians), and Eastern oysters (Crassostrea virginica). Limnology and Oceanography 54, 2072.

Talmage, S.C., Gobler, C.J., 2010. Effects of past, present, and future ocean carbon dioxide concentrations on the growth and survival of larval shellfish. Proceedings of the National Academy of Sciences 107, 17246-17251.

Talmage, S.C., Gobler, C.J., 2011. Effects of elevated temperature and carbon dioxide on the growth and survival of larvae and juveniles of three species of northwest Atlantic bivalves. PLOS ONE 6, e26941.

Tans, P., Keeling, R., 2015. Trends in Atmospheric Carbon Dioxide, Global Greenhouse Gas Reference Network. NOAA, Mauna Loa, HI, USA.

Tatián, M., Sahade, R., Mercuri, G., Fuentes, V.L., Antacli, J.C., Stellfeldt, A., Esnal, G.B., 2008. Feeding ecology of benthic filter-feeders at Potter Cove, an Antarctic coastal ecosystem. Polar Biology 31, 509-517. 
Thiyagarajan, V., Hung, O., Chiu, J., Wu, R., Qian, P., 2005. Growth and survival of juvenile barnacle Balanus amphitrite: interactive effects of cyprid energy reserve and habitat. Marine Ecology Progress Series 299, 229-237.

Thomsen, J., Gutowska, M., Saphörster, J., Heinemann, A., Trübenbach, K., Fietzke, J., Hiebenthal, C., Eisenhauer, A., Körtzinger, A., Wahl, M., 2010. Calcifying invertebrates succeed in a naturally $\mathrm{CO}_{2}$-rich coastal habitat but are threatened by high levels of future acidification. Biogeosciences 7, 3879-3891.

Thomsen, J., Haynert, K., Wegner, K., Melzner, F., 2015. Impact of seawater carbonate chemistry on the calcification of marine bivalves. Biogeosciences Discussions 12, 1543-1571.

Thomsen, J., Melzner, F., 2010. Moderate seawater acidification does not elicit long-term metabolic depression in the blue mussel Mytilus edulis. Marine Biology 157, 2667-2676.

Timmins-Schiffman, E., O’Donnell, M., Friedman, C., Roberts, S., 2013. Elevated $p \mathrm{CO}_{2}$ causes developmental delay in early larval Pacific oysters, Crassostrea gigas. Marine Biology 160, 1973-1982.

Tocher, D., Fraser, A., Sargent, J., Gamble, J., 1985. Lipid class composition during embryonic and early larval development in Atlantic herring (Clupea harengus, L.). Lipids 20, 84-89.

Todgham, A.E., Hofmann, G.E., 2009. Transcriptomic response of sea urchin larvae Strongylocentrotus purpuratus to CO2-driven seawater acidification. Journal of Experimental Biology 212, 2579-2594.

Tunnicliffe, V., Davies, K.T., Butterfield, D.A., Embley, R.W., Rose, J.M., Chadwick Jr, W.W., 2009. Survival of mussels in extremely acidic waters on a submarine volcano. Nature Geoscience 2, 344-348.

Urban, H.-J., Silva, P., 1998. Upper temperature tolerance of two Antarctic mollusks (Laternula elliptica and Nacella concinna) from Potter Cove, King George Island, Antarctic Peninsula. Reports on Polar Research, Alfred Wegener Institut for Polar and Marine Research, Bremerhaven 299, 230-236.

Urban, H., Mercuri, G., 1998. Population dynamics of the bivalve Laternula elliptica from Potter cove, King George Island, South Shetland islands. Antarctic Science 10, 153-160.

Van Colen, C., Debusschere, E., Braeckman, U., Van Gansbeke, D., Vincx, M., 2012. The early life history of the clam Macoma balthica in a high $\mathrm{CO}_{2}$ world. PLoS ONE 7, e44655.

Vargas, C.A., de la Hoz, M., Aguilera, V., San Martín, V., Manríquez, P.H., Navarro, J.M., Torres, R., Lardies, M.A., Lagos, N.A., 2013. $\mathrm{CO}_{2}$-driven ocean acidification reduces larval feeding efficiency and changes food selectivity in the mollusk Concholepas concholepas. Journal of Plankton Research 35, 1059-1068.

Vehmaa, A., Brutemark, A., Engström-Öst, J., 2012. Maternal effects may act as an adaptation mechanism for copepods facing $\mathrm{pH}$ and temperature changes. PLoS ONE 7, e48538 
Villinski, J.T., Villinski, J.C., Byrne, M., Raff, R.A., 2002. Convergent maternal provisioning and life-history evolution in echinoderms. Evolution 56, 1764-1775.

Waldbusser, G.G., Brunner, E.L., Haley, B.A., Hales, B., Langdon, C.J., Prahl, F.G., 2013. A developmental and energetic basis linking larval oyster shell formation to acidification sensitivity. Geophysical Research Letters 40, 2171-2176.

Waldbusser, G.G., Hales, B., Langdon, C.J., Haley, B.A., Schrader, P., Brunner, E.L., Gray, M.W., Miller, C.A., Gimenez, I., 2015. Saturation-state sensitivity of marine bivalve larvae to ocean acidification. Nature Climate Change 5, 273-280.

Waldbusser, G.G., Voigt, E.P., Bergschneider, H., Green, M.A., Newell, R.I., 2011. Biocalcification in the eastern oyster (Crassostrea virginica) in relation to long-term trends in Chesapeake Bay pH. Estuaries and Coasts 34, 221-231.

Waller, T.R., 1981. Functional morphology and development of veliger larvae of the European oyster Ostrea edulis Linné. Smithsonian Contributions to Zoology 328, 1-70.

Waller, C.L., Overall, A., Fitzcharles, E.M., Griffiths, H., 2016. First report of Laternula elliptica in the Antarctic intertidal zone. Polar Biology 1-4.

Watson, S.-A., Southgate, P.C., Tyler, P.A., Peck, L.S., 2009. Early larval development of the Sydney rock oyster Saccostrea glomerata under near-future predictions of $\mathrm{CO}_{2}$-driven ocean acidification. Journal of Shellfish Research 28, 431-437.

Watson, S.A., Peck, L.S., Tyler, P.A., Southgate, P.C., Tan, K.S., Day, R.W., Morley, S.A., 2012. Marine invertebrate skeleton size varies with latitude, temperature and carbonate saturation: implications for global change and ocean acidification. Global Change Biology 18, 3026-3038.

Weiss, I.M., Tuross, N., Addadi, L., Weiner, S., 2002. Mollusc larval shell formation: amorphous calcium carbonate is a precursor phase for aragonite. Journal of Experimental Zoology 293, 478-491.

White, M.M., McCorkle, D.C., Mullineaux, L.S., Cohen, A.L., 2013. Early exposure of bay scallops (Argopecten irradians) to high $\mathrm{CO}_{2}$ causes a decrease in larval shell growth. PLoS ONE 8, e61065.

White, M.M., Mullineaux, L.S., McCorkle, D.C., Cohen, A.L., 2014. Elevated pCO2 exposure during fertilization of the bay scallop Argopecten irradians reduces larval survival but not subsequent shell size. Marine Ecology Progress Series 498, 173-186.

Whittmann, A., Pörtner, H., 2013. Sensitivities of extant animal taxa to ocean acidification Nature Climate Change 3, 995-1001.

Wicks, L.C., Roberts, J.M., 2012. Benthic invertebrates in a high $\mathrm{CO}_{2}$ world. Oceanography and Marine Biology 50, 127-187.

Wilt, F.H., 2005. Developmental biology meets materials science: morphogenesis of biomineralized structures. Developmental Biology 280, 15-25. 
Wong, K.K., Lane, A.C., Leung, P.T., Thiyagarajan, V., 2011. Response of larval barnacle proteome to $\mathrm{CO}_{2}$-driven seawater acidification. Comparative Biochemistry and Physiology Part D: Genomics and Proteomics 6, 310-321.

Yamamoto-Kawai, M., McLaughlin, F.A., Carmack, E.C., Nishino, S., Shimada, K., 2009. Aragonite undersaturation in the Arctic Ocean: effects of ocean acidification and sea ice melt. Science 326, 1098-1100.

Yu, P.C., Matson, P.G., Martz, T.R., Hofmann, G.E., 2011. The ocean acidification seascape and its relationship to the performance of calcifying marine invertebrates: Laboratory experiments on the development of urchin larvae framed by environmentally-relevant $p \mathrm{CO}_{2} / \mathrm{pH}$. Journal of Experimental Marine Biology and Ecology 400, 288-295. 


\section{Appendix}

Appendix 1. Detailed summary of lipid content and ratios in embryos of Laternula elliptica, $2 \mathrm{~d}$ PF (n $=8, \sim 500$ larvae ea.) and in D-larvae, $31 \mathrm{~d} \mathrm{PF}(\mathrm{n}=4, \sim 500$ larvae ea.), determined by Iatroscan TLC/FID. Data is mean \pm SD. Total lipids: sum of all lipid classes, energetic lipids $=\mathrm{AH}+\mathrm{WE}$ $+\mathrm{TAG}+\mathrm{DAG}$, structural lipids $=\mathrm{ST}+\mathrm{AMPL}+\mathrm{PL} . \mathrm{nd}=$ not detectable.

\begin{tabular}{|lrrrr|}
\hline \multicolumn{5}{c|}{ Average across all treatments } \\
\hline \multicolumn{4}{c}{ Embryo } & \multicolumn{2}{c|}{ D-Larvae } \\
\hline & $\begin{array}{c}\text { Amount per } \\
\text { embryo (ng) }\end{array}$ & $\begin{array}{c}\text { \% of Total } \\
\text { lipid }\end{array}$ & $\begin{array}{c}\text { Amount per } \\
\text { larvae (ng) }\end{array}$ & $\begin{array}{c}\text { \% of Total } \\
\text { lipid }\end{array}$ \\
\hline Total Lipids & $201.99 \pm 3.21$ & & $152.38 \pm 5.38$ & \\
Energetic Lipids: & & & & \\
TAG & $131.00 \pm 2.45$ & $64.82 \pm 0.41$ & $94.48 \pm 3.39$ & $62.02 \pm 0.30$ \\
WE & $7.42 \pm 0.28$ & $3.65 \pm 0.08$ & $6.93 \pm 0.38$ & $4.53 \pm 0.17$ \\
AH & $2.50 \pm 0.03$ & $1.24 \pm 0.01$ & $2.29 \pm 0.05$ & $1.52 \pm 0.06$ \\
DAG & $0.17 \pm 0.07$ & $0.09 \pm 0.04$ & $5.91 \pm 0.51$ & $3.89 \pm 0.34$ \\
Total & $141.03 \pm 2.73$ & $69.77 \pm 0.43$ & $109.61 \pm 3.85$ & $71.97 \pm 0.68$ \\
Structural Lipids: & & & & \\
PL & $46.13 \pm 0.91$ & $22.85 \pm 0.33$ & $29.43 \pm 1.79$ & $19.22 \pm 0.79$ \\
AMPL & $10.75 \pm 0.30$ & $5.36 \pm 0.15$ & $9.55 \pm 0.49$ & $6.32 \pm 0.29$ \\
ST & $4.08 \pm 0.06$ & $2.03 \pm 0.03$ & $3.78 \pm 0.07$ & $2.50 \pm 0.05$ \\
Total & $60.96 \pm 1.05$ & $30.23 \pm 0.43$ & $42.76 \pm 1.94$ & $28.03 \pm 0.68$ \\
Ratios & & & & \\
Energetic:Structural & $2.33 \pm 0.04$ & & $2.60 \pm 0.08$ & \\
TAG:ST & $32.19 \pm 0.55$ & & $25.15 \pm 0.57$ & \\
TAG:PL & $2.86 \pm 0.05$ & & $3.34 \pm 0.15$ & \\
\hline
\end{tabular}




\begin{tabular}{|c|c|c|c|c|}
\hline \multicolumn{5}{|c|}{$\mathrm{pH} 8.00 /-1.7^{\circ} \mathrm{C}$} \\
\hline & \multicolumn{2}{|c|}{ Embryo } & \multicolumn{2}{|c|}{ D-Larvae } \\
\hline & $\begin{array}{l}\text { Amount per } \\
\text { embryo (ng) }\end{array}$ & $\begin{array}{l}\% \text { of Total } \\
\text { lipid }\end{array}$ & $\begin{array}{l}\text { Amount per } \\
\text { larvae (ng) }\end{array}$ & $\begin{array}{l}\% \text { of Total } \\
\text { lipid }\end{array}$ \\
\hline Total Lipids & $197.47 \pm 14.60$ & & $151.26 \pm 2.40$ & \\
\hline \multicolumn{5}{|l|}{ Energetic Lipids: } \\
\hline TAG & $126.66 \pm 9.64$ & $64.13 \pm 0.91$ & $95.20 \pm 1.00$ & $62.95 \pm 0.42$ \\
\hline WE & $6.85 \pm 0.43$ & $3.48 \pm 0.04$ & $6.39 \pm 0.28$ & $4.23 \pm 0.20$ \\
\hline $\mathrm{AH}$ & $2.46 \pm 0.24$ & $1.24 \pm 0.06$ & $2.33 \pm 0.25$ & $1.53 \pm 0.15$ \\
\hline DAG & nd & nd & $4.41 \pm 0.88$ & $2.91 \pm 0.58$ \\
\hline Total & $136.56 \pm 10.02$ & $69.18 \pm 1.03$ & $108.32 \pm 1.83$ & $71.62 \pm 0.78$ \\
\hline \multicolumn{5}{|l|}{ Structural Lipids: } \\
\hline PL & $46.46 \pm 4.08$ & $23.52 \pm 1.13$ & $29.96 \pm 2.11$ & $19.79 \pm 1.30$ \\
\hline AMPL & $10.40 \pm 0.85$ & $5.26 \pm 0.12$ & $9.10 \pm 1.01$ & $6.02 \pm 0.69$ \\
\hline ST & $4.06 \pm 0.44$ & $2.04 \pm 0.07$ & $3.89 \pm 0.40$ & $2.56 \pm 0.23$ \\
\hline Total & $60.92 \pm 5.12$ & $30.82 \pm 1.03$ & $42.94 \pm 1.50$ & $28.38 \pm 0.78$ \\
\hline \multicolumn{5}{|l|}{ Ratios } \\
\hline Energetic:Structural & $2.25 \pm 0.11$ & & $2.53 \pm 0.10$ & \\
\hline TAG:ST & $31.49 \pm 0.87$ & & $25.12 \pm 2.07$ & \\
\hline TAG:PL & $2.75 \pm 0.16$ & & $3.23 \pm 0.25$ & \\
\hline \multicolumn{5}{|c|}{$\mathrm{pH} 7.65 /-1.7^{\circ} \mathrm{C}$} \\
\hline & \multicolumn{2}{|c|}{ Embryo } & \multicolumn{2}{|c|}{ D-Larvae } \\
\hline & $\begin{array}{l}\text { Amount per } \\
\text { embryo (ng) }\end{array}$ & $\begin{array}{l}\% \text { of Total } \\
\text { lipid }\end{array}$ & $\begin{array}{l}\text { Amount per } \\
\text { larvae (ng) }\end{array}$ & $\begin{array}{l}\% \text { of Total } \\
\text { lipid }\end{array}$ \\
\hline Total Lipids & $207.68 \pm 3.61$ & & $188.29 \pm 13.17$ & \\
\hline \multicolumn{5}{|l|}{ Energetic Lipids: } \\
\hline TAG & $133.46 \pm 1.72$ & $64.30 \pm 1.37$ & $117.30 \pm 8.87$ & $62.22 \pm 0.43$ \\
\hline WE & $8.41 \pm 0.66$ & $4.04 \pm 0.27$ & $8.60 \pm 0.77$ & $4.60 \pm 0.42$ \\
\hline $\mathrm{AH}$ & $2.57 \pm 0.10$ & $1.24 \pm 0.04$ & $2.30 \pm 0.13$ & $1.24 \pm 0.10$ \\
\hline DAG & $0.37 \pm 0.31$ & $0.19 \pm 0.19$ & $7.16 \pm 1.57$ & $3.95 \pm 0.99$ \\
\hline Total & $144.72 \pm 1.41$ & $69.73 \pm 1.32$ & $135.36 \pm 8.44$ & $72.01 \pm 0.94$ \\
\hline \multicolumn{5}{|l|}{ Structural Lipids: } \\
\hline $\mathrm{PL}$ & $47.13 \pm 2.30$ & $22.67 \pm 0.79$ & $36.98 \pm 5.15$ & $19.42 \pm 1.60$ \\
\hline AMPL & $11.66 \pm 1.44$ & $5.60 \pm 0.61$ & $11.77 \pm 1.18$ & $6.32 \pm 0.67$ \\
\hline ST & $4.16 \pm 0.30$ & $2.00 \pm 0.13$ & $4.18 \pm 0.12$ & $2.25 \pm 0.14$ \\
\hline Total & $62.95 \pm 3.72$ & $30.27 \pm 1.32$ & $52.93 \pm 5.04$ & $27.99 \pm 0.94$ \\
\hline \multicolumn{5}{|l|}{ Ratios } \\
\hline Energetic:Structural & $2.32 \pm 0.14$ & & $2.59 \pm 0.12$ & \\
\hline TAG:ST & $32.31 \pm 1.80$ & & $28.00 \pm 1.65$ & \\
\hline TAG:PL & $2.85 \pm 0.15$ & & $3.27 \pm 0.25$ & \\
\hline
\end{tabular}




\begin{tabular}{|c|c|c|c|c|}
\hline \multicolumn{5}{|c|}{$\mathrm{pH} 8.00 /-0.5^{\circ} \mathrm{C}$} \\
\hline & \multicolumn{2}{|c|}{ Embryo } & \multicolumn{2}{|c|}{ D-Larvae } \\
\hline & $\begin{array}{l}\text { Amount per } \\
\text { embryo (ng) }\end{array}$ & $\begin{array}{c}\% \text { of Total } \\
\text { lipid }\end{array}$ & $\begin{array}{l}\text { Amount per } \\
\text { larvae (ng) }\end{array}$ & $\begin{array}{c}\% \text { of Total } \\
\text { lipid }\end{array}$ \\
\hline Total Lipids & $217.34 \pm 20.99$ & & $\begin{array}{c}159.52 \pm \\
10.86\end{array}$ & \\
\hline \multicolumn{5}{|l|}{ Energetic Lipids: } \\
\hline TAG & $145.81 \pm 15.47$ & $66.92 \pm 0.66$ & $98.72 \pm 6.11$ & $61.97 \pm 0.81$ \\
\hline WE & $8.53 \pm 1.59$ & $3.83 \pm 0.33$ & $8.44 \pm 1.90$ & $5.15 \pm 0.79$ \\
\hline $\mathrm{AH}$ & $2.64 \pm 0.28$ & $1.22 \pm 0.03$ & $2.20 \pm 0.11$ & $1.39 \pm 0.04$ \\
\hline DAG & nd & nd & $7.46 \pm 1.09$ & $4.66 \pm 0.53$ \\
\hline Total & $156.89 \pm 17.32$ & $71.93 \pm 1.01$ & $116.82 \pm 8.62$ & $73.18 \pm 0.92$ \\
\hline \multicolumn{5}{|l|}{ Structural Lipids: } \\
\hline PL & $47.01 \pm 3.54$ & $21.76 \pm 0.46$ & $30.38 \pm 2.88$ & $19.03 \pm 1.32$ \\
\hline AMPL & $9.17 \pm 1.25$ & $4.33 \pm 0.63$ & $8.44 \pm 0.79$ & $5.37 \pm 0.62$ \\
\hline ST & $4.27 \pm 0.28$ & $1.98 \pm 0.08$ & $3.88 \pm 0.34$ & $2.43 \pm 0.10$ \\
\hline Total & $60.45 \pm 3.92$ & $28.07 \pm 1.01$ & $42.70 \pm 2.70$ & $26.82 \pm 0.92$ \\
\hline \multicolumn{5}{|l|}{ Ratios } \\
\hline Energetic:Structural & $2.58 \pm 0.14$ & & $2.74 \pm 0.13$ & \\
\hline TAG:ST & $33.92 \pm 1.47$ & & $25.65 \pm 1.16$ & \\
\hline TAG:PL & $3.08 \pm 0.09$ & & $3.30 \pm 0.24$ & \\
\hline \multicolumn{5}{|c|}{$\mathrm{pH} 7.65 /-0.5^{\circ} \mathrm{C}$} \\
\hline & \multicolumn{2}{|c|}{ Embryo } & \multicolumn{2}{|c|}{ D-Larvae } \\
\hline & $\begin{array}{l}\text { Amount per } \\
\text { embryo (ng) }\end{array}$ & $\begin{array}{c}\% \text { of Total } \\
\text { lipid }\end{array}$ & $\begin{array}{l}\text { Amount per } \\
\text { larvae (ng) }\end{array}$ & $\begin{array}{c}\% \text { of Total } \\
\text { lipid }\end{array}$ \\
\hline Total Lipids & $201.38 \pm 14.74$ & & $153.31 \pm 6.07$ & \\
\hline \multicolumn{5}{|l|}{ Energetic Lipids: } \\
\hline TAG & $130.37 \pm 9.58$ & $64.73 \pm 0.28$ & $93.27 \pm 3.70$ & $60.86 \pm 1.07$ \\
\hline WE & $7.69 \pm 0.91$ & $3.78 \pm 0.20$ & $5.76 \pm 0.25$ & $3.77 \pm 0.18$ \\
\hline $\mathrm{AH}$ & $2.50 \pm 0.14$ & $1.26 \pm 0.09$ & $2.09 \pm 0.18$ & $1.37 \pm 0.12$ \\
\hline DAG & $0.10 \pm 0.07$ & $0.05 \pm 0.04$ & $4.87 \pm 1.62$ & $3.15 \pm 0.97$ \\
\hline Total & $140.64 \pm 10.47$ & $69.82 \pm 0.20$ & $105.97 \pm 4.90$ & $69.14 \pm 1.78$ \\
\hline \multicolumn{5}{|l|}{ Structural Lipids: } \\
\hline $\mathrm{PL}$ & $46.82 \pm 4.52$ & $23.12 \pm 0.61$ & $36.04 \pm 4.04$ & $23.45 \pm 2.29$ \\
\hline AMPL & $10.10 \pm 0.56$ & $5.15 \pm 0.67$ & $7.81 \pm 0.55$ & $5.13 \pm 0.46$ \\
\hline ST & $3.82 \pm 0.20$ & $1.91 \pm 0.09$ & $3.49 \pm 0.20$ & $2.28 \pm 0.13$ \\
\hline Total & $60.74 \pm 4.29$ & $30.18 \pm 0.20$ & $47.34 \pm 3.44$ & $30.86 \pm 1.78$ \\
\hline \multicolumn{5}{|l|}{ Ratios } \\
\hline Energetic:Structural & $2.31 \pm 0.02$ & & $2.27 \pm 0.17$ & \\
\hline TAG:ST & $34.12 \pm 1.56$ & & $26.86 \pm 1.28$ & \\
\hline TAG:PL & $2.81 \pm 0.08$ & & $2.67 \pm 0.25$ & \\
\hline
\end{tabular}




\begin{tabular}{|c|c|c|c|c|}
\hline \multicolumn{5}{|c|}{$\mathrm{pH} 8.00 / 0.5^{\circ} \mathrm{C}$} \\
\hline & \multicolumn{2}{|c|}{ Embryo } & \multicolumn{2}{|c|}{ D-Larvae } \\
\hline & $\begin{array}{l}\text { Amount per } \\
\text { embryo (ng) }\end{array}$ & $\begin{array}{c}\% \text { of Total } \\
\text { lipid }\end{array}$ & $\begin{array}{l}\text { Amount per } \\
\text { larvae (ng) }\end{array}$ & $\begin{array}{c}\% \text { of Total } \\
\text { lipid }\end{array}$ \\
\hline Total Lipids & $196.90 \pm 6.74$ & & $146.41 \pm 9.69$ & \\
\hline \multicolumn{5}{|l|}{ Energetic Lipids: } \\
\hline TAG & $123.93 \pm 7.27$ & $62.85 \pm 2.26$ & $88.98 \pm 6.09$ & $60.79 \pm 1.28$ \\
\hline WE & $6.53 \pm 0.19$ & $3.32 \pm 0.07$ & $6.29 \pm 0.40$ & $4.33 \pm 0.28$ \\
\hline $\mathrm{AH}$ & $2.55 \pm 0.19$ & $1.29 \pm 0.08$ & $2.64 \pm 0.27$ & $1.81 \pm 0.17$ \\
\hline DAG & nd & nd & $3.68 \pm 1.05$ & $2.50 \pm 0.65$ \\
\hline Total & $132.95 \pm 7.62$ & $67.44 \pm 2.34$ & $101.58 \pm 7.09$ & $69.42 \pm 1.99$ \\
\hline \multicolumn{5}{|l|}{ Structural Lipids: } \\
\hline PL & $48.65 \pm 5.14$ & $24.72 \pm 2.50$ & $29.58 \pm 3.30$ & $20.19 \pm 1.63$ \\
\hline AMPL & $11.02 \pm 0.96$ & $5.66 \pm 0.67$ & $11.41 \pm 1.25$ & $7.74 \pm 0.45$ \\
\hline ST & $4.28 \pm 0.20$ & $2.18 \pm 0.09$ & $3.84 \pm 0.09$ & $2.65 \pm 0.14$ \\
\hline Total & $63.95 \pm 4.41$ & $32.56 \pm 2.34$ & $44.83 \pm 4.53$ & $30.58 \pm 1.99$ \\
\hline \multicolumn{5}{|l|}{ Ratios } \\
\hline Energetic:Structural & $2.12 \pm 0.22$ & & $2.32 \pm 0.24$ & \\
\hline TAG:ST & $28.94 \pm 1.13$ & & $23.12 \pm 1.25$ & \\
\hline TAG:PL & $2.64 \pm 0.32$ & & $3.10 \pm 0.36$ & \\
\hline \multicolumn{5}{|c|}{$\mathrm{pH} 7.65 / 0.5^{\circ} \mathrm{C}$} \\
\hline & \multicolumn{2}{|c|}{ Embryo } & \multicolumn{2}{|c|}{ D-Larvae } \\
\hline & $\begin{array}{l}\text { Amount per } \\
\text { embryo (ng) }\end{array}$ & $\begin{array}{l}\% \text { of Total } \\
\text { lipid }\end{array}$ & $\begin{array}{l}\text { Amount per } \\
\text { larvae (ng) }\end{array}$ & $\begin{array}{l}\% \text { of Total } \\
\text { lipid }\end{array}$ \\
\hline Total Lipids & $211.78 \pm 14.19$ & & $141.05 \pm 2.42$ & \\
\hline \multicolumn{5}{|l|}{ Energetic Lipids: } \\
\hline TAG & $135.92 \pm 8.82$ & $64.23 \pm 0.87$ & $87.33 \pm 2.78$ & $61.87 \pm 1.04$ \\
\hline WE & $7.98 \pm 0.66$ & $3.77 \pm 0.19$ & $5.68 \pm 0.16$ & $4.03 \pm 0.11$ \\
\hline $\mathrm{AH}$ & $2.52 \pm 0.15$ & $1.20 \pm 0.05$ & $2.25 \pm 0.11$ & $1.59 \pm 0.07$ \\
\hline DAG & $0.09 \pm 0.04$ & $0.04 \pm 0.02$ & $5.39 \pm 1.11$ & $3.85 \pm 0.84$ \\
\hline Total & $146.51 \pm 9.58$ & $69.23 \pm 1.01$ & $100.65 \pm 1.91$ & $71.35 \pm 0.15$ \\
\hline \multicolumn{5}{|l|}{ Structural Lipids: } \\
\hline PL & $48.96 \pm 3.54$ & $23.12 \pm 0.58$ & $27.72 \pm 1.91$ & $19.60 \pm 1.05$ \\
\hline AMPL & $12.06 \pm 1.80$ & $5.64 \pm 0.67$ & $9.05 \pm 1.45$ & $6.48 \pm 1.15$ \\
\hline ST & $4.25 \pm 0.28$ & $2.01 \pm 0.06$ & $3.63 \pm 0.22$ & $2.57 \pm 0.15$ \\
\hline Total & $65.27 \pm 5.33$ & $30.77 \pm 1.01$ & $40.40 \pm 0.53$ & $28.65 \pm 0.15$ \\
\hline \multicolumn{5}{|l|}{ Ratios } \\
\hline Energetic:Structural & $2.26 \pm 0.11$ & & $2.49 \pm 0.02$ & \\
\hline TAG:ST & $32.06 \pm 0.86$ & & $24.34 \pm 1.64$ & \\
\hline TAG:PL & $2.79 \pm 0.10$ & & $3.18 \pm 0.13$ & \\
\hline
\end{tabular}




\begin{tabular}{|c|c|c|c|c|}
\hline \multicolumn{5}{|c|}{$\mathrm{pH} 8.00 / 1.5^{\circ} \mathrm{C}$} \\
\hline & \multicolumn{2}{|c|}{ Embryo } & \multicolumn{2}{|c|}{ D-Larvae } \\
\hline & $\begin{array}{l}\text { Amount per } \\
\text { embryo (ng) }\end{array}$ & $\begin{array}{c}\% \text { of Total } \\
\text { lipid }\end{array}$ & $\begin{array}{l}\text { Amount per } \\
\text { larvae (ng) }\end{array}$ & $\begin{array}{c}\% \text { of Total } \\
\text { lipid }\end{array}$ \\
\hline Total Lipids & $196.03 \pm 8.61$ & & $142.71 \pm 7.43$ & \\
\hline \multicolumn{5}{|l|}{ Energetic Lipids: } \\
\hline TAG & $128.67 \pm 5.86$ & $65.63 \pm 0.56$ & $90.54 \pm 4.15$ & $63.48 \pm 0.47$ \\
\hline WE & $7.14 \pm 0.47$ & $3.63 \pm 0.11$ & $7.48 \pm 1.54$ & $5.16 \pm 0.80$ \\
\hline $\mathrm{AH}$ & $2.37 \pm 0.13$ & $1.22 \pm 0.09$ & $2.34 \pm 0.18$ & $1.64 \pm 0.10$ \\
\hline DAG & nd & nd & $6.52 \pm 1.46$ & $4.49 \pm 0.76$ \\
\hline Total & $138.31 \pm 6.24$ & $70.55 \pm 0.56$ & $106.88 \pm 7.18$ & $74.78 \pm 1.10$ \\
\hline \multicolumn{5}{|l|}{ Structural Lipids: } \\
\hline PL & $43.13 \pm 2.37$ & $22.01 \pm 0.72$ & $21.62 \pm 1.18$ & $15.32 \pm 1.58$ \\
\hline AMPL & $10.70 \pm 0.87$ & $5.45 \pm 0.34$ & $10.53 \pm 0.96$ & $7.35 \pm 0.28$ \\
\hline ST & $3.89 \pm 0.19$ & $1.99 \pm 0.11$ & $3.68 \pm 0.47$ & $2.56 \pm 0.19$ \\
\hline Total & $57.72 \pm 2.73$ & $29.45 \pm 0.56$ & $35.84 \pm 0.26$ & $25.22 \pm 1.10$ \\
\hline \multicolumn{5}{|l|}{ Ratios } \\
\hline Energetic:Structural & $2.40 \pm 0.07$ & & $2.98 \pm 0.18$ & \\
\hline TAG:ST & $33.25 \pm 1.94$ & & $25.09 \pm 2.01$ & \\
\hline TAG:PL & $2.99 \pm 0.12$ & & $4.23 \pm 0.44$ & \\
\hline \multicolumn{5}{|c|}{$\mathrm{pH} 7.65 / 1.5^{\circ} \mathrm{C}$} \\
\hline & \multicolumn{2}{|c|}{ Embryo } & \multicolumn{2}{|c|}{ D-Larvae } \\
\hline & $\begin{array}{l}\text { Amount per } \\
\text { embryo (ng) }\end{array}$ & $\begin{array}{c}\% \text { of Total } \\
\text { lipid }\end{array}$ & $\begin{array}{l}\text { Amount per } \\
\text { larvae (ng) }\end{array}$ & $\begin{array}{c}\% \text { of Total } \\
\text { lipid }\end{array}$ \\
\hline Total Lipids & $187.35 \pm 10.75$ & & $136.45 \pm 5.86$ & \\
\hline \multicolumn{5}{|l|}{ Energetic Lipids: } \\
\hline TAG & $123.21 \pm 7.30$ & $65.75 \pm 0.35$ & $84.54 \pm 3.10$ & $62.02 \pm 0.69$ \\
\hline WE & $6.23 \pm 0.28$ & $3.34 \pm 0.06$ & $6.82 \pm 0.80$ & $4.97 \pm 0.45$ \\
\hline $\mathrm{AH}$ & $2.36 \pm 0.13$ & $1.29 \pm 0.15$ & $2.20 \pm 0.08$ & $1.62 \pm 0.07$ \\
\hline DAG & nd & nd & $7.77 \pm 1.17$ & $5.61 \pm 0.66$ \\
\hline Total & $131.68 \pm 7.46$ & $70.30 \pm 0.42$ & $101.33 \pm 4.93$ & $74.23 \pm 0.91$ \\
\hline \multicolumn{5}{|l|}{ Structural Lipids: } \\
\hline PL & $40.88 \pm 2.25$ & $21.83 \pm 0.09$ & $23.15 \pm 1.98$ & $16.93 \pm 1.09$ \\
\hline AMPL & $10.87 \pm 1.28$ & $5.76 \pm 0.48$ & $8.30 \pm 0.90$ & $6.14 \pm 0.77$ \\
\hline ST & $3.91 \pm 0.07$ & $2.10 \pm 0.11$ & $3.67 \pm 0.11$ & $2.70 \pm 0.07$ \\
\hline Total & $55.67 \pm 3.41$ & $29.70 \pm 0.42$ & $35.12 \pm 1.66$ & $25.77 \pm 0.91$ \\
\hline \multicolumn{5}{|l|}{ Ratios } \\
\hline Energetic:Structural & $2.37 \pm 0.05$ & & $2.90 \pm 0.15$ & \\
\hline TAG:ST & $31.47 \pm 1.49$ & & $23.02 \pm 0.51$ & \\
\hline TAG:PL & $3.01 \pm 0.02$ & & $3.71 \pm 0.24$ & \\
\hline
\end{tabular}


Appendix 2. Summary table of 2-way ANOVA for factors $\mathrm{pH}$ and temperature on lipid content and classes (as described in Chapter 3, Table 1) in Laternula elliptica, 2 d PF.

\begin{tabular}{|ccrrrrrr|}
\hline & \multicolumn{2}{c}{$\mathrm{pH}$} & \multicolumn{2}{c}{ Temperature } & \multicolumn{2}{c|}{ Interactive } \\
& $\mathrm{F}_{(1,23)}$ & $\mathrm{p}$ & $\mathrm{F}_{(3,23)}$ & $\mathrm{p}$ & $\mathrm{F}_{(3,23)}$ & $\mathrm{p}$ \\
\hline Total Lipids & 0.000 & 0.991 & 0.647 & 0.593 & 0.623 & 0.607 \\
TAG & 0.006 & 0.937 & 0.617 & 0.611 & 0.891 & 0.460 \\
WE & 0.326 & 0.574 & 1.217 & 0.326 & 1.519 & 0.236 \\
DAG & 0.509 & 0.486 & 1.429 & 0.103 & 0.900 & 0.463 \\
AH & 0.016 & 0.902 & 0.489 & 0.693 & 0.158 & 0.923 \\
PL & 0.019 & 0.891 & 1.261 & 0.311 & 0.062 & 0.979 \\
AMPL & 1.052 & 0.316 & 0.971 & 0.424 & 0.080 & 0.970 \\
ST & 0.238 & 0.630 & 0.687 & 0.569 & 0.440 & 0.727 \\
& & & & & & \\
Energetic & 0.002 & 0.969 & 0.664 & 0.583 & 0.927 & 0.444 \\
Structural & 0.017 & 0.896 & 1.241 & 0.318 & 0.087 & 0.966 \\
& & & & & & \\
Energetic:Structural & 0.071 & 0.793 & 1.847 & 0.167 & 1.117 & 0.363 \\
TAG:ST & 0.344 & 0.563 & 2.141 & 0.123 & 1.042 & 0.393 \\
TAG:PL & 0.001 & 0.977 & 1.471 & 0.249 & 0.748 & 0.535 \\
\hline
\end{tabular}

